\title{
A MICRO-SIMULATION APPROACH TO THE ANALYSIS OF PRIORITY CROSSING PROGRAMS AT LAND BORDER CROSSINGS
}

by

Andy Brijmohan

Bachelor of Engineering (Civil), 1997

University of Guyana

A thesis submitted to the Faculty of Graduate Studies \& Research in partial fulfillment of the requirements for the Degree of Masters of Applied Science (M.A.Sc.)

Department of Civil and Environmental Engineering

Carleton University

Ottawa, Ontario

The Masters of Applied Science Program in Civil and Environmental Engineering is a joint program with the University of Ottawa, administered by the

Ottawa-Carleton Institute for Civil Engineering.

(C) Copyright by Andy Brijmohan, 2006 


$\begin{array}{ll}\begin{array}{l}\text { Library and } \\ \text { Archives Canada }\end{array} & \begin{array}{l}\text { Bibliothèque et } \\ \text { Archives Canada }\end{array} \\ \begin{array}{l}\text { Published Heritage } \\ \text { Branch }\end{array} & \begin{array}{l}\text { Direction du } \\ \text { Patrimoine de l'édition }\end{array} \\ \begin{array}{l}\text { 395 Wellington Street } \\ \text { Ottawa ON K1A ON4 }\end{array} & \begin{array}{l}\text { 395, rue Wellington } \\ \text { Ottawa ON K1A ON4 } \\ \text { Canada }\end{array}\end{array}$

Your file Votre référence ISBN: 978-0-494-23330-6 Our file Notre référence ISBN: 978-0-494-23330-6

NOTICE:

The author has granted a nonexclusive license allowing Library and Archives Canada to reproduce, publish, archive, preserve, conserve, communicate to the public by telecommunication or on the Internet, loan, distribute and sell theses worldwide, for commercial or noncommercial purposes, in microform, paper, electronic and/or any other formats.

The author retains copyright ownership and moral rights in this thesis. Neither the thesis nor substantial extracts from it may be printed or otherwise reproduced without the author's permission.
AVIS:

L'auteur a accordé une licence non exclusive permettant à la Bibliothèque et Archives Canada de reproduire, publier, archiver, sauvegarder, conserver, transmettre au public par télécommunication ou par l'Internet, prêter, distribuer et vendre des thèses partout dans le monde, à des fins commerciales ou autres, sur support microforme, papier, électronique et/ou autres formats.

L'auteur conserve la propriété du droit d'auteur et des droits moraux qui protège cette thèse. $\mathrm{Ni}$ la thèse ni des extraits substantiels de celle-ci ne doivent être imprimés ou autrement reproduits sans son autorisation.
In compliance with the Canadian

Privacy Act some supporting forms may have been removed from this thesis.

While these forms may be included in the document page count, their removal does not represent any loss of content from the thesis.
Conformément à la loi canadienne sur la protection de la vie privée, quelques formulaires secondaires ont été enlevés de cette thèse.

Bien que ces formulaires aient inclus dans la pagination, il n'y aura aucun contenu manquant.

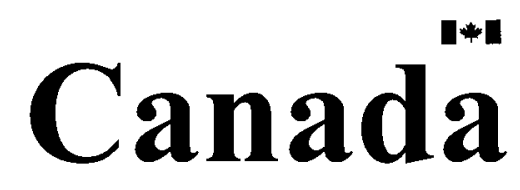




\begin{abstract}
Over ninety percent of the movement of people and goods between Canada and the U.S. pass through Land Border Crossings. Given the existing and predicted demand levels, border crossing officials are faced with issues such as congestion, national security and pollution, which need to be addressed to ensure sustained efficient operation. Besides physical infrastructure expansion a number of Transportation System Management (TSM) measures have been suggested. This research investigates using a microsimulation approach, the effectiveness of priority crossing programs as a feasible alternative in addressing these issues under different scenarios of travel demand, customs processing times, queue jump lanes and priority penetration rates for auto and truck traffic at land border crossings. The findings were that priority crossing programs generally does make a significant impact in reducing travel time delays and increasing percent of traffic demand serviced. These benefits increase even more when queue jump lanes are implemented for priority crossing users.
\end{abstract}




\section{DEDICATION}

To my parents ...

.... thanks for everything.

iii 


\section{ACKNOWLEDGEMENTS}

This project would not have been successfully completed without the help of the following persons. To them I am sincerely grateful.

- To my supervisor, Professor Ata Khan, for his help and guidance throughout the entire duration of my studies at Carleton University.

- To the examining committee, for their review and constructive comments that led to improvement.

- To my wife, Gillian, for her prayers, constant support and patience shown throughout the duration of my research and studies.

- Finally, to the supreme being, the one and only Lord Jesus, for his constant help, wisdom granted and the gift of eternal life. 


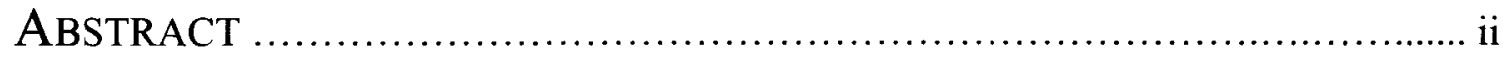

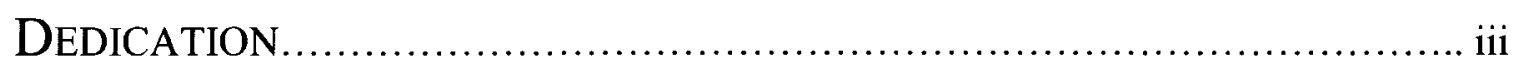

ACKNOWLEDGEMENTS............................................. iv

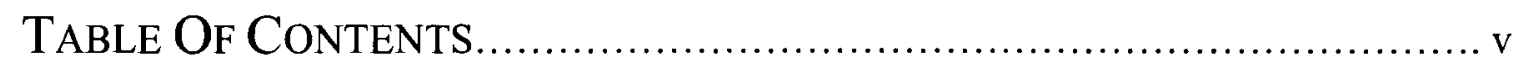

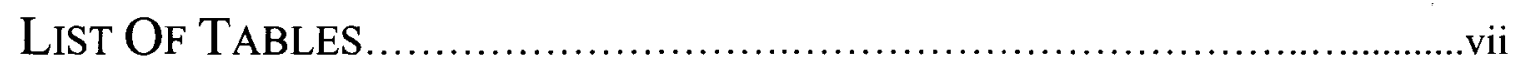

LIST OF FIGURES ............................................................ vii

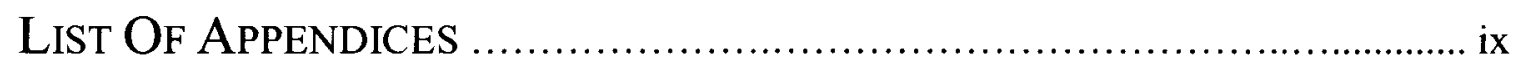

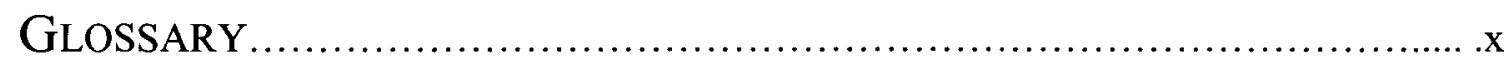

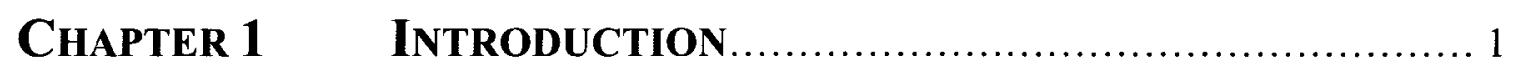

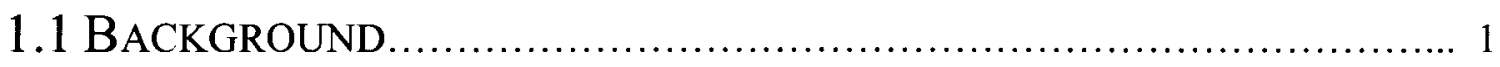

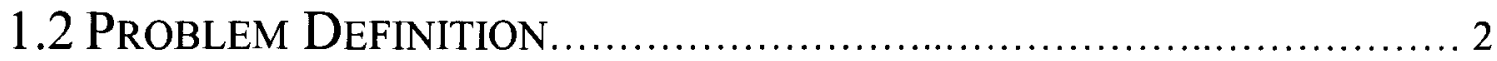

1.3 ObJectives And Scope...................................................

1.4 Methodological FrameWORK .......................................

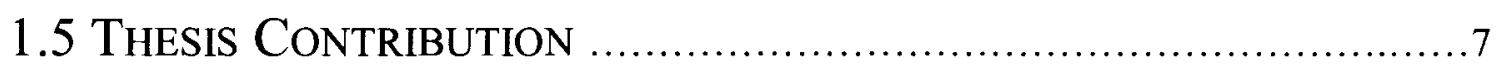

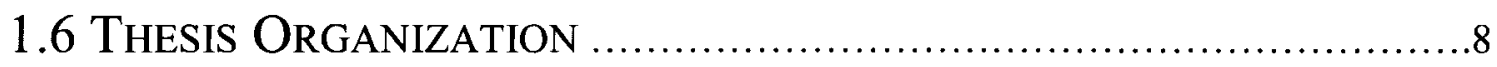

Chapter 2 Literature Review................................. 10

2.1 Significance Of U.S.-Canada Land Border Crossings ........10

2.2 LAND Border CROSSINGS ChALlENGES/ISSUES ..................... 12

2.2.1 CONGESTION .................................................. 12

2.2.2 NATIONAL SECURITY ISSUES.............................. 20

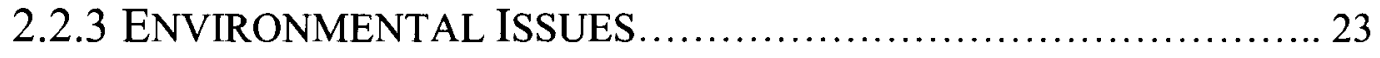

2.2.4 VARYING STAKEHOLDER INTERESTS ........................ 26

2.3 Alternatives Implemented And Proposed Solutions........ 27

2.3.1 PRIORITY CROSSING PROGRAMS ............................ 27

2.3.2 INTELLIGENT TRANSPORTATION SYSTEMS ................... 32 
2.3.3 TRANSPORTATION DEMAND MANAGEMENT...................... 35

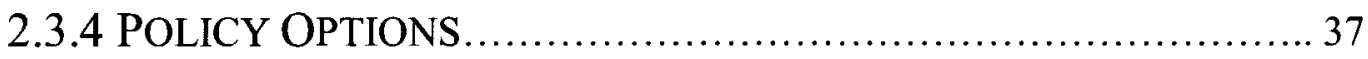

2.4 Previous Micro-Simulation Modelling EfForts.................. 41

2.4.1 COMPUTER SIMULATION OVERVIEW .............................. 41

2.4.2 USE OF MICRO-SIMULATION TO EVALUATE TECHNOLOGY DEPLOYMENT AT LAND BORDER CROSSINGS...................43

2.4.3 USE OF MICRO - SIMULATION TO DEVELOP A MATHEMATICAL DELAY MODEL AT LAND BORDER CROSSINGS ........................................................ 49

2.5 SOFTWARE OVERVIEW ....................................................... 50

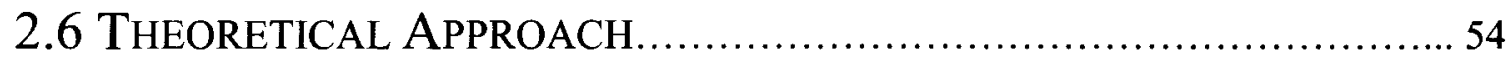

Chapter 3 Micro-Simulation Modelling...................... 58

3.1 Micro-Simulation Modeling ToOls \& TechniQues ................58

3.2 LAND BORdER CROSSING INFRASTRUCTURE............................. 64

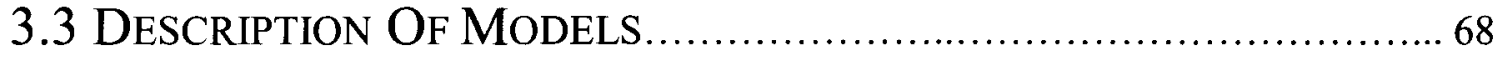

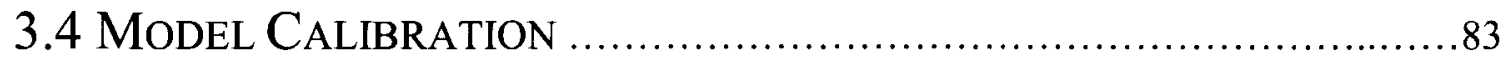

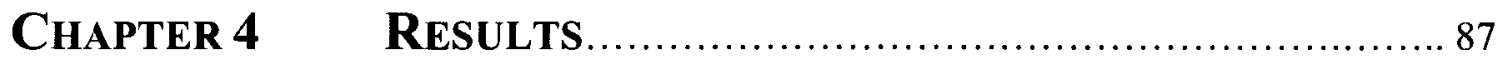

4.1 The Peace Bridge - Canada Bound................................. 87

4.2 AMBASSADOR BRIDGE - U.S. BOUND.................................. 95

Chapter 5 Discussion........................................ 110

5.1 The Peace Bridge - Canada Bound................................... 110

5.2 AMBASSADOR BRIDGE - U.S. BOUND............................... 116

Chapter 6 Conclusions.......................................... 136

Chapter 8 References.......................................... 142 


\section{LIST OF TABLES}

Description Page

TABLE 2-1: $\quad$ Forecasted Increase In Annual Demand For Major $\quad 17$ Crossings In Ontario - Michigan Area.

TABLE 2-2: $\quad$ Capacity Estimation For Detroit - Windsor Crossings. 19

TABLE 2-3: $\quad$ Homeland Security Advisory System - Guidance For 22

TABLE 3-1: $\quad$ Processing Lane Allocations - Peace Bridge - Canada 73

TABLE 3-2: $\quad$ Ranges Of Customs Times Used In Ambassador 81 TABLE 4-1: $\quad$ Summary of Results - Linear Multivariate Regression 106

TABLE 5-1: $\quad$ Minimum Overall Auto Crossing Travel Time And 115

TABLE 5-2: $\quad$ Summary Of Auto Regression Models, Ambassador $\quad 117$

TABLE 5-3: $\quad$ Summary Of Truck Regression Models, Ambassador Bridge - U.S. Bound (No Queue Jump Lane).

TABLE 5-4: $\quad$ Summary Of Auto Regression Models, Ambassador Bridge - U.S. Bound (Queue Jump Lane).

TABLE 5-5: $\quad$ Summary Of Truck Regression Models, Ambassador Bridge - U.S. Bound (Queue Jump Lane). (1) 9 2 3 1 


\section{LIST OF FIGURES}

DESCRIPTION PAGE

FIGURE 1-1: $\quad$ Canadian - U.S. Border Boundary.

FIGURE 1-2: $\quad$ Typical Layout of Major Functional Components of a 2 Land Border Crossing

FIGURE 1-3: $\quad$ Methodological Framework 6

FIGURE 2-1: $\quad$ Total Canadian - U.S. Trade Modal Share By Value. 10

FIGURE 2-2: $\quad$ Total Canadian - U.S. Passenger Travel Modal Share 11

FIGURE 2-3: $\quad$ Total Trade Value By Truck Mode, Canada - U.S., $\quad 13$

FIGURE 2-4: $\quad$ Total Person Trips Across All Modes, Canada - U.S. 14

FIGURE 2-5: $\quad$ Trade Value By Truck Mode, Major U.S. - Canada 15 Crossings.

FIGURE 2-6: $\quad$ Auto Trips For Three Highest Demand Crossings For 16 2003.

FIGURE 3-1: $\quad$ Figure 3-1: Car Following Logic (Weidmann 1974) 63

FIGURE 3-2: $\quad$ Schematic Of Main Infrastructure Elements Of The 65 Border Crossing Process Between Canada-U.S.

viii 


\section{LIST OF APPENDICES}

APPENDIX A PEACE BRIDGE MODEL CANADA BOUND INPUTS \& RESULTS ................................... 145

APPENDIX B AMBASSADOR BRIDGE U.S. BOUND MODEL INPUTS AND RESULTS............................. 168

APPENDix C MUltivariate REgRESSION_.............................. 231 


\section{GLOSSARY}

CANPASS Canada Pass

PAPS Pre-arrival Processing System

PARS Pre-arrival Review System

FAST Free And Secure Trade

PPC Pre-processing Center

ACS Automated Customs System

C-TPAT U.S. Customs Trade Partnership Against Terrorism

PIP Partners In Protection - Canada

QJL Queue Jump Lane

ITS Intelligent Transportation System

FOT Field Operational Test

NAFTA North American Free Trade Agreement 


\section{ChAPTER 1 INTRODUCTION}

\subsection{BACKGROUND}

Canada and the United States share the world's longest undefended border which is 8,891 kilometres long (CBC News Online, July 2004). The boundary follows the $49^{\text {th }}$ parallel from the Straight of Juan de Fuca on the West Coast to Lake of the Woods in Ontario/Minnesota and the $43^{\text {rd }}$ parallel between New England and Quebec.

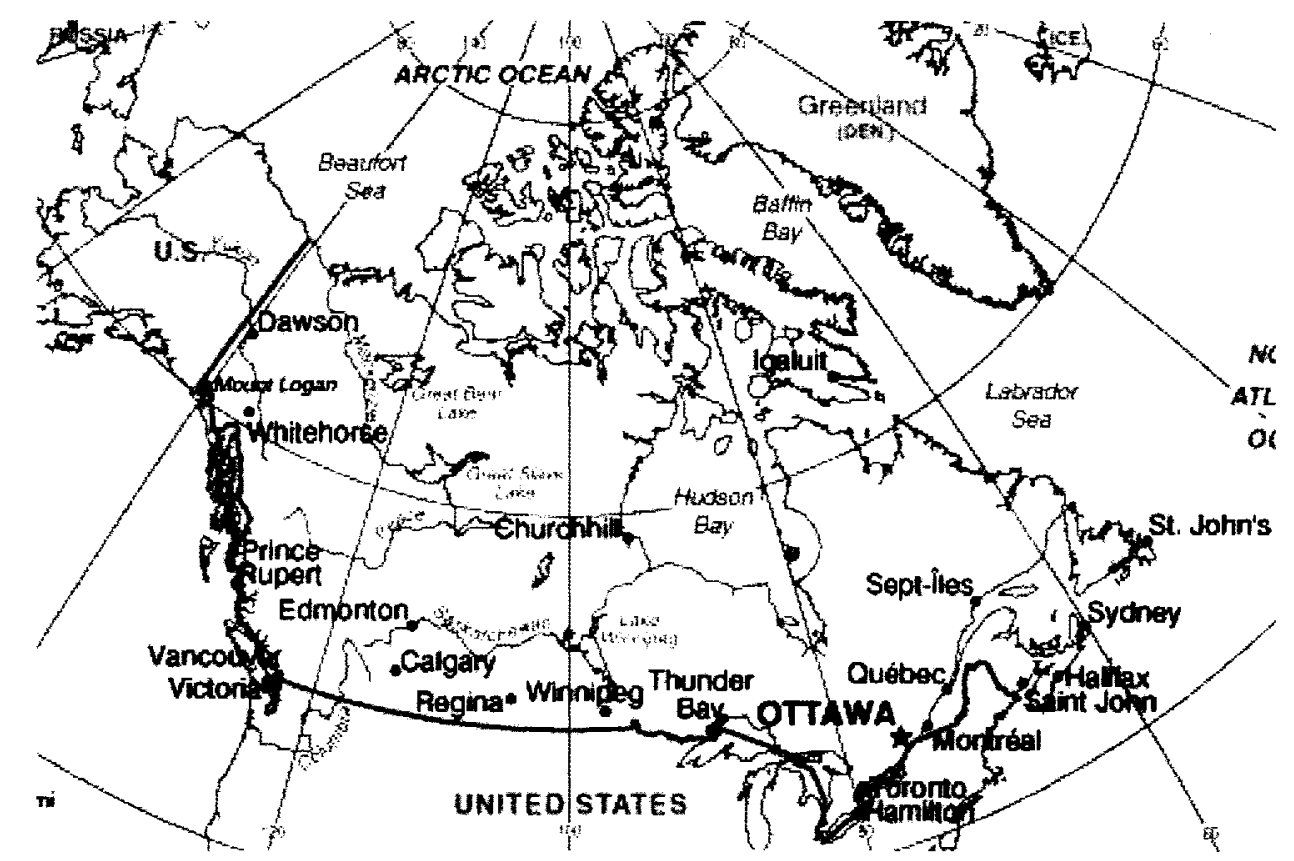

Figure 1-1: Canadian - U.S. Border Boundary

A land border crossing is a node in the transportation network between two countries where all travellers and cargo are expected to undergo some form of customs inspection. There are 140 land border crossing points along the Canada - U.S. boundary and they are staffed with customs officials. Land border crossings include those that are bridge crossings (i.e. over water) as well as those that are not separated by a bridge but solely 
over land. Figure 1-2 below shows the typical layout of the major functional components of a land border crossing. The diagram shows the functionality for two way auto and truck traffic travelling into and out of the respective countries.

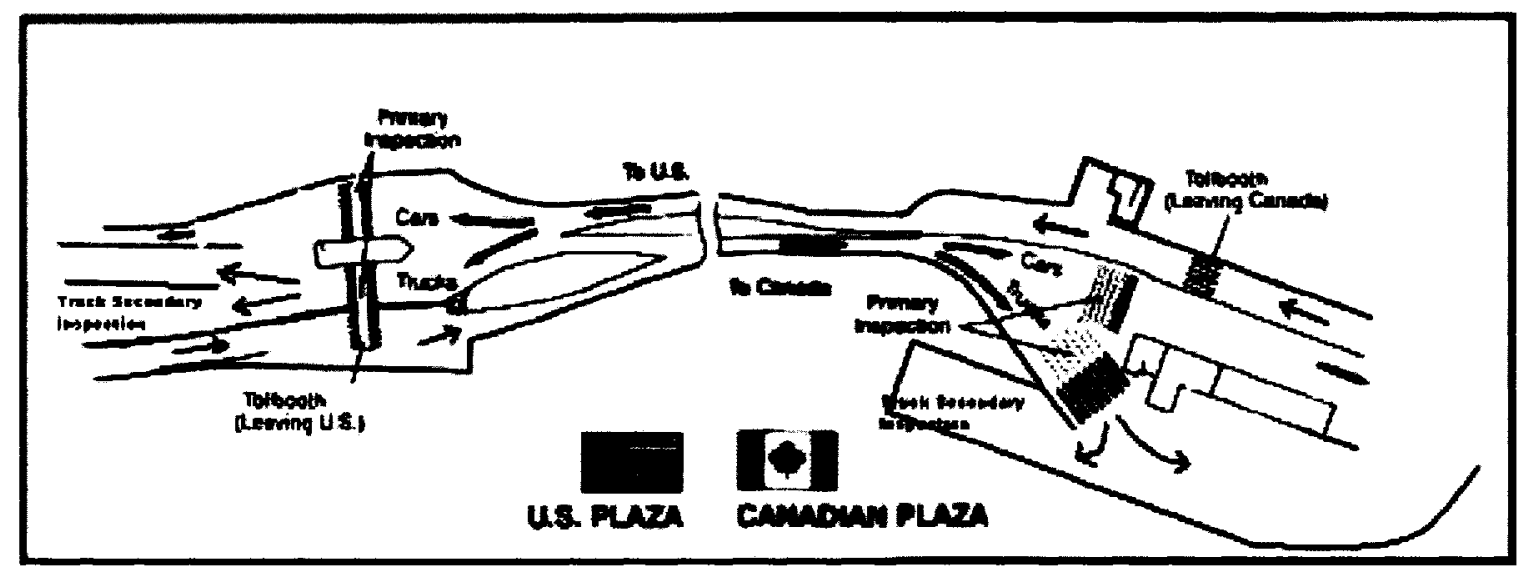

Figure 1-2: Typical Layout of Major Functional Components of a Land Border Crossing Source: Adapted from the Blue Water Bridge website, www.bwba.org/frames.html, 2006.

\subsection{Problem Definition}

Many factors have combined to cause severe congestion at the main land border crossings between Canada and the United States. Increased demand and customs processing times have resulted in major delays at many points of entry. Historical and predicted demand trends indicate that volumes for auto and truck crossings will increase as we move ahead into the $21^{\text {st }}$ century. The events of $9 / 11$ have caused increased security measures at all ports of entry into the United States and Canada and this has further compounded the congestion problem. Besides the long term solutions of major infrastructure expansion there are a number of Transportation Demand Management (TDM) approaches that have been proposed to help optimize existing infrastructure 
capacity, these are discussed further in Section 2.3.3. One of the alternatives that has taken on increased importance and was implemented at many border crossings is the priority crossing program for pre-screened users. More detailed information on the importance of land border crossings and the challenges and issues facing planners and users can be found in Chapter 2 - Literature Review of this document.

\subsection{ObJectives And SCOPE}

The main objective of this research was to determine the effectiveness of priority crossing programs in improving the efficiency of traffic flow through land border crossings.

This was investigated by performing two case studies using micro-simulation models constructed for the following crossings:

- Peace Bridge - Canada Bound

- Ambassador Bridge - U.S. Bound

The models were for unidirectional traffic inclusive of infrastructure on the origin and destination side of the border. The links forming part of the road network before and after the crossing were not modeled since area wide network analysis was not part of the scope for this research. 
The base-case models were calibrated and then hypothetical scenarios were modeled to determine the effectiveness of priority crossing programs. Average travel time, throughput and percent of demand serviced were used as performance measures in the analysis.

\subsection{Methodological Framework}

This research is concerned with using a micro-simulation approach to evaluate the strategy of implementing a priority crossing program for pre-screened users at land border crossings between Canada and the United States. The performance measures of travel time, throughput and percent of demand serviced were derived from the model outputs and have been used to evaluate the impact of this strategy on crossing efficiency.

As part of the literature review process, information was gathered that emphasised the importance of land border crossings between Canada and the United States. Historical and future predicted demand levels are also summarized. The challenges and issues standing in the way of efficient operation of the crossings were highlighted as well as various alternatives that have been or can potentially be used to increase the efficiency of border crossing operations. Additionally, previously published micro-simulation attempts at modelling land border crossings are discussed. 
The model construction was done using WESTA for the Peace Bridge - Canada Bound case study, and VISSIM was used for the Ambassador Bridge - U.S. Bound case study. The model inputs were derived from the literature review process and data for the basecase models were obtained from a combination of published reports and papers and field survey data-bases. After the base-case models were constructed and calibrated hypothetical scenarios were programmed into the models and the model outputs were analyzed. The method of analysis used for the model outputs in this research was a combination of two approaches:

- Summarizing model outputs for the different scenarios graphically and comparing scenarios. This approach was used extensively for the Peace Bridge - Canada Bound case study.

- Using Linear Multivariate Regression techniques to develop model equations with the dependent variables being selected from the model outputs and the independent variables from the model inputs. This approach was used extensively for the Ambassador Bridge - U.S. Bound case study.

After the results were analyzed the discussions and conclusions were carried out. 


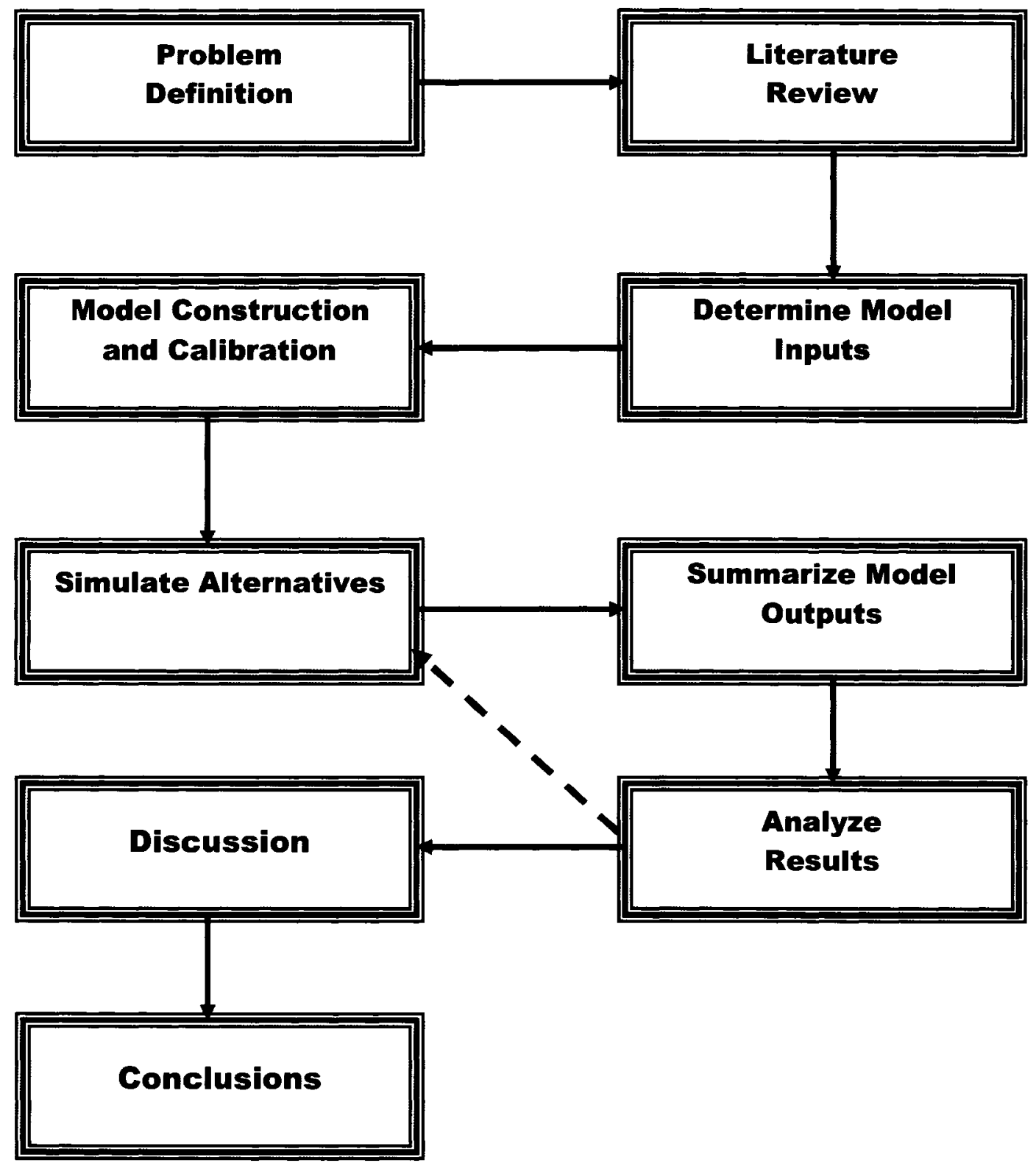

Figure 1-3: Methodological Framework 


\subsection{Thesis CONTRIBUTION}

This research has a number of unique features when compared with previous studies published on land border crossings. Firstly the micro-simulation model is constructed to include each segment of the crossing infrastructure including, access, tolls, bridge structure, customs inspection and egress. This unified model will reflect and take into account the points of limiting capacity throughout the crossing for the different scenarios.

A statistical regression modelling approach is adopted for the model output. The researcher did not encounter any published material that analysed land border crossings using this extensive regression modelling approach.

Also unique is that the benefits of the priority crossing programs for autos and trucks are determined from the model scenarios and are quantified. With the recent implementation of the new forms of priority crossing programs (i.e. Nexus and Fast) much information has not been published with regard to the quantifiable benefits of priority crossing programs. A micro-simulation approach enables us to be able to assess the overall system and user benefits of a priority crossing program in the absence of relevant field data. 


\subsection{THESIS ORGANIZATION}

Chapter 2: Literature Review - In this section published material concerning the importance and significance of land border crossings in the transportation network between Canada and the United States are reviewed and presented. Also challenges and issues facing land border crossing administrators and users are discussed at length along with the potential of various alternatives to address these issues. Previous microsimulation studies done for land border crossings between Canada and the United States were also examined as part of this literature review. The theoretical analysis approach was discussed and the uniqueness of land border crossings as a node in the transportation infrastructure between two countries was highlighted.

Chapter 3: Micro-simulation Model Description and Calibration - This chapter outlines the importance of micro-simulation models in the analysis of transportation infrastructure and reviews the software packages used in this research i.e. WESTA and VISSIM. Each component of the crossings that were modeled are discussed and the model inputs used for each model constructed are described and the source of the information given. The calibration process is also described and the results presented. After model calibration, the various hypothetical scenarios are described. For the Peace Bridge - Canada Bound case study there were nine general alternative scenarios each with ten determined modelling scenarios, while for the Ambassador Bridge - U.S. Bound case study there were two general alternatives within which the main model inputs were randomized resulting in over 150 modelling scenarios. 
Chapter 4: Results - The model outputs for the numerous scenarios simulated were summarized and presented in this section. Discernable trends and differences between the scenarios analyzed were highlighted.

Chapter 5: Discussion - The results were discussed further and related to system and user benefits.

Chapter 6: Conclusions - Based on the preceding results and discussions specific conclusions are presented about the impact priority crossing programs can potentially have on land border crossings. 


\section{Chapter 2 Literature Review}

\subsection{Significance Of U.S.-CANAdA LAND Border Crossings}

Land border crossings are important to the efficient movement of people and goods between Canada and the United States (U.S.). Most of Canada's trade is with the U.S. and this trend has existed for quite some time and is expected to continue well into the future. In 2003, of all of Canada's total trade with the world, 75 percent was with the U.S for which the majority was transported by trucks passing through land border crossings (Transport Canada, Annual Report, 2003). The historical trend indicating modal share by value is shown in Figure 2-1 below and includes for total imports and exports combined. Consistently, the road (i.e. truck) mode carries the majority of the modal share of goods.

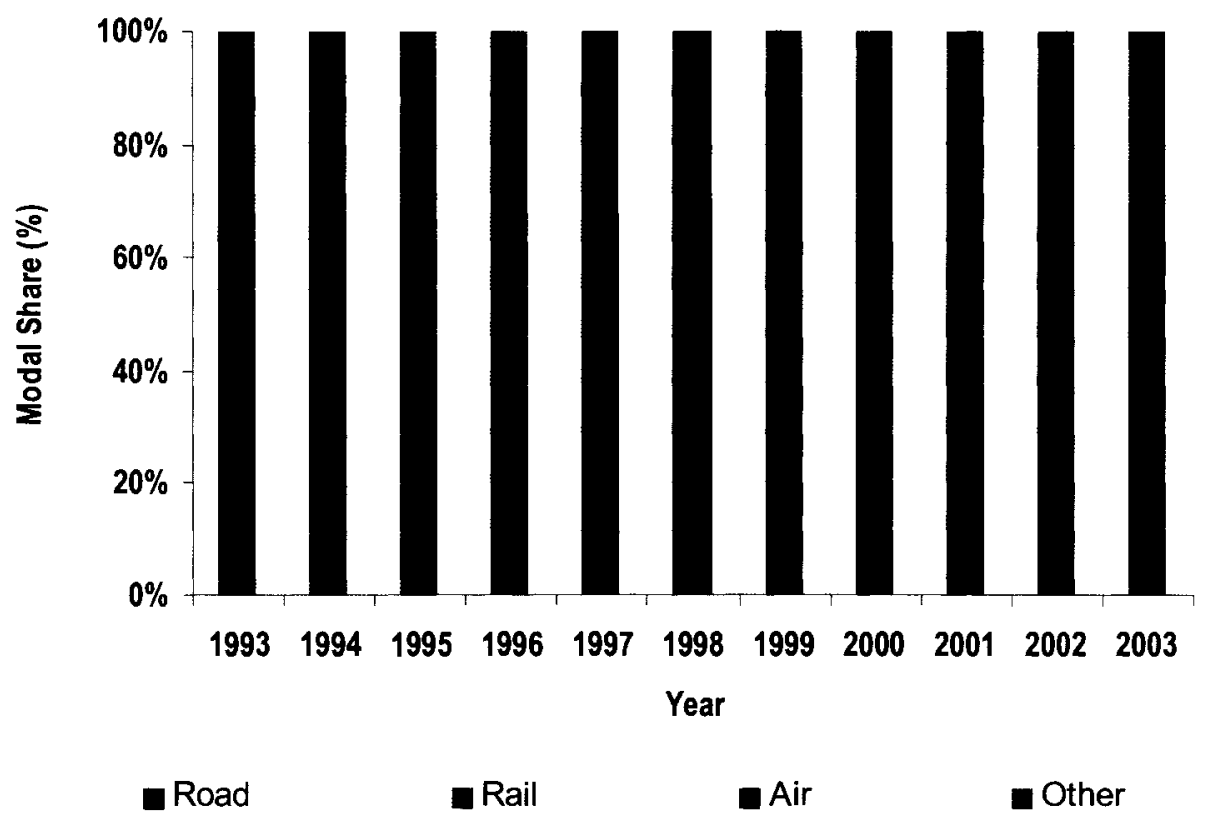

Figure 2-1: Total Canadian -U.S. Trade Modal Share by Value

Source: Transportation in Canada 2003, Annual Report - Table A2-1: Modal Shares in Canada-United States Trade, 1993 - 2003. 
Passenger travel between Canada and the United States is also crucial to the exchange of skills and social interaction between the residents. In 1999 over 86 million person trips were made between Canada and the United States (Transport Canada, Annual Report, 2003). After the events of September 11, 2001 there has been a significant drop in the amount of passenger travel between two countries, in 2003 approximately 70 million person trips were made. However, the modal share of passenger travel between Canada and the U.S. has been a consistent trend in the recent past with Autos capturing 82 percent of the travelers. This trend is summarized in Figure 2-2 below and includes for Same Day and Overnight Trips for both Canadian and U.S. residents.

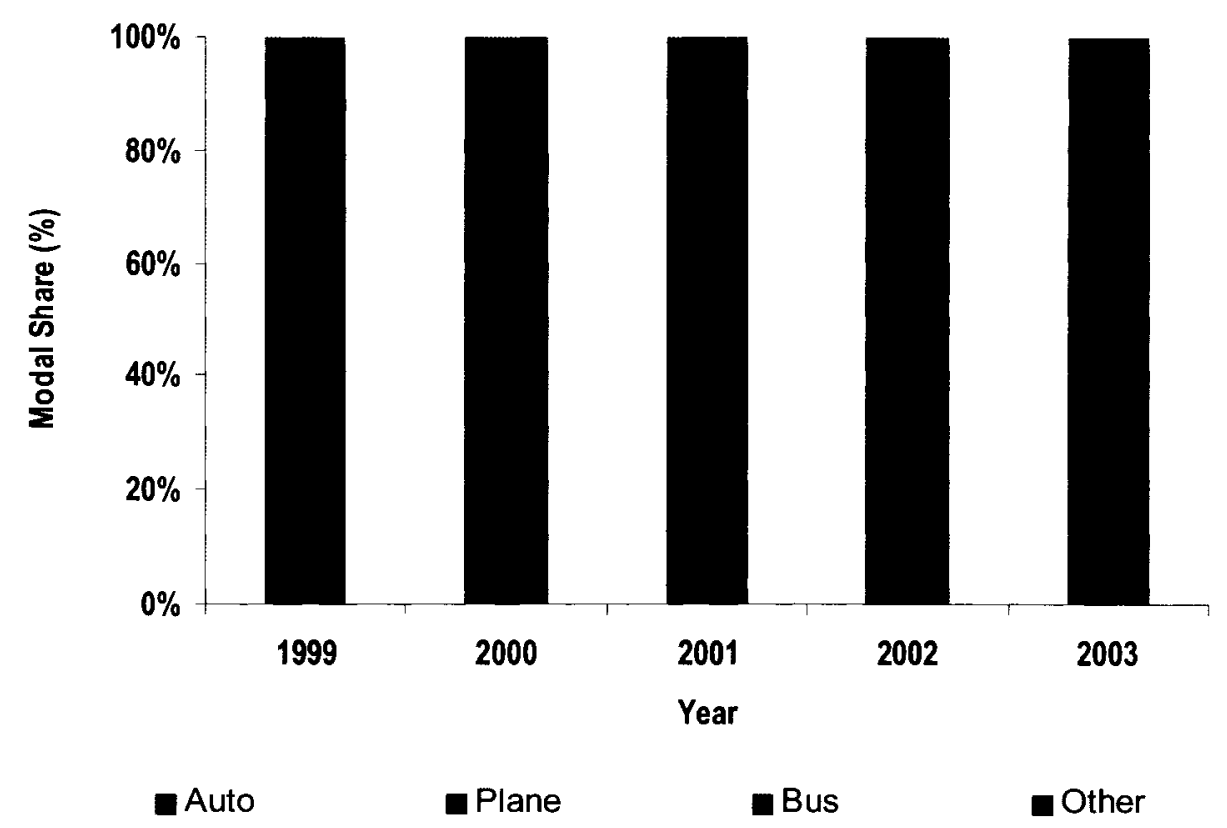

Figure 2-2: Total Canadian - U.S. Passenger Travel Modal Share by Person Trips

Source: Transportation in Canada 2003, Annual Report - Table A2-14: International Travel Summary, $1999-2003$. 
From the above trends we can see that land border crossings facilitate the majority of the travel between Canada and the United States, both for cars and trucks.

\subsection{LAND Border CRossings Challenges/IsSues}

\subsubsection{CONGESTION}

Congestion always results when demand exceeds capacity, and in the case of border crossings the build up of queues becomes evident at the major crossing points between Canada and the United States. Tremendous growth in crossing demand over the past decade has caused enormous strain on border crossing facilities. Where trade is concerned, even before NAFTA went into effect on January 01, 1994 the overall truck crossing demand on border facilities between Canada and the U.S. has been increasing steadily. Canada is the number one trading partner of the U.S. and this is reflected in the fact that between 1993 and 2003 U.S. trade with Canada increased from $\$ 264$ billion to $\$ 531$ billion, an average annual growth rate of approximately 27 percent. Approximately 65 percent of this trade was transported via trucks across land/surface border crossings during 2003 (Transport Canada, Annual Report, 2003).

Figure 2-3 shows the total trade value by truck mode between Canada and the United States from 1993 to 2003 . The decline in trade value after Year 2000 is due mainly to the slow down in the economies of the two countries related to the events of September 11 , 2001 as well as the restrictions on beef imports from Canada into the U.S. 


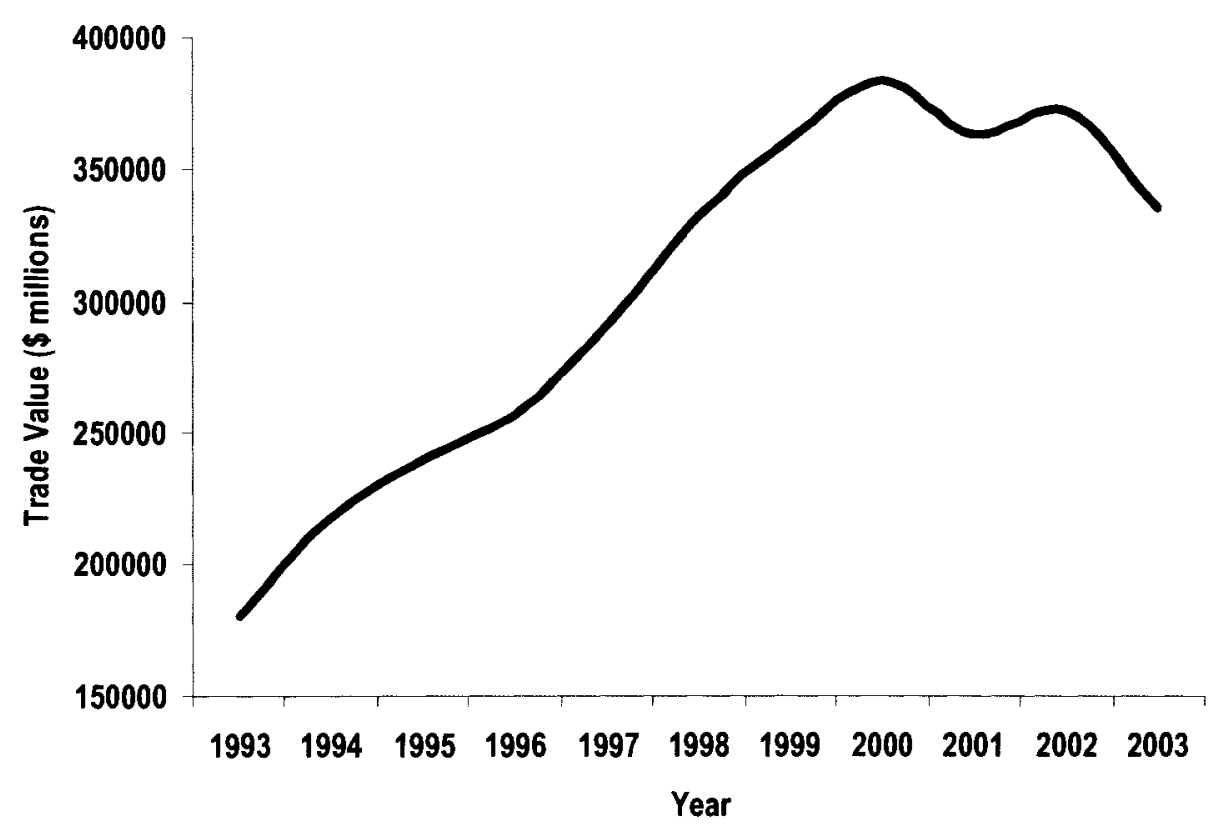

Figure 2-3: Total Trade Value by Truck Mode, Canada - U.S., 1993 to 2003

Source: Transportation in Canada 2003, Annual Report - Table A2-1: Modal Shares in Canada - United States Trade, $1993-2003$.

Since the peak in passenger travel occurred in the early nineties there has been a steady decline in total travel between the two countries. The early nineties peak was approximately 112 million person trips between Canada and the United States. However since 1997 this number has not been above 90 million person trips and has been steadily declining, in 2003 the total person trips between Canada and the U.S. was approximately 70 million. Recent trends after the events of September 11, 2001 have suggested a steep decline in the travel between Canada and the U.S. and this is shown in Figure 2-4. 


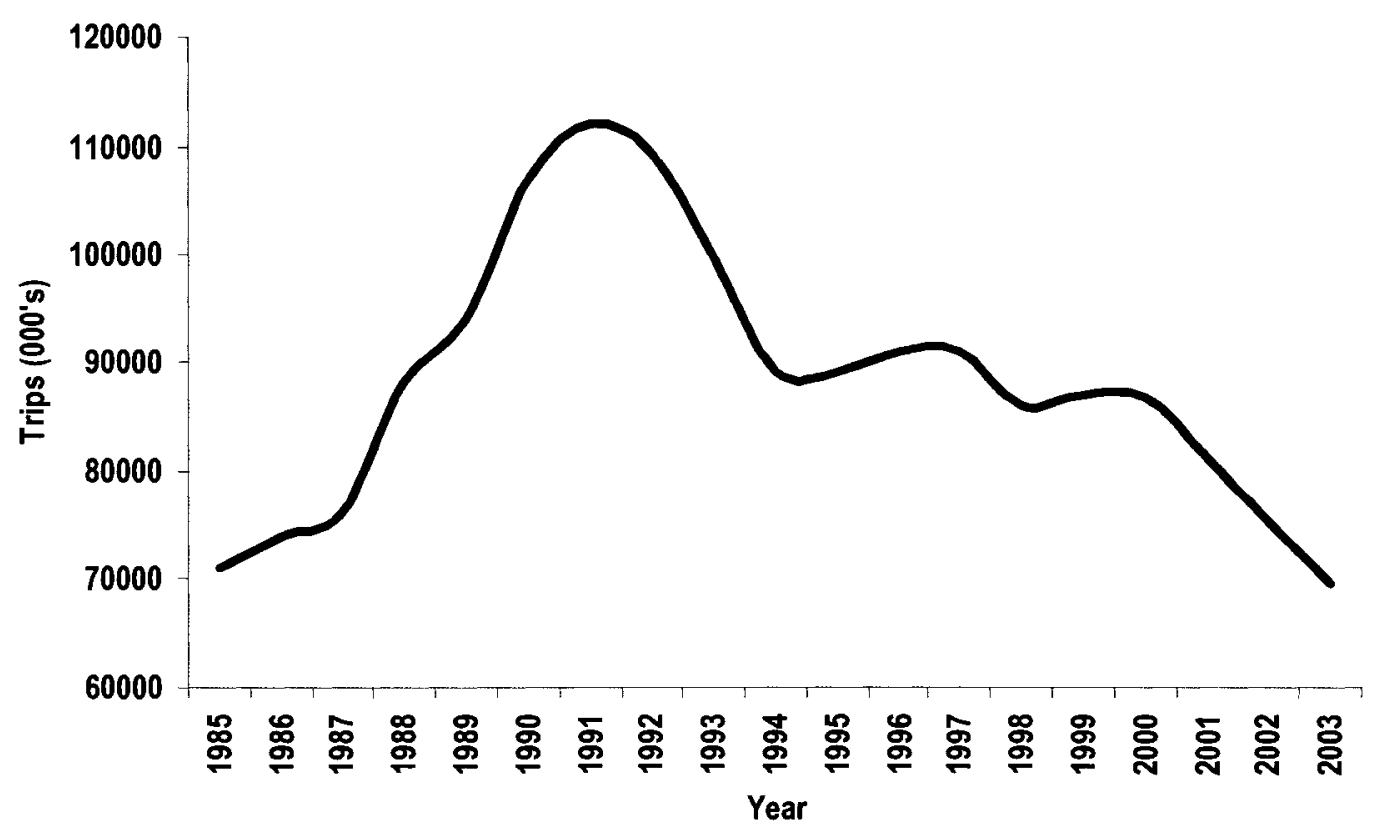

Figure 2-4: Total Person Trips Across All Modes, Canada - U.S.

Source: Transportation in Canada 2003, Annual Report - Table A2-14: International Travel Summary, 1999 - 2003. \& Statistics Canada, "Touriscope: International Travel", \#66-201

The crossing specific trends generally do not follow the same trend as the aggregated values across all crossings. The demand varies significantly between crossings and there has been a steep general increase in demand at some crossings even though the overall national data does not correspond to the increasing trend. The busiest border crossings for trade in 2003 were Ambassador Bridge, Windsor; Blue Water Bridge, Sarnia; Peace Bridge, Fort Erie; these crossings are all located in Southern Ontario which is the busiest corridor for goods movement between Canada and the United States. Figure 2-5 below indicates that there is a recent trend of increased demand for the last three years at the 
busiest crossing points contrary to the recent declining trend in the overall national trade value transported by trucks as was shown in Figure 2-3.

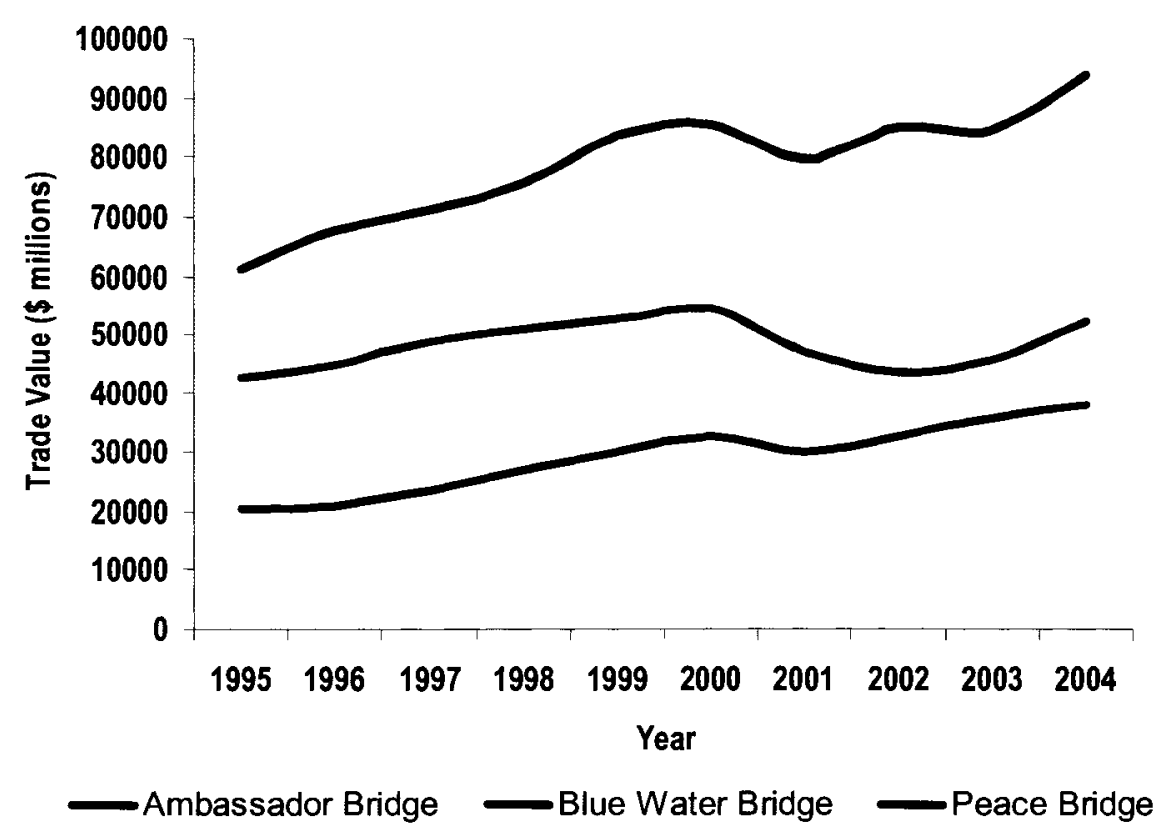

Figure 2-5: Trade Value By Truck Mode, Major U.S. - Canada Crossings

Source: U.S. Department of Transportation, Bureau of Transportation Statistics, Trans-border Surface Freight Database.

The top three crossings for passenger vehicle demand in 2003 were The Detroit-Windsor Tunnel, The Ambassador Bridge and The Peace Bridge. As was with the freight transportation demand, all of these crossings are in the Southern Ontario region however the overall decline in auto crossing demand on the national scale is reflected in the volumes reported for the highest demand crossings in 2003 (see Figure 2-6 below). The reason for the drop in auto crossing volume is due mainly to the slow down in the economies between the two countries and this decline accelerated after the events of September, 112001. 


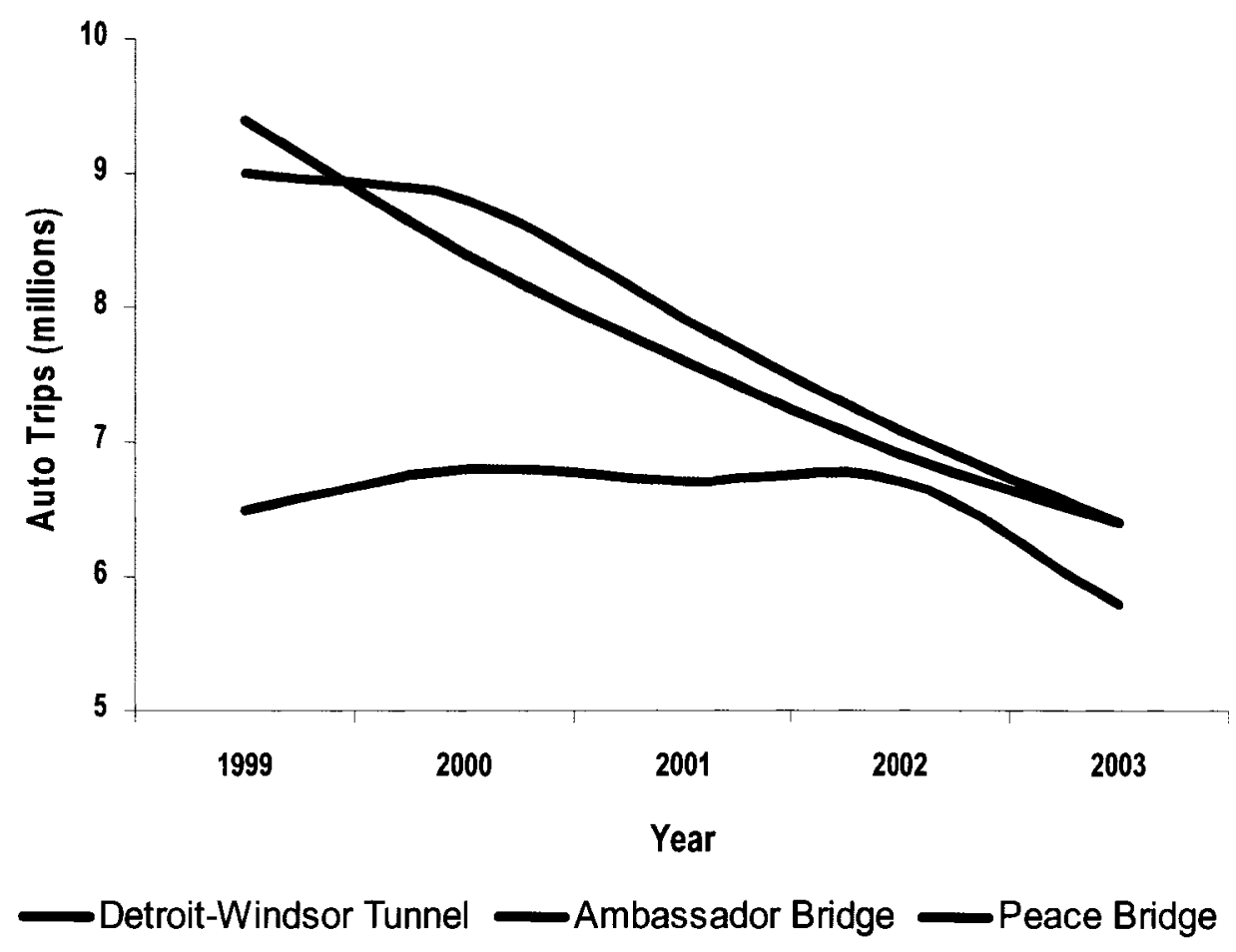

Figure 2-6: Auto Trips For Three Highest Demand Crossings For 2003

Source: Transportation in Canada 2003, Annual Report - Table A7-13: Twenty Largest Border Crossings For Cars/Other Vehicles, 1999 - 2003.

Border crossing demand is expected to increase in the future for both truck and auto crossings. For the 22 principal truck crossings between Canada and the United States demand volumes are projected to grow from 11.8 million in 1999 to 19.2 million in 2020 , an increase of 63\% (Eastern Border Transportation Coalition, 2002). It is more difficult to find long range forecasts of passenger travel between the United States and Canada since the factors influencing auto travel tend to be more volatile than the factors influencing trade. The Office of Travel and Tourism Industries has predicted that the visitors from Canada to the United States will continually increase through 2007 by $17 \%$ 
over the 2003 level (Baker, 2004). Support for this prediction is given by the sustained good performance of the Canadian dollar and a buoyant Canadian economy. The general consensus is that there will be a steady increase in demand at Land Border Crossings between Canada and the United States in the future.

As part of the Canada-United States-Ontario-Michigan Planning/Need and Feasibility Study travel demand forecasting was done for the three major crossings in the study area. These crossings are the Ambassador Bridge, the Detroit-Windsor Tunnel and the Blue Water Bridge. The forecasting approach adopted in this study was based on the identification and mapping of the historical trends and causal factors influencing the cross-border traffic in the study area. Both quantitative and qualitative methods were used to help project future growth rates for autos and commercial vehicles. The results of this forecasting process is given in the table below for both autos and commercial vehicles and the percentage increase are referenced to Year 2000 as the base year.

Table 2-1: Forecasted Increase In Annual Demand For Major Crossings In OntarioMichigan Area

\begin{tabular}{|c|c|c|c|c|}
\hline Year & $\begin{array}{c}\text { Ambassador } \\
\text { Bridge }\end{array}$ & D-W Tunnel & Blue Water Bridge & Overall Study Area \\
\hline \multicolumn{5}{|c|}{ Autos } \\
\hline $\mathbf{2 0 1 0}$ & $18.1 \%$ & $11.4 \%$ & $16.1 \%$ & $15.1 \%$ \\
\hline $\mathbf{2 0 2 0}$ & $12.5 \%$ & $7.3 \%$ & $11.6 \%$ & $10.4 \%$ \\
\hline $\mathbf{2 0 3 0}$ & $8.0 \%$ & $7.4 \%$ & $7.8 \%$ & $7.7 \%$ \\
\hline $\mathbf{2 0 0 0 - 2 0 3 0}$ & $43 \%$ & $28 \%$ & $40 \%$ & $37 \%$ \\
\hline \multicolumn{5}{|c|}{ Commercial Vehicles } \\
\hline $\mathbf{2 0 1 0}$ & $23.3 \%$ & $24.4 \%$ & $23.1 \%$ & $23.3 \%$ \\
\hline $\mathbf{2 0 2 0}$ & $30.1 \%$ & $30.0 \%$ & $31.1 \%$ & $30.4 \%$ \\
\hline $\mathbf{2 0 3 0}$ & $35.8 \%$ & $33.6 \%$ & $37.3 \%$ & $36.2 \%$ \\
\hline $\mathbf{2 0 0 0 - 2 0 3 0}$ & $118 \%$ & $116 \%$ & $122 \%$ & $119 \%$ \\
\hline
\end{tabular}

Source: URS \& IBI Group, Existing and Future Travel Demand Working Paper, Canada-United StatesOntario-Michigan Transportation Partnership Planning/Need and Feasibility Study, November 2002. 
Given the dramatic increase in demand that is projected for the next three decades, border crossing systems would need to upgrade their facilities to ensure that the safe efficient movement of people and goods between Canada and the United States is maintained.

The capacity of a transportation system can be defined as the volume of traffic that can be serviced for unit time (usually 1 hour) under prevailing conditions. The flow of traffic through Border Crossings can be considered to be operating under interrupted flow conditions hence capacity assessments are generally more complex than for systems with uninterrupted flow conditions (e.g. freeway section without on and off ramps). Border crossings are unique in their structure and operation and traditional procedures are not sufficient to estimate border crossing capacities on their own. The components of land border crossings each have their individual capacities and the overall capacity of the entire system is equal to the component with the lowest capacity. Hence the capacity of each component has to be assessed separately and then the overall capacity of the system determined. The Existing and Future Demand Working Paper (URS \& IBI Group, 2002) estimated capacities for the Detroit-Windsor crossings by dividing the border crossing into four sections, access/egress roads, tolls, bridge/tunnel capacity and customs processing. The table below displays the findings for the Ambassador Bridge, DetroitWindsor Tunnel and Blue-Water Bridge for crossings from Canada into the United States. 
Table 2-2: Capacity Estimation For Detroit-Windsor Crossings

\begin{tabular}{|c|c|c|c|}
\hline Crossing & Section & Auto Capacity & Truck Capacity \\
\hline \multirow{3}{*}{$\begin{array}{c}\text { Ambassador } \\
\text { Bridge }\end{array}$} & Tolls (veh/h) & 5400 & 611 \\
\hline & Bridge (PCE/h) & \multicolumn{2}{|c|}{3500} \\
\hline & Customs Processing (veh/h) & 1440 & 270 \\
\hline \multirow{3}{*}{$\begin{array}{c}\text { Detroit- } \\
\text { Windsor } \\
\text { Tunnel }\end{array}$} & Tolls (veh/h) & 2700 & 103 \\
\hline & Bridge (PCE/h) & \multicolumn{2}{|c|}{1500} \\
\hline & Customs Processing (veh/h) & 1080 & 135 \\
\hline \multirow{3}{*}{$\begin{array}{c}\text { Blue Water } \\
\text { Bridge }\end{array}$} & Tolls (veh/h) & 2700 & 206 \\
\hline & Bridge (PCE/h) & \multicolumn{2}{|c|}{5700} \\
\hline & Customs Processing (veh/h) & 960 & 240 \\
\hline
\end{tabular}

Source: URS \& IBI Group, Existing and Future Travel Demand Working Paper, Canada-United StatesOntario-Michigan Transportation Partnership Planning/Need and Feasibility Study, November 2002.

Note 1: Access/egress capacities were not evaluated in terms of traffic flow but Level of Service classifications were done for the approach roads leading up to the crossings.

The table above displays that for all three of the crossings the limiting capacity component is the customs processing of the vehicles except for trucks at the DetroitWindsor Tunnel and Blue Water Bridge where tolls are the limiting capacity component. When the demand for crossing exceeds the capacity of the limiting component congestion, delays occur. For the three major crossings in the Windsor-Detroit area the limiting capacity component is near capacity if not at capacity during peak hour demand conditions.

Delays at border crossings are costly to both Canada and the United States, it is estimated that about CDN $\$ 13.6$ billion is lost annually due to delays experienced by transport 
trucks at Canada - U.S. land border crossings. A four hour delay at the Ambassador Bridge costs the Ontario economy approximately CDN $\$ 7$ million in lost production (Ontario Chamber of Commerce, 2004). Border delays have a negative impact on the ability of economies to attract investors and the cost of goods to consumers is increased to cover losses. The tourism industry is also affected negatively as well as the environmental impact that the border communities absorb as a result of congestion cannot be overlooked. Given the expected increase in future demand at land border crossings, capacity will need to be increased for many crossings in the near future. Different alternatives for increasing capacity at border crossings are discussed later in this literature review.

\subsubsection{NATIONAL SECURITY ISSUES}

Another challenge facing border crossing administrators and users is the preservation of national security. This issue always existed but after the events of $9 / 11$ its importance increased dramatically. The heightened security concerns at ports of entry into Canada and the United States has impacted negatively on tourism and trade due to the increased customs and immigration processing times generally experienced by all travelers between Canada and the United States after 9/11. Even before these events there were delays being experienced by border crossing users however the increased security concerns added to the already existing delays. Both Canada and the U.S. have an interest in secure and efficient transport of goods and people. It is generally believed that the U.S. is more likely to be a target of terrorism; however the effects this would have on Canadian 
exports will be just as crippling as a terrorist attack. Hence some experts believe that Canada has a considerably greater economic stake in preserving and enhancing the safe and efficient movement of goods between the two countries (Shea 2001). The two countries have declared their commitment to working towards addressing the threats through co-operation and collaboration on creating a Secure and Smart Border. The agreement between the two countries has been formalized in 'The Smart Border Declaration' which outlines an action plan for working towards the secure flow of people and goods, secure infrastructure and coordination and information sharing in the enforcement of the various objectives (The Smart Border Declaration, 2001).

The U.S. Department of Homeland Security has developed an advisory system that categorizes the terrorism threat level into the color coded categories as outlined in Table 2-3 below. As the security level increases in severity the customs processing time at border crossings also increases for both autos and trucks. Data concerning the variation in processing time with the changes in Security Alert Levels is currently unpublished, however anecdotal evidence suggests that there is a noticeable change in border crossing times with posted security alert levels. Customs officers are required to ask more questions and conduct more thorough and frequent inspections as the Security Alert Level increases, this translates into greater delays at border crossings. It is also important to realize that when the alert level is raised for vehicles entering the United States, Canadian officials are also required to increase their alertness in keeping with the agreement between the two countries to cooperate and work together to create a secure 
and smart border. This usually results in additional delays for vehicles entering Canada as well.

Table 2-3: Homeland Security Advisory System - Guidance for Federal Departments and Agencies

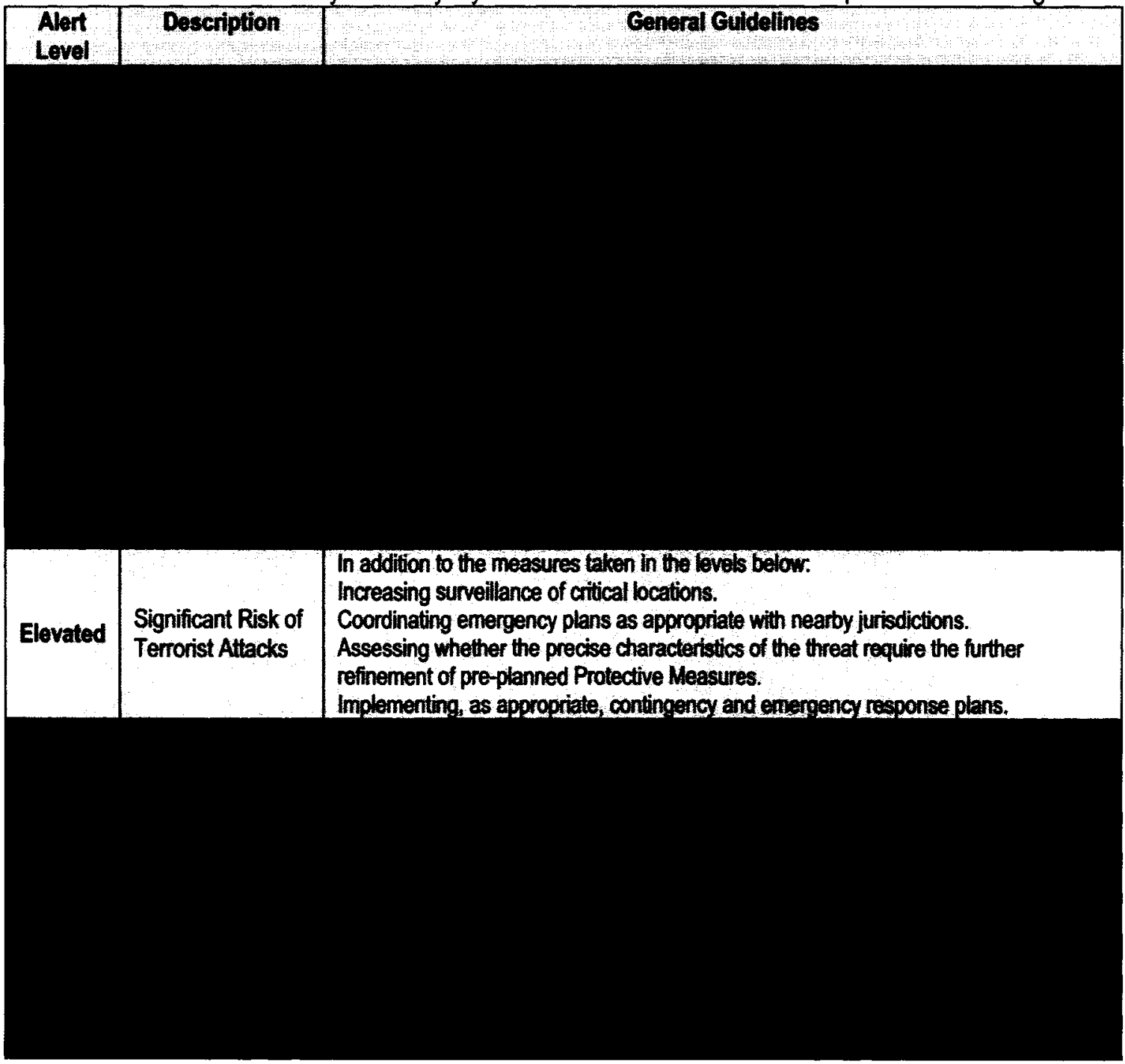

Source: U.S. Department of Homeland Security, http://www.dhs.gov/dhspublic/dislay

The guidelines listed above are general and not specific to any agency and the outworking of these measures will be manifested differently and to different extents across federal departments and agencies depending on the specific nature of the threat. 
Border crossing times generally increase as we move from the Low Alert Level thru' the Severe Alert Level.

\subsubsection{ENVIRONMENTAL ISSUES}

Traffic congestion at land border crossings also brings with it a number of environmental problems such as air and noise pollution. This directly affects surrounding communities in the vicinity of the crossing. The U.S. Environmental Protection Agency (EPA) has established a National Ambient Air Quality Standard (NAAQS) for seven air contaminants that are considered to be harmful to human health and the environment. Special standards are also established to protect high risk members of the populace e.g. asthmatics, children and seniors. Any federally funded transportation project in the U.S. has to be examined and meet these criteria before it can be implemented. In Canada, nationwide standards have been established for certain air quality contaminants that are detrimental to environmental and human health. The province of Ontario through its Environmental Protection Act has stated desirable limits for the main contaminants that are in conformance with the Canada Wide Standard (CWS). A study of routinely collected air quality data for areas around border crossings found that air quality improves as we move farther away from the crossing and is also dependent on the volume of traffic using the crossing as well as the back up of queues (Brauer, 2003). One limitation of the study was that routine air quality control measurement stations were not set up close enough to the crossing in order to assess the air quality at the crossing itself. A study performed as part of the Peace Bridge Expansion Project indicated that 
highway vehicles account for the majority of $\mathrm{CO}$ emissions in the Buffalo Fort-Erie area as well as being a major contributor to $\mathrm{NO}_{\mathrm{x}}$ emissions (Sources of Air Pollutants in the Buffalo - Fort Erie Region, 2002). Even though the study determined that the air quality in the Buffalo Fort Erie Region was below U.S. and Canadian criteria levels, it is important that we do not overlook the environmental impact of congested border crossings. In any transportation system where there is congestion of idling vehicles for extended periods of time, the air quality in the vicinity of the facility will be poor especially during hot summer days.

As part of the Needs and Feasibility Planning study conducted by the Canadian, U.S., Michigan and Ontario governments for border crossings in the South Western Ontario and South East Michigan crossings, air quality and noise pollution were investigated as part of the Environmental Assessment and discussed in the Environmental Overview Report. Measurements of ambient air quality data in the Detroit - Windsor area indicates the concentration level of some contaminants to be above the criteria established for the area. For example, one hour ozone levels on the Canadian side are above the $0.08 \mathrm{ppm}$ limit however when measured against the U.S. limit of $0.12 \mathrm{ppm}$ the ozone concentration levels are acceptable. The other concern for air quality in the Detroit - Windsor area is the Particulate Matter 10 microns and lower $\left(\mathrm{PM}_{10}\right)$; on the Canadian side the average measurements are above the regulated standard of $50 \mu \mathrm{g} / \mathrm{m}^{3}$ but are below the U.S. established standard of $150 \mu \mathrm{g} / \mathrm{m}^{3}$ for the 24 hour concentration level. The same can also be said for the Particulate Matter 2.5 microns and lower $\left(\mathrm{PM}_{2.5}\right)$. The measurements of 
the other contaminants are all below the U.S. NAAQS and Ontario AAQC levels for Carbon Monoxide, Nitrogen Dioxide, Lead and Sulphur Dioxide. The measurements were taken for widely dispersed measuring stations in the Detroit-Windsor area, however readings at the border crossings were not taken and hence it was not possible to map with confidence the variation of air quality with traffic demand and congestion at the crossing. There is no question that border crossing traffic contribute to the contaminant concentrations in the areas surrounding the crossings, however to what extent this is so depends on the location and type of other industrial developments and climate variables typical of the area. Detailed conclusive studies of the influence of border crossing traffic on the air quality are scarce/unpublished if not non-existent (URS, IBI Group, Corradino \& HLB, 2004).

Land border crossings are prime sources for noise pollution that affects neighbouring communities. Both Canada and the U.S. have similar methodologies for controlling noise even though the standards which are based on the surrounding land use patterns in the area might be different. Different units of measurement for noise is used in Canada than the U.S., in Canada the Decibel (dBA) is the regulatory unit while in the U.S. noise is represented by an index $\left(\mathrm{L}_{\mathrm{eq}}\right)$ defined by the "steady state sound level which in a stated period of time contains the same acoustic energy as a time varying sound level during the same period', or $\mathrm{L}_{10}-$ which is 'the sound level that is exceeded 10 percent of the time (the $90^{\text {th }}$ percentile) for the period under consideration'. Noise is an important consideration in border crossing studies and noise impact analysis should be done as part 
of the planning process for any improvements that may possibly affect the noise generated by border traffic (URS, IBI Group, Corradino \& HLB, 2004).

\subsubsection{VARYING STAKEHOLDER INTERESTS}

One of the difficult challenges facing border crossing improvement measures is the varying stakeholder interests that are present at most crossings. The major stakeholders for a land border crossing are typically, the bridge/tunnel operators, U.S. and Canadian Customs, Brokers, U.S. Government agencies, Canadian Government agencies, nearby municipalities/townships, manufacturers, freight movers and the travelling public. The co-ordination of these different entities whose interests are many times divergent from each other results in difficulties in the implementation of any project aimed at improving conditions at border crossings. For example a proposal to increase security checks on vehicles which will result in a reduction in the flow of traffic and increased delays will be fine with the Customs and Immigration and Department of Homeland Security in each country but will conflict with the objective to achieve revenue targets of the bridge/tunnel operators who own and operate the crossing infrastructure. The travelling public and freight movers would also be affected negatively since their interest is to reduce delays and crossing time. For any plan to improve border crossing conditions to be successful 'buy-in' from multiple stakeholders is necessary. 


\subsection{Alternatives ImPlemented And Proposed Solutions}

Alternatives that decrease the volume to capacity ratio at border crossings can take many forms, such as short term solutions by way of improvements to border processing, travel demand management options, technology deployment and/or long term solutions in the form of major infrastructure investments. Various alternatives have already been implemented with varying degrees of success in order to improve the flow of traffic through border crossings.

\subsubsection{PRIORITY CROSSING PROGRAMS}

Priority crossing programs refer to pre-screened crossing users who have obtained a certain level of clearance so that they are not subjected to the full customs examination at the crossing, hence reducing their travel time. The idea is that the more users registered in the priority crossing program, the more overall processing capacity is increased and as a result the overall crossing time for all users improves especially for the registered users. The concept of servicing priority traffic is not new for land border crossings between Canada and the U.S., the concept was first implemented in the early '90s during the heydays of cross-border shopping. The earliest priority programs were known as PACE and CANPASS, in this program a card was issued to approved crossing users who were screened and registered in the program. PACE cards gave vehicles and occupants fasttrack into the U.S. using dedicated lanes while CANPASS cards provided similar entry into Canada. By the end of the ' 90 s, PACE and CANPASS lanes had taken $30 \%$ of cross border vehicle traffic out of regular lanes. At the time of the September 11, 2001 attacks 
on the World Trade Center there were 189,000 Canadians and Americans who held PACE and CANPASS cards (Ward, 2002). Frequent cross border travellers who live near the border are the majority of the registered crossing program members, many of whom live in one country and work in the other. Hence during the morning and evening peak hour demand periods a priority crossing program comes in useful for these travellers who typically travel during these times. After the September 11 attacks on the world trade center the governments of Canada and more so the U.S. required an intense reevaluation of the security measures in place at their international border crossing entry points. As a result a new priority crossing program for autos referred to as NEXUS (which began development in 1999 and gained momentum after 9/11) has been implemented at most of the busiest border crossings between Canada and the U.S. NEXUS programs also use a card for its registered members to cross, however there are more security features on the card as well as photo ID to make it more difficult to duplicate. The qualifications for obtaining a NEXUS card are more stringent than it was for the CANPASS/PACE program. The advantage of the NEXUS program is that the registration allows entry to the U.S. and re-entry into Canada. NEXUS cardholders are allowed to use dedicated lanes at the border crossing and cards are issued after an application is made and background checks are done. This is intended to facilitate the flow of low risk pre-screened, pre-authorized frequent users of land border crossings. Nexus users are not subjected to the usual questioning that non-registered users are subjected. It is reported that there are currently some 30,000 registered members in the program about fifty percent of the participants crosses the border in less than seven 
seconds (Nexus, 2004). It is very likely that most if not all of the former PACE and CANPASS members have applied or will be applying for NEXUS registration.

A priority crossing system for commercial vehicles also exists for cargo entering the U.S. from Canada the Pre-Arrival Processing System (PAPS) is employed. This system is geared to provide the shipping information such as the carrier's unique barcode, invoice and corresponding manifest to customs brokers prior to the cargo arriving to the border so that the information can be processed and entered into the U.S. Customs Automated Commercial System (ACS). When the cargo arrives at the primary customs inspection booths the inspector scans the barcode from the hard copy invoice submitted by the truck driver and accesses the information on the ACS. The primary customs inspector then makes a decision to release or examine based on the selectivity results presented on the ACS. The aim of this system is to reduce unnecessary truck congestion at the U.S. Plaza by decreasing wait times for prepared drivers and reducing the inspectors' clerical tasks. The Pre-arrival Processing System for U.S. bound commercial traffic is not interchangeable with the Canadian Pre-Arrival Review System (PARS) which is designed for Canadian bound commercial vehicles. Most of the major land border crossings between Canada and the U.S. have these programs in place. The disadvantage of this type of program is that the prepared drivers are mixed in with the unprepared drivers and as a result spend a lot of time in queue waiting on the drivers not registered under the PAPS/PARS system. A unique solution to this problem has been the implementation of a Pre-Processing Center (PPC) at the Peace Bridge. Initially this centre was called the 
Commercial Vehicle Processing Centre (CVPC) which was opened in November, 1999 to facilitate the processing of commercial vehicles heading into the U.S. from Canada. In November 2004 the PPC was opened providing new and improved facilities and services and it replaced the CVPC. Drivers without the complete paper work are required to stop at the PPC before proceeding to the primary customs plaza for processing. At the PPC the paper work is processed by the broker and entered into the ACS. The truck can then travel across the bridge to the primary customs inspection booths after the paperwork has been completed.

Before the PPC over 700 vehicles a day were being sent to secondary customs inspection due to incomplete paperwork (Commercial Vehicle Processing Center, 2005). These vehicles were causing unnecessary congestion and delays to other carriers whose paper work were in order. With the PPC operating efficiently prepared carriers are no longer stuck in queues behind unprepared drivers and fewer trucks are being sent to secondary customs inspection, hence the resources of customs officers, space and equipment can be directed to focus more on high risk cargo and carriers. The U.S. and Canada have implemented another harmonized crossing program for commercial vehicles referred to as the Free and Secure Trade Program (FAST). This program provides an expedited clearance process for those carriers and importers who are regarded as low risk. These stakeholders have to be enrolled in the U.S. Customs - Trade Partnership Against Terrorism (C-TPAT) or Canada's Partners in Protection (PIP) and similar programs which call for the client to minimize exposure of their business process to criminal 
elements. For a commercial vehicle to qualify for FAST expedited clearance the shipment must be entered by a C-TPAT/PIP approved importer/exporter, carried by a FAST/C-TPAT/PIP approved cross border carrier and driven by FAST approved commercial drivers. In advance of the cargo arriving at the border the data is transmitted electronically to customs. When the shipment arrives at the border it will be processed through a dedicated lane where the driver will present their registration card and bar-code or transponder technology will be used to identify the pre-authorized carrier and preauthorized importer. The cargo shipped via the FAST program is generally low risk but are still subjected to physical inspections at the discretion of the customs officer however this happens at a significantly lower frequency than the non-registered users. In order to maintain the integrity of the program compliance account managers are dedicated to building and maintaining client partnerships and auditing client compliance. Client compliance audits can be done randomly at any point of the supply chain, whether at the border or away from the border. The aim of this program is to reduce the amount of information processing required for customs clearance, reducing the rate of border examinations, and overall reduction in travel time for registered crossing users. FAST has been implemented at the busiest border crossings between Canada and the United States since 2002; to date over fifteen land border crossings have FAST clearance available for registered users.

The response to the NEXUS and FAST priority crossing program to date has been encouraging and the continuing funding of the U.S. government for these programs to be 
maintained and improved indicates that the priority crossing programs will continue to be an important feature of land border crossings into the future (Department of Homeland Security Appropriations Bill - 2006, $109^{\text {th }}$ Congress Report, 2005).

Dedicated crossing lanes are essential in facilitating the passage of priority crossing traffic, however the access to these lanes are many times congested at busy crossings. One way of preventing priority crossing traffic from being caught in this congestion is to provide queue jump lanes from a non-congested location upstream in order to allow for NEXUS and FAST users to get around other vehicles waiting in queue for inspection. This alternative is feasible only if space and the geometric configuration allow for these lanes.

\subsubsection{INTELLIGENT TRANSPORTATION SYSTEMS}

Cross border traffic flow can also be aided by Intelligent Transportation Systems (ITS). ITS in the form of changeable message signs are useful for directing and streamlining different categories of traffic in approach management. For example priority vehicles can be directed to their dedicated lanes where processing is expedited faster. Transponder technology, smart cards, e-seals and Weigh in Motion can also be used to communicate via electronic receivers to customs officials, brokers and automated toll collections can be made without stopping. The technology allows for information about travellers or cargo to be transferred in a timely manner to customs officers and brokers. This translates overall to more efficient processing and operation of border facilities. 
Electronic Screening is one ITS technique that can be used to improve the overall efficiency of the border crossings especially for commercial vehicles. The concept involves the utilization of roadside readers to verify the size, weight and credentials information for a particular shipment. This information can be transmitted in advance of the vehicle arriving at the border crossing and the truck driver can be directed to the appropriate lane for clearance depending on the advanced information read and transmitted to customs officials ahead of time. This process can potentially lead to an automated or semi-automated border crossing process in the future. Field Operational Tests have been and are being carried out to test the potential use of this system at international land border crossings between Canada and the United States. The primary benefit of such a system if it can be implemented successfully is a reduction in delays and delivery costs. One of the field operational tests carried out is described below.

In an effort to provide a transparent, seamless border crossing interface between Canada and the United States, field operational tests (FOT) of ITS were carried out at various border crossings as part of the U.S. - Canada International Border Crossings Project (Booz-Allen \& Hamilton, 2000). One of the crossings chosen for this test was the Ambassador Bridge and the purpose of the experiment was to demonstrate the ability of ITS technology to expedite safe and legal international border crossings for both commercial and commuter vehicles in an operational environment. The Ambassador Bridge Border Crossing System (ABBCS) as it was referred to, was implemented with the objective to demonstrate how the system will expedite the crossing of pre-processed 
vehicles. The system was designed to be able to detect and identify commercial vehicles, crews and commuter vehicles and occupants using an integrated system centered around the use of transponders, roadside detection equipment and smart card \& readers. The system allowed for the electronic collection of tolls and the ability to electronically screen registered vehicles, cargo, and occupants upon entry into the U.S. utilizing the system of single mounted transponders, smartcard and readers and dedicated short-range radio communications (DSRC). The results of the tests carried out indicated that expedited border processing is a technically feasible option even though there were some minor glitches in the system e.g. transponder batteries were discharged quite rapidly when it was continually being read by the DSRC. One limitation of the FOT was that it was not possible to replace the existing system with the ABBCS being tested and it was used in parallel with the existing system hence resulted in more work load for border officials and employees hence the efficiency benefits could not be realized. However computer simulation of the crossing operating under ABBCS indicates that with careful lane assignments and proper deployment of technology, travel time for vehicles can be reduced significantly. Surveys done as part of the FOT indicate that bridge users will not enrol and use the ABBCS unless they can be convinced of any significant tangible benefit that will accrue to them. It was also not possible to assess the degree to which a system like the ABBCS would influence the levels of regulatory and safety compliance of commercial vehicles and autos. This was due partially to the narrow scope of the FOT which did produce modest technical and operational success that support the concept of emerging compliance based heavily on advanced screening technologies. 
ITS technologies can definitely contribute significantly to the efficiency of the Border Crossing Process. In some areas the technology needs to evolve and be customized for border crossing processes. The challenge then will be to select the appropriate technology and network it in a way that will meet the needs of the various stakeholders. More field testing will be required in order to prove the reliability and suitability of the ITS to the decision makers. What we can expect to see in the future is a phased deployment of technology over time at land border crossings between Canada and the United States.

\subsubsection{TRANSPORTATION DEMAND MANAGEMENT}

Transportation Demand Management (TDM) is a general term that refers to strategies that result in more efficient use of the transportation resources. For border crossings it can be the application of technology, policies or other methods to shift, reduce, divert or better handle existing crossing demand. Some TDM strategies that may apply to border crossings are ride sharing, bus/rail rapid transit, promoting modal shifts, demand time shifting, demand diversion to nearby crossings, demand reduction by telecommuting, etc.

As part of the Canada-United States-Ontario-Michigan Transportation Partnership Planning/Need and Feasibility Study, an examination of Transportation Demand Management options for the crossings in South-western Ontario - Michigan was carried out (URS \& IBI Group, 2003). The possibility of modal split in the transportation patterns for commuters and freight is predicted to remain constant in the long term. Autos and trucks predominantly are the primary modes for commuters and freight in the 
region and this trend is expected to continue for a long time into the future except for a slight shift from truck to rail in the freight sector. This shift is expected due to the committed investments into improving the rail sector, however it is predicted that the increased market share of the rail mode will not negate the need for border capacity increase in the future. For passenger travel, improvements to transit, rail and marine services will contribute marginally to demand reduction at land border crossings. Increase of cross border transit level of service is a feasible option and will service mainly the local community residents who make up the majority of rush hour traffic at the crossings. For transit to be successful it would have to offer timely and convenient service to potential users. The current cross border transit system does not offer a level of service attractive enough to be able to compete with the auto mode and even if there was an appreciable increase in rider-ship it will not prevent queue formation and congestion during rush hour periods at the crossing. The marine mode is available during the summer months, however even if there is a major increase in the capacity of this mode it is not expected to be adequate to pull enough volume away from the land crossings to reduce demand noticeably. A ride share program is not expected to have much of an additional effect as a demand reduction measure in the Detroit - Windsor area since there is evidence that it is already being practiced. The average auto occupancy across the Ambassador Bridge is 1.85 and at the Detroit - Windsor Tunnel it is 1.75 . For highly populated metropolitan areas the average auto occupancy is around 1.1 , hence it is believed that implementation of a ride share program would only yield marginal results in demand reduction. 


\subsubsection{POLICY OPTIONS}

Governmental policies also play a role in the way border crossings are operated. For example the decision to hire more customs and immigration staff to supplement capacity during peak hours is a management decision that is based on fiscal policy guidelines handed down from government. The government of Canada and the United States have been collaborating on border crossing policies for quite some time. Recently the need for a fresh look and a new approach has been discussed especially after the advent of NAFTA and more so after the events of $9 / 11$.

Figure 2-3 in this literature review indicates the steep rise in trade between Canada and the U.S. since 1993 when NAFTA was launched. This increased trade volume passing through land border ports placed huge demand on border clearance processes. This prompted the co-operation between Canada and the U.S. to establish The Shared Border Accord which was announced on February 25, 1995. The Accord signed between the two countries commit both governments to promoting international trade; facilitating the movement of people; providing enhanced protection against drugs, smuggling and the illegal and irregular movement of people; and reducing the costs to both governments and the public. The implementation of the Commercial Vehicle Processing Center (CVPC), Chemical Detection and X-ray Systems Projects to detect contraband and illegal goods are successful ventures of this shared accord. 
The challenge for land border planners and policy makers remains facilitating the quick flow of goods and people while maintaining national and economic security. Andrew Shea in a Conference Board of Canada Paper discusses three broad policy scenarios for freight carrier crossing at land border crossings (Shea, 2001). The first scenario involves enhancing border efficiency by exploiting more intelligent methods of processing border examinations. Shea points out some of the keys that will make this option a success is close cooperation between the two countries, appropriate and timely information sharing and the implementation of appropriate technology to enhance the border crossing process. The second scenario discussed by Shea is a move away from the border location being the primary and only location for inspection. The point is made that the U.S. - Canada border is basically a random check point where only a small percentage of trucks are inspected thoroughly. Any increase in the intensity and frequency of the inspections will result in more than normal traffic queues. The shift away from the border as the only line of defence to the more in-depth approach, where inspections are done at points of loading, sea ports of entry or other locations before the truck reaches the border is suggested in this scenario. The suggestion of this perimeter security approach means that standardization and mutual recognition of each country's inspection procedure is required. The third scenario suggested by Shea is one of 'Close Compatibility for InDepth Security', this means when fully implemented Canada and the United States will have a comprehensive harmonization of all policies, laws and agencies dealing with security issues. It is conceded that this is quite arduous to achieve and the length of time 
the European Union took to be where they are today gives an idea as to how challenging the process of harmonization is.

There has been an increased level of collaboration and commitment between Canada and the United States after September, 2001. In December 2001, 'The Smart Border Declaration' and associated 30-point action plan was signed by the two countries. The Smart Border Declaration highlights the need for new approaches to meet the challenges facing stakeholders at land border crossings and commits the governments of Canada and the U.S. to work together to build a 'smart border for the $21^{\text {st }}$ century. A smart border is one that securely facilitates the free flow of people and commerce; ...' (The Smart Border Declaration, 2001). A 'North American Zone of Confidence' is introduced as the foundation for the Smart Border concept. This refers to efforts away from the border to promote the secure flow of people and goods. The governments agreed on a 30-point action plan to stimulate the effort toward creating a Smart Border. The plan is supported and guided by four pillars by which commitment of the two countries are categorized.

1.) The Secure Flow of People - collaboration in identifying security threats existing internally and outside of North America before entry. Also the establishing of a secure system that facilitates the flow of low risk travellers between the two countries.

2.) The Secure Flow of Goods - collaboration in identifying high risk goods within the borders at points of entry into North America and outside the borders at points of loading abroad. Common standards for screening cargo will be developed as 
well as compatible security standards at production and distribution facilities to minimize security threats. Procedure for expediting the flow of low risk goods to be developed, by inspection procedures away from the border.

3.) Secure infrastructure - commitment to relieving congestion at crossing points through investments in border infrastructure and technology that will help to improve flow across the border.

4.) Coordination and Information Sharing in the Enforcement of these Objectives the commitment to put in place the necessary tools and legislative framework to ensure the sharing of information and intelligence between the two countries.

In addition to the Smart Border Declaration signed between Canada and the United States, the Federal Transportation agencies of the two countries have expressed their commitment to cooperation via a Memorandum of Cooperation between the USDOT and Transport Canada. This document is an expression to cooperate on solving transportation issues of mutual interest and the need to develop a common border/corridor strategy is specifically mentioned (Transport Canada \& USDOT Memorandum, 2004).

Progress has been made towards achieving a Smart Border, with regard to the secure flow of people. The NEXUS program is seen as a step on the way and is currently in place at most of the major crossings (White House Press Release, June 2002). The FAST program has been implemented and is a contribution toward achieving the Secure Flow of Goods objective in the Smart Border Declaration. The 'Customs Trade Partnership Against Terrorism' has been created where certain companies have agreed to take 
concrete steps to tighten security along the entire supply chain. In exchange these companies are given expedited clearance for their goods at ports of entry into the U.S. and Canada. This expedited crossing program is FAST which is seen as the first step in how Canada and the U.S. will eventually process all commercial shipments using the principles of risk assessment and pre-approval. Efforts to enhance secure infrastructure has been made in the form of bi-national steering committees being set up to assess security treats at shared infrastructure between Canada and the U.S., this process has resulted in security improvements at many locations. An increase in the investment from government at different levels has improved processing capacity at many land border ports of entry. Computer simulation modelling has been used to help optimize infrastructure investments. Information sharing between the two countries has also increased as a result of the commitment to work together towards a Smart Border.

\subsection{Previous Computer Simulation Modelling Efforts}

\subsubsection{Computer Simulation Overview}

Computer simulation has been used in many areas of research and border crossings are no exception. It is a relatively inexpensive and useful tool that is employed to help analyze a real system when direct experimentation is impossible, too costly, or unsafe. A computer simulation is an abstraction of a real world system that is representative but in many cases not identical in every regard. Every model has its limitations but as long as it has been established to be representative of the real world situation (i.e. calibrated), it can be 
used to help predict performance of the system under different conditions. There have been a number of attempts at modelling border crossings and some have been examined as part of this review.

Computer simulation models of transportation systems are generally classified according to the level of detail with which they represent the traffic stream (Traffic Analysis Tool Box Volume 111 - Appendix A, USDOT \& FHWA, June 2004). There are three categories:

Microscopic Models: In these models the interaction of individual vehicles with each other is simulated and algorithms and rules describing how vehicles move and interact are usually built into the modelling software. Vehicle parameters of acceleration, deceleration, lane-changing and passing manoeuvres are determined using deterministic or stochastic relationships.

Mesoscopic Models: These models simulate individual vehicles but their interactions are based on aggregated relationships. For example mesoscopic models can simulate individual vehicles in a network and determine their travel times from the simulated average speeds on the network links. The average travel times are computed based on the speed-distance relationship. 
Macroscopic Models: These types of models simulate traffic flow by utilizing aggregated traffic stream flow parameters such as speed, flow and density. These models are useful for mapping the spatial and temporal extent of congestion caused by traffic demand or incidents in a network. Individual vehicles are not modelled but traffic flow parameters and resulting effects are modelled based on aggregated relationships.

Microscopic models are potentially more accurate than macroscopic simulation models; however they usually require a lot more information and effort to calibrate. Also computational time is usually more for microscopic models than for macroscopic.

\subsubsection{Use Of Micro-Simulation To Evaluate Technology}

\section{DePloyment At LAND Border Crossings.}

There is not a lot of information published from previous micro-simulation studies of land border crossings and they revolved mainly around the use of micro-simulation as a tool to evaluate technology applications at land border crossings. A study was done by Cornel University \& Rensselaer Polytechnic (Cornel University \& Rensselaer Polytechnic, 1999) as part of a North American Trade Automation Prototype (NATAP) pilot project conducted at the Peace Bridge joining Buffalo, New York to Fort Erie, Ontario. This project was a result of the NAFTA Accord between the Canada, the United States and Mexico and was implemented to develop technologies for sensing, inspection and communication to help reduce congestion and time delays at border crossings. This 
project is normally referred to as the Intelligent Border Crossing System (ITBCS) project and was carried out for The Buffalo and Fort Erie Public Bridge Authority.

The ITBCS is a transponder based system where load-driver-vehicle combinations are provided electronically to border crossing officials while the truck approaches the inspection booth to help expedite the clearance process. The field test was done on a limited number of trucks and the information gathered from this test was used to determine the parameters for micro-simulation analysis.

A micro-simulation model was created for the crossing process using ARENA and it was used to evaluate the impact of different penetration rates of ITBCS technology on the overall travel time delays experienced at crossings. The different scenarios modeled also considered the varying of the lane use configurations of the approach to the inspection plazas. Calibration of the model was done using measured data of the system throughput for a given time and a total count of occupancy at any time within the crossing. The standard used for model calibration was that over a few model runs the average system occupancy should be close to the average occupancy on the observed day and the range of number of trucks in the system across model runs should be close to the observed range.

The model accounted for auto flows and truck flows together and for both entering the U.S. and entering Canada. Trucks entering the U.S. were categorized into different 
categories for the purpose of customs processing. The categories were Monthly, InTransit, Line Release, ITBCS, Empty and General. The line release program was set up to facilitate high volume; low risk repetitive shipments and participants must display a history of error free documentation and not present an enforcement risk. Line Release trucks are rarely sent to secondary inspection and are released at the point of primary customs inspection. ITBCS trucks are those that were given an information technology upgrade during the field investigation of this research. The percentage of Autopass participants was reflected in the total auto demand profile along with the rest of the auto demand. The results of the modelling process indicate that information technology can have a major impact on time spent in the system. Time savings of $66 \%$ from were derived from the simulation model for average time in the system across all categories of trucks for a $50 \%$ ITBCS participation rate. The $90^{\text {th }}$ percentile value for average time in system also dropped by $78 \%$. These times reported include for trucks sent to secondary inspection and the improvements in average time spent in the system due to increased participation rate was primarily because of the reduction in the number of trucks sent to secondary inspection. Trucks sent to secondary inspection dropped by $64 \%$ from 90 to 33. Average primary inspection delays also fell dramatically by $64 \%$ as a result of increased ITBCS participation. U.S. bound auto travel times also decreased dramatically with increased ITBCS participation. The overall average time in the system dropped $35 \%$ while the $90^{\text {th }}$ percentile value dropped $48 \%$ for an increase of ITBCS participation from twenty percent to fifty percent. The simulation results also showed that when there was an increase in the number of dedicated ITBCS lanes that replaces regular use lanes 
there was a significant drop in average time in system. For example an increase in dedicated ITBCS lanes from one to two resulted in a $21 \%$ drop in average time in system and a $28 \%$ decline in the $90^{\text {th }}$ percentile time in the system. The same dramatic results were obtained with increased ITBCS participation rates for traffic entering Canada from the U.S. For trucks a drop of $34 \%$ for average time in system was obtained for an increased ITBCS penetration rate of $50 \%$. The $90^{\text {th }}$ percentile value decreased by $34 \%$, this reduction was as a result of the decrease in the number of trucks sent to secondary inspection as ITBCS participation increased. The findings for autos entering Canada show that in order to maintain an adequate level of service over the range of traffic volumes using the bridge one dedicated ITBCS lane is needed for a $35 \%$ participation rate and at a 50\% participation rate two dedicated lanes are needed.

The research performed by Cornel University and Rensselear Polytechnic involved the analysis of the Peace Bridge border crossing by considering the Canadian side separately from the U.S. side even though traffic in both directions were considered. The primary variable of the simulation model was the different penetration rates of ITBCS technology and selective lane use configurations. In this research the penetration rates for NEXUS and FAST are varied inputs into the simulation model as well as demand for crossing and appropriate changes to lane use configurations. The Cornel-Rensselaer study proved that significant reductions in overall delay can be obtained for greater penetration levels of technology and priority clearance. 
The simulation models constructed for this research are unified models simulating all the infrastructure elements of the crossing in one direction as one continuous traffic system. The advantage of this unified model is that the outputs will be representative of the system as a whole.

Another study that investigated the use of technology at land border crossings was carried out by Glassco, FHWA, 1999. This paper documents a study of the North American Trade Automation Prototype (NATAP) operations at the US Customs facility at the Ambassador Bridge in Detroit, Michigan. The results of a Field Operational Test (FOT) of NATAP technology implementation was used to create a model using the WESTA software to simulate the deployment of NATAP equipment to cars, trucks, and custom inspection stations at levels greater than could be achieved during the FOT.

Outside of the base case three sets of analyses were conducted for truck customs processing where there were three, four or five lanes available for primary inspection. For each set the proportion of trucks with NATAP transponders varied from 5 percent to 75 percent and the policy for lane usage varied among (a.) dedicated to NATAP trucks (b.) non-NATAP trucks only and (c.) mixed use allowing either type of truck. Increasing the NATAP participation resulted in shorter queues and reduced risk of gore blocking. The alteration in primary inspection lane configurations also made a difference to the results, for example dedicated NATAP lanes for trucks showed a negative impact on gore (i.e. point where truck and car traffic are directed to their respective primary inspection 
sites) blocking time with respect to mix use lanes until a $50 \%$ participation rate is reached.

Overall the impact of increased NATAP participation is the reduction of time-in-system for both line release and NATAP trucks. For an all-mixed lane configuration the average time-in-system for NATAP trucks dropped from 12.6 minutes at the $10 \%$ participation level to 6.0 minutes at the $75 \%$ participation level. The impact on average line release truck time-in-system is similar; 12.8 minutes at the $10 \%$ participation level drops to 6.8 minutes at the $75 \%$ participation level. For both NATAP and Line Release trucks the time-in-system is reduced by roughly 1 minute for each additional $10 \%$ growth in NATAP participation.

Similar analyses were conducted for cars, varying the proportion of cars in the registered commuter program with transponders, and the number and usage of Dedicated Commuter Lanes (DCL). Increasing participation in the DCL program resulted in reduced queue growth and gore blocking from cars backing up at primary inspection. The base case condition considered $5 \%$ of the cars in the registered crossing program using dedicated lanes, the simulation results indicated that there will be gore blockage $94 \%$ of the time. Raising the participation to $25 \%$ and using mixed lane operations eliminates the gore blocking problem. At $75 \%$ participation the average queue length was 7 vehicles. 
The scope of this study included the U.S. Customs facility at the Ambassador Bridge and did not model the entire crossing infrastructure as a whole. The performance of the system exposed to traffic demand variation was not investigated.

\subsubsection{Use Of Micro - Simulation To DeVelop A Mathematical Delay Model At Land Border Crossings.}

Lin and Lin, 2001, used micro-simulation techniques to develop a delay model for quick evaluation of changes in operating policies and plaza designs for border crossings in the northern New York area. The Seaway, Thousand Islands, and Ogdensburg crossings were the focus of the analysis. The software used in this analysis was an enhanced version of a simulation model, referred to as the Toll Plaza Simulation (TPS) model (Lin and $\mathrm{Su}$ 1994). This model treats individual vehicle attributes and driver behaviour as probabilistic entities, and it updates the speed, location, and acceleration rate of each simulated vehicle once every second. The paper referred to three types of delays, the first being "time-in-queue" and is the elapsed time from the moment a vehicle joins a queue until the moment the rear end of that vehicle crosses the reference line near a booth. The second type of delay is called "approach delay" which refers to all the delays upstream of a booth up to the moment when the rear end of a vehicle crosses the reference line. The third type of delay is total delay that is the sum of approach delay and acceleration delay beyond the reference line before a vehicle reaches its expected cruising speed. The output of the TPS model includes the three types of delay described previously and it was 
found that estimates of "time-in queue" and queue length obtained from the TPS model were largely within $10 \%$ of observed values. The TPS model did not analyze the entire crossing system including tolls and customs inspection booths simultaneously but dealt only with delays at customs inspection booths.

\subsection{SOFTWARE OVERVIEW}

There has not been a lot of micro-simulation modelling done for land border crossings and the generic traffic simulation software packages available commercially were not developed to be applied to the unique structure and functionality of land border crossings. The software packages developed for modelling urban street networks come closest since they were designed to simulate traffic flow in an urban setting containing, traffic control mechanisms (e.g. intersections) that produce the similar traffic stream flow properties to that found at border crossings. For example the car following, lane changing and queuing theoretical models featured in urban traffic simulation programs are generally representative of traffic and vehicle/driver behaviours at border crossings. The classical car following theory describes the longitudinal movement of vehicles in a traffic stream as a vehicle attempts to advance at its desired speed while maintaining a safe following distance from the vehicle ahead. The lane changing theory describes lateral traffic behaviour in terms of a number of perception thresholds governing the consideration of risk of gap acceptance in a neighbouring lane. The program algorithm processes a set of decision rules to determine if a speed advantage may be obtained by changing lanes. 
Land border crossings are characteristic of areas of intense traffic mixing, especially after primary customs inspection booths when drivers are trying to change lanes to get to their exit ramp or to secondary inspection parking lots as designated by the customs and immigration staff. The fact that this phenomenon usually happens in merge areas and approaches to primary customs inspection booths, makes the task of micro-simulation very difficult if not impossible using the common urban traffic simulation models that are programmed to use the lane changing theory as mentioned above.

The software programs used in the studies discussed above were not developed specifically for modelling land border crossings. WESTA was developed to model Truck Weigh Stations on highways or any vehicle inspection or toll collection stations. It was developed by the Federal Highway Administration (FHWA) in the United States to help quantify the benefits of ITS to commercial vehicle operations (CVO) and state highway authorities (WESTA User Manual, 1999). The model was tested on a number of Weigh Stations and Truck Inspection sites and was declared by officials in each State that it has been helpful in analyzing alternatives and in presenting the results of analysis to others. The advantage of WESTA is its capability of modelling the various physical infrastructure components of a border crossing such as access, toll facilities, bridge crossing, inspection facilities, parking, egress, fixed cycle and actuated traffic signals. Additionally WESTA takes into account various behavioural aspects of drivers and vehicles operation characteristics such as aggressive drivers, acceleration, deceleration, lane changing and merging traffic. One of the advantages of WESTA that makes it suitable for modelling border crossings is its ability to route vehicles to inspection booths 
depending on queue length pending for each booth. However WESTA is not quite suited for modelling the mixing of traffic across lanes after the inspection booths, because lanes are modelled as individual links and lane changes are done only when links are arranged parallel to each other. Hence the intense mixing of traffic that takes place under congested conditions at border crossings are not replicated accurately using WESTA. The other disadvantage with using WESTA is that creating the model is usually done using an input text file with programming language vocabulary unique to WESTA. Therefore the creation of a model using WESTA is a tedious and time consuming process, also the link locations are programmed by stipulating the start and end coordinates since no graphical user interface (GUI) for input purposes is available in WESTA. The computing time of a model using WESTA also tends to increase dramatically with an increase in the number of links programmed and the amount of vehicle entities needed to be represented by the model. Another limitation of WESTA is the limited amount of links that a single simulation can accommodate. WESTA can only model a maximum of 300 links per simulation which is typically not enough to accurately simulate land border crossings. WESTA was used to model the Peace Bridge - Canada Bound, auto and truck traffic.

Other software has been used previously to model border crossings, for example ARENA and the Toll Plaza Software mentioned in the study review above. One of the popular micro-simulation software that was developed to model traffic in an urban area setting is VISSIM. VISSIM version 3.7 was used in this research to model the Ambassador Bridge 
U.S. bound border crossing facilities. Even though it has not been tailor made for modelling land border crossings, VISSIM has the functionality to replicate many of the border processes and traffic dynamics. VISSIM uses the psycho-physical driver behaviour model developed by WEIDEMANN (1974). This model results in an iterative acceleration and deceleration process for car following depending on the driver perception threshold of the speed of the leading vehicle. For lateral lane changing there must be suitable time headway between vehicles in the adjacent lane that the vehicle wants to go. Besides the driver-vehicle modelling strengths of VISSIM it also has enough capacity to accommodate a large amount of links and its processing capacity allows it to compute at relatively quick simulation speeds. VISSIM also has a graphical user interface (GUI) to allow model construction to be quicker and more user friendly (VISSIM User Manual, 2004).

The Federal Highway Administration in cooperation with the Border Station Partnership Council is developing a customized analytical tool to assist in the coordination of improvements to border ports of entry. Border Wizard is a border crossing simulation model software and is currently in use by the U.S. government but has not been made available to the public for commercial use. Border Wizard is said to be able to simulate all federal inspection activities at any land border station to determine infrastructure, facility, and operational needs to ensure safe and secure operations. The facility layout and operational data are entered into the program via data entry screens. Border Wizard can then construct and help in the analysis of border station design and operations. At 
all major border crossings information is being collected to help with the development of the model software.

The use of Border Wizard has been reported to result in millions of dollars of savings in reducing unnecessary or redundant capital investments (Freight News, April 2002). In the future it is expected that the software will be used to run multiple border stations simultaneously or comparatively while monitoring the effect of one to another.

\subsection{THEORETICAL APPROACH}

Land Border Crossings can be classified generally as a transportation system consisting of the same general elements as can be found in typical transportation systems, such as fixed facilities, flow entities and control mechanisms. The unique component is the nature and administration of the control system, specifically customs processing and inspection, found at land border crossings. The stream flow variables of concentration, speed and flow differ significantly for each section of border crossings especially when operating under high demand conditions. It can be said that traffic at land border crossings have more similarity to traffic in an urban setting than it does to traffic in uninterrupted flow conditions. Border crossings are also unique in the method and form of technology deployment for the control system when compared to typical transportation systems.

The main goal of any transportation system is to provide a means of safe mobility for people and goods in a timely and efficient manner. At land border crossings the 
emphasis on maintaining and enforcing secure and safe transportation many time takes precedence over the interests of mobility and travel time delays. This is not typical of other transportation infrastructure outside of the border crossing. Hence in evaluating the impacts or consequences of transportation related proposals the same value system as is used for typical transportation systems away from the crossing (i.e. freeways, at grade intersections, public transit etc.) cannot be applied without modification to land border crossings. An efficient transportation system refers to one that is well balanced in meeting a variety of often conflicting requirements that society generally considers to be important. These usually include but are not limited to cost considerations, convenience, protection of environmental quality, and protection of individual rights, which may have a variable priority depending on the issue (Papacostas and Prevedouros, 2001). At land border crossings one of the additions to this list will be how will the proposed changes impact on the ability of the crossing to maintain and enforce measures related to national security.

Capacity and Level of Service (LOS) analysis as is applied to typical transportation systems can be adapted for border crossings as well. Traffic at land border crossings can be classified under interrupted flow conditions; however the difference between urban traffic flow and border crossing traffic flow is the fact that border crossing process is arranged in a series of sequential infrastructure and activities. This series relationship typically includes access roads, toll collection, the bridge crossing, customs inspection and egress roads. The overall capacity of the crossing is governed by the limiting 
capacity of each component. The component with the lowest capacity will be the governing overall capacity of the crossing. The Existing and Future Travel Demand Working Paper (URS \& IBI Group, 2002) discusses capacity estimation approaches for each component for crossings in the Southeast Michigan/South-western Ontario border crossings. For access roads to the crossing the Highway Capacity Manual (HCM) Urban Streets Methodology based on average speed on links and through intersections was used to determine the operating LOS for different segments of the approach roadways. The results of the analysis indicated that the access roads leading to the Ambassador Bridge are functioning close to capacity during peak periods and a short term increase in demand in the near future can result in the access roads becoming a bottleneck point for the crossing.

Toll capacity was estimated also for the crossings mentioned above, average toll service times were estimated for autos and trucks and these were applied to determine the hourly service capacity per lane which was factored by the number of booths available at the facility. The results for U.S. bound autos and trucks across the Ambassador Bridge indicate that the $\mathrm{V} / \mathrm{C}$ ratios are well below capacity being 0.69 and 0.58 respectively.

The bridge crossing roadbed capacity was also estimated in the working paper utilizing earlier estimates by MTO, MDOT and Transport Canada which used 1985 HCM procedures. The estimate was updated using HCM 2000 procedures and was based on LOS E with a Passenger Car Equivalence (PCE) Factor of 3.0 for commercial vehicles. 
It was acknowledged in the paper that standardized engineering techniques do not exist for estimation of international bridge roadbed capacity given the unique physical, traffic use and vehicle configuration mix. Nevertheless the estimated peak hour $\mathrm{V} / \mathrm{C}$ ratio for the Ambassador Bridge roadbed capacity is 0.72 indicating that there is room to accommodate additional traffic as may be required during peak periods.

Customs processing capacities is a function of the number processing lanes and the processing times for each vehicle. Estimates of average processing times for autos and trucks were performed and the hourly service capacity per lane was determined. The lane processing capacity was factored by the number of processing booths available in order to determine the processing capacity for the crossing. The peak hour $\mathrm{V} / \mathrm{C}$ ratio was determined for U.S. bound Ambassador Bridge traffic to be 0.86 for autos and 1.32 for trucks. These estimates were done for the base year 2000 conditions.

From the working paper analysis the Ambassador Bridge U.S. Bound Border Crossing is at capacity for its border processing component. This research will examine the impact that priority crossing programs can have on increasing the crossing efficiency. In the working paper it was estimated for future base-case capacity estimations that a twenty five percent NEXUS participation rate will result in an overall system benefit where customs processing times are reduced by a weighted average of three seconds per vehicle. 


\section{Chapter 3 Micro-simulation Modelling}

\subsection{Micro-simulation Modelling Tools And Techniques}

The geographic scope of the simulation models in this research can be considered to be isolated locations. Land border crossings are facilities that services traffic of two major modes which are autos and trucks. The management strategy that will be evaluated using the model is the promotion of the priority crossing program for pre-screened users in the form of NEXUS \& FAST. The effect of increased proportion of priority crossing users will produce different crossings efficiencies depending on demand and capacity at a particular time. The model outputs that will be used as the main performance measures are throughput, travel time and percent of demand serviced.

Micro-simulation models can be classified into two general categories depending on how the model allocates driver-vehicle characteristics as vehicles are generated and during their path of travel through the network. These categories are termed deterministic and stochastic models. In deterministic models the driver-vehicle characteristics do not vary during the simulation, for example, a critical gap acceptance of 6 seconds applies to all vehicles merging into traffic or the weights of all cars in the simulation are equal. On the other hand stochastic models apply a random process using statistical distributions to determine driver-vehicle characteristics. An example of this is the selection of vehicle acceleration and deceleration rates using a truncated normal statistical distribution where the mean is $1.0 \mathrm{~m} / \mathrm{s}^{2}$ and the standard deviation is $0.3 \mathrm{~m} / \mathrm{s}^{2}$. The statistical distributions 
that govern the various driver-vehicle characteristics are selected and defined during the model construction phase.

Typical traffic micro-simulation involves various intrinsic sub-models that are integral to the modelling process. Three of the major sub-models in traffic micro-simulation are listed and discussed below in relation to the modelling programs used in this research.

\section{Vehicle Generation:}

In WESTA the vehicle generation sub-model inputs vehicles into the simulation at the start of an origin link. The headway between arrivals is determined randomly according to an exponential distribution for which the average is the inter-arrival rate given by the user. This sub-model is also responsible for determining the vehicle class of which the different proportions are defined by the user for thirteen different vehicle categories. From the vehicle classification other vehicle attributes such as weight, length, maximum acceleration rate and maximum deceleration rate can be determined. For weight and length the maximum and minimum values are defined by the user for each vehicle class in the simulation and also the percentages falling into ten equally spaced bands between the minimum and maximum are defined by the user. A random number determines the weight band within which each vehicle falls and a second number determines the weight using a uniform distribution between the minimum and maximum weight for the chosen band. The same process is carried out to determine vehicle length. In WESTA the maximum acceleration rate is randomly chosen from a uniform distribution between the 
specified minimum and maximum for the vehicle class. Default minimum values of $0.15 \mathrm{~g}$ for autos and $0.06 \mathrm{~g}$ for trucks were used in this research along with the default maximum values of $0.30 \mathrm{~g}$ for autos and $0.12 \mathrm{~g}$ for trucks. A similar process is followed for the determination of maximum deceleration rate. The default values were used in this research, these are, minimum deceleration rate, $0.68 \mathrm{~g}$ for autos and $0.40 \mathrm{~g}$ for trucks and default maximum values of $1.00 \mathrm{~g}$ for autos and $0.50 \mathrm{~g}$ for trucks. WESTA also allows for the user to specify vehicle characteristics relevant to the study done. For example, vehicles considered pre-cleared or priority crossing users can be designated as such and color coded as well so that its path through the simulation can be verified by looking at the animation screen. In addition to vehicle attributes there are also driver characteristics and behavioural attributes considered by WESTA. The default value in WESTA for proportion of aggressive drivers is 20 percent and this was used in this research. In the simulation aggressive drivers by default travel up to $20 \%$ higher than the specified speed limit for each link and require shorter headways for lane changes and braking. For Driver Perception-Reaction Time (PRT), WESTA uses a Weibull distribution to generate values for individual drivers. The default value corresponds to an average PRT of 1.20 seconds and was used in this research.

Vehicle generation in VISSIM is done via a defined cross-section across selected links in the network. Vehicles are classified by type (e.g. cars, trucks, buses etc.) and are further sub-divided into classes (i.e. different kinds of cars, trucks, etc.) and category (i.e. other differences within a particular class; e.g. priority or non-priority). VISSIM allows the 
user the flexibility to create his/her own kind of vehicle and define basic vehicle attributes such as length, weight, maximum speed, desired speed, acceleration, deceleration, etc. Many of these attributes can be defined so that they are assigned to individual vehicles via a stochastic process. Many distributions are allowed in VISSIM and are based on user defined choices. Default distributions and values for acceleration, deceleration, length, width and weight supplied by VISSIM were used in this research.

\section{Vehicle Movement:}

WESTA performs vehicle routing by performing tests before the vehicle enters the link to determine which lane should be taken to expedite the flow of traffic through the network. The user sets up the various tests that are to be done during the model construction phase. The tests are mainly deterministic to determine routing of each class and category of vehicle. Stop signs along the network are implemented by placing stop markers where required and stochastic service time distributions are assigned to each stop location depending on the vehicle category.

VISSIM routes vehicle through the network using static assignment or dynamic assignment. In this research static assignment was used to route vehicles according to type, class and category through the border crossing. The routing of the vehicles where pre-defined before the simulation run and it depended on the traffic mix for the particular scenario being simulated. Stop locations in the model were defined and dwell time distributions were used to control the stop duration. 


\section{Vehicle Interactions:}

WESTA's vehicle following logic governs driver's decisions to change speed and to change lanes. It is based primarily on the gap acceptance principle where the size of the gap accepted during a merge or the spacing maintained in the traffic stream depends on whether the driver is aggressive or non-aggressive. Two safety regimes are assumed in WESTA's vehicle following logic. The one for aggressive drivers assumes maximum acceleration for a merge or lane change and maximum deceleration for a stopping distance. The safety regime for non-aggressive drivers assumes comfortable rates of acceleration and deceleration.

VISSIM's car following logic is based on the Weidman (1974) model which based on the premise that as the driver of a faster moving vehicle approaches a slower moving vehicle he/she starts to decelerate as they approach their perception threshold (which varies depending on the level of driver aggressiveness). 


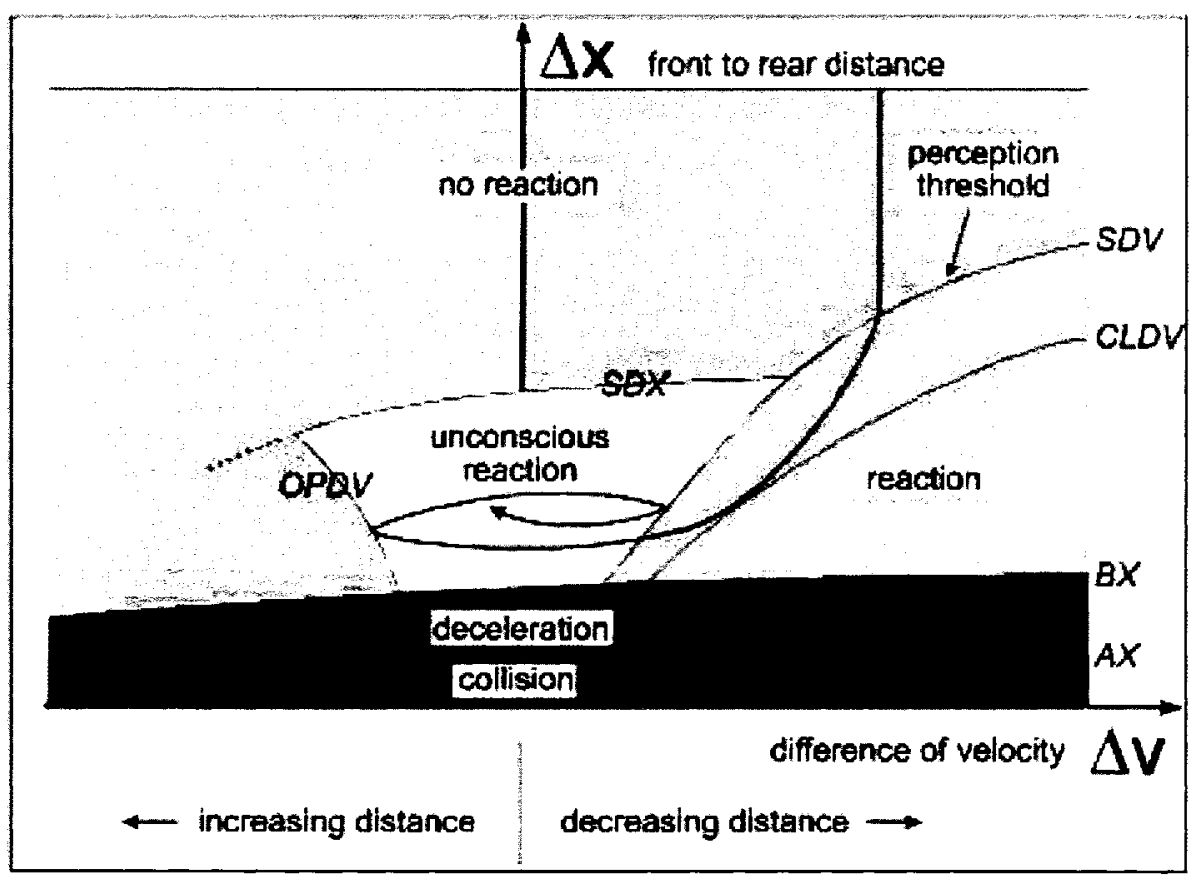

Car followng logic (Wiedemann 1974)

Figure 3-1: Car Following Logic (Weidmann 1974)

Source: VISSIM 4.00 User Manual

Since the exact speed of the lead vehicle cannot be determined the driver of the following vehicle will decelerate to a speed below that of the lead vehicle and then they will start to accelerate again after reaching another perception threshold. This results in an iterative process of acceleration and deceleration. VISSIM allows the user to select various stochastic distributions of speed and spacing thresholds to replicate individual driver behaviour characteristics.

There are two kinds of lane changes in VISSIM, one where a lane change is necessary in order to be connected with the correct succeeding link and the other the free lane change 
that takes place because of available room in the adjacent lane. In the case of the necessary lane change the various parameters of maximum deceleration and acceleration are taken into account together with the emergency stopping distance for the connecter to the next route. In the case of the free lane change VISSIM is capable of assessing the desired safety distance to determine if a sufficient gap exists based on the relative speeds of vehicles and available distance to make the lane change. Lane change parameters are defined by the user in VISSIM.

\subsection{LAND Border CROSSING INFRASTRUCTURE}

Figure 3-2 shows a generic outline of the main functional components of a land border crossing between Canada and the United States. Each of the main components are described briefly below.

\section{Access Roads:}

The approach roads to land border crossings are important in that they provide the necessary access to crossing users. On many occasions at busy crossings traffic is backed up onto the access roads which usually do not have the capacity to accommodate queues and maintain flows at the same time. This creates a traffic flow problem in the area before the crossing.

\section{Tolls Queue Storage Area:}

The Toll Queue Storage Area is the area that is immediately before the toll collection booths. This area is usually divided up into lanes some of which are designated for specific classifications of vehicles e.g. trucks, cars, E-Z Pass etc. 


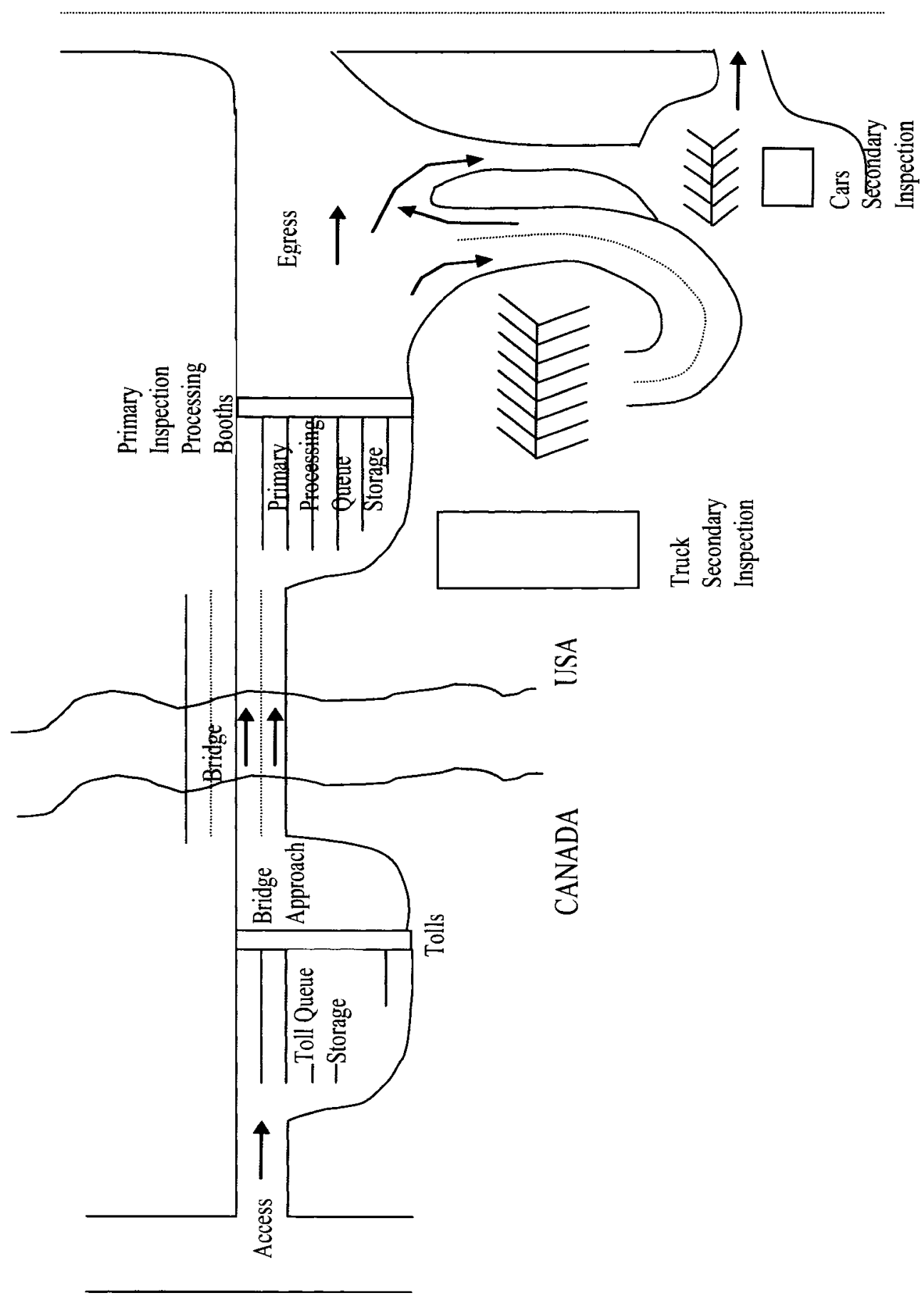

Figure 3-2: Schematic showing the main infrastructure elements of the border crossing process for one direction of travel between two countries 
Tolls:

These facilities are usually managed by the bridge owners/operators. At most crossings cars pay a fixed toll while trucks are charged based on weight. In order to expedite the toll process various initiatives have been implemented or are being tested e.g. electronic toll collection, Weigh In Motion, etc. At most crossing the tolls are located before the Primary Customs Inspection Facilities, however at a few crossings the tolls come after the inspection facilities.

\section{Bridge Approach:}

This is the area after the tolls and before the bridge. The area is characteristic of merging traffic exiting from the tolls and accessing the bridge. Depending on the number of tolls opened the level of congestion in this area varies.

\section{Bridge:}

Bridge capacity is the most expensive to upgrade for border crossings and the busier crossings have multilane bi-directional crossing, thus allowing for multi-lane flow out and into the two countries. Canada's busiest crossing is the Ambassador Bridge and is a four lane structure with two lanes in each direction. On Bridges where there is multilane travel in any direction, the right lane is usually occupied by trucks this allows cars to be able to bypass the slower moving trucks.

\section{Primary Inspection Queue Storage Area:}

This is the queue storage area immediately before the primary customs inspection booths. Designated lane uses are usually separated according to vehicle classification, e.g. NEXUS, FAST, non-registered, etc. 


\section{Primary Inspection:}

This process is managed by the customs and immigration officials of the country entered and is mandatory for all vehicles crossing the border. The U.S. and Canada have instituted programs to expedite the crossing process in order to reduce delays. Preregistered "low-risk" travelers are allowed to use a designated lane and experience lower processing times. This enables resources to be directed to the inspection of nonregistered users. This program is called NEXUS for cars and FAST for trucks.

One of the challenges of the pre-clearance program is that the full benefit of the expedited crossing cannot be experienced since both registered and non-registered vehicles use the bridge. When the queues are backed up in the primary inspection queue storage area to such an extent that the routing of pre-cleared vehicles are hindered then additional delays are experienced. Alternatives to help alleviate these difficulties are discussed in detail later in this literature review.

\section{Secondary Inspection:}

Secondary inspection is additional to primary inspection and is typically required when there is a problem with the crossing user in the form of incomplete/incorrect paperwork or a random selection of vehicle for secondary inspection. This phase of inspection is the longest in terms of time and pre-cleared vehicles are rarely sent. The secondary inspection plazas are usually separate for cars and trucks and a small fraction of trucks that are sent to secondary inspection undergo physical inspection of cargo as well. 


\section{Egress:}

This section of a border crossing is the egress lanes that lead out of the crossing after the primary customs inspection booths and is characteristic of severe traffic mixing in the form of lane changes and merging traffic. Usually vehicles required to go into the secondary inspection area must change lanes to get to the entrance.

\subsection{DesCription Of MOdels}

\section{The Peace Bridge - Canada Bound}

The micro simulation model for Canada bound car and truck traffic at the Peace Bridge crossing was constructed using the WESTA software. The Peace Bridge at Fort Erie Ontario has been one of the busiest crossing points between Canada and the U.S., travelers coming into Canada are charged a toll and undergo customs inspection by the Canadian authorities. The toll collection facility is located on the U.S. side before the bridge and the Customs inspection is on the Canadian side. The model was constructed to cater for both truck and auto demand into Canada from the U.S. This demand is represented by hourly arrival rates for cars and trucks separately.

The base-case analysis was done for the peak arrival periods of autos and the corresponding truck demand during this period. For this research the peak period was taken as the two-hour period during a 24-hour day with the highest arrivals. One hour on either side of the 2-hour peak was modeled in order to capture the preceding and succeeding effects of peak hour demand. 
Analysis was also done for crossing demand at a future horizon year. The researcher is not aware of any future travel demand study being done for the Peace Bridge, therefore a factored increase in the existing demand of $20 \%, 50 \%$ and $100 \%$ over the base-case has been considered for future year analysis.

The various components that make up a border crossing such as approach, tolls, the bridge crossing, customs, etc., each have their limiting throughput i.e. capacity. Various model inputs contribute to the crossing capacity these are the geometric limits of various links that make up the crossing, the limiting speed on each link and the service rate for each part of the process.

The inspection processing times at border crossings vary depending on the category of the crossing vehicle. For cars there are two crossing categories.

- $\quad$ Priority Registered (NEXUS)

- Non-Priority, Non Registered

The analysis was done for NEXUS participation levels between $10 \& 90$ percent with increments of 10 .

For trucks there are more categories to consider depending on the frequency of crossing and type of crossing program registered in. 
The three major categories of trucks were considered as part of the model. These are:

1. Line Release: these trucks are part of an expedited clearance program. In most cases, they are released directly by the primary inspectors as long as their paperwork is in order. Occasionally these trucks are sent to secondary inspection.

2. FAST (Priority Registered): are those that are registered in a pre-clearance program and are equipped with the information technology to expedite the clearance process. These trucks are rarely sent to secondary inspection.

3. General: Trucks in the general category do not fit any of the two categories above.

Either the parties involved are not participating in a pre-clearance program or the shipment is one that occurs infrequently. These trucks have the longest overall processing times and will most likely be sent to secondary inspection.

The scope of the model includes the toll storage area, toll facilities, bridge approach, bridge, primary inspection queue storage area, secondary inspection parking and egress from the crossing. The study area does not extend to connecting freeways and side streets and as such the model was constructed to allow analysis of an isolated location and not area wide network analysis.

\section{Description of the crossing infrastructure:}

1. Approach roads: There are various arteries that connect to the Peace Bridge from the American side. Incorporating these arteries into the simulation model is beyond the scope of this research and hence they were not included. 
2. Toll Collection: Toll collection at the Peace Bridge Canada bound is done on the U.S. side before the bridge crossing for both autos and trucks. There are a total of 8 toll lanes for which 4 are usually used for auto EZ Pass and 2 are for cash and charge tolls trucks. The other 2 toll lanes are for cash autos and one is shared with cash trucks.

3. Bridge approach and Crossing: The number of approach lanes decreases as traffic gets closer to the bridge which is a three lane structure with two lanes in the direction of peak traffic flow. Trucks normally use the right lane and autos use the left lane for the direction that is serviced by two bridge lanes. In the simulation it was assumed that one bridge lane representing the critical scenario was servicing Canada bound traffic which is shared by both autos and trucks.

4. Customs Processing: For the Peace Bridge-Canada Bound the customs inspection booths for both autos and trucks are located after the bridge crossing. There are 6 processing booths for autos and 4 for trucks on the Canadian Side. After passing through the primary inspections some trucks are directed toward the secondary inspection for further inspection. The trucks that are to undergo secondary inspection are directed to a parking lot where the driver can park and consult brokers and customs officials. A small percentage of the vehicles that undergo secondary inspection are subjected to a physical inspection of their cargo, these trucks are directed to a warehouse where this inspection is done. A small percentage of auto traffic also undergoes secondary inspection however this fraction is small and is considered insignificant for the purposes of this research. 
The crossing infrastructure modelled for the Peace Bridge in this research represents base year 1999. The base-case model was constructed to cater for the input parameters as outlined in Table A-1 in Appendix A, the base-case data was obtained from the CornelRenssellaer Study (Cornel University \& Renssellaer Polytechnic, 1999). This model has been used as a means for model calibration and to provide a bench mark for comparison with other alternatives. The different scenarios that were modelled and compared to the base-case scenario are described below. The differences between the various scenarios are based on changes in demand, changes in processing time, changes in lane use configurations and variation in priority vehicle penetration rates within each scenario. The morning peak hour interval for autos was chosen and a 4 hour simulation window was modelled.

The lane allocation policy that was adopted in this research was the direct substitution of existing processing lanes as dedicated priority lanes depending on the level of priority vehicle penetration. A lane allocation policy needs to be prudent so that it optimizes system benefits across the categories of vehicles. Also lane allocation needs to be designated in such a way to maintain the feasibility of priority crossing programs so that average travel time for priority vehicles is consistently lower than non-priority vehicles. It therefore means that there may be cases of average travel time increase for a particular or more than one vehicle category depending on the processing lane allocation for a particular scenario. In this research the following processing lane allocations gave the best results in terms of system benefits for the Peace Bridge- Canada bound model. 
Table 3-1: Processing Lane Allocations - Peace Bridge - Canada Bound Model

\begin{tabular}{|c|c|c|}
\hline Priority Vehicle Penetration (\%) & \# NEXUS Lanes & \# FAST Lanes \\
\hline $0-30$ & 2 & 2 \\
\hline $40-50$ & 3 & 2 \\
\hline $60-70$ & 4 & 3 \\
\hline $80-90$ & 4 & 3 \\
\hline
\end{tabular}

Description of Scenarios Modeled:

Scenario 1: Base Case - 1999 condition. This scenario provides a benchmark and a means for calibration of the model. Demand and service times used were 1999 levels and no priority crossing traffic.

Scenario 2: In this scenario base case demand and increased primary customs processing times applied to all vehicle categories were used for different penetration rates of priority crossing vehicles. The customs processing times were doubled over the base case to represent the effect of an increased security alert level. The objective of this scenario is to investigate how the variation of penetration rates would affect travel time for different categories of vehicles with an increased customs processing time and base case demand and infrastructure. This scenario would help to investigate how much does priority crossing vehicles having relatively lower customs processing times affect travel times at border crossings for the different categories of vehicles when security levels are elevated above the base-case.

Scenario 3: This scenario applies the same primary customs clearance times for cars and trucks as was used in scenario 2, with a 20 percent increase in demand over the base case 
for both auto and truck traffic. This demand and serviceability was applied for different penetration levels of priority crossing vehicles. This scenario would help to investigate how much does priority crossing vehicles having relatively lower customs processing times affect travel times at border crossings for the different categories of vehicles when security levels are elevated above the base-case coupled with an increased demand.

Scenario 4: This scenario investigated the effect of Queue Jump lanes dedicated for priority crossing vehicles. Base case customs processing times were used and a $20 \%$ increase in demand over the base-case was considered for both auto and truck traffic.

Scenario 5: Scenario 5 represented a modification to scenario 4 in that the customs processing time for autos and trucks were double the base case scenario and the same demand and queue jump lane configuration was maintained as was used in scenario 4 . This scenario was applied across different penetration rates.

Scenario 6: This scenario was modeled to represent a 50 percent increase in demand in auto and truck traffic over the base case. The customs processing times were the same as the base case scenario and no Queue Jump lanes for priority vehicles were considered. However there were dedicated lanes leading up to the processing booths for priority vehicles. The purpose of modelling this scenario is to investigate the performance of the crossing at a future year demand across the different penetration rates of priority crossing vehicles.

Scenario 7: This scenario is modification to scenario 6 in that Queue jump lanes for priority vehicles replaced the dedicated lanes. The same demand and processing times as was used in scenario 6 were maintained. This scenario is intended to investigate the 
effect queue jump lanes for priority vehicles will have when coupled with levels of high demand expected in the medium term.

Scenario 8: This scenario was developed to investigate the performance of the priority crossing program with expected long term future demand. The demand levels for autos and trucks were increased by 100 percent over the base case. No queue jump lanes were considered for this scenario. The primary customs processing time was modelled to be similar to base case time.

Scenario 9: This scenario is a modification to Scenario 8 in that the queue jump lanes replaced the dedicated crossing lanes for priority crossing vehicles. The same demand and processing times as was used in Scenario 8 were used for this scenario. The intent of modelling this scenario is to investigate the effect of queue jump lanes servicing priority crossing vehicles long term future year forecasted demand levels.

\section{Ambassador Bridge - U.S. Bound}

The ambassador bridge is one of the main crossing points for autos and trucks traveling between Canada and the US. This research simulates and analyses the US bound auto and truck traffic to determine the effectiveness of various alternatives in improving the flow of traffic through the crossing. The first milestone of the analysis is to construct and calibrate a base-case model of the US bound crossing. 


\section{Description of the crossing infrastructure:}

1. Approach roads: There are various arteries that connect to the ambassador bridge from the Canadian side. Incorporating these arteries into the simulation model is beyond the scope of this research and hence they were not included.

2. Bridge approach and Crossing: Autos and trucks are separated as they approach the bridge structure; there are six dedicated lanes for autos and two dedicated lanes for trucks. The number of lanes decreases as traffic gets closer to the bridge which is a four lane structure with two lanes in each direction. Trucks normally use the right lane and autos use the left lane. In the simulation the two bridge crossing lanes were modeled for the right lane to be a dedicated truck lane and the left lane was modeled to be a dedicated auto lane.

3. Customs Processing: There are twelve customs auto processing booths that are located after the bridge crossing. The primary customs processing for trucks are separate from autos and there are nine booths that are positioned after the bridge crossing. After passing through the primary inspections some trucks are directed toward the secondary inspection for further inspection.

4. Toll Collection: Toll collection at the ambassador bridge US bound is done after the primary customs inspection both for autos and trucks. For each inspection lane there is a toll collection booth. 
The infrastructure described above represents the year 2003 and was considered to be the base case scenario for analysis.

Base-case Model Inputs:

The model inputs for the base-case scenario were obtained from a number of sources as referenced in this section. The traffic demand information was obtained from the 1999/2000 Commercial Vehicle Survey database and was supplied by MTO. This database provides information regarding the hourly variation in traffic over a twenty four hour period for different days of the week. The information has also been disaggregated according to auto category and various configurations for trucks (e.g. straight truck, tractor trailer, etc.). The percentage of Priority Auto and Priority Truck vehicles were assumed to be zero for the base case scenario since they were not part of the crossing program of the Ambassador Bridge during 2003.

This information was used to determine the peak period volumes for autos and the corresponding truck demand during that period. Figure B-1 and B-2 in Appendix B shows the hourly variation of traffic for US bound autos and trucks across the Ambassador Bridge for the week of 20 September, 1999.

The data was the only data available for the hourly variation of traffic across the Ambassador Bridge; however this data was obtained in 1999. With the year 2003 considered the base year for this analysis the peak period data was extrapolated based on an analysis of trends of annual aggregated volumes after 1999. Annual truck volumes 
crossing the Ambassador Bridge are available and they indicate a reduction in the truck traffic at this crossing since 2000 the reason for this is cited as being the slow down in the U.S. economy and the ramifications of the $9 / 11$ disaster. The annual truck crossing at the Ambassador Bridge for 2003 was 3.25 million which is $5.2 \%$ below the 1999 volume (Transport Canada, Annual Report, 2003). Since hourly traffic data is only available for 1999 and 2003 is the base year selected for this analysis the 1999 peak period hourly volumes were adjusted based on the decrease in the annual aggregated volumes. It was assumed that the variation in annual aggregated volume would impact the disaggregated peak period hourly volumes by the same scale.

Annual aggregated data for auto annual volumes indicate a steep drop in auto travel for the Ambassador Bridge since the peak in 1999. Annual auto crossing volumes for 2003 was $29 \%$ below 1999 volumes (Transport Canada, Annual Report, 2003). This trend of reduction in annual auto crossing volumes exists for all the major U.S. Canada Border Crossings although not as drastic as it is for the two crossings linking Windsor and Detroit. The 1999 volumes were adjusted based on the annual percentage drop for 2003 compared to 1999 and also adjustments were made to represent the variation in monthly volumes for autos crossing the Ambassador Bridge. Typically July and August are the two busiest months for auto crossings across the Ambassador Bridge. The hourly traffic data gathered during the 1999 MTO Roadside Survey was done during a week in September, 1999 and as such did not represent traffic volumes during the peak months of July and August which are typically $20 \%$ above September volumes. Therefore the net 
adjustment of the auto peak period hourly data used in this model is a decrease of $9 \%$ from the 1999 volumes obtained as part of the MTO/NRS Survey (Commercial Vehicle Survey Data, MTO, 1999). The same assumption as was made for trucks was made for auto volume adjustments i.e. the variation in annual (and monthly) aggregated volumes would impact the disaggregated peak period hourly volumes by the same scale.

Table B-1 in Appendix B summarizes the adjusted demand values used for the base-case model. The MTO data-base also provided information concerning the proportion of various types of trucks that are part of the traffic crossing the border. This information was adapted into the model to represent the various major truck configurations that use the crossing, i.e. straight trucks and tractor trailers.

Another major model input was the processing times for primary customs inspection, secondary customs inspection and tolls. The data used for the base-case model has been summarized in Table B-2 in Appendix B. The times represented are pre- 9/11 which is lower than customs clearance times immediately after $9 / 11$ which were increased due to security measures. However as we moved further away from $9 / 11$ customs clearance times have been returning close to pre-9/11 values during periods of normal operating conditions (URS \& IBI Group, 2002). Occasionally the Department of Homeland Security elevates the security levels for all ports of entry into the U.S. and this results in increased customs clearance times at land border crossings. The base-case scenario 
constructed in this research considers operation of the crossing during periods of normal security levels and using pre-9/11 times.

\section{$\underline{\text { Scenarios modeled: }}$}

The scenarios analysed after the construction and calibration of the base-case model were generated randomly. After the base case model was calibrated, a series of 153 model simulations were run for different randomly chosen input scenarios. VISSIM's wide functionality and user friendly Graphic User Interface (GUI) made the analysis of these many diverse scenarios much more feasible when compared to WESTA's functionality. The raw data randomly generated for the model inputs and the corresponding outputs can be found in Table B-5 and B-6. The base-case auto and truck demand were factored based on randomly selected "Demand Change Factor Values" generated using the random seed function in MS Excel. An independent random seed was used for Autos as was used for Trucks and the base-case demand was considered as having a factor of 1.00 . The "Demand Change Factor Values" for Autos and trucks were randomized within the range of 0.75 to 2.00 inclusive. Linear interpolation within the range was assumed when applying the randomly derived factors. These factors were applied to the base-case hourly demand values for each of the four hours modelled.

Due to the lack of data with regard to the relationship between the processing times of the different categories of vehicles that use the crossing, it was assumed that the factors that contribute to a change in Customs Processing Time at the crossing will affect all the 
categories of users the same way. Hence one random seed was used to generate random customs processing times. The table below indicates the ranges between which the values for the different customs processing times were randomized. Linear interpolation was assumed to determine the values within the ranges.

Table 3-2: Ranges of Customs Times Used In Ambassador Bridge Modelling Scenarios

\begin{tabular}{|l|c|c|}
\hline \multirow{2}{*}{\multicolumn{1}{|c|}{ Customs Processing Times }} & \multicolumn{2}{c|}{ Range } \\
\cline { 2 - 3 } & Minimum Value (s) & Maximum Value (s) \\
\hline Nexus Customs Processing & 10 & 40 \\
\hline Non-nexus Customs Processing & 25 & 60 \\
\hline Fast Customs Processing & 25 & 70 \\
\hline Non-Fast Primary Customs Processing & 40 & 100 \\
\hline Secondary Trucks Primary Customs Processing & 65 & 120 \\
\hline Truck Secondary Inspection Processing Times & 1820 & 3500 \\
\hline
\end{tabular}

In Table B-5 and B-6 the 'Process Time Factor' value is a representation of the randomly scaled factor (with base-case being 1.00) by which the Customs processing times are linearly adjusted within the above ranges. The Process Time Factor is really an assumed index formulated to represent the various states/conditions that affect customs processing time. For example security alert levels are one factor that influences the processing times and this is assumed to be across all categories of vehicles. The processing time for tolls was assumed to be the same as the base-case values for all the scenarios considered.

The other model inputs that were randomized using independent random seeds were the percentage of priority auto penetration, percentage of priority truck penetration and the 
proportion of Non-priority trucks sent to Secondary inspection. As was done for the base-case scenario it was assumed that the percentage of autos sent to secondary inspection will have a negligible effect on the model output. The vehicles regarded as priority vehicles in this research do not only include NEXUS and FAST categories but also any other vehicle that may be eligible for priority clearance as a result of some other crossing program (e.g. CVPC pre-cleared users). Hence the term Priority Vehicle is conceptual and refers to a more general group of users that may be entitled to priority clearance and result in a travel time saving while traversing through the crossing. Currently at land border crossing NEXUS and FAST are the main categories of priority crossing users.

The model outputs of the VISSIM model scenarios are summarized in Appendix B. The model outputs have been categorized into three (3) general categories of Average Travel Time, Throughput and Percent of Demand Serviced. The resulting data base generated is similar to a randomly selected sample with the population in this case being border crossing scenarios at the Ambassador Bridge - U.S. Bound. Even though the data generated is hypothetical it will provide a means for evaluation and mapping of the performance of the crossing system under different conditions of demand, traffic mix and processing time. 


\subsection{MODEL CALIBRATION}

Micro-simulation being an abstraction that is used to help predict performance under different conditions needs to be representative of the modeled real world system. This process of model verification is done through model calibration and its importance cannot be overemphasized. It should be noted that no micro-simulation model is identical to the real world system in every regard, however fair representation of the system is important.

\section{The Peace Bridge - Canada Bound}

Information in the form of travel time and queue growth rate for a given supply and demand is ideal for calibrating a border crossing micro-simulation model, however this information is not available to the researcher. The information that will be used to give a measure of calibration can be described as objective evidence that was obtained for different segments of the crossing and is only available for trucks.

Average time delays have been measured for a given supply (i.e. \# of open primary inspection booths) and demand (i.e. average hourly arrival rates for trucks). This can be used to provide a measure of calibration for the primary truck inspection process, however for the other components of border processing (e.g. tolls and secondary inspection) no information is available for model calibration. The analysis of the different scenarios will be done relative to a benchmark. In this way improvements in crossing times will be presented as difference from the benchmark value. 
Measurements of truck travel times were done with the help of video tapes for ROL trucks leaving the bridge crossing and passing through customs (Cornel University \& Rensselaer Polytechnic, 1999), an average time of 4 minutes was determined. The basecase simulation model constructed in this research produced an average travel time of 3.52 minutes for ROL trucks traveling from the bridge through customs. Field measurements were also done as part of the Battelle study (Battelle, 2002) for the total travel time of the truck from the time it joins the queue before the toll on the US side to the time it leaves the border crossing area after customs clearance on the Canadian side. The study was done by means of a physical count and matching the license plates of the trucks when they enter the crossing and when they leave. The average measured time over a 2-hour period was 12.43 minutes, the WESTA simulation constructed in this research yielded a travel time of 11.2 minutes.

Additional evidence supporting the model results is the fact that the queues in front of the truck primary inspection booth during the simulation never exceeded three. This was consistent with observations made as part of the video-tape survey done during the Cornell - Rensselaer study (Cornel University \& Rensselaer Polytechnic, 1999)

\section{Ambassador Bridge - U.S. Bound}

The results of the base-case model were compared with data from other sources to ensure model calibration. The VISSIM model generated travel time results for the different vehicle categories. These results are summarized in Table B-3 and a comparison is made with data obtained from other sources. 
The comparison data for the truck travel time above was obtained from a survey performed by a trucking company in Ingersoll, Ontario. Over 1,100 individual cross border trips were surveyed for crossings in Windsor, Sarnia and the Niagara Region. The survey was done using automated tractor log devices that recorded the truck location at regular intervals. These positions were geo-coded and the resulting co-ordinates were found to be accurate compared to fixed reference points along the route. This data provided a very good estimate of time the truck spent crossing the border. The simulation model can be said to possess a suitable level of calibration for this research since the model outputs compare closely with the data from the truck survey (Using GPS - encoded tractor logs to estimate travel times at Borders in Southern Ontario, 2002).

Data for auto travel times crossing the ambassador bridge is not available from previous studies however reasonable estimates of travel time are reported on the Canadian Border Services Agency website (CBSA), (www.cbsa-asfc.gc.ca). These times are updated regularly and a web survey of the data was performed by the researcher for the peak period simulated in this research. This data is summarized in Table B-4 in Appendix B. The average total auto travel time is close to the times reported for the same period on the CBSA website. The times reported on the CBSA website were compared to the times reported on the website maintained by the U.S. Customs and Border Security (www.aps.cbp.gov/bwt/) and were found to correspond closely. 
The results of the travel time outputs for the base case model are summarized in Figure B-3 and B-4 in Appendix B. One observation at this stage is that the variation in travel time for autos and trucks increases and decreases depending on the demand variation for the different hour intervals. This is further proof of model calibration given that this phenomenon is usually consistent with increased demand for a fixed service capacity for any transportation facility. 


\section{Chapter 4 Results}

\subsection{The Peace Bridge - Canada Bound}

For base-case demand and base-case customs times with no queue jump lanes the auto travel time can be said to be constant as priority vehicle penetration rate increased (for all practical purposes, see Figure A-1). For all the penetration rates the priority crossing autos had slightly less than or equal travel time compared to the non-priority vehicles. It is important that the travel time of priority crossing vehicles be continually less than nonpriority vehicles in order to maintain the attraction of the priority-crossing alternative to current and potential users. For trucks, base case scenario, the overall average value across all categories of trucks decreased with an increase of priority penetration rate (Figure A-2). The travel time values for Priority trucks and the Release-On-Line categories are almost constant across the different penetration rates with the Priority trucks being slightly lower. The travel time for the Y28 category was much higher than the other categories since these are the trucks that are pulled over for secondary customs inspection. There is an overall decline in travel time for this category as penetration rate of priority users' increase, this is due mainly to the decrease in the amount of trucks sent to secondary inspection. There was no notable queue build up at the primary customs inspection service booths for any of the penetration rates. This is in keeping with the observations of the field survey referred to earlier under "3.4 Model Calibration".

The second scenario involved base-case demand and an increase in the primary customs processing time for all the categories of cars and trucks (Figures A-3 and A-4). The 
results of the simulation showed a slight increase in the average travel time for all the categories of cars and trucks over scenario 1 and it was observed that the difference between the travel time for priority vehicles and non-priority vehicles was larger when compared to the first scenario. The priority vehicles consistently had a lower travel time than the non-priority vehicles across all penetration rates for both cars and trucks. It should be noted that for this second scenario there was no notable congestion at the primary customs inspection booth even with the doubling of the primary inspection processing time, this is due to the supply of primary inspection service still being adequate for the given demand.

Scenario 3 was modeled for a $20 \%$ increase in demand of cars and the same increase for trucks with the increased primary customs processing times as used in scenario 2 and no queue jump lanes. This scenario was modeled to determine how well the system will perform under an increase in demand that is likely to occur in the short term (i.e. 5 years) depending on the changes in socio-economic factors influencing cross border trip generation between Canada and the US. The increase in demand resulted in the overall auto time being higher for the most part when compared to the base-case demand scenarios. However a more drastic decrease in the travel time as priority crossing penetration rate increased has been observed (Figures A-5 and A-6). The overall auto travel time decreased up to the $70 \%$ penetration level and then increased for the $90 \%$ penetration levels. This increase is mainly the result of the dedicated priority lanes before the tolls becoming more congested leading to longer wait times for the tolls for the 
priority vehicles, however the travel times for non-priority autos were still much higher than priority autos at the $90 \%$ level. At the $70 \%$ penetration level the travel time for nonpriority cars dropped significantly, this was mainly due to the supply of service for nonpriority vehicles being adequate for the demand. The increase in the penetration level of priority vehicles from 60 to 70 percent has led to a corresponding decrease in demand for servicing non-priority vehicles thus resulting in a lower travel time through the border crossing. For trucks the overall travel time decreases steadily as the penetration level increases. There was a sharp increase in the travel time for ROL trucks at the $40 \%$ penetration rates, this was due to the lane use configuration before the tolls not being able to absorb the ROL demand in a timely manner. The travel time for priority trucks was steady and always less than the time for ROL and Y28 trucks.

Scenarios $4 \& 5$ investigated the use of queue jump lanes for priority vehicles and their effect on the travel time across the different categories of vehicles. Scenario 4 modeled a $20 \%$ increase in demand and base-case customs clearance times. The results indicate variable declines and increases in travel time for autos depending on percentage penetration of priority crossing users and the lane use configuration of the vehicles approaching the tolls (Figures A-7 and A-8). For example the overall travel time for autos steadily reduces up to the forty percent penetration rate for priority vehicles and then rises for the fifty percent penetration level due mainly to a steep rise in the nonpriority auto travel time. The increase in the travel time of non-priority vehicles at the fifty percent penetration rate can be attributed to the over-saturation of the lanes servicing 
this category of vehicles leading to and away from the toll facilities. After the fifty percent penetration rate, the value of overall travel time for autos steadily decreased until the eighty percent penetration rate. The is a result of the lane use configuration changes that were made for the sixty and seventy percent penetration rates of priority crossing vehicles where the number of dedicated queue jump lanes for priority vehicles were increased and the number of lanes available for non-priority autos were reduced. At the eighty percent penetration rate the undesirable case of the travel time for the priority registered crossing users is more than the non-priority users. The reason for this is due to the priority crossing queue jump lanes becoming congested and the non-priority vehicle lane volumes reduces to the point where delays are experienced by priority crossing vehicles that are greater than non-priority vehicles. It is expected that in a real world scenario that equilibrium tendencies will result in the system correcting itself before this condition develops. This effect is represented by the results as shown in Figure A-7, where the travel time for non-priority autos begins decreasing steadily after the fifty percent penetration level and the travel time of priority vehicles increases steadily. The overall truck average travel time for Scenario 4 gradually reduces as the penetration rate increases. The travel time for Priority crossing trucks and Release-On-Line trucks follow similar trends across the different penetration rates with the priority trucks travel time being slightly lower than the Release-On-Line.

Scenario 5 modeled the same demand as was used in Scenario 4 (i.e. $20 \%$ above basecase demand) with the difference being primary customs processing rates doubling. 
Similar variations in travel time as were obtained for Scenario 4 were obtained for Scenario 5 (see Figures A-9 and A-10). Overall there were slightly higher travel times for the different categories of autos and trucks when compared with scenario 4 and the difference in travel time between Priority vehicles and Non-Priority vehicles was more in scenario 5 especially for the lower penetration levels of priority vehicles. This is because of the higher volumes of non-priority vehicles causing congestion in non-priority lanes requiring more time for processing than priority vehicles.

Scenario 6 was modeled to determine the effect of a $50 \%$ increase in demand on the border crossing system without queue jump lanes. An increase in demand of about $50 \%$ over the base-case for both cars and trucks were applied to the model as well as the same lane use configuration with corresponding penetration rates that were used for scenario 3 . The results of the model for scenario 6 showed a much higher travel time for the different penetration rates when compared with the previous scenarios (Figures A-11 \& A-12). There was a steep decrease in priority and non-priority auto travel time up to the fifty percent penetration rate and then a steep increase up to the sixty percent priority penetration rate. This increase for the sixty percent penetration rate can be said to be as a result of the change in lane use configuration when moving from the fifty to sixty percent penetration rate. This resulted in inadequate service capacity for the priority and nonpriority toll lanes thus creating queue build up and increased travel time. Truck travel times variation was similar to the autos however the travel times were significantly 
higher than autos. At no stage for the different penetration rates did the crossing time for priority crossing autos and trucks exceeded the crossing time for non-priority vehicles.

Scenario 7 involved modelling the conversion of the dedicated priority lanes used in scenario 6 to queue jump lanes for priority crossing vehicles. The travel times for this scenario are generally lower across the board for all classes of vehicles when compared to scenario 6 with no queue jump lanes (Figures A-13 and A-14). Characteristic but lower peaks in the travel time exist as there was in scenario 6 for the same reasons as discussed above. For autos, between the eighty and ninety percent penetration rates the travel time for priority crossing vehicles became more than the non-priority vehicles. This was mainly due to the reduction in demand for service in the dedicated non-priority tolls and customs lanes resulting in little or no queue build up and hence wait time for non-priority vehicles. For trucks the priority vehicle crossing time was always lower than non-priority trucks.

Scenario 8 was modeled to determine the effect of a $100 \%$ increase in demand on the border crossing system without queue jump lanes. The model results indicate a similar pattern to that for scenario 6 but higher values of travel time were obtained across most of the penetration increments considered. Scenario 9 modeled $100 \%$ increase in demand over the base-case with queue jump lanes. The pattern of travel time was similar to that obtained for scenario 7 but with higher values across the different penetration rates. 
In scenarios 6 and 8 , the reason for the steep rise in travel time when moving from the $50 \%$ to the $60 \%$ penetration rate is as a result of changes in the lane use configuration where toll lanes for priority autos increased by one and toll lanes for non-priority autos dropped by one. This resulted in long queue build ups in all of the non priority lanes extending upstream of the bridge crossing approach, thus resulting in excessive delays of priority vehicles caught in the upstream traffic. This phenomenon was not observed to the same extent in scenarios that considered the use of queue jump lanes, since bypass lanes were considered for the priority vehicles. It should be noted that, for no change in the lane use configuration when moving from the $50 \%$ to $60 \%$ penetration rate for the no queue jump lane scenario, there was a lower travel time across all categories of vehicles for the 60 percent penetration rate than when there was a change in the lane use configuration. However when this comparison was done for the $70 \%$ priority penetration rate the travel time for when there was no change in the lane use configuration was higher for the truck categories than for when there was a change.

The Figures A-19 to A-25 shows a comparison of travel time across the different scenarios and for the different categories of autos and trucks. It can be seen that for all categories of increased demand, (i.e. base-case to $100 \%$ increase) there was a progressive increase in travel time for all categories of vehicles.

Scenario 4 and Scenario 5 were modeled to compare the effect of increased customs processing times on crossing travel time. There was marginal increase in travel time with 
an increase in customs processing time. The reason for the marginal increase and not one of more significance was because the critical bottleneck point of the crossing was the access from the tolls to the single Canada bound service lane on the bridge, customs processing was not the critical point of limiting capacity. Therefore the area of bottleneck before the bridge crossing served as a deterrent for the formation of excessive queues on the Canada side (i.e. side with Canada customs processing). The marginal increase in travel time for scenario 5 over scenario 4 is due to the increase in processing time and not queue build up on the Canadian side as a result of the increased customs processing time. The same observation was made for scenario 1 and scenario 2 with scenario 1 being modeled for base-case demand and processing time with no queue jump lanes and scenario 2 being modeled for base-case demand and increased processing time with no queue jump lanes.

Except for the 50, 80 and 90 percent priority auto penetration rate for the higher demands of 50 and $100 \%$ increase over base-case, the travel time for autos when there were queue jump lanes was always less than for when there was no queue jump lanes. This is true across all the categories of autos and trucks. For the $50 \%$ penetration rate there was a higher overall travel time for the queue jump lane scenario over the non-queue jump lane scenario, however this does not apply to all categories of vehicles. The priority crossing autos and trucks had a lower crossing time when there were queue jump lanes than when there was none, this was as a result of the queue jump lanes providing better access to the bridge for priority vehicles. This observation was noted for both the $50 \%$ and $100 \%$ 
increases in demand. The reason for the travel time for the 80 and $90 \%$ penetration rate of queue jump lane scenarios being higher than for no queue jump lane scenarios is due to the designated queue jump lanes for priority vehicles becoming over-saturated. This increases the time required for the priority vehicles to cross. The results of the simulation show that as demand increases there is an associated increase in travel time. This increase in travel time is depicted in the histograms where it can be seen that the travel time increases for an increase in the crossing demand from $20 \%$ to $100 \%$ of the basecase. This is mainly due to the increased congestion at the merge point of traffic onto the bridge and as a result increased congestion and queues upstream of the merge point. It can be said that the efficiency of the border crossing system is affected negatively as a result of the increase in demand.

\subsection{AMBASSADOR BRIDGE - U.S. BOUND}

The analysis of the data was done separately for autos and trucks since for the Ambassador Bridge U.S. bound traffic autos and trucks are separated via dedicated lanes for tolls and customs processing as well as bridge crossing. This is typical of most land border crossings, hence the assumption is made in this research that auto and truck traffic interaction with each other through the crossing is minimal.

The results of the regression process are summarized in Table B-7 in Appendix B. 
Regression models were developed for the following dependent variables which were all outputs of the micro-simulation process:

- Average Overall Auto Travel Time

- Average Overall Truck Travel Time

- Average Priority Auto Travel Time

- SQRT Average Priority Truck Travel Time

- Average Non-Priority Auto Travel Time

- Average Non-Priority Truck Travel Time

- Average Priority Auto Travel Time Advantage

- SQRT Average Priority Truck Travel Time Advantage

- Overall Auto Throughput

- Overall Truck Throughput

- Percent Of Demand Serviced

Three scenarios were developed for the dependent variables based on the No Queue Jump Lane for Priority Vehicles, with Queue Jump Lanes for Priority Vehicles and the difference between the dependent variables for the two scenarios mentioned before (i.e. Queue Jump Lane vs. No Queue Jump Lane scenario).

The outputs from the regression process including the unstandardized regression coefficients (B), standardized regression coefficients $(\beta)$, partial correlation coefficient, $t-$ value, and adjusted $R^{2}$ have been included in Table 4-1. The relative effect of each independent variable on the dependent variable has also been computed. 
The regression model equations that were developed for the Ambassador Bridge U.S. bound traffic are summarized below.

\section{Equation 1}

Average Overall Auto Travel Time No QJL $=$

$0.033^{*}[$ Average Hourly Auto Demand $]+3.671 *[$ Process Time Factor $]-0.101^{*}[$ Priority Auto Penetration] - 20.061

\section{Equation 2}

Average Overall Auto Travel Time $\mathrm{QJL}=$

$0.021 *[$ Average Hourly Auto Demand $]+2.754 *[$ Process Time Factor $]-0.022 *[$ Priority Auto Penetration] - 12.966

\section{Equation 3}

Average Overall Auto Travel Time No QJL - QJL $^{-}$

$0.014 *[$ Average Hourly Auto Demand $]+0.944^{*}[$ Process Time Factor $]-0.078^{*}[$ Priority Auto Penetration] - 8.386

\section{Equation 4}

Average Overall Truck Travel Time ${ }_{\text {No QJL }}=$

$0.103^{*}[$ Average Hourly Truck Demand $]+3.463^{*}[$ Process Time Factor $]-$

$0.265^{*}[$ Priority Truck Penetration $]+0.259 *[$ Percent Secondary Truck $]-19.375$ 


\section{Equation 5}

Average Overall Truck Travel Time ${ }_{\mathrm{QJL}}=$

$0.071^{*}[$ Average Hourly Truck Demand $]+2.756^{*}[$ Process Time Factor $]-$

$0.202 *[$ Priority Truck Penetration $]+0.197 *[$ Percent Secondary Truck $]-9.836$

\section{Equation 6}

Average Overall Truck Travel Time ${ }_{\text {No QJL - QJL }}=$

$0.031^{*}[$ Average Hourly Truck Demand $]+1.158^{*}[$ Process Time Factor $]-$

$0.031 *[$ Priority Truck Penetration $]+0.007 *[$ Percent Secondary Truck $]-12.817$

\section{Equation 7}

Average Priority Auto Travel Time No QJL $=$

$$
32.576 *\left[\frac{\text { Average Hourly Priority Auto Demand }}{\text { Priority Auto Hourly Processing Capacity }}\right]-3.587
$$

\section{Equation 8}

Average Priority Auto Travel Time ${ }_{\mathrm{QJL}}=$

$$
19.514 *\left[\frac{\text { Average Hourly Priority Auto Demand }}{\text { Priority Auto Hourly Processing Capacity }}\right]+1.187
$$




\section{Equation 9}

Average Priority Auto Travel Time No QJL - QJL $=$

$$
15.736 *\left[\frac{\text { Average Hourly Priority Auto Demand }}{\text { Priority Auto Hourly Processing Capacity }}\right]-3.153
$$

\section{Equation 10}

SQRT Average Priority Truck Travel Time ${ }_{\text {No }}$ QJL $=$

$$
5.647 *\left[\frac{\text { Average Hourly Priority Truck Demand }}{\text { Priority Truck Hourly Processing Capacity }}\right]+1.309
$$

\section{Equation 11}

SQRT Average Priority Truck Travel Time QJL $^{=}$

$$
3.678 *\left[\frac{\text { Average Hourly Priority Truck Demand }}{\text { Priority Truck Hourly Processing Capacity }}\right]+1.233
$$

\section{Equation 12}

Average Priority Truck Travel Time ${ }_{\text {No }}$ QJL - QJL $=$

$$
44.839 *\left[\frac{\text { Average Hourly Priority Truck Demand }}{\text { Priority Truck Hourly Processing Capacity }}\right]-7.521
$$




\section{Equation 13}

Average Non-Priority Auto Travel Time No QJL $^{=}$

$$
63.425 * \sqrt{\left[\frac{\text { Average Hourly Non-Priority Auto Demand }}{\text { Non-Priority Auto Hourly Processing Capacity }}\right]}-37.808
$$

\section{Equation 14}

Average Non-Priority Auto Travel Time ${ }_{\mathrm{QJL}}=$

$$
38.828 * \sqrt{\left[\frac{\text { Average Hourly Non-Priority Auto Demand }}{\text { Non-Priority Auto Hourly Processing Capacity }}\right]}-21.537
$$

\section{Equation 15}

Average Non-Priority Auto Travel Time No QJL - QJL $=$

$$
21.696 * \sqrt{\left[\frac{\text { Average Hourly Non-Priority Auto Demand }}{\text { Non-Priority Auto Hourly Processing Capacity }}\right]}-14.596
$$

\section{Equation 16}

Average Non-Priority Truck Travel Time No QJL $^{=}$

$33.523 *\left[\frac{\text { Average Hourly Non-Priority Truck Demand }}{\text { Non-Priority Truck Hourly Processing Capacity }}\right]$ 


\section{Equation 17}

Average Non-Priority Truck Travel Time $\mathrm{QJL}^{=}$

$39.082 *\left[\frac{\text { Average Hourly Non-Priority Truck Demand }}{\text { Non-Priority Truck Hourly Processing Capacity }}\right]-10.194$

\section{Equation 18}

Average Non-Priority Truck Travel Time ${ }_{\text {No QJL - QJL }}=$

$$
-15.107 *\left[\frac{\text { Average Hourly Non-Priority Truck Demand }}{\text { Non-Priority Truck Hourly Processing Capacity }}\right]-11.564
$$

\section{Equation 19}

Average Priority Auto Travel Time Advantage ${ }_{\text {No } \mathrm{QJL}}=$

$0.003 *[$ Average Hourly Auto Demand $]+0.330^{*}[$ Process Time Factor $]-0.048^{*}[$ Priority Auto Penetration] -0.126

\section{Equation 20}

Average Priority Auto Travel Time Advantage $\mathrm{QJL}_{\mathrm{L}}$

$0.005 *[$ Average Hourly Auto Demand $]+0.375^{*}[$ Process Time Factor $]-0.007 *[$ Priority Auto Penetration] -2.547 


\section{Equation 21}

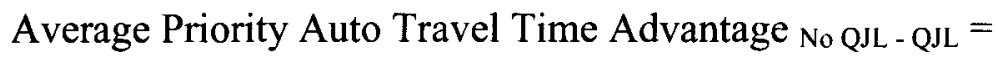
$-0.001 *[$ Average Hourly Auto Demand $]-0.024 *[$ Process Time Factor $]-0.013^{*}[$ Priority Auto Penetration] -1.627

\section{Equation 22}

$\sqrt{\text { Average Priority Truck Travel Time Advantage } \text { No QJL }}=$ $0.110 * \sqrt{[\text { Average Hourly Truck Demand }]}+0.173 *[$ Process Time Factor $]-$ $0.022 * \sqrt{[\text { Priority Truck Penetration }]}-0.021 * \sqrt{[\text { Percent Primary Inspection }]}-0.704$

\section{Equation 23}

$\sqrt{\text { Average Priority Truck Travel Time Advantage }_{\mathrm{QJL}}}=$

$0.408 * \sqrt{[\text { Average Hourly Truck Demand }]}+0.509 *[$ Process Time Factor $]+$

$0.119 * \sqrt{[\text { Priority Truck Penetration }]}-0.061 * \sqrt{[\text { Percent Primary Inspection }]}-7.184$

\section{Equation 24}

$\sqrt{\text { Average Priority Truck Travel Time Advantage } \text { No QJL - QJL }_{2}}=$

$1.630 * \sqrt{[\text { Average Hourly Truck Demand }]}+2.455^{*}[$ Process Time Factor $]$ -

$0.078 * \sqrt{[\text { Priority Truck Penetration }]}-0.674 * \sqrt{[\text { Percent Primary Inspection }]}-29.574$ 


\section{Equation 25}

Overall Auto Throughput ${ }_{\text {No QJL }}=$

$1.001 *[$ Average Hourly Auto Demand $]-197.027 *[$ Process Time Factor $]+$ $5.654 *[$ Priority Auto Penetration $]+2352.596$

\section{Equation 26}

Overall Auto Throughput ${ }_{\mathrm{QJL}}=$

$0.938 *[$ Average Hourly Auto Demand $]-212.587 *[$ Process Time Factor $]+$ $6.851 *[$ Priority Auto Penetration $]+2454.425$

\section{Equation 27}

Overall Truck Throughput No QJL $=$

$0.955^{*}[$ Average Hourly Truck Demand $]-50.886^{*}[$ Process Time Factor $]+$

$4.715^{*}[$ Priority Truck Penetration $]-4.297 *[$ Percent Secondary Truck $]+806.137$

\section{Equation 28}

Overall Truck Throughput ${ }_{\mathrm{QJL}}=$

$1.062 *[$ Average Hourly Truck Demand $]-59.236^{*}[$ Process Time Factor $]+$ $1.475^{*}[$ Priority Truck Penetration $]-0.474 *[$ Percent Secondary Truck $]+821.283$ 


\section{Equation 29}

Percent Overall Auto Demand Serviced No QJL $^{=}$ $-0.064 *[$ Average Hourly Auto Demand $]-5.788 *[$ Process Time Factor $]+$ $0.153^{*}[$ Priority Auto Penetration $]+151.001$

\section{Equation 30}

Percent Overall Truck Demand Serviced No QJL $^{=}$ $-0.126 *[$ Average Hourly Truck Demand $]-3.877^{*}[$ Process Time Factor $]+$ $0.337 *[$ Priority Truck Penetration $]-0.322 *[$ Percent Secondary Truck $]+130.378$

It is important to note that the above regression model equations should only be applied and interpreted within the ranges of independent variables from the population modeled. Prediction by extrapolation outside of these ranges may be inaccurate and misleading. The predictive power of the model equations are measured by the value of the Pearson Regression Coefficient (i.e. adj. $\mathrm{R}^{2}$ ). Many of the equations above have high adjusted $\mathrm{R}^{2}$ value. This means that the model achieves a high degree of variable explanation and posses excellent predictive powers. These values for adjusted $\mathrm{R}^{2}$ are summarized in Table 4-1 below.

The significance of the parameters estimated was determined at a $95 \%$ confidence level by performing the alternative hypothesis analysis. Table $4-1$ below summarizes the $t$ values estimated for each coefficient. Except for the Equations 22 to 24 above for the 
dependent variable [SQRT Average Priority Truck Travel Time Advantage] all the null hypothesis was rejected for all the parameters estimated for the No Queue Jump Lane Scenario, this means that there exist a statistically significant relationship between the respective IV's and the DV's for the No Queue Jump Lane scenario. For the scenarios where the null hypothesis was not rejected it means all the independent variables were not found to be in a statistically significant relationship with the DV from hypothesis testing using t-values. These variables are usually omitted from the model for reasons of insignificance, however for the purpose of comparison between the scenarios the same form of model that was maintained for the No Queue Jump Lane Scenario was maintained for the other scenarios. 


\begin{tabular}{|c|c|c|c|c|c|c|c|c|}
\hline $\begin{array}{c}\text { Dependent } \\
\text { Variable }\end{array}$ & Scenario & Independent Variable & B & B & $\begin{array}{l}\text { Relative } \\
\text { effect } \\
\text { on DV }\end{array}$ & $\mathbf{T}$ & $\begin{array}{c}\text { Partial } \\
\text { Correlation } \\
\text { Coefficient }\end{array}$ & $\begin{array}{c}\text { adj } \\
\mathbf{R}^{2}\end{array}$ \\
\hline \multirow{12}{*}{$\begin{array}{l}\text { Average Overall } \\
\text { Auto Travel Time }\end{array}$} & \multirow{4}{*}{$\begin{array}{l}\text { No Queue Jump } \\
\text { Lanes for Priority } \\
\text { Autos }\end{array}$} & Average Hourly Auto Demand & 0.033 & 0.734 & 45 & 38.434 & 0.960 & \multirow{4}{*}{0.955} \\
\hline & & Process Time Factor & 3.671 & 0.804 & 49 & 40.523 & 0.964 & \\
\hline & & Priority Auto Penetration & -0.101 & -0.107 & -6 & -5.469 & -0.439 & \\
\hline & & Intercept & 20.06 & - & - & -23.525 & - & \\
\hline & \multirow{4}{*}{$\begin{array}{l}\text { With Queue Jump } \\
\text { lanes for Priority } \\
\text { Autos }\end{array}$} & Average Hourly Auto Demand & 0.021 & 0.822 & 50 & 13.870 & 0.934 & \multirow{4}{*}{0.900} \\
\hline & & Process Time Factor & 2.754 & 0.774 & 47 & 13.042 & 0.927 & \\
\hline & & Priority Auto Penetration & -0.022 & -0.035 & -3 & -0.614 & -0.115 & \\
\hline & & Intercept & 12.96 & - & - & -7.553 & - & \\
\hline & \multirow{4}{*}{$\begin{array}{c}\text { Difference between } \\
\text { No Queue Jump } \\
\text { Lane and Queue } \\
\text { Jump Lane }\end{array}$} & Average Hourly Auto Demand & 0.014 & 0.884 & 59 & 9.883 & 0.882 & \multirow{4}{*}{0.773} \\
\hline & & Process Time Factor & 0.944 & 0.426 & 28 & 4.756 & 0.668 & \\
\hline & & Priority Auto Penetration & -0.078 & -0.199 & -13 & -2.324 & -0.402 & \\
\hline & & Intercept & -8.386 & - & - & -5.186 & - & \\
\hline \multirow{15}{*}{$\begin{array}{l}\text { Average Overall } \\
\text { Truck Travel Time }\end{array}$} & \multirow{5}{*}{$\begin{array}{l}\text { No Queue Jump } \\
\text { Lanes for Priority } \\
\text { Trucks }\end{array}$} & Average Hourly Truck Demand & 0.103 & 0.680 & 37 & 22.202 & 0.883 & \multirow{5}{*}{0.868} \\
\hline & & Process Time Factor & 3.463 & 0.386 & 21 & 12.607 & 0.730 & \\
\hline & & Priority Truck Penetration & -0.265 & -0.372 & -20 & -12.246 & -0.720 & \\
\hline & & Percent Secondary Truck & 0.259 & 0.406 & 22 & 13.371 & 0.750 & \\
\hline & & Intercept & 19.37 & - & - & -7.959 & - & \\
\hline & \multirow{5}{*}{$\begin{array}{l}\text { With Queue Jump } \\
\text { lanes for Priority } \\
\text { Trucks }\end{array}$} & Average Hourly Truck Demand & 0.071 & 0.651 & 35 & 8.166 & 0.839 & \multirow{5}{*}{0.818} \\
\hline & & Process Time Factor & 2.756 & 0.434 & 23 & 5.252 & 0.704 & \\
\hline & & Priority Truck Penetration & -0.202 & -0.397 & -21 & -4.870 & -0.677 & \\
\hline & & Percent Secondary Truck & 0.197 & 0.373 & 21 & 4.759 & 0.669 & \\
\hline & & Intercept & -9.836 & - & - & -1.970 & - & \\
\hline & \multirow{5}{*}{$\begin{array}{l}\text { Difference between } \\
\text { No Queue Jump } \\
\text { Lane and Queue } \\
\text { Jump Lane }\end{array}$} & Average Hourly Truck Demand & 0.031 & 0.750 & 54 & 5.481 & 0.732 & \multirow{5}{*}{0.497} \\
\hline & & Process Time Factor & 1.158 & 0.461 & 33 & 3.298 & 0.543 & \\
\hline & & Priority Truck Penetration & 0.031 & 0.150 & 11 & 1.094 & 0.210 & \\
\hline & & Percent Secondary Truck & 0.007 & 0.034 & 2 & 0.255 & 0.050 & \\
\hline & & Intercept & 12.81 & 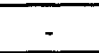 & - & -3.900 & - & \\
\hline
\end{tabular}




\begin{tabular}{|c|c|c|c|c|c|c|c|}
\hline $\begin{array}{l}\text { Dependent } \\
\text { Variable }\end{array}$ & Scenario & Independent Variable & $\mathbf{B}$ & $\mathbf{B}$ & $\mathbf{T}$ & $\begin{array}{l}\text { Partial } \\
\text { Correlation } \\
\text { Coefficient }\end{array}$ & $\begin{array}{l}\text { adj } \\
R^{2}\end{array}$ \\
\hline \multirow{6}{*}{$\begin{array}{c}\text { Average } \\
\text { Priority } \\
\text { Auto } \\
\text { Travel } \\
\text { Time }\end{array}$} & \multirow{2}{*}{$\begin{array}{l}\text { No Queue Jump Lanes } \\
\text { for Priority Autos }\end{array}$} & PriorityDemand / PriorityProcCap & 32.576 & 0.936 & 32.111 & 0.936 & \multirow{2}{*}{0.876} \\
\hline & & Intercept & -3.587 & - & -5.267 & - & \\
\hline & \multirow{2}{*}{$\begin{array}{l}\text { With Queue Jump lanes } \\
\text { for Priority Autos }\end{array}$} & PriorityDemand / PriorityProcCap & 19.514 & 0.664 & 4.788 & 0.664 & \multirow{2}{*}{0.422} \\
\hline & & Intercept & 1.187 & - & 0.567 & - & \\
\hline & \multirow{2}{*}{$\begin{array}{l}\text { Difference between No Queue } \\
\text { Jump Lane and Queue Jump Lane }\end{array}$} & PriorityDemand / PriorityProcCap & 15.736 & 0.669 & 4.852 & 0.669 & \multirow{2}{*}{0.429} \\
\hline & & Intercept & -3.153 & - & -1.915 & - & \\
\hline \multirow{4}{*}{$\begin{array}{c}\text { SQRT } \\
\text { Average } \\
\text { Priority } \\
\text { Truck Travel } \\
\text { Time }\end{array}$} & \multirow{2}{*}{$\begin{array}{l}\text { No Queue Jump Lanes } \\
\text { for Priority Autos }\end{array}$} & PriorityDemand / PriorityProcCap & 5.647 & 0.805 & 15.905 & 0.805 & \multirow{2}{*}{0.646} \\
\hline & & Intercept & 1.309 & - & 7.192 & - & \\
\hline & \multirow{2}{*}{$\begin{array}{l}\text { With Queue Jump lanes } \\
\text { for Priority Autos }\end{array}$} & PriorityDemand / PriorityProcCap & 3.687 & 0.761 & 6.426 & 0.761 & \multirow{2}{*}{0.565} \\
\hline & & Intercept & 1.233 & - & 3.643 & - & \\
\hline \multirow{2}{*}{$\begin{array}{c}\text { Average } \\
\text { Priority Truck } \\
\text { Travel Time }\end{array}$} & \multirow{2}{*}{$\begin{array}{l}\text { Difference between No Queue } \\
\text { Jump Lane and Queue Jump Lane }\end{array}$} & PriorityDemand / PriorityProcCap & 44.839 & 0.802 & 6.851 & 0.781 & \multirow{2}{*}{0.630} \\
\hline & & Intercept & -7.521 & - & -3.709 & - & \\
\hline \multirow{6}{*}{$\begin{array}{l}\text { Average } \\
\text { Non- } \\
\text { Priority } \\
\text { Auto } \\
\text { Travel } \\
\text { Time }\end{array}$} & \multirow{2}{*}{$\begin{array}{l}\text { No Queue Jump Lanes } \\
\text { for Priority Autos }\end{array}$} & SQRT (NonPriorityDemand / NonPriorityProcCap) & 63.425 & 0.968 & 44.626 & 0.968 & \multirow{2}{*}{0.937} \\
\hline & & Intercept & -37.808 & - & -28.862 & - & \\
\hline & \multirow{2}{*}{$\begin{array}{l}\text { With Queue Jump lanes } \\
\text { for Priority Autos }\end{array}$} & SQRT (NonPriorityDemand / NonPriorityProcCap) & 38.828 & 0.954 & 17.370 & 0.954 & \multirow{2}{*}{0.907} \\
\hline & & Intercept & -21.537 & - & -10.656 & - & \\
\hline & \multirow{2}{*}{$\begin{array}{l}\text { Difference between No Queue } \\
\text { Jump Lane and Queue Jump Lane }\end{array}$} & SQRT (NonPriorityDemand / NonPriorityProcCap) & 21.696 & 0.859 & 9.206 & 0.859 & \multirow{2}{*}{0.730} \\
\hline & & Intercept & -14.596 & - & -6.853 & - & \\
\hline \multirow{6}{*}{$\begin{array}{c}\text { Average } \\
\text { Non- } \\
\text { Priority } \\
\text { Truck } \\
\text { Travel } \\
\text { Time }\end{array}$} & \multirow{2}{*}{$\begin{array}{l}\text { No Queue Jump Lanes } \\
\text { for Priority Autos }\end{array}$} & NonPriorityDemand / NonPriorityProcCap & 33.523 & 0.839 & 18.745 & 0.839 & \multirow{2}{*}{0.702} \\
\hline & & Intercept & -8.446 & - & -5.039 & - & \\
\hline & \multirow{2}{*}{$\begin{array}{l}\text { With Queue Jump lanes } \\
\text { for Priority Autos }\end{array}$} & NonPriorityDemand / NonPriorityProcCap & 39.082 & 0.924 & 13.265 & 0.924 & \multirow{2}{*}{0.849} \\
\hline & & Intercept & -10.194 & - & -4.473 & - & \\
\hline & \multirow{2}{*}{$\begin{array}{l}\text { Difference between No Queue } \\
\text { Jump Lane and Queue Jump Lane }\end{array}$} & NonPriorityDemand / NonPriorityProcCap & -15.107 & $\cap 365$ & -2.039 & -0.365 & \multirow{2}{*}{0.101} \\
\hline & & Intercept & 11.564 & - & 2.059 & - & \\
\hline
\end{tabular}




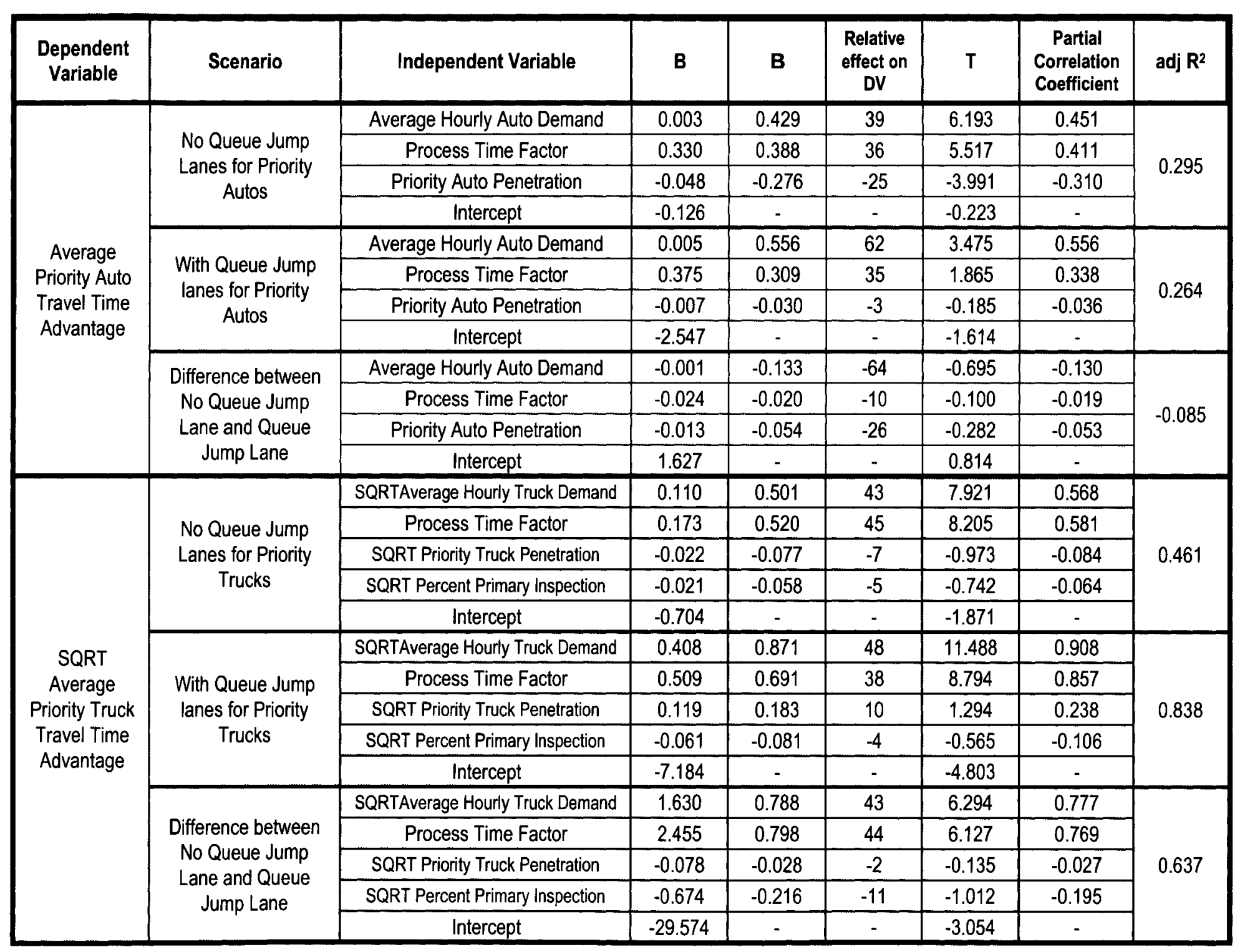




\begin{tabular}{|c|c|c|c|c|c|c|c|c|}
\hline $\begin{array}{l}\text { Dependent } \\
\text { Variable }\end{array}$ & Scenario & Independent Variable & B & $\mathbf{B}$ & $\begin{array}{l}\text { Relative } \\
\text { effect on } \\
\text { DV }\end{array}$ & $T$ & $\begin{array}{c}\text { Partial } \\
\text { Correlation } \\
\text { Coefficient }\end{array}$ & $\operatorname{adj} R^{2}$ \\
\hline \multirow{8}{*}{$\begin{array}{l}\text { Overall Auto } \\
\text { Throughput }\end{array}$} & \multirow{4}{*}{$\begin{array}{l}\text { No Queue Jump } \\
\text { Lanes for } \\
\text { Priority Autos }\end{array}$} & Average Hourly Auto Demand & 1.001 & 0.451 & 33 & 17.244 & 0.821 & \multirow{4}{*}{0.902} \\
\hline & & Process Time Factor & -197.027 & -0.780 & -58 & -29.345 & -0.926 & \\
\hline & & Priority Auto Penetration & 5.654 & 0.117 & 9 & 4.445 & 0.347 & \\
\hline & & Intercept & 2352.596 & - & - & 39.495 & - & \\
\hline & \multirow{4}{*}{$\begin{array}{l}\text { With Queue } \\
\text { Jump Lanes for } \\
\text { Priority Autos }\end{array}$} & Average Hourly Auto Demand & 0.938 & 0.440 & 34 & 8.238 & 0.837 & \multirow{4}{*}{0.914} \\
\hline & & Process Time Factor & -212.587 & -0.734 & -56 & -13.621 & -0.930 & \\
\hline & & Priority Auto Penetration & 6.851 & 0.129 & 10 & 2.453 & 0.415 & \\
\hline & & Intercept & 2454.425 & - & - & 18.569 & - & \\
\hline \multirow{10}{*}{$\begin{array}{c}\text { Overall Truck } \\
\text { Throughput }\end{array}$} & \multirow{5}{*}{$\begin{array}{l}\text { No Queue Jump } \\
\text { Lanes for } \\
\text { Priority Trucks }\end{array}$} & Average Hourly Truck Demand & 0.955 & 0.404 & 24 & 10.094 & 0.654 & \multirow{5}{*}{0.777} \\
\hline & & Process Time Factor & -50.886 & -0.370 & -22 & -9.261 & -0.622 & \\
\hline & & Priority Truck Penetration & 4.715 & 0.458 & 27 & 11.462 & 0.701 & \\
\hline & & Percent Secondary Truck & -4.297 & -0.464 & -27 & -11.605 & -0.705 & \\
\hline & & Intercept & 806.137 & - & - & 17.208 & - & \\
\hline & \multirow{5}{*}{$\begin{array}{l}\text { With Queue } \\
\text { Jump Lanes for } \\
\text { Priority Trucks }\end{array}$} & Average Hourly Truck Demand & 1.062 & 0.499 & 42 & 4.071 & 0.610 & \multirow{5}{*}{0.570} \\
\hline & & Process Time Factor & -59.236 & -0.481 & -41 & -3.783 & -0.582 & \\
\hline & & Priority Truck Penetration & 1.475 & 0.150 & 13 & 1.194 & 0.220 & \\
\hline & & Percent Secondary Truck & -0.474 & -0.046 & -4 & -0.385 & -0.073 & \\
\hline & & Intercept & 821.283 & - & - & 5.517 & - & \\
\hline \multirow{9}{*}{$\begin{array}{l}\text { Percent of } \\
\text { Demand } \\
\text { Serviced }\end{array}$} & \multirow{4}{*}{$\begin{array}{l}\text { No Queue Jump } \\
\text { Lanes for } \\
\text { Priority Autos }\end{array}$} & Average Hourly Auto Demand & -0.064 & -0.837 & -51 & -42.483 & -0.960 & \multirow{4}{*}{0.942} \\
\hline & & Process Time Factor & -5.788 & -0.702 & -43 & -34.831 & -0.942 & \\
\hline & & Priority Auto Penetration & 0.153 & 0.093 & 6 & 4.707 & 0.356 & \\
\hline & & Intercept & 151.001 & - & - & 96.785 & - & \\
\hline & \multirow{5}{*}{$\begin{array}{l}\text { No Queue Jump } \\
\text { Lanes for } \\
\text { Priority Trucks }\end{array}$} & Average Hourly Truck Demand & -0.126 & -0.681 & -37 & -22.179 & -0.883 & \multirow{5}{*}{0.868} \\
\hline & & Process Time Factor & -3.877 & -0.353 & -19 & -11.507 & -0.698 & \\
\hline & & Priority Truck Penetration & 0.337 & 0.387 & 21 & 12.691 & 0.733 & \\
\hline & & Percent Secondary Truck & -0.322 & -0.412 & -23 & -13.531 & -0.754 & \\
\hline & & Intercept & 130.378 & - & - & 43.672 & - & \\
\hline
\end{tabular}




\section{Chapter 5 Discussion}

\subsection{The Peace Bridge - Canada Bound}

The first micro-simulation model constructed in this research was for the Peace Bridge Canada Bound crossing. The results for the different scenarios modelled are summarized in appendix $\mathrm{A}$.

An increase of Priority Auto and Priority Truck Penetration generally results in a reduction in overall average travel time across the categories (i.e. overall system benefit), this can be seen in the simulation model results displayed in Figures A-1 to A-18 in Appendix A. In cases of low congestion characterized by little or no queue build up before the primary customs processing (example scenario S-1 for autos), the effect of priority penetration increase in the reduction of overall average auto travel time is not that pronounced (Figure A-1). For truck traffic in Scenario 1 (S-1) more congestion and queue build up exists at the primary customs clearance and the effect of priority penetration increase in reducing overall average truck travel time is more pronounced (Figure A-2). This points to the fact that priority penetration programs makes a greater impact in providing system benefits at crossing situations where there is congestion and delays.

The intermediate increases in overall average travel time at certain penetration levels for specific scenarios is primarily due to the blocking of the access to processing booths by 
one particular category of crossing vehicles. This results in an increased average travel time across all the categories resulting in an overall average travel time increase. This situation can be corrected by a modification of the lane allocation policy for these particular scenarios to reduce queue length formation for the particular vehicle category causing the blockage of the gore. The lane allocation policy adopted for the Peace Bridge simulation model is the conversion of non-priority traffic lanes to dedicated priority traffic lanes as the penetration rate increases for priority vehicles. In some cases the category specific increase could also be as a result of the access to dedicated processing lanes being blocked by the extended queues and as a result the available capacity for that category is not utilized fully since the vehicles are caught in the queue upstream. Generally it can be said that increased priority vehicle penetration results in an overall reduction in average travel time across the various categories and as demand and customs processing time increases the impact of the priority penetration rate is significantly greater. For example in scenario $8(100 \%$ increase in demand, Increased Customs Time, No Queue Jump Lane) there has been a decrease in overall auto travel time of about 29 minutes moving from the $10 \%$ to $30 \%$ penetration level. It is important to note that sometimes the overall vehicle travel time is higher at the lower penetration levels when compared to the $0 \%$ penetration for the scenario. This is as a result of the dedicated processing lane for priority vehicles being taken from the non-priority processing lanes resulting in a significant reduction in processing capacity for nonpriority vehicles. Therefore for certain scenarios, depending on the importance placed on 
overall system benefit it might not be feasible to implement the priority crossing program for lower levels of priority vehicle penetration.

The implementation of queue jump lanes for priority vehicles also had a significant impact on the travel times for the various categories of vehicles and overall as well. In Figures A-19 to A-25 it can be seen that for the queue jump lane scenarios the travel times were generally lower for the specific categories and overall for the different penetration rates. Queue jump lanes for priority vehicles tend to in most cases reduce not only the travel time of priority vehicles (user benefit) but also reduce travel time for nonpriority vehicles due to the reduction in traffic mixing between the different categories. This results in overall system benefit. The greatest impact of the queue jump lanes in reducing travel times occurs at the higher demand levels. As much as a 20 minute reduction of overall average auto travel time with the implementation of queue jump lanes at a $100 \%$ demand increase for the $20 \%$ penetration rate has been observed from the simulation output (Figure A-21). The same can be said for truck traffic, the model results show that with the implementation of queue jump lanes there can be as much as a 40 minute reduction in overall average truck travel time (Figure A-25) for a 100\% demand increase over base-case and $60 \%$ priority penetration rate.

The difference in travel times between priority vehicles and non-priority crossing users increases as congestion increases in the form of increased demand and increased processing times. This can be seen especially when we compare the scenarios with $20 \%$ 
demand increase with the base-case demand scenarios. This lower travel time for priority traffic compared to non-priority traffic is important in order to maintain the feasibility and attractiveness of the priority crossing program. The trends of increased difference as demand and customs processing time increases is an indication that the viability and sustainability of a priority crossing program is crucial for the regular crossing users who are more likely to be participants especially given the future predicted demand increases at land border crossings.

Travel time should not be used as the only measure for the performance of a border crossing, it should be interpreted along with other performance indicators such as throughput and percent of demand serviced. The reason being that a small travel time result may be skewed as a result of a low demand period early in the simulation however as the demand increases the congestion and queue lengths increases. By the end of the simulation the early low travel times can result in an overall relatively low travel time which can be misleading taken by itself, this is further explained below.

In this research throughput and proportion of demand serviced were considered along with travel time for the different categories of vehicles. Figures A-34 to A-41 in the appendix shows the variation of these parameters with each other, the general trend of throughput decreasing with an increase in travel time is evident. Figures A-40 and A-41 gives an indication of the trends of percent of demand serviced (i.e. throughput/demand) versus priority penetration rates for the different scenarios. For both autos and trucks the 
percent of demand serviced decreases with an increase in overall demand. Also for most of the priority vehicle penetration rates there is a higher proportion of demand serviced for the queue jump lane scenarios than those without queue jump lanes. The penetration rates for which there were lower demand service rates were the $80 \%$ and $90 \%$ percent penetration rate and this is due to the over saturation of the priority toll lanes thus causing excessive queue build up and flow breakdown upstream of the toll facilities.

Table 5-1 below summarizes for each scenario the minimum overall crossing travel time* and other associated performance indicators. The data is a selection from the results of the simulation and indicates the importance of interpreting travel time values by considering other performance indicators such as throughput and proportion of demand serviced. For example the travel times for S6, S7, S8 and S9 are higher when compared with the other scenarios. However these times of themselves are not very high crossing times but when the other suggested performance criteria are examined it becomes evident why these scenarios (which are for 50 and $100 \%$ increases in demand) are not feasible. The most significant indicator being the "percent of auto demand serviced" for which none of the scenarios mentioned above was greater than $65 \%$. For these scenarios it can also be noticed that the implementation of queue jump lanes does not increase the percent of demand serviced by much. The selected results for the first five scenarios (S1, S2, S3, S4 \& S5) indicated good results for the travel times and the other performance indicators, high throughputs (> 2100 autos in 4-hours) and percent of auto demand serviced (>90\%) were obtained. This is an indication that after a certain level of demand increase priority- 
crossing programs and queue jump lanes are not feasible for border crossings unless there is an increase in physical infrastructure capacity.

Table 5-1: Minimum Overall Auto Crossing Travel Time and Associated Performance Indicators.

\begin{tabular}{|c|c|c|c|c|c|c|c|c|c|}
\hline & S1 & S2 & S3 & S4 & S5 & S6 & S7 & S8 & S9 \\
\hline $\begin{array}{l}\text { Overall Minimum Auto } \\
\text { Travel Time (minutes) }\end{array}$ & 4.90 & 5.17 & 6.80 & 7.82 & 8.53 & 10.80 & 9.15 & 14.43 & 9.87 \\
\hline Penetration Level & 60 & 70 & 70 & 40 & 40 & 50 & 60 & 80 & 60 \\
\hline $\begin{array}{l}\text { Overall Auto Throughput } \\
\text { (4-hours) }\end{array}$ & 2126 & 2101 & 2541 & 2395 & 2372 & 2084 & 1771 & 1493 & 1766 \\
\hline $\begin{array}{l}\text { Percent of Auto Demand } \\
\text { Serviced }\end{array}$ & 99.3 & 99.8 & 98.8 & 93.2 & 92.3 & 64.8 & 55.1 & 34.8 & 41.2 \\
\hline $\begin{array}{l}\text { Overall Truck Time at } \\
\text { Penetration level }\end{array}$ & 8.90 & 9.95 & 9.75 & 11.93 & 12.92 & 15.80 & 11.57 & 23.82 & 16.13 \\
\hline $\begin{array}{l}\text { Overall Truck Throughput } \\
\text { (4hours) }\end{array}$ & 514 & 529 & 587 & 552 & 551 & 720 & 683 & 857 & 878 \\
\hline $\begin{array}{l}\text { Percent of Truck Demand } \\
\text { Serviced }\end{array}$ & 97.3 & 98.1 & 86.1 & 80.9 & 80.9 & 94.7 & 89.9 & 84.5 & 86.6 \\
\hline Average Queue Length & 49.1 & 51.0 & 74.0 & 79.8 & 87.2 & 118.2 & 78.0 & 169.5 & 106.9 \\
\hline Minimum Truck Time & 7.78 & 8.40 & 9.32 & 8.18 & 8.50 & 10.65 & 11.57 & 23.82 & 16.13 \\
\hline $\begin{array}{l}\text { Penetration Level For Min. } \\
\text { Truck Time }\end{array}$ & 90 & 90 & 80 & 90 & 90 & 90 & 60 & 80 & 60 \\
\hline $\begin{array}{l}\text { Mean Overall Auto Travel } \\
\text { Time }\end{array}$ & 5.01 & 5.69 & 9.87 & 9.04 & 9.82 & 21.74 & 15.28 & 27.31 & 19.52 \\
\hline $\begin{array}{l}\text { Std. Dev. Overall Auto } \\
\text { Travel Time }\end{array}$ & 0.06 & 0.72 & 2.59 & 1.63 & 2.22 & 10.63 & 3.82 & 12.16 & 6.43 \\
\hline $\begin{array}{l}\text { Mean Overall Truck Travel } \\
\text { Time }\end{array}$ & 10.27 & 11.08 & 12.15 & 11.22 & 12.51 & 29.63 & 19.94 & 45.90 & 35.50 \\
\hline $\begin{array}{l}\text { Std. Dev. Overall Truck } \\
\text { Travel Time }\end{array}$ & 2.10 & 2.54 & 3.40 & 1.98 & 3.30 & 17.79 & 7.92 & 20.79 & 12.19 \\
\hline
\end{tabular}

S1- Base-case Demand and Customs Processing Times

S2 - Base-case Demand and increased Customs processing Times

S3 - 20\% Increased Demand and Increased Customs Processing Times (No Queue Jump Lanes)

S4 - 20\% Increased Demand and Base-case Customs Processing Times (With Queue Jump Lanes)

S5 - 20\% Increased Demand and Increased Customs Processing Times (With Queue Jump Lanes)

S6 - 50\% Increased Demand and Increased Customs Processing Times (No Queue Jump Lanes)

S7 - 50\% Increased Demand and Increased Customs Processing Times (With Queue Jump Lanes)

S8 - 100\% Increased Demand and Increased Customs Processing Times (No Queue Jump Lanes)

S9 - 100\% Increased Demand and Increased Customs Processing Times (With Queue Jump Lanes)

* The $90 \%$ and $100 \%$ priority penetration rates were not considered when choosing the overall minimum auto travel time. 


\subsection{AMBASSADOR BRIDGE - U.S. BOUND}

The second micro-simulation model constructed in this research was for the Ambassador Bridge U.S. bound traffic. All the scenarios modelled were taken from the database of model inputs (Table B-5 and B-6). The first set of model simulations for the U.S. bound traffic were done for the existing border crossing facility without the implementation of Queue Jump Lanes (QJL). The results of the model outputs for each data set were summarized (see Table B-5) and the regression models were developed.

\section{No Queue Jump Lane Scenario}

Table 5-2 below summarizes the dependent variables, independent variables and intercept for the OLS regression model equations derived as part of this research for the Ambassador Bridge U.S. Bound without Queue Jump Lanes.

The regression equations provide a means for us to be able to assess the impact of a priority crossing program on the efficiency of a crossing in terms of the overall average travel time, throughput and the category specific average travel time. Particularly the standardized partial regression coefficients allow us to compare the relative effect of the independent variables on the dependent variable. 
Table 5-2: Summary Of Auto Regression Models, Ambassador Bridge - U.S. Bound (No Queue Jump Lane)

\begin{tabular}{|c|c|c|c|c|}
\hline Dependent Variable & Independent Variable 1 & Independent Variable 2 & Independent Variable 3 & Intercept \\
\hline OverallAutoTravTime & 0.033[AvgHrlyDemandAuto] & 3.671[ProcTimeFactor] & - 0.101 [PriorityAutoPenet] & -20.061 \\
\hline $\begin{array}{c}\text { Standardized } \\
\text { Coefficients }\end{array}$ & 0.734 & 0.804 & -0.107 & \\
\hline $\begin{array}{c}\text { Relative Impact on } \\
\text { DV }\end{array}$ & 45 & 49 & -6 & \\
\hline $\begin{array}{l}\text { AveragePriority } \\
\text { AutoTravTime }\end{array}$ & \multicolumn{3}{|c|}{ 32.576[PriorityAutoDemand/PriorityAutoProcCap] } & -3.587 \\
\hline $\begin{array}{l}\text { Standardized } \\
\text { Coefficients }\end{array}$ & \multicolumn{3}{|c|}{0.936} & \\
\hline $\begin{array}{c}\text { Relative Impact on } \\
\text { DV }\end{array}$ & \multicolumn{3}{|c|}{100} & \\
\hline $\begin{array}{l}\text { AverageNonPriority } \\
\text { AutoTravTime }\end{array}$ & \multicolumn{3}{|c|}{ 63.425SQRT[NonPriorityAutoDemand/NonPriorityAutoProcCap] } & -37.808 \\
\hline $\begin{array}{l}\text { Standardized } \\
\text { Coefficients }\end{array}$ & \multicolumn{3}{|c|}{0.968} & \\
\hline $\begin{array}{c}\text { Relative Impact on } \\
\text { DV }\end{array}$ & \multicolumn{3}{|c|}{100} & \\
\hline $\begin{array}{c}\text { Priority } \\
\text { AutoTravTimeAd }\end{array}$ & 0.003[AvgHrlyDemandAuto] & 0.330[ProcTimeFactor] & $-0.048[$ PriorityAutoPenet] & -0.126 \\
\hline $\begin{array}{l}\text { Standardized } \\
\text { Coefficients }\end{array}$ & 0.429 & 0.388 & -0.276 & \\
\hline $\begin{array}{c}\text { Relative Impact on } \\
\text { DV }\end{array}$ & 39 & 36 & 25 & \\
\hline OvrAutoThrput & 1.001 AvgHrityDemandAuto & $\begin{array}{l}-197.027 \\
\text { ProcTimeFactor }\end{array}$ & 5.654 PriorityAutoPenet & 2352.596 \\
\hline $\begin{array}{l}\text { Standardized } \\
\text { Coefficients }\end{array}$ & 0.451 & -0.780 & 0.117 & \\
\hline $\begin{array}{c}\text { Relative Impact on } \\
\text { DV }\end{array}$ & 33 & -58 & 9 & \\
\hline
\end{tabular}

\section{Overall Average Auto Travel Time - No QJL}

The Dependent Variable [OverallAutoTravTime] (Table 5-2 above) has been impacted in different magnitudes by the IV's, it is important to note that the effect of Priority Auto Penetration on Average Overall Travel Time is negative which is desirable. However the impact of Average Hourly Demand and Process Time Factor on Average Auto Travel Time is positive and over 7 times greater than the impact of Priority Auto Penetration. 
This means that at an overall system level for auto travel through a border crossing, a priority crossing program does make an impact in reducing the overall average travel time across categories however Overall Average Travel Time is impacted much more heavily by Average Hourly Demand and Customs Processing Time when all other variables remain constant. From the regression equation, for a unit change in process time factor and holding the other independent variables constant, there is an increase in average travel time of 3.671 minutes. To compensate for this increased travel time across categories there needs to be a $36 \%$ increase in Priority Auto Penetration for a fixed demand. This is illustrated in Figure B-7 for a fixed auto demand of $1168 \mathrm{veh} / \mathrm{hour}$ across all categories. It should be noted that the regression model was formulated for a crossing where priority crossing lanes replaced lanes used for non-priority traffic as the demand for priority crossing clearance increased. It therefore means that there needs to be sizeable priority crossing penetration for there to be a noticeable improvement in the Overall Average Auto Travel Time across categories. Increased penetration has to be coupled with increased processing capacity and demand reduction measures for there to be significant system benefits in the form of Overall Auto Travel Time reduction at border crossings. The maximum average auto travel time for the ranges of independent variables in the data set was 41.5 minutes at an Average Hourly Auto Demand of 1168 veh/hour, Process Time Factor of 6.27 and a Priority Auto Penetration Rate of 0 . The minimum average auto travel time was 19.1 minutes at an Average Hourly Auto Demand of 1168 veh/hour, Process Time Factor of 1 and a Priority Auto Penetration Rate of 30. 
Figure B-7 shows the variation of Average Overall Auto Travel Time with Process Time Factor (PTF) and Priority Auto Penetration. The base-case scenario for the Ambassador Bridge was for zero percent penetration and 1.00 PTF. The decrease of travel time with an increase in priority vehicle penetration and increase with PTF can be seen in Figure B11 for the base-case demand scenario.

\section{Category Specific Average Auto Travel Times - No QJL}

For the category specific average auto travel times the independent variables of Demand and Processing Capacity were combined and transformed by square root to obtain the best regression models with a high level of explanation of variance. Figure B-12 to B23 show the variation of Priority Auto Travel Time and Non-Priority Auto Travel Time with the respective independent variables of the mathematical model equation. The general trend of increasing travel time with increasing Demand/Processing Capacity ratios is evident.

\section{Priority Auto Travel Time Advantage - No QJL}

Priority Auto Travel Time Advantage is important in order to maintain the feasibility of the priority crossing program. The relationship relating Priority Auto Travel Time Advantage over Non-Priority Auto Travel Time was determined from the data base using linear multivariate regression. The challenge for land border crossing planners and administrators is to service the entire volume of priority crossing traffic and maintain an acceptable travel time advantage over non-priority traffic. This travel time advantage is 
crucial to ensuring the feasibility of the priority crossing program. The difference between the Non-priority Travel Time and the Priority Travel Time represents the travel time advantage for Priority Crossing Vehicles. A regression model was developed from the data base for Priority Auto Travel Time Advantage with the independent variables being Average Hourly Auto Demand, Process Time Factor and Priority Auto Penetration. The relative effects of the independent variables on the dependent variables were relatively close to each other with priority Auto penetration being least at $25 \%$. Figure B24 represents the variation of Priority Auto Travel Time Advantage with Priority Auto Penetration and Average Hourly Auto Demand for a Process Time Factor value of 6.27. The general trend of decreasing advantage with increasing Priority Penetration and increasing advantage with increased Average Hourly Auto Demand is consistent with the policy of utilizing processing lanes that are Non-priority and designating them dedicated priority lanes as demand for priority crossing increases. Figure B-18 shows that Average Non-priority Auto Travel Time decreases as priority penetration increases, this is consistent with the lane allocation policy adopted, where an increase in priority auto processing capacity means a reduction in non-priority vehicle processing lanes. The optimization results indicate that the greatest advantage for the Ambassador Bridge U.S. bound scenario occurs during periods of low priority penetration, high demand and high customs clearance times. The maximum Priority Travel Time Advantage for the ranges of independent variables in the data set was 5.4 minutes at an Average Hourly Demand of 1168 veh/hour, Process Time Factor of 6.27 and a Priority Auto Penetration of 1. The minimum Priority Travel Time Advantage for the ranges of independent variables in the 
data set was 0.18 minutes at an Average Hourly Demand of 1168 veh/hour, Process Time Factor of 1 and a Priority Auto Penetration of 30. The scatter plots of Figures B-27 to B29 indicate the variation of Priority Auto Travel Time Advantage with various variables in the data base. Figure B-27 indicates the increasing trend as Overall Average Auto Travel Time increases. This is significant of the fact that as congestion increases the priority crossing programs will become more attractive for regular crossing users because of the travel time advantage that it provides. Figure B-28 indicates that the priority travel time advantage decreases with an increase in priority crossing demand. This can be expected since an increase in the demand for priority crossing has to be accommodated by an increase in priority processing capacity. Figure B-29 shows that as customs processing time increases the travel time advantage of priority vehicles increases as well.

\section{Overall Auto Throughput - No QJL}

The regression equation relating [OverallAutoThroughput] to Average Hourly Demand, Process Time Factor and Priority Auto Penetration reveals that the IV with the greatest impact on the DV is the Process Time Factor which has a negative impact that is almost twice the desirable positive impact of Average Hourly Demand and over 6 times the impact of PriorityAutoPenetration. The increase in Priority Auto Penetration will improve the throughput as is shown in Figure B-32 for an average hourly demand of 1168 autos the throughput increases with Priority Auto Penetration, however the throughput is reduced more significantly with unit change in Process Time Factor. 
Table 5-3: Summary Of Truck Regression Models. Ambassador Bridge - U.S. Bound (No Queue Jump Lane)

\begin{tabular}{|c|c|c|c|c|c|}
\hline $\begin{array}{l}\text { Dependent } \\
\text { Variable }\end{array}$ & $\begin{array}{l}\text { Independent } \\
\text { Variable } 1\end{array}$ & $\begin{array}{l}\text { Independent } \\
\text { Variable } 2\end{array}$ & $\begin{array}{c}\text { Independent } \\
\text { Variable } 3\end{array}$ & $\begin{array}{l}\text { Independent } \\
\text { Variable } 4\end{array}$ & Intercept \\
\hline $\begin{array}{l}\text { OverallTruck } \\
\text { TravTime }\end{array}$ & $\begin{array}{c}0.103 \\
{[\text { AvgHrlyDemandTruck] }}\end{array}$ & $\begin{array}{c}3.463 \\
\text { [ProcTimeFactor] }\end{array}$ & $\begin{array}{c}-0.265 \\
\text { [PriorityTruckPenet] }\end{array}$ & $\begin{array}{c}0.259 \\
\text { [PercentSecTruck] }\end{array}$ & -19.375 \\
\hline $\begin{array}{l}\text { Standardized } \\
\text { Coefficients }\end{array}$ & 0.680 & 0.386 & -0.372 & 0.406 & \\
\hline $\begin{array}{c}\text { Relative Impact } \\
\text { On DV }\end{array}$ & 37 & 21 & -20 & 22 & \\
\hline $\begin{array}{c}\text { SQRTPriority } \\
\text { TruckTravelTime }\end{array}$ & \multicolumn{4}{|c|}{5.647 [PriorityTruckDemand/PriorityTruckProcCapacity] } & 1.309 \\
\hline $\begin{array}{l}\text { Standardized } \\
\text { Coefficients }\end{array}$ & \multicolumn{4}{|c|}{0.805} & \\
\hline $\begin{array}{c}\text { Relative Impact } \\
\text { On DV }\end{array}$ & \multicolumn{4}{|c|}{100} & \\
\hline $\begin{array}{c}\text { NonPriority } \\
\text { TruckTravelTime }\end{array}$ & \multicolumn{4}{|c|}{39.082 [NonPriorityTruckDemand/NonPriorityTruckProcCap] } & -8.446 \\
\hline $\begin{array}{l}\text { Standardized } \\
\text { Coefficients }\end{array}$ & \multicolumn{4}{|c|}{0.702} & \\
\hline $\begin{array}{l}\text { Relative Impact } \\
\text { On DV }\end{array}$ & \multicolumn{4}{|c|}{100} & \\
\hline $\begin{array}{l}\text { SQRTPriorityTruck } \\
\text { TravelTimeAd }\end{array}$ & $\begin{array}{c}0.110 \\
\text { SQRTAvgHrlyDemTruck }\end{array}$ & $\begin{array}{c}0.173 \\
\text { ProcTimeFactor }\end{array}$ & $\begin{array}{c}-0.022 \\
\text { SQRTPriorityTruckPenet } \\
\end{array}$ & $\begin{array}{c}-0.021 \\
\text { SQRTPercentPrimlnsp }\end{array}$ & -0.704 \\
\hline $\begin{array}{l}\text { Standardized } \\
\text { Coefficients }\end{array}$ & 0.501 & 0.520 & -0.077 & -0.058 & \\
\hline $\begin{array}{c}\text { Relative Impact } \\
\text { On DV }\end{array}$ & 43 & 45 & 7 & 5 & \\
\hline OvrTruckThrput & $\begin{array}{c}0.955 \\
{[\text { AvgHrlyDemandTruck] }}\end{array}$ & $\begin{array}{c}-50.866 \\
\text { [ProcTimeFactor] }\end{array}$ & $\begin{array}{c}4.715 \\
\text { [PriorityTruckPenet] }\end{array}$ & $\begin{array}{c}-4.297 \\
\text { [PercentSecTruck] }\end{array}$ & 806.137 \\
\hline $\begin{array}{l}\text { Standardized } \\
\text { Coefficients }\end{array}$ & 0.404 & -0.370 & 0.458 & -0.464 & \\
\hline $\begin{array}{c}\text { Relative Impact } \\
\text { On DV }\end{array}$ & 24 & -22 & 27 & -27 & \\
\hline
\end{tabular}

\section{$\underline{\text { Overall Average Truck Travel Time - No QJL }}$}

For the regression models involving trucks crossing the Ambassador Bridge into the U.S. the first equation relates Overall Average Truck Travel Time to four independent variables. Three of the variables are similar in impact on the DV these are Process Time Factor, Fast Penetration and Percent Secondary Trucks. The IV with the highest impact on the DV is Average Hourly Truck Demand which influences the Overall Average 
Travel Time positively. Figure B-34 shows the variation of Average Truck Travel Time with Process Time Factor and Priority Truck Penetration for an Average Hourly Truck Demand of $531 \mathrm{veh} / \mathrm{hour}$ and a Percent Truck sent to Secondary inspection of 20. The decrease in travel time as Priority Truck Penetration Rate increases and the increase in travel time with Process Time Factor is evident. The comparative effect of Priority Truck Penetration rate on Average Truck Travel Time is similar to the effect of Process Time Factor as is confirmed by the close values of standardized regression coefficients. For a unit increase in PTF a Priority Penetration rate increase of $13 \%$ is required to compensate while holding all the other independent variables in the equation constant. The reason that the influence of Percent Priority Crossing Penetration is significant and comparable to the other IV's in the equation is due to the significant time benefits for trucks registered in a priority crossing program. The difference in processing times for registered priority crossing users and non-registered priority crossing users is significant for trucks when compared to autos, this explains the greater impact of truck priority crossing penetration on overall average truck travel time compared to the regression involving Overall Average Auto Travel Time.

\section{Category Specific Average Truck Travel Times - No QJL}

For the category specific average truck travel times the level of variance explanation achieved was reasonably high (see Table 4-1). Figure B-37 to B-42 shows the variation of Priority Auto Travel Time and Non-Priority Auto Travel Time with the respective independent variables of the mathematical model equation. As was the case for autos the 
general trend of increasing travel time with increasing Demand/Processing Capacity ratios is evident.

\section{Priority Truck Travel Time Advantage - No QJL}

The difference between the Non-priority Truck Travel Time and the Priority Truck Travel Time represents the travel time advantage for Priority Crossing Trucks. A regression model was developed from the data base relating SQRT Priority Truck Travel Time Advantage with the independent variables being SQRTAverage Hourly Truck Demand, Process Time Factor, SQRT Priority Truck Penetration and SQRT Percent Primary Inspection. The relative effect of the independent variables on the dependent variables was highest and relatively close to each other for SQRT Average Hourly Truck Demand and Process Time Factor. The other two independent variables were low but similar in their relative impact on the DV. Figure B-43 to B-45 represents the variation of Priority Truck Travel Time Advantage with Priority Auto Penetration and Average Hourly Truck Demand for a Process Time Factor value of 6.27 and for Percent Primary Inspection being held at 20 . The general trend of decreasing advantage with increasing Priority Penetration and increasing advantage with increased Average Hourly Truck Demand is consistent with the policy of utilizing processing lanes that are Non-priority and designating them dedicated priority lanes as demand for priority crossing increases. The scatter plots shown in Figure B-46 to B-49 indicate the similar trends shown for auto priority travel time advantage. Priority Truck travel time advantage increases with 
Overall Average Truck Travel Time and Process Time Factor and decreases with an increase in Priority Truck Penetration.

\section{Overall Truck Throughput - No QJL}

The regression equation relating Overall Truck Throughput to Average Hourly Demand, Process Time Factor, Priority Truck Penetration and Percent Secondary Truck reveals that all the independent variables have similar impact on the dependent variable with Priority Truck Penetration and Percent Secondary Trucks being the highest but opposite sign effect. The increase in Priority Truck Penetration will improve the throughput as is shown in Figure B-51 for an average hourly demand of 531 trucks/hour and a percent Secondary Truck of 20 the throughput increases with Priority Truck Penetration and reduces by similar gradient with an increase in Process Time Factor.

\section{Queue Jump Lanes Model}

The micro-simulation model used for the Ambassador Bridge No Queue Jump Lane Scenario was modified to allow for the customs processing to be done on the Canadian Side before the bridge crossing.

The same dependent variables and corresponding independent variables used in the No Queue Jump Lane Scenario was also used in the Queue Jump Lane Scenario in order to facilitate parallel comparison. The dedicated lanes used for priority crossing vehicles 
were provided by taking lanes from non priority crossing users as the demand for priority crossing increased.

Table 5-4: Summary Of Auto Regression Models, Ambassador Bridge - U.S. Bound (Queue Jump Lane)

\begin{tabular}{|c|c|c|c|c|}
\hline Dependent Variable & Independent Variable 1 & Independent Variable 2 & Independent Variable 3 & Intercept \\
\hline OverallAutoTravTime & 0.021[AvgHrlyDemandAuto] & $2.754[$ ProcTimeFactor] & -0.022 [PriorityAutoPenet] & -12.966 \\
\hline $\begin{array}{l}\text { Standardized } \\
\text { Coefficients }\end{array}$ & 0.822 & 0.774 & -0.035 & \\
\hline $\begin{array}{c}\text { Relative Impact } \\
\text { on DV }\end{array}$ & 50 & 47 & 3 & \\
\hline $\begin{array}{l}\text { AveragePriority } \\
\text { AutoTravTime }\end{array}$ & \multicolumn{3}{|c|}{ 19.514[PriorityAutoDemand/PriorityAutoProcCap] } & 1.187 \\
\hline $\begin{array}{l}\text { Standardized } \\
\text { Coefficients }\end{array}$ & \multicolumn{3}{|c|}{0.664} & \\
\hline $\begin{array}{c}\text { Relative Impact } \\
\text { on DV }\end{array}$ & \multicolumn{3}{|c|}{100} & \\
\hline $\begin{array}{l}\text { AverageNonPriority } \\
\text { AutoTravTime }\end{array}$ & \multicolumn{3}{|c|}{ 38.828SQRT[NonPriorityAutoDemand/NonPriorityAutoProcCap] } & -21.537 \\
\hline $\begin{array}{l}\text { Standardized } \\
\text { Coefficients }\end{array}$ & \multicolumn{3}{|c|}{0.954} & \\
\hline $\begin{array}{l}\text { Relative Impact } \\
\text { on DV }\end{array}$ & \multicolumn{3}{|c|}{100} & \\
\hline NexTravTimeAd & $\begin{array}{c}0.005 \\
\text { [AvgHrlyDemandAuto] }\end{array}$ & 0.375[ProcTimeFactor] & $\begin{array}{c}-0.007 \\
\text { [PriorityAutoPenet] }\end{array}$ & -2.547 \\
\hline $\begin{array}{l}\text { Standardized } \\
\text { Coefficients }\end{array}$ & 0.556 & 0.309 & -0.030 & \\
\hline $\begin{array}{l}\text { Relative Impact } \\
\text { on DV }\end{array}$ & 62 & 35 & 3 & \\
\hline OvrAutoThrput & 0.938 AvgHrlyDemandAuto & -212.587 ProcTimeFactor & 6.851 PriorityAutoPenet & 2454.425 \\
\hline $\begin{array}{l}\text { Standardized } \\
\text { Coefficients }\end{array}$ & 0.440 & -0.734 & 0.129 & \\
\hline $\begin{array}{c}\text { Relative Impact on } \\
\text { DV }\end{array}$ & 34 & 56 & 10 & \\
\hline
\end{tabular}




\section{Overall Average Auto Travel Time - QJL}

For the Queue Jump Lane scenario the Average Auto Travel Time is generally lower than the No Queue Jump Lane Scenario. Figures B-8, B-9 and B-10 depict this showing the lower Average Auto Travel Time for all the ranges of values of independent variables used in the No Queue Jump Lane scenario for an Average Hourly Auto Demand of 1168. The impact of Average Hourly Demand and Process Time Factor on Average Auto Travel time is positive and over 16 times greater than the impact of Priority Auto Penetration. This means that at an overall system level for auto travel through a border, a priority crossing program with Queue Jump Lanes does make an impact in reducing the overall average travel time across categories however Overall Average Travel Time is impacted much more heavily by Average Hourly Demand and Customs Processing Time when all other variables remain constant. Figure B-9 shows the considerably lower gradient along the Priority Auto Penetration Axis compared to the Process Time Factor. This is an indication that the impact of increasing Priority Auto Penetration in a Queue Jump Lane Scenario yields much smaller improvements in Overall Average Auto Travel Time across the categories when compared to the No Queue Jump Lane scenario. This does not mean that the No Queue Jump Lane alternative is better than having Queue Jump Lanes for priority vehicles since it has already been shown that across all the ranges of values for the independent variables that the Queue Jump Lane scenario produces a significantly lower Overall Average Auto Travel Time (Figure B-10). However the difference is the rate of reduction in Overall Average Auto Travel Time with Priority Auto Penetration being much lower for the Queue Jump Lane scenario. From the 
regression coefficients, a unit increase in Priority Auto Penetration for the No Queue Jump Lane Scenario results in a 0.101 minute reduction in Overall Average Auto Travel Time while for the Queue Jump Lane Scenario a unit increase in Priority Auto Penetration results in a 0.022 minute reduction in Overall Average Auto Travel Time with all other variables remaining constant. This is a result of the Queue Jump Lane Scenario being the better alternative in terms of lower travel time, hence the case of an already advantageous average travel time means that the impact of increased priority penetration will result in relatively smaller increments of overall average travel time reduction when compared to the No Queue Jump Lane Scenario.

It therefore means that Queue Jump lane implementation does result in significant system benefits in the form of Overall Auto Travel Time reduction at border crossings. However, as long as it has been implemented, increases in priority crossing penetration results in relatively lower rates of reduction of Overall Auto Travel Time when compared to the No Queue Jump Lane Scenario. The maximum overall average auto travel time difference between the Queue Jump Lane and No Queue Jump Lane scenario was 12.6 minutes at an Average Hourly Auto Demand of 1168 veh/hour, Process Time Factor of 6.27 and a Priority Auto Penetration Rate of 1 . The minimum average auto travel time was 5.5 minutes at an Average Hourly Auto Demand of 1168 veh/hour, Process Time Factor of 1 and a Priority Auto penetration Rate of 30 . 
Category Specific Average Auto Travel Times - QJL

For the category specific average auto travel times in the queue jump lane scenarios the independent variables of Demand and Processing Capacity were combined in the same format as the No Queue Jump lane Scenario. Figure B-14 to B-17 and B-20 to B-23 shows that overall for an Average Hourly Auto Demand of 1168 the category specific auto travel times for priority and non priority autos was lower for the Queue Jump Lane Scenario than the No Queue Jump Lane scenario for the entire range of Process Time Factor and Priority Auto Penetration in the data set.

\section{Priority Auto Travel Time Advantage - QJL}

Priority Auto Travel Time Advantage is important in order to maintain the feasibility of the priority crossing program. Figures B-25 and B-26 shows that for all the ranges of independent variables there is a Priority Travel Time advantage for the Queue Jump lane Scenario as there was for the No Queue Jump lane Scenario. In some cases as shown in Figure B-26 some combinations of independent variables result in a larger Priority Auto Travel Time advantage for Queue Jump Lane scenario than for the No Queue Jump Lane scenario. It is difficult to pinpoint the pattern of variable combinations that result in such a scenario since regression models derived for Priority Travel Time Advantage difference between Queue Jump Lane and No Queue Jump Lane Scenarios had very low predictive power based on very small R-square values (i.e. $<1$ ). 


\section{Overall Auto Throughput - QJL}

The regression equation for Overall Auto Throughput for the Queue Jump Lane scenario has similar trends compared to the No Queue Jump Lane Scenario as it concerns the impact of the independent variable on the dependent variables. The same pattern of relative impact of the independent variable on the dependent variable exists for the Queue Jump Lane scenario as it was for the No Queue Jump Lane scenario. The increase in nexus penetration will generally improve the throughput as is shown in Figure B-33.

\section{Overall Average Truck Travel Time - QJL (see Table 5-5 below)}

As it concerns truck traffic a similar pattern of influence of the IV's on the DV exists as there was for the No Queue Jump Lane Scenario. Three of the variables are similar in impact on the DV these are Process Time Factor, Priority Truck Penetration and Percent Secondary Trucks. The IV with the highest impact on the DV is Average Hourly Truck Demand which influences the Overall Average Travel Time positively. Figure B-35 shows the variation of Average Truck Travel Time with Process Time Factor and Priority Truck Penetration for and Average Hourly Truck Demand of 531 veh/hour and a Percent Truck sent to Secondary inspection of 20. For the Queue Jump Lane a unit increase in PTF a Priority Penetration rate increase of $12 \%$ is required to compensate while holding all the other independent variables in the equation constant, this is similar to the No Queue Jump Lane Scenario. Figure B-36 shows that there is a travel time advantage for all combinations of Process Time Factor and Priority Truck Penetration for an Overall Average Hourly Truck Demand of 531veh/hour and a Percent Secondary Penetration of 20\%. This means that the Queue Jump Lane scenario does produce overall better 
Average Travel Time when compared to the No Queue Jump Lane Scenario, this effect is greatest for higher values of Process Time Factor and Priority Penetration. For example in some cases there is a lower overall average travel time of more than twelve minutes, hence the Queue Jump lanes for trucks does result in significant overall system benefits.

Table 5-5: Summary Of Truck Regression Models, Ambassador Bridge - U.S. Bound (Queue Jump Lane)

\begin{tabular}{|c|c|c|c|c|c|}
\hline $\begin{array}{l}\text { Dependent } \\
\text { Variable }\end{array}$ & $\begin{array}{l}\text { Independent } \\
\text { Variable } 1\end{array}$ & $\begin{array}{l}\text { Independent } \\
\text { Variable } 2\end{array}$ & $\begin{array}{l}\text { Independent } \\
\text { Variable } 3\end{array}$ & $\begin{array}{l}\text { Independent } \\
\text { Variable } 4\end{array}$ & Intercept \\
\hline $\begin{array}{l}\text { OverallTruck } \\
\text { TravTime }\end{array}$ & $\begin{array}{c}0.071 \\
\text { [AvgHHlyDemandTruck] }\end{array}$ & $\begin{array}{c}2.756 \\
\text { [ProcTimeFactor] }\end{array}$ & $\begin{array}{c}-0.202 \\
\text { [PriorityTruckPenet] }\end{array}$ & $\begin{array}{c}0.197 \\
\text { [PercentSecTruck] }\end{array}$ & -9.836 \\
\hline $\begin{array}{l}\text { Standardized } \\
\text { Coefficients }\end{array}$ & 0.651 & 0.434 & -0.397 & 0.373 & \\
\hline $\begin{array}{c}\text { Relative Impact } \\
\text { on DV }\end{array}$ & 35 & 23 & 21 & 21 & \\
\hline $\begin{array}{l}\text { SQRTPriority } \\
\text { TruckTravelTime }\end{array}$ & \multicolumn{4}{|c|}{3.687 [PriorityTruckDemand/PriorityTruckProcCapacity] } & 1.233 \\
\hline $\begin{array}{l}\text { Standardized } \\
\text { Coefficients }\end{array}$ & \multicolumn{4}{|c|}{0.761} & \\
\hline $\begin{array}{c}\text { Relative Impact } \\
\text { on DV }\end{array}$ & \multicolumn{4}{|c|}{100} & \\
\hline $\begin{array}{c}\text { NonPriority } \\
\text { TruckTravelTime }\end{array}$ & \multicolumn{4}{|c|}{ 39.082[NonPriorityTruckDemand/NonPriorityTruckProcCap] } & -10.194 \\
\hline Stand. Coeff. & \multicolumn{4}{|c|}{0.924} & \\
\hline $\begin{array}{l}\text { Relative Impact } \\
\text { on DV }\end{array}$ & \multicolumn{4}{|c|}{100} & \\
\hline $\begin{array}{c}\text { SQRTPriority } \\
\text { TruckTravelTimeAd }\end{array}$ & $\begin{array}{c}0.408 \\
\text { SQRTAvgHrlyDemTruck }\end{array}$ & $\begin{array}{c}0.509 \\
\text { ProcTimeFactor }\end{array}$ & $\begin{array}{c}0.119 \\
\text { SQRTPriorityTruckPenet }\end{array}$ & $\begin{array}{c}0.061 \\
\text { SQRTPercentPrimInsp }\end{array}$ & -7.184 \\
\hline Stand. Coeff. & 0.871 & 0.691 & 0.183 & -0.081 & \\
\hline $\begin{array}{c}\text { Relative Impact } \\
\text { on DV }\end{array}$ & 48 & 38 & 10 & 4 & \\
\hline OvrTruckThrput & $\begin{array}{c}1.062 \\
\text { [AvgHHrlyDemandTruck] }\end{array}$ & $\begin{array}{c}-59.236 \\
\text { [ProcTimeFactor] }\end{array}$ & $\begin{array}{c}1.475 \\
\text { [PriorityTruckPenet] }\end{array}$ & $\begin{array}{c}-0.474 \\
\text { [PercentSecTruck] }\end{array}$ & 821.283 \\
\hline Stand. Coeff. & 0.499 & -0.481 & 0.150 & 0.046 & \\
\hline $\begin{array}{c}\text { Relative Impact } \\
\text { on DV }\end{array}$ & 42 & 41 & 13 & 4 & \\
\hline
\end{tabular}




\section{Overall Average Truck Travel Time - QJL}

As it concerns truck traffic a similar pattern of influence of the IV's on the DV exists as there was for the No Queue Jump Lane Scenario. Three of the variables are similar in impact on the DV these are Process Time Factor, Priority Truck Penetration and Percent Secondary Trucks. The IV with the highest impact on the DV is Average Hourly Truck Demand which influences the Overall Average Travel Time positively. Figure B-35 shows the variation of Average Truck Travel Time with Process Time Factor and Priority Truck Penetration for and Average Hourly Truck Demand of 531 veh/hour and a Percent Truck sent to Secondary inspection of 20. For the Queue Jump lane Scenario a unit increase in PTF a Priority Penetration rate increase of $12 \%$ is required to compensate while holding all the other independent variables in the equation constant, this is similar to the No Queue Jump Lane Scenario. Figure B-36 shows that there is a travel time advantage for all combinations of Process Time Factor and Priority Truck Penetration for an Overall Average Hourly Truck Demand of $531 \mathrm{veh} / \mathrm{hour}$ and a Percent Secondary Penetration of 20\%. This means that the Queue Jump Lane scenario does produce overall better Average Travel Time when compared to the No Queue Jump Lane Scenario, this effect is greatest for higher values of Process Time Factor and Priority Penetration. For example in some cases there is a lower overall average travel time of more than twelve minutes, hence the Queue Jump lanes for trucks does result in significant overall system benefits. 


\section{Category Specific Average Truck Travel Times - QJL}

The same format as was used for the No Queue Jump Lane regression model was used for the Queue Jump Lane scenario where the untransformed independent variables in a Demand to Processing Capacity ratio format. The level of variable explanation achieved was reasonably high. Figures B-38 to B-39 and B-41 to B-42 show the variation of Priority Auto Travel Time and Non-Priority Auto Travel Time with the respective independent variables of the mathematical model equation. As was the case for autos the general trend of increasing travel time with increasing Demand/Processing Capacity ratios is evident. Figure B-39 demonstrates that for all the combinations of independent variables the Priority Auto Travel Time is lower for the Queue Jump Lane Scenario than it was for the No Queue Jump Lane Scenario. However for Non-Priority Auto Travel Time there are combinations of independent variables where the Queue Jump Lane scenario time is higher than the No Queue Jump Lane scenario (Figure B-42). This is particularly true for cases of higher Demand/Capacity ratios and the reason could be that in some cases the lane allocation policy adopted in the particular Queue Jump Lane Scenario caused more of a disadvantage for the Non-priority Trucks than for the No Queue Jump Lane Scenario.

\section{Priority Truck Travel Time Advantage - QJL}

Figure B-44 represents the variation of Priority Truck Travel Time Advantage with Priority Truck Penetration and Average Hourly Truck Demand for a Process Time Factor of 6.27 and for Percent Primary Inspection being held at 20. The general trend of 
decreasing advantage with increasing Priority Penetration and increasing advantage with increased Average Hourly Truck Demand is consistent with the policy of utilizing processing lanes that are Non-priority and designating them dedicated priority lanes as demand for priority crossing increases. Figure B-45 shows that for the all the ranges of independent variables the Priority Truck Travel Time Advantage is greater for the Queue Jump Lane scenario than it is for the No Queue Jump Lane Scenario for a Process Time Factor of 6.27 and a Percent Primary Inspection of 20.

\section{Overall Truck Throughput - QJL}

The regression equation relating Overall Truck Throughput to Average Hourly Demand, Process Time Factor, Priority Truck Penetration and Percent Secondary Truck reveals that Average Hourly Demand and Process Time Factor have similar but opposite impact on the dependent variable. The impact of Priority Truck Penetration and Percent Secondary Trucks is significantly lower relative to the other two independent variables and also when compared with the No Queue Jump Lane Scenario. The increase in Priority Truck Penetration will improve the throughput as is shown in Figure B-42 for an average hourly demand of 531 trucks/hour and a percent Secondary Truck of 20 the throughput increases with Priority Truck Penetration and reduces by a larger gradient with an increase in Process Time Factor. 


\section{Percent of Demand Serviced}

The Travel Time values of the model output must also be interpreted along with the Percent of Demand Serviced. As was demonstrated in the Peace Bridge analysis, sometimes it is possible to have low Travel Times with low Percent of Demand Serviced. In these situations the Travel Time taken by itself can be misleading in pointing to an efficiently performing crossing. For the Ambassador Bridge Figure B-30 and B-49 show the variation of percent of Demand Serviced with other variables. Equation 29 tells us that Percent of Overall Auto Demand for the No QJL scenario decreases with an increase in Average Hourly Auto Demand and Process Time Factor. The Percent of Demand Serviced increases with an increase of Priority Auto Demand, the relative effect of the IV's (Table B-7) indicate that Average Hourly Auto Demand and Process Time Factor are much higher in their impact on the DV compared to the Priority Auto Demand Penetration. For Percent of Overall Truck Demand Serviced for the No QJL Scenario (Equation 30), there is a decrease with an increase in Average Hourly Truck Demand, Process Time Factor and Percent Secondary Inspection. As was the case for autos the same trend exists for trucks in that there is an increase in Percent of Demand Serviced with and increase of Priority Truck Demand. The relative effect of the IV's on the DV is summarized in Table B-7 and the effect of Average Hourly Truck Demand is highest (37\%) compared to the other variables which are relatively similar in their effect on the

DV. Figure B-31 and B-50 shows that as Overall Average Travel Time increases for autos and trucks the Percent of Demand serviced decreases. 


\section{Chapter 6 CONCLUSIONS}

Land border crossings are important to the efficient movement of people and goods between Canada and the United States. Most of Canada's trade is with the U.S. and this trend is expected to continue well into the future. The modal share of people and goods transported between Canada and the U.S. is predominantly across land. This makes the land border ports of entry for the two countries very significant in ensuring the efficient and secure passage of people and goods.

Land border crossings face major challenges in their operation, some of which are common to typical transportation systems while some are unique to border crossings as a localized component of the international transportation infrastructure between two countries. One major challenge is the problem of congestion resulting in travel time delays to crossing users during periods of high demand. The expected future increase in auto and truck traffic across land border ports of entry between Canada and the U.S. makes this challenge one of the major concerns for planners. Another challenge is to facilitate the efficient movement of people and goods while preserving national security. This has taken on increased importance since the events of $9 / 112001$. There are also environmental issues to contend with in the form of air and noise pollution at these ports of entry, especially during periods of high demand which results in long idling time spent in queues. The feature of many stakeholders with varying interests is one of the unique challenges facing land border crossing administration. The interests of major 
stakeholders are many times divergent from each other resulting in difficulties related to the coordination and implementation of any project aimed at improving conditions at land border crossings.

Various alternatives have been implemented and proposed with varying degrees of success, the aim being the improvement of traffic flow through land border crossings. The alternatives can be classified in the general categories of short to medium term solutions and long term solutions. Alternatives that have been implemented or proposed can be further classified into the sub-categories of priority crossing programs, intelligent transportation systems, transportation demand management and policy options. Priority crossing programs have been investigated in detail in this research through the use of micro-simulation models. Microscopic simulation models are the best type of computer models for the analysis of traffic at land border crossings. The fundamental properties of traffic flow and operation of border crossings, such as car following, lane changing, interarrival times, vehicle headway, tolls and customs service times, etc. are best simulated by a stochastic process typical of micro-simulation models. Even though macroscopic simulation models have considerably fewer computer requirements compared to microscopic simulation models, they do not however have the ability to analyze the transportation alternatives in as much detail as micro-simulation models. The alternatives of increasing priority crossing penetration and facilitating the registered priority crossing vehicles using dedicated queue jump lanes are best investigated using microscopic simulation models. Micro-simulation models were constructed for the Peace Bridge 
(Canada Bound) and the Ambassador Bridge (U.S. Bound) and various scenarios involving priority crossing programs for both autos and trucks were investigated.

The results of the model simulations indicate that Priority Crossing Programs does make an impact in improving crossing efficiencies especially during periods of high demand and conditions characterized by high processing times. With prudent lane use policies where dedicated lanes are provided for priority autos, priority programs can be effective in improving the efficiency of the crossing. This overall system benefit is manifested via a reduction in the overall average travel time across vehicle categories and an improvement in the percent of demand serviced. For example, for $100 \%$ increase in demand over the base-case with increased customs clearance times (i.e. Peace Bridge Canada Bound, Scenario 8) there was a decrease in overall average auto travel time of 29 minutes in moving from $10 \%$ to $30 \%$ priority penetration level. For truck traffic there was a decrease in overall average travel time of 50 minutes for the same scenario when priority penetration rate changed from 10 to $50 \%$. For all the regression equations developed for the Ambassador Bridge case study, the average travel time always decreased with priority vehicle penetration.

When dedicated queue jump lanes providing access for priority crossing users are implemented there are significant benefits achieved over the no queue jump lane scenario. The overall travel time for autos and trucks are generally reduced as well as the category specific average travel times for priority crossing users. For the Peace Bridge 
Canada Bound case study there is a 20 minute lower overall average travel time for the Queue Jump Lane scenario compared to the No Queue Jump Lane scenario for the $100 \%$ increased demand and $20 \%$ priority auto penetration rate (Figure A-21). The same can also be said for truck traffic where there is a $\mathbf{4 0}$ minute lower travel time when there are Queue Jump Lanes compared to No Queue Jump Lanes for the 60\% priority truck penetration rate (Figure A-25). For the Ambassador Bridge - U.S. Bound case study, the general trend is for Queue Jump Lane travel times to be lower overall for both autos and trucks. For some scenarios it is possible for the time difference to be as much as 13 minutes (Figure B-10 and B-36).

There are also user benefits and advantages to be achieved through the implementation of Priority Crossing Programs at land border crossings. Users registered in a priority crossing program will benefit from lower crossing times compared to non-priority crossing users as long as the processing capacity and access to dedicated lanes facilitates this. This travel time advantage for priority users over non-priority users is essential to maintain the feasibility and attractiveness of the Priority Crossing Program. The results for the Peace Bridge and Ambassador Bridge case study reveal a general decrease in travel time for the category specific auto and truck traffic as priority vehicle penetration rate increases. For the most part priority auto and truck travel time through the crossing is lower than non-priority vehicles. In some instances the difference can be as much as 25 minutes for autos as well as trucks (e.g. Figure A-17 \& A-18). For the Ambassador Bridge case study there are also significant travel time advantages for priority vehicles 
over non-priority vehicles. Travel time advantage can be as much as 5 minutes for autos and 20 minutes for trucks as shown in Figures B-25 and B-44.

The Percent of Demand Serviced is an important performance indicator in the analysis of land border crossings because travel times can be misleading when taken in isolation (see Table 5-1). For the Peace Bridge case study, the Percent of Demand Serviced decreases as the demand increases over the base-case and generally increases with an increase in priority penetration rate. The implementation of Queue Jump Lanes also improves the Percent of Demand Serviced. For auto traffic and the scenarios where the demand is more than 20\% over base-case the Percent of Demand Serviced is always less than 70 . For the Ambassador Bridge case study the same general trends exists as there was for the Peace Bridge. This is an indication that after a certain level of demand increase priority crossing programs and queue jump lanes are not feasible for border crossings unless there is an increase in physical infrastructure capacity.

Throughput is another performance indicator that needs to be considered along with Travel Time and Percent of Demand Serviced. The model results indicate that throughput generally increases with priority vehicle penetration however is impacted more heavily by demand and customs processing times.

The micro-simulation models constructed in this research are specific to the Peace Bridge - Canada Bound direction and Ambassador Bridge - U.S. Bound direction. The results 
and regression model equations developed as a result of this research cannot be extrapolated to accurately represent other border crossings since geometric layout varies between crossings. However the approach and method of analysis can be adapted for other crossings. 


\section{Chapter 7 References}

1. Baker D. B., Presentation On International Travel Forecast Highlights, U.S. Department of Commerce, Los Angeles CA, April 2004.

2. Battelle, Evaluation of Travel Time Methods to Support Mobility Performance Monitoring - Peace Bridge (Final Site Report), Office of Freight Management and Operations FHWA and USDOT, Washington DC, April 2002.

3. Booz-Allen \& Hamilton, Final Evaluation Report: Ambassador Bridge Border Crossing System (ABBCS), Field Operational Test (FOT), ABBCS FOT Partners, May 2000 .

4. Brauer, Michael. Air Quality at Congested Border Crossings: A preliminary Assessment Using Routinely Collected Data, North American Commission For Environmental Cooperation, February 2003.

5. Canada-United States-Ontario-Michigan Transportation Partnership Planning/ Need and Feasibility Study, Feasible Transportation Alternatives Working Paper, Transport Canada, USDOT, MTO, MDOT, June 2003.

6. Canadian Border Services Agency, "Border Wait Times Website Survey", www.cbsa-asfc.gc.ca, 2003.

7. Canadian Embassy, Washington DC, The Smart Border Declaration, Government of Canada, December 2001.

8. CBC News Online, In-depth: Airport and Border Security, By The Numbers: The Canada/US Border, July 2004.

9. Committee on Appropriations, "Department of Homeland Security Appropriations Bill - 2006, $109^{\text {th }}$ Congress Report", House of Representatives, May 2005.

10. Cornel University \& Rensselaer Polytechnic Institute, Evaluation of Advanced Information Technology at the Peace Bridge - Final Report, Buffalo and Fort Erie Public Bridge Authority, April 1999.

11. Data Management and Analysis Office, "Commercial Vehicle Survey Data", MTO, 1999.

12. Eastern Border Transportation Coalition, Executive Summary - Truck Freight Crossing the Canada - U.S. Border, September 2002. 
13. Exponent, Sources of Air Pollutants in the Buffalo - Fort Erie Region, The Peace Bridge Expansion Project Bi-national Integrated Environmental Process, April 2002.

14. Freight News, Border Wizard, USDOT and FHWA, April 2002.

15. Glassco Richard A., Simulation and Analysis of North American Trade Automation Prototype (NATAP) Operations at the Ambassador Bridge, Federal Highway Administration, September 1999.

16. Lin, F. B. and Lin, M. W., Modelling Traffic Delays at Northern New York Border Crossings, Journal of Transportation Engineering, November/December 2001.

17. Mitretek Systems, Westa Version 2.3, System Description and User's Manual, Washington DC, July 1999.

18. OCC Borders \& Trade Development Committee, Cost of Border Delays to Ontario, Ontario Chamber of Commerce, May 2004.

19. Papacostas and Prevedouros, "Transportation Engineering and Planning", $3^{\text {rd }}$ edition; Prentice Hall, NJ, 2001.

20. PTV, VISSIM User Manual, Version 4.00, June 2004.

21. Shea Andrew, Special Report-Border Choices, Balancing the Need for Security and Trade, The Conference Board of Canada, October 2001.

22. The White House News Release, Progress Report - Security and Opportunity at the U.S. - Canada Border, June 2002.

23. Transport Canada, USDOT, Memorandum of Cooperation between the USDOT and Transport Canada, Federal Highway Administration, April 2004.

24. Transport Canada, Transportation in Canada 2003, Annual Report, Minister of Public Works and Government Services, Canada, 2003.

25. URS, IBI Group, Corradino \& HLB, Environmental Overview Report, CanadaUnited States-Ontario-Michigan Transportation Partnership Planning/Need and Feasibility Study, January 2004. 
26. URS \& IBI Group, Existing and Future Travel Demand Working Paper, CanadaUnited States-Ontario-Michigan Transportation Partnership Planning/Need and Feasibility Study, November 2002.

27. U.S. Customs and Border Protection, "Border Wait Times Website Survey", www.aps.cbp.gov/bwt/, U.S. Department of Homeland Security, 2003.

28. "Using GPS-encoded tractor logs to estimate travel times at borders in Southern Ontario", Transport Canada, 2002.

29. Ward, Doug, Using fast lane is in the cards, Vancouver Sun, June 27, 2002.

30. www.canadianembassy.org/border/declaration, The Smart Border Declaration, Government of Canada, December 2001.

31. www.peacebridge.com/cvpc.php, Commercial Vehicle Processing Center, The Peace Bridge Authority, 2005.

32. www.fhwa.dot.gov/uscanada/issues/nexus.htm, Nexus, USDOT \& FHWA, April 2004. 


\section{APPENDIX A}

145 
Table A-1: Base-case Model Inputs, WESTA Model

\begin{tabular}{|c|c|}
\hline Description & Value \\
\hline Toll Lanes - Auto & 4 \\
\hline No. Cash Toll Lanes - Auto & 2 (1 shared with cash paying trucks) \\
\hline No. Charge/Cash Toll Lanes - Trucks & 2 \\
\hline Toll Times - Auto & $4.5 \mathrm{~s}$ - Token; $8 \mathrm{~s}$ - Cash \\
\hline Toll Times - Truck & $15 s$ - Charge; $26 s$ - Cash \\
\hline No. Primary Customs Lanes - Auto & 7 \\
\hline No. Primary Customs Lanes - Truck & 3 \\
\hline Primary Customs Service Times - Auto & 14s (average) Normal Distribution; Std. Dev. 6s \\
\hline Primary Customs Service Times - Trucks & $\begin{array}{l}\text { 10s to } 90 \text { s Uniform Distribution - Y28; } 9.5 \text { s to } \\
70 \text { s Uniform Distribution - ROL }\end{array}$ \\
\hline Secondary Inspection - Trucks & $\begin{array}{l}\text { 1520s (average) Exponential - Consult Broker; } \\
2220 \text { s (average) Exponential - Physical Truck } \\
\text { Inspection }\end{array}$ \\
\hline$\%$ Registered Crossing Vehicles - Autos & 0 \\
\hline \% Registered Crossing Vehicles - Trucks & 0 \\
\hline Arrival Rate - Cars & 600 vph - Peak Hour \\
\hline Arrival Rate - Trucks & $140 \mathrm{vph}-$ Peak Hour \\
\hline Simulated Time & 4 hours \\
\hline
\end{tabular}




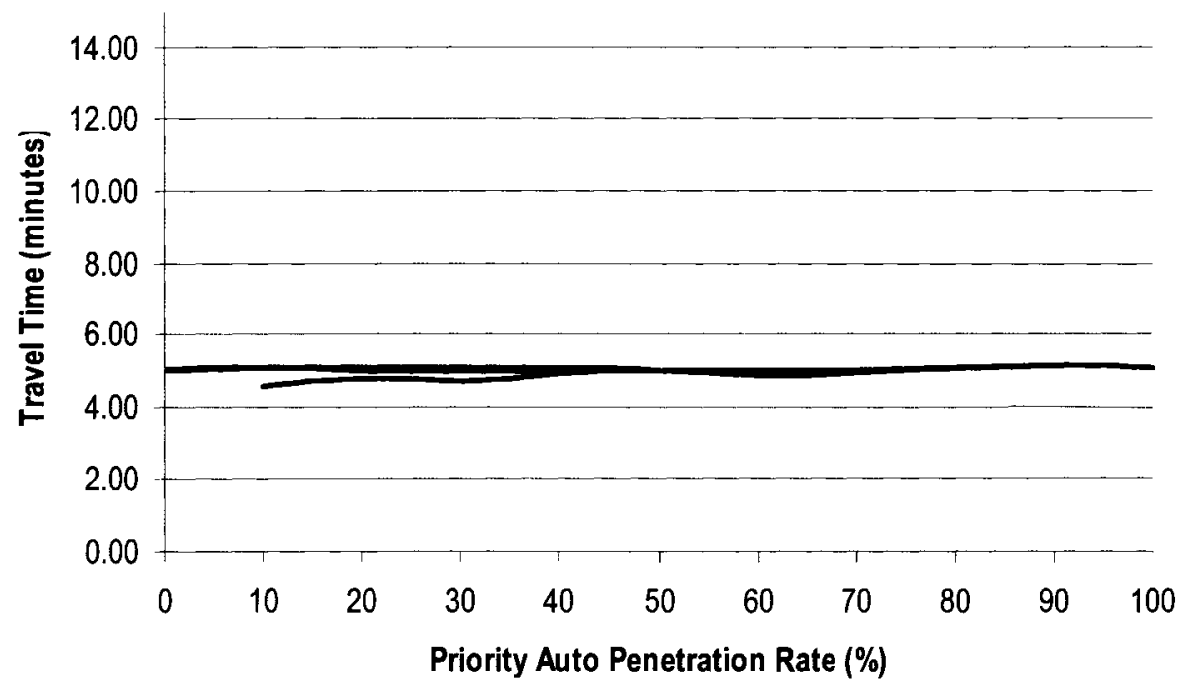

Figure A-1: Average Auto Travel Time

Base-case Demand and Customs Times; No Queue Jump Lanes

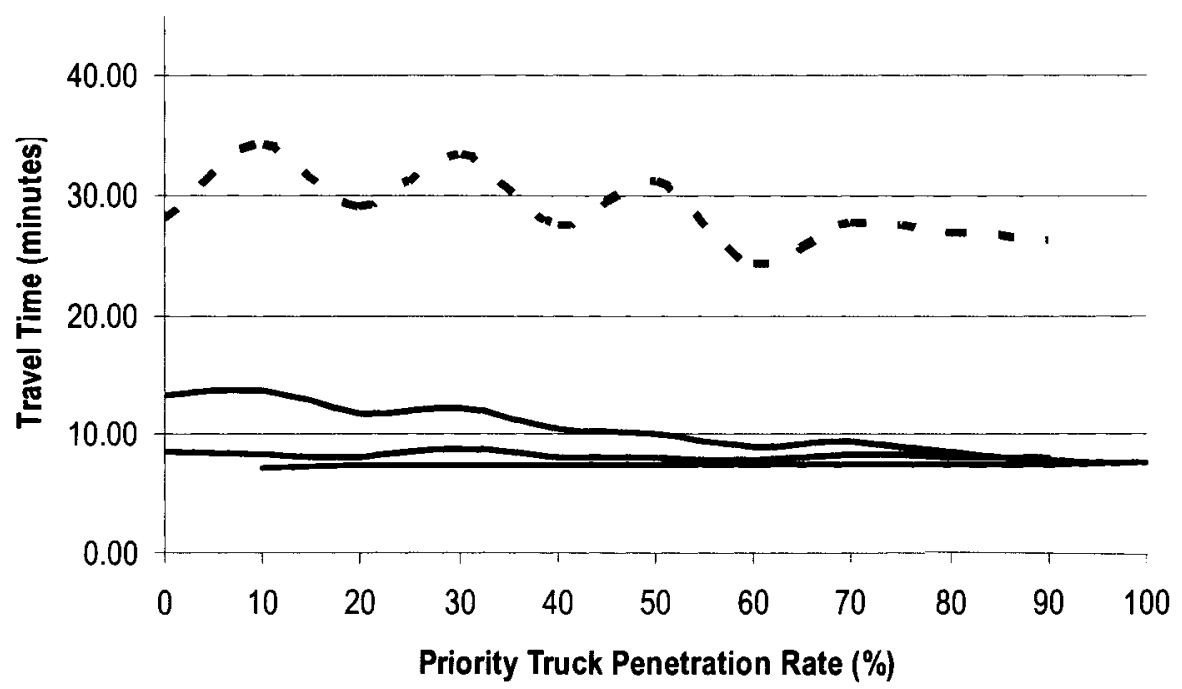

Figure A-2: Average Truck Travel Time

Base-case Demand and Customs Times; No Queue Jump Lanes

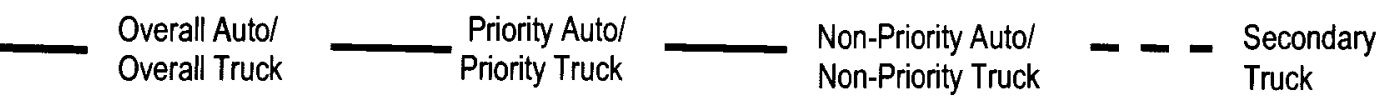




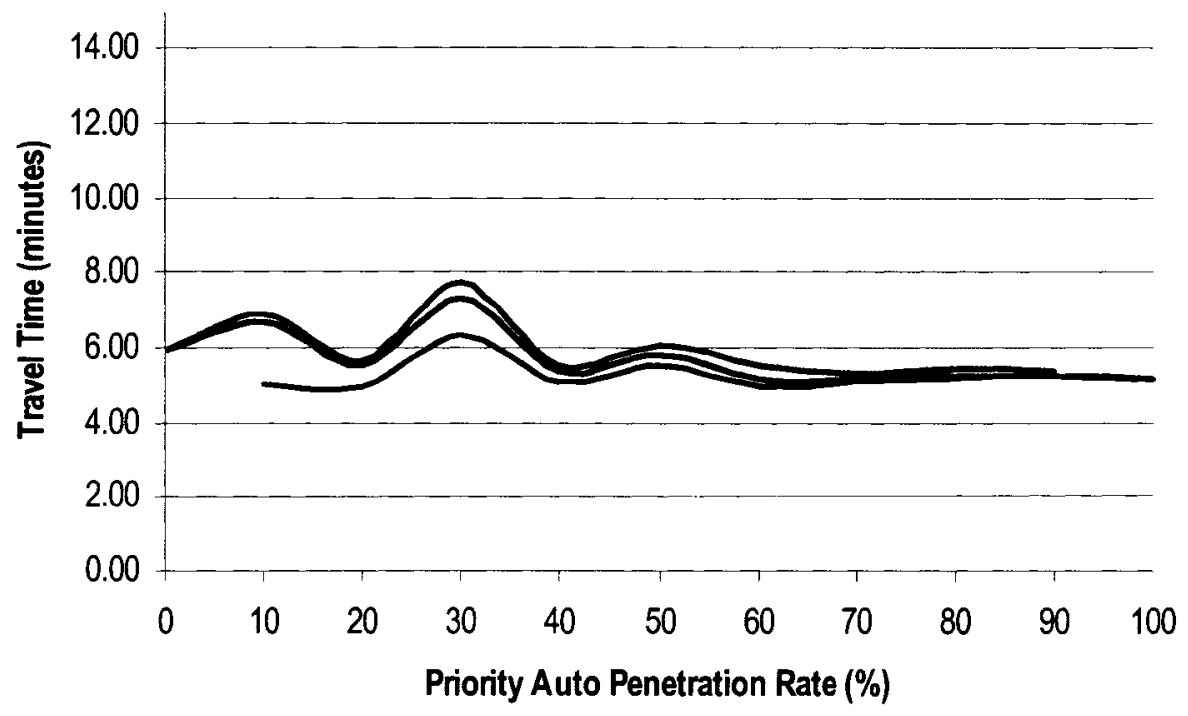

Figure A-3: Average Auto Travel Time Base-case Demand and Increased Customs Times; No Queue Jump Lanes

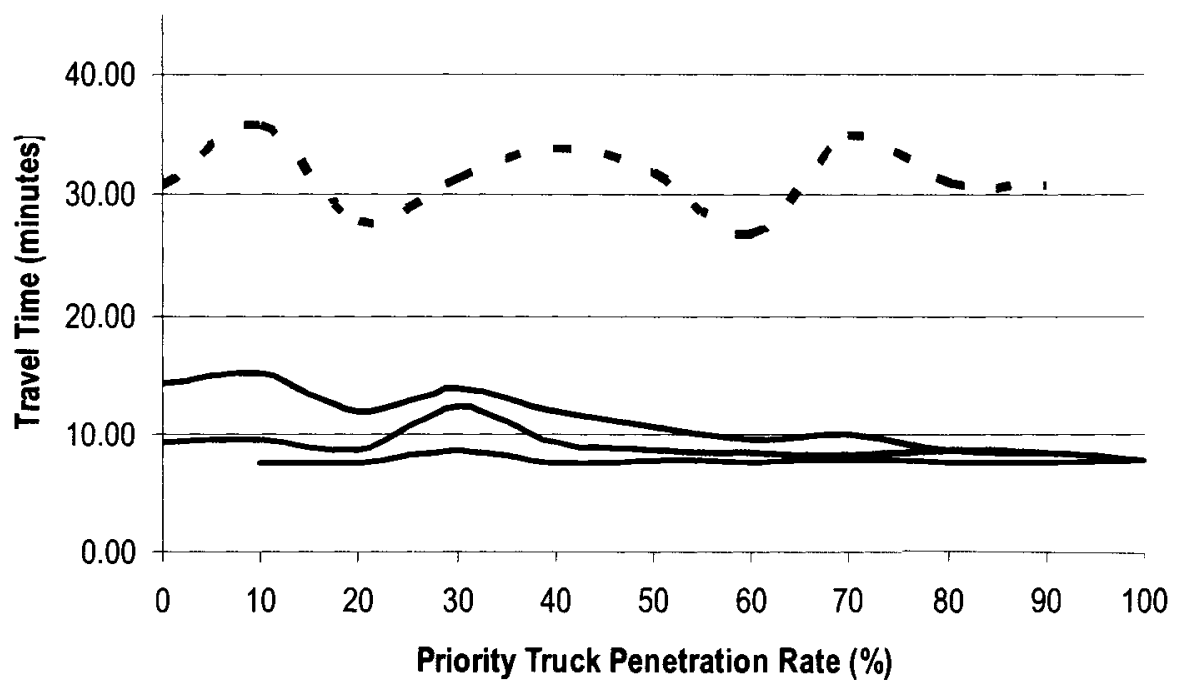

Figure A-4: Average Truck Travel Time

Base-case Demand; Increased Customs Times and No Queue Jump Lanes

Overall Auto/

Overall Truck

Priority Auto/

Priority Truck

Non-Priority Auto/

Non-Priority Truck

Secondary

Truck 


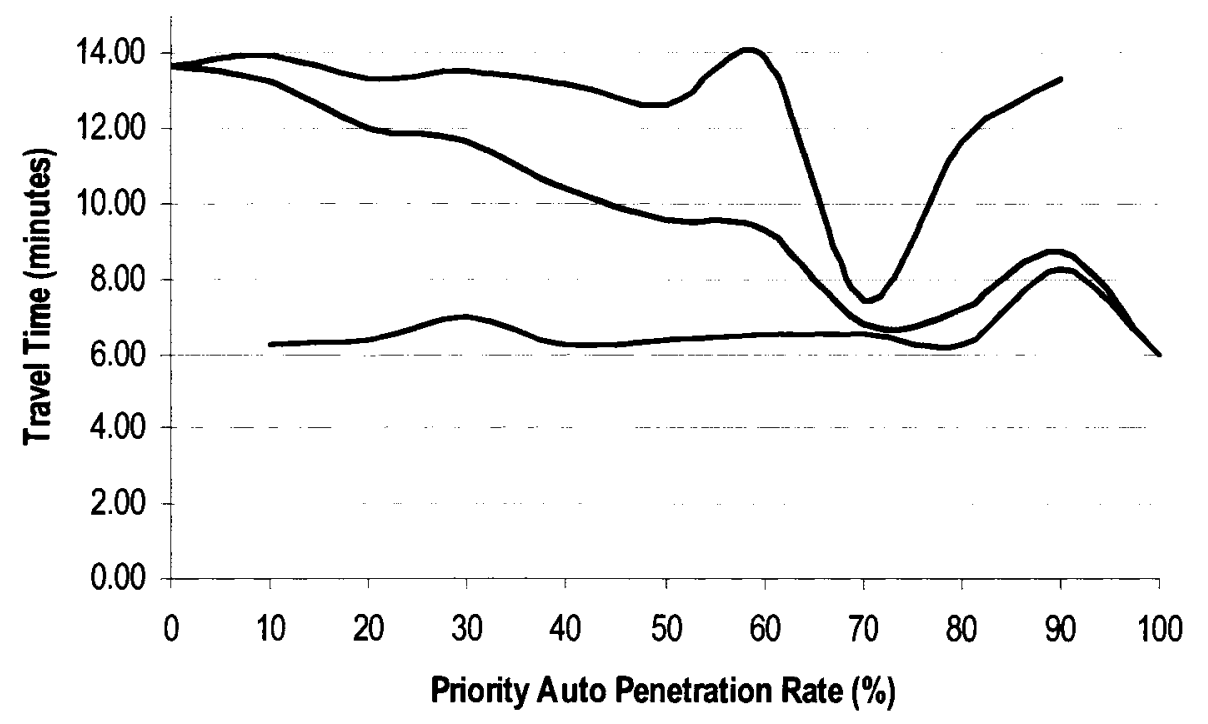

Figure A-5: Average Auto Travel Time 20\% Increase in Demand; Increased Customs Times and No Queue Jump Lanes

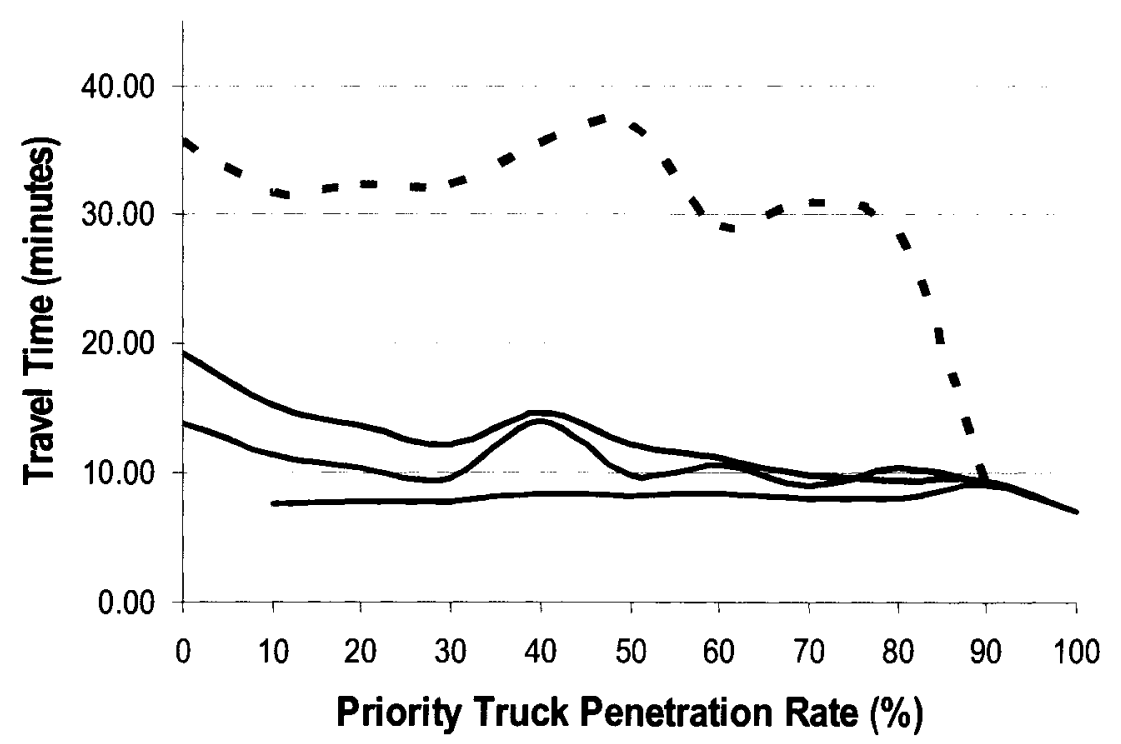

Figure A-6: Average Truck Travel Time

$20 \%$ Increase in Demand; Increased Customs Times and No Queue Jump Lanes

$\begin{aligned} & \text { Overall Autol } \\ & \text { Overall Truck }\end{aligned} \quad \begin{aligned} & \text { Priority Auto/ } \\ & \text { Priority Truck }\end{aligned} \quad \begin{aligned} & \text { Non-Priority Auto/ } \\ & \text { Non-Priority Truck }\end{aligned}-\begin{aligned} & \text { Secondary } \\ & \text { Truck }\end{aligned}$ 


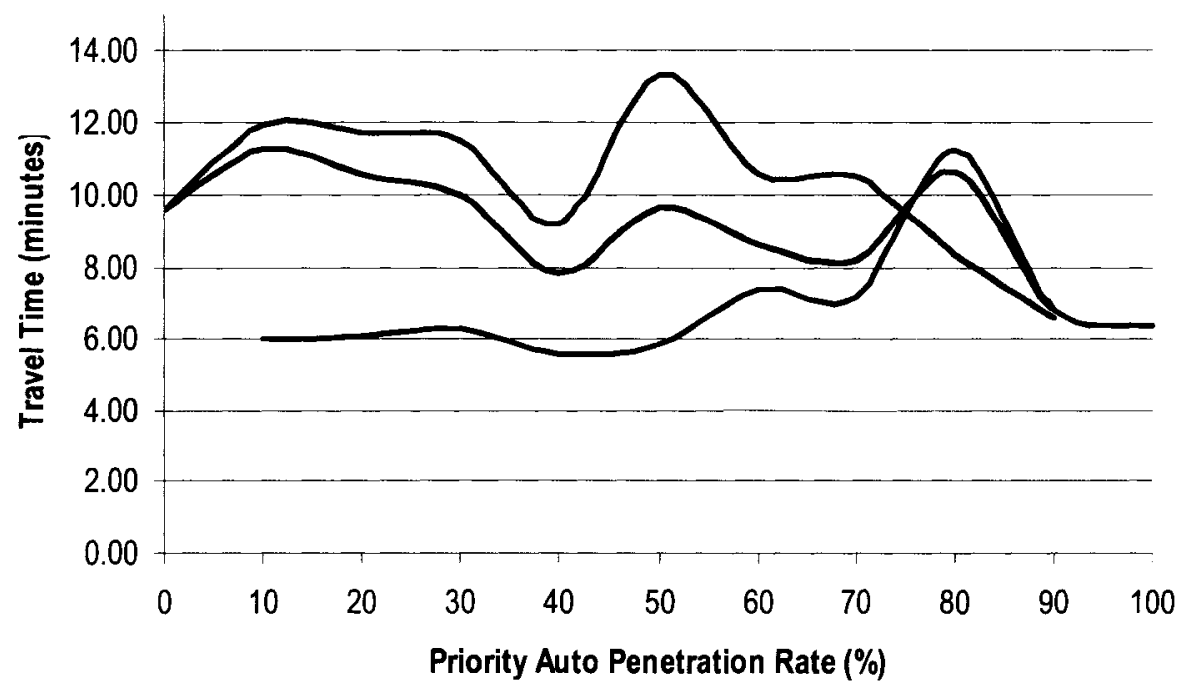

Figure A-7: Average Auto Travel Time

$20 \%$ Increase in Demand; Base-case Customs Times and Queue Jump Lanes

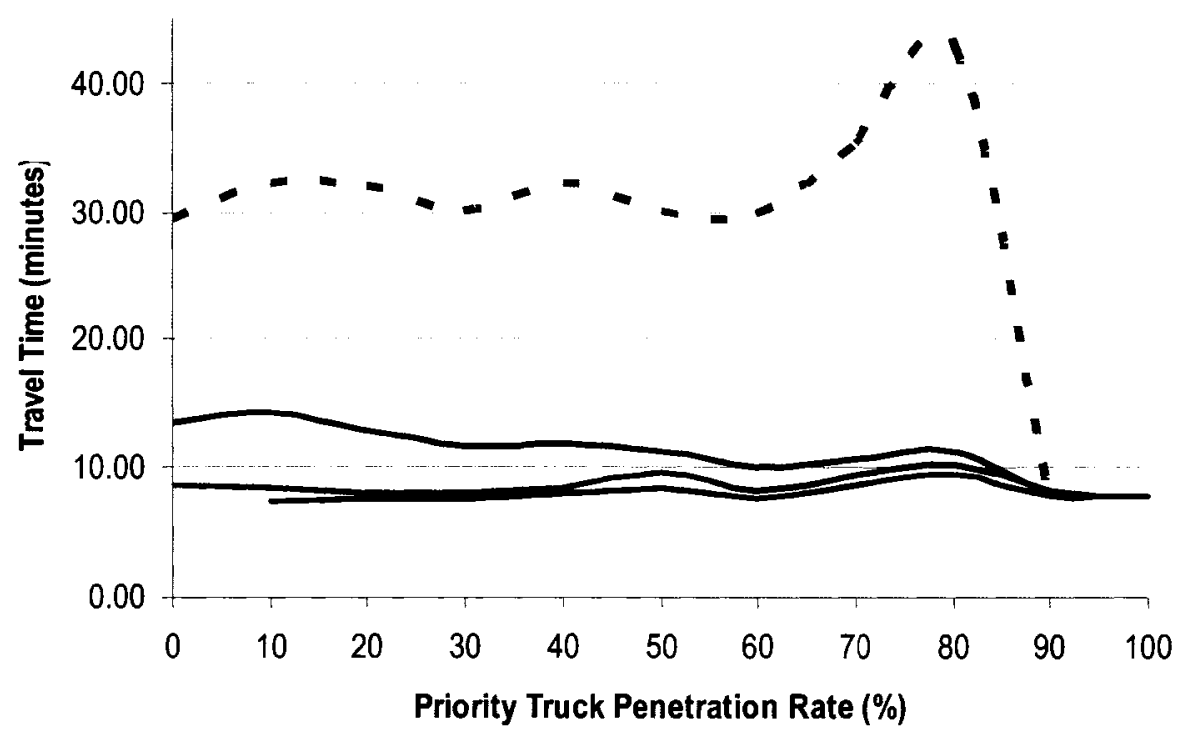

Figure A-8: Average Truck Travel Time

$20 \%$ Increase in Demand; Base-case Customs Times and Queue Jump Lanes

Overall Auto/

Priority Auto/

Overall Truck

Priority Truck

Non-Priority Auto/ $\quad--2 \begin{aligned} & \text { Secondary } \\ & \text { Truck }\end{aligned}$
Non-Priority Truck 


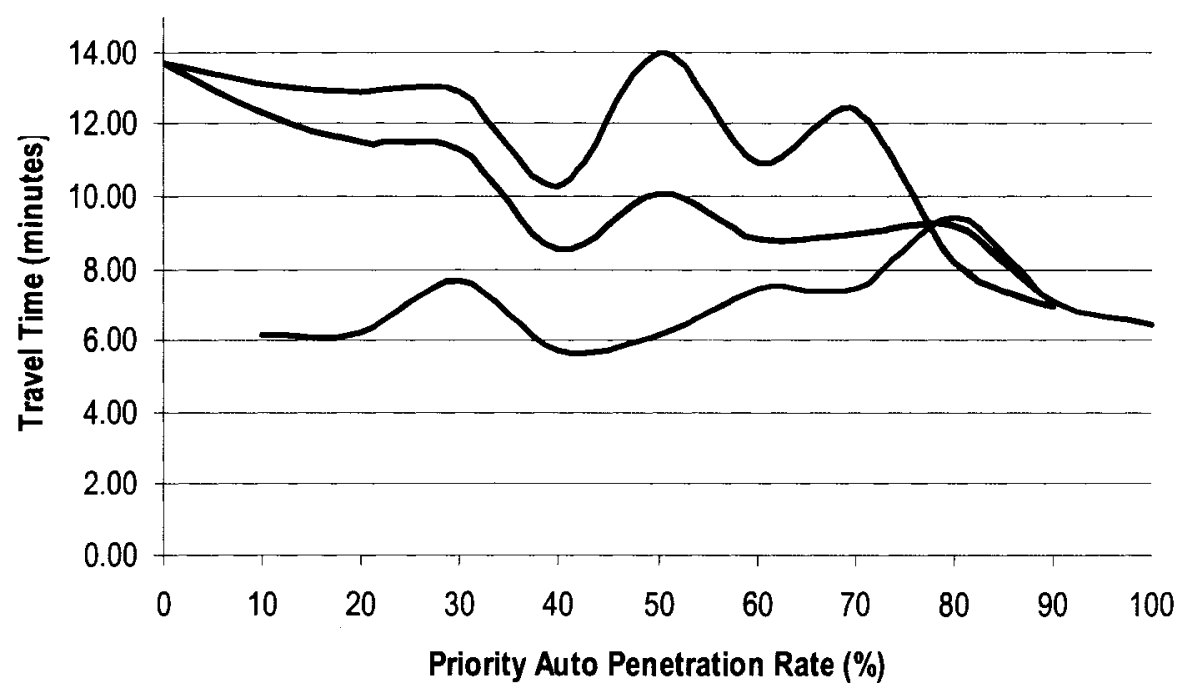

Figure A-9: Average Auto Travel Time $20 \%$ Increase in Demand; Increased Customs Times and Queue Jump Lanes

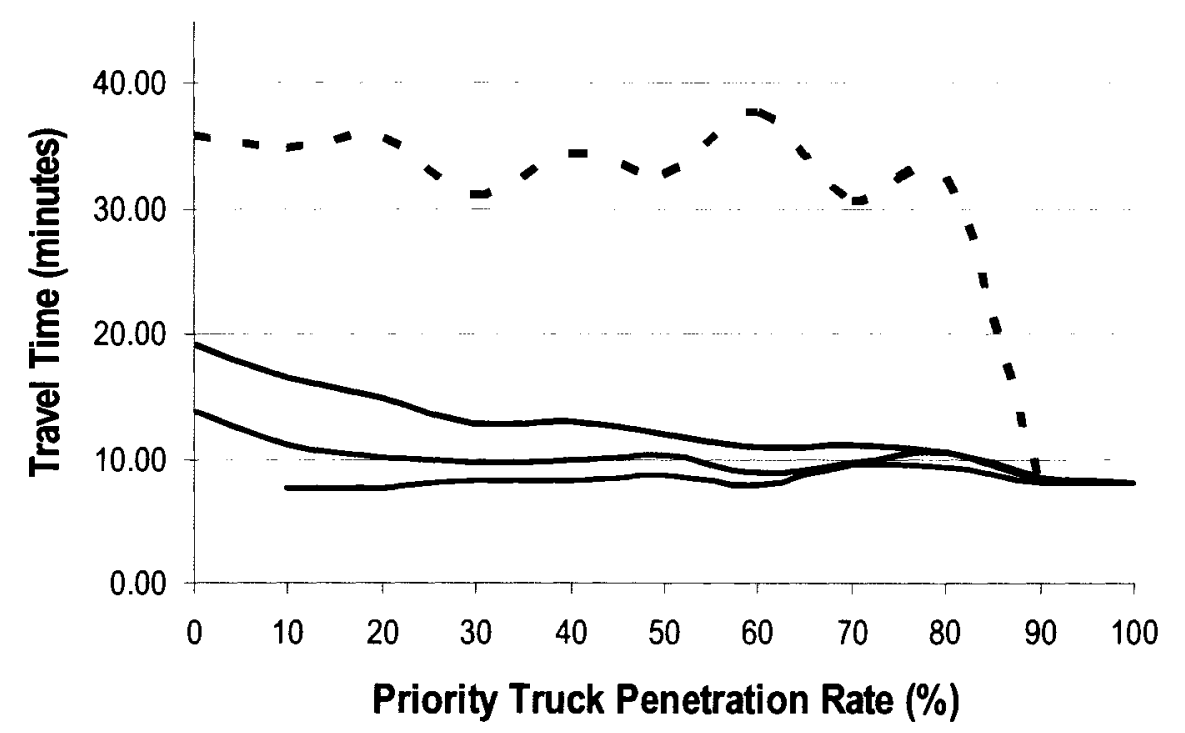

Figure A-10: Average Truck Travel Time $20 \%$ Increase in Demand; Increased Customs Times and Queue Jump Lanes

$\begin{array}{lll}\text { Overall Auto/ } & \text { Priority Autol } \\ \text { Overall Truck } & \text { Priority Truck } & \text { Non-Priority Autol } \\ \text { Non-Priority Truck } & -\infty\end{array}$ 


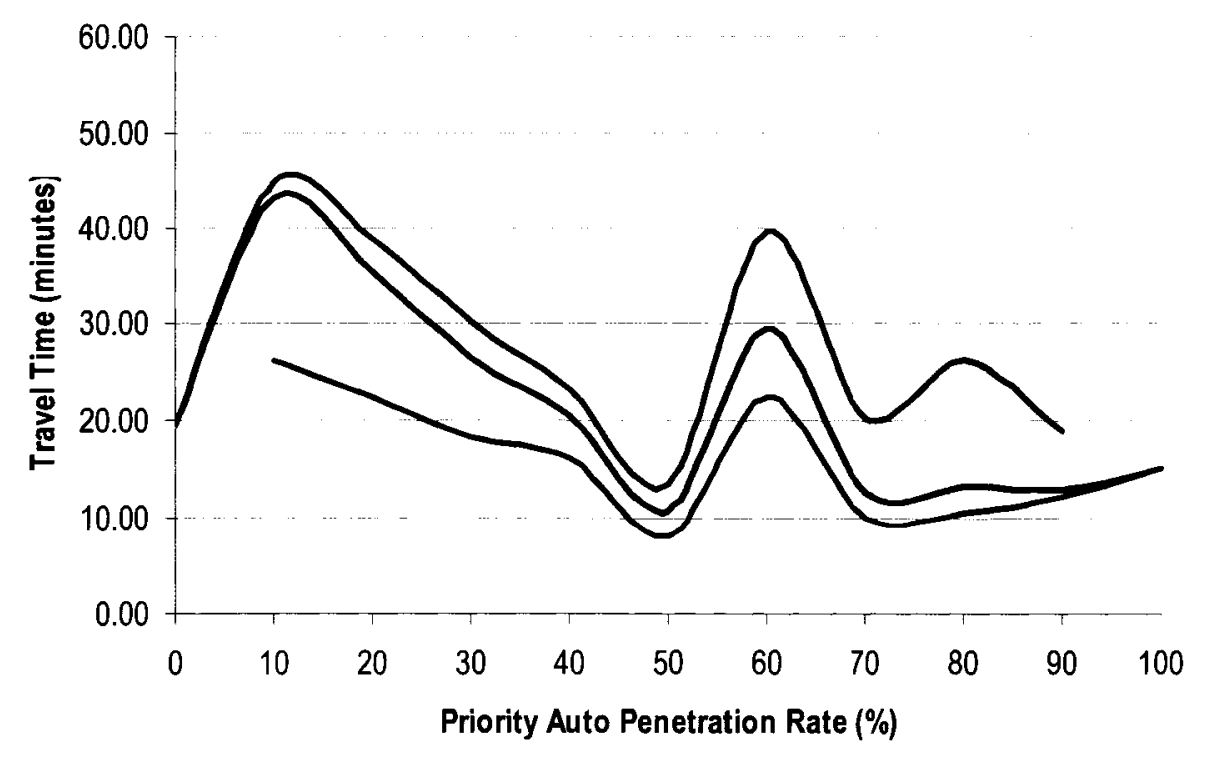

Figure A-11: Average Auto Travel Time $50 \%$ Increase in Demand; Increased Customs Times and No Queue Jump Lanes

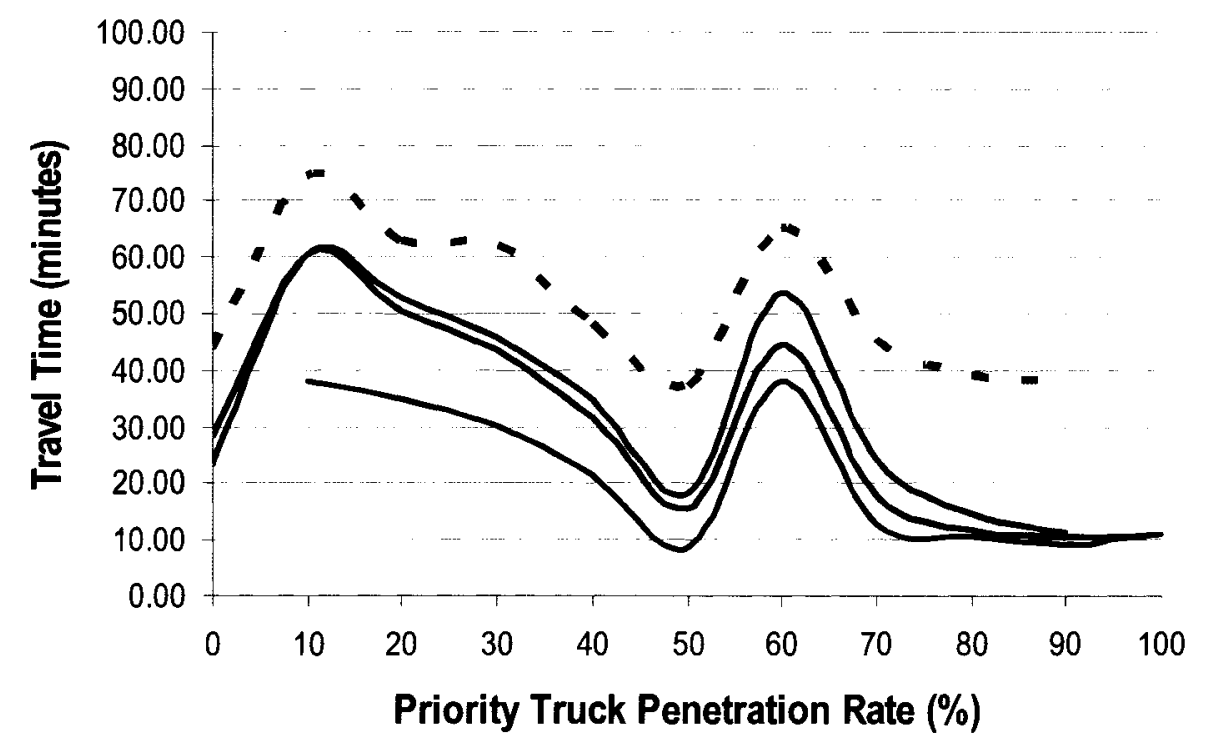

Figure A-12: Average Truck Travel Time 50\% Increase in Demand; Increased Customs Times and No Queue Jump Lanes

$-\begin{aligned} & \text { Overall Autol } \\ & \text { Overall Truck }\end{aligned}-\begin{aligned} & \text { Priority Auto/ } \\ & \text { Priority Truck }\end{aligned}-\begin{aligned} & \text { Non-Priority Autol } \\ & \text { Non-Priority Truck }\end{aligned}---\begin{aligned} & \text { Secondary } \\ & \text { Truck }\end{aligned}$ 


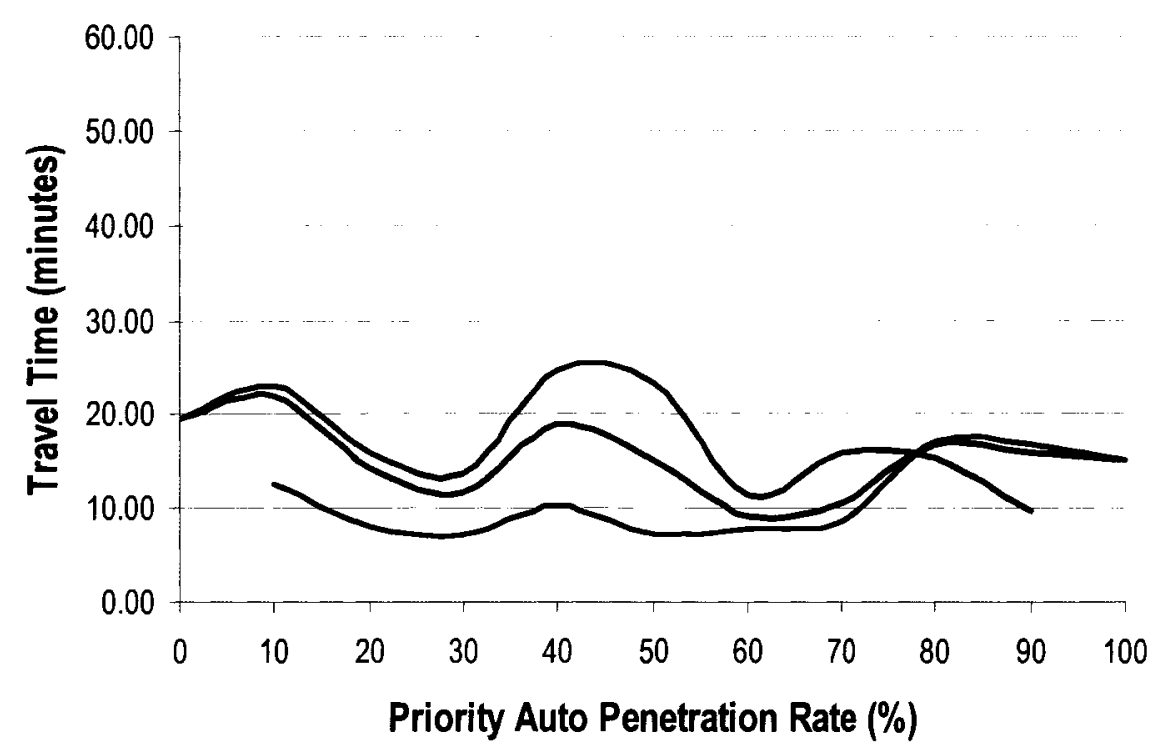

Figure A-13: Average Auto Travel Time $50 \%$ Increase in Demand; Increased Customs Times and Queue Jump Lanes

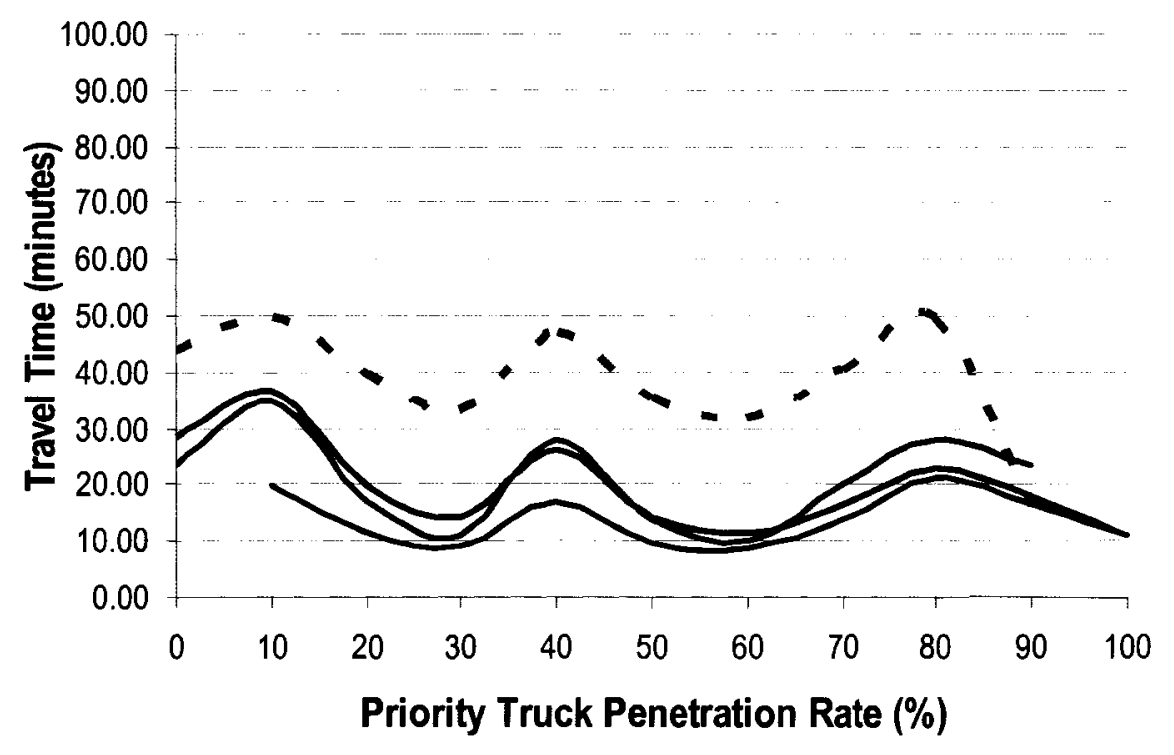

Figure A-14: Average Truck Travel Time $50 \%$ Increase in Demand; Increased Customs Times and Queue Jump Lanes

$\begin{array}{lll}\text { Overall Auto/ } & \text { Priority Auto/ } \\ \text { Overall Truck } & \text { Priority Truck } & \text { Non-Priority Auto/ } \\ \text { Non-Priority Truck } & - & -\begin{array}{l}\text { Secondary } \\ \text { Truck }\end{array}\end{array}$ 


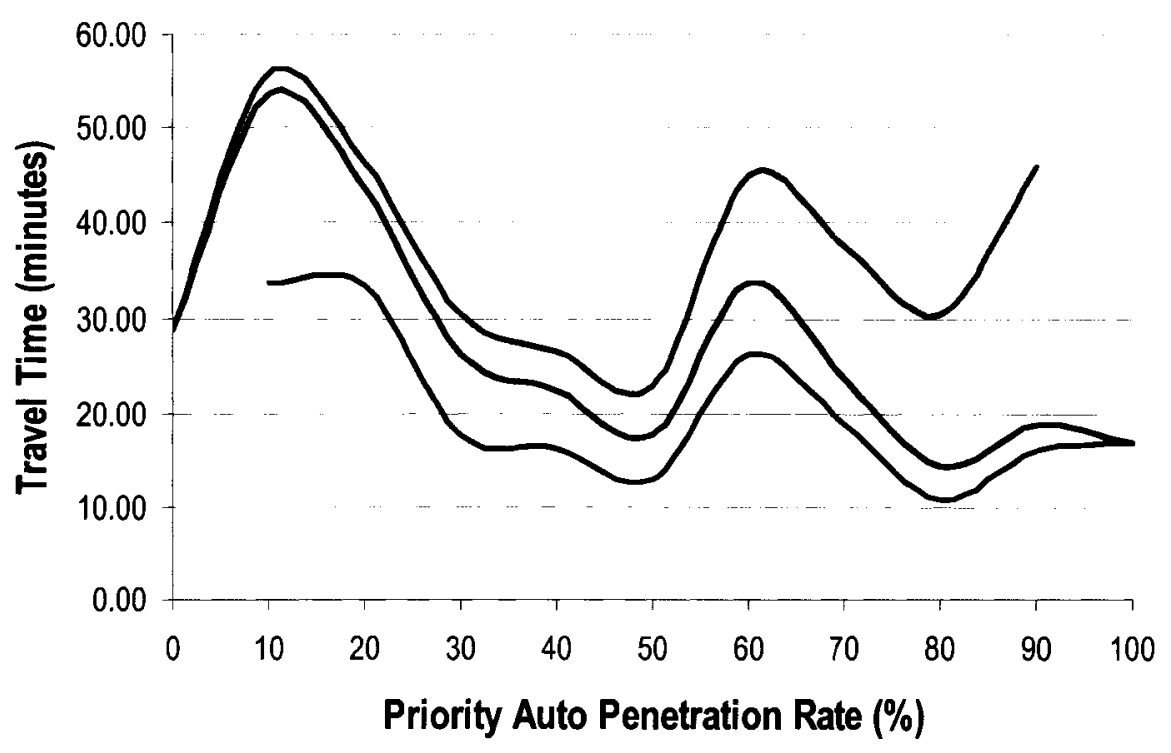

Figure A-15: Average Auto Travel Time $100 \%$ Increase in Demand; Increased Customs Times and No Queue Jump Lanes

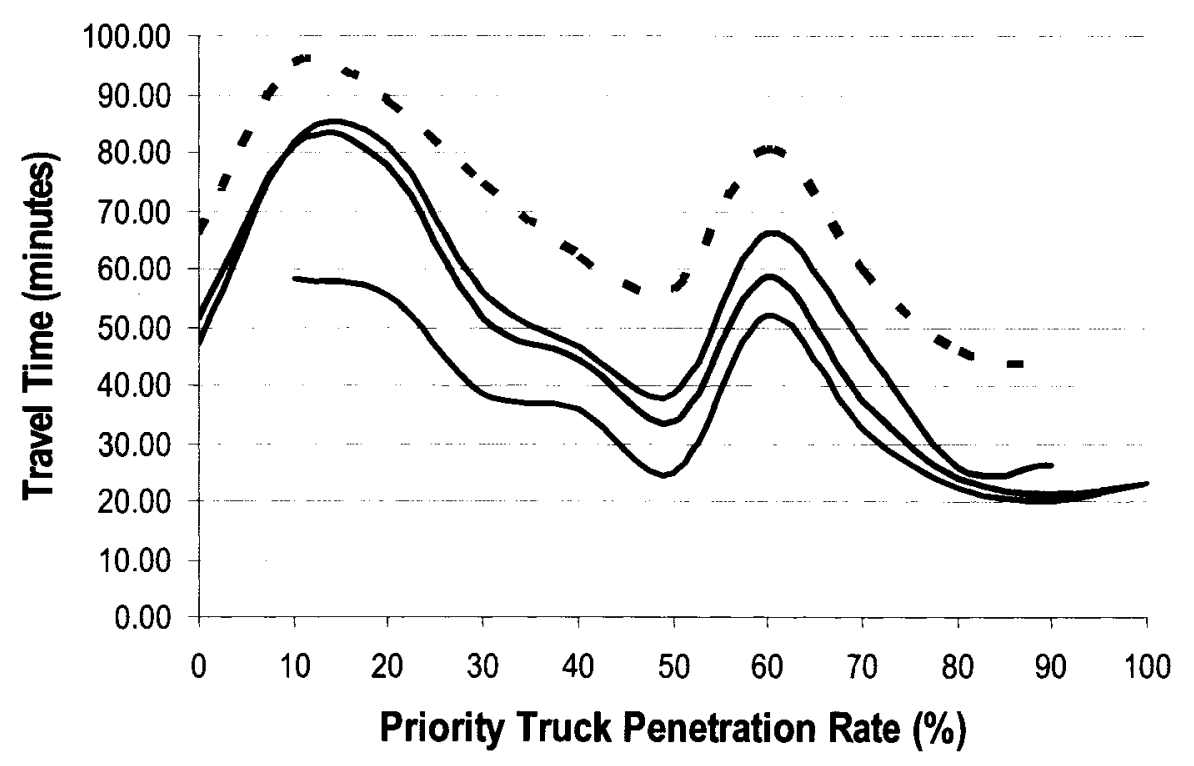

Figure A-16: Average Truck Travel Time

$100 \%$ Increase in Demand; Increased Customs Times and No Queue Jump Lanes

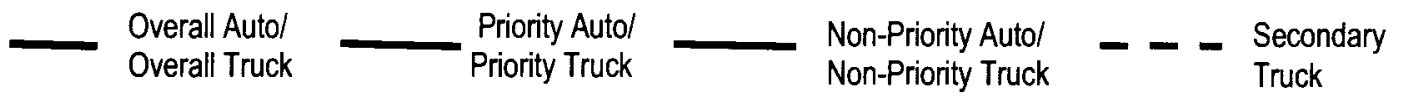




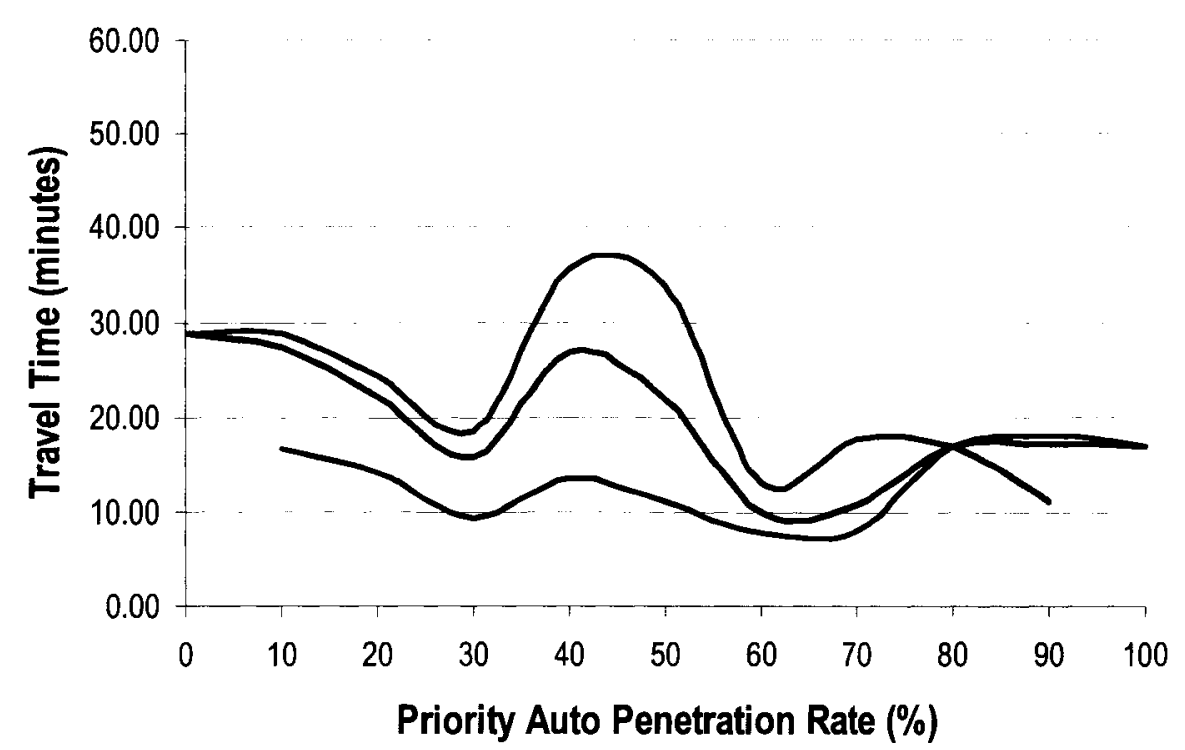

Figure A-17: Average Auto Travel Time $100 \%$ Increase in Demand; Increased Customs Times and Queue Jump Lanes

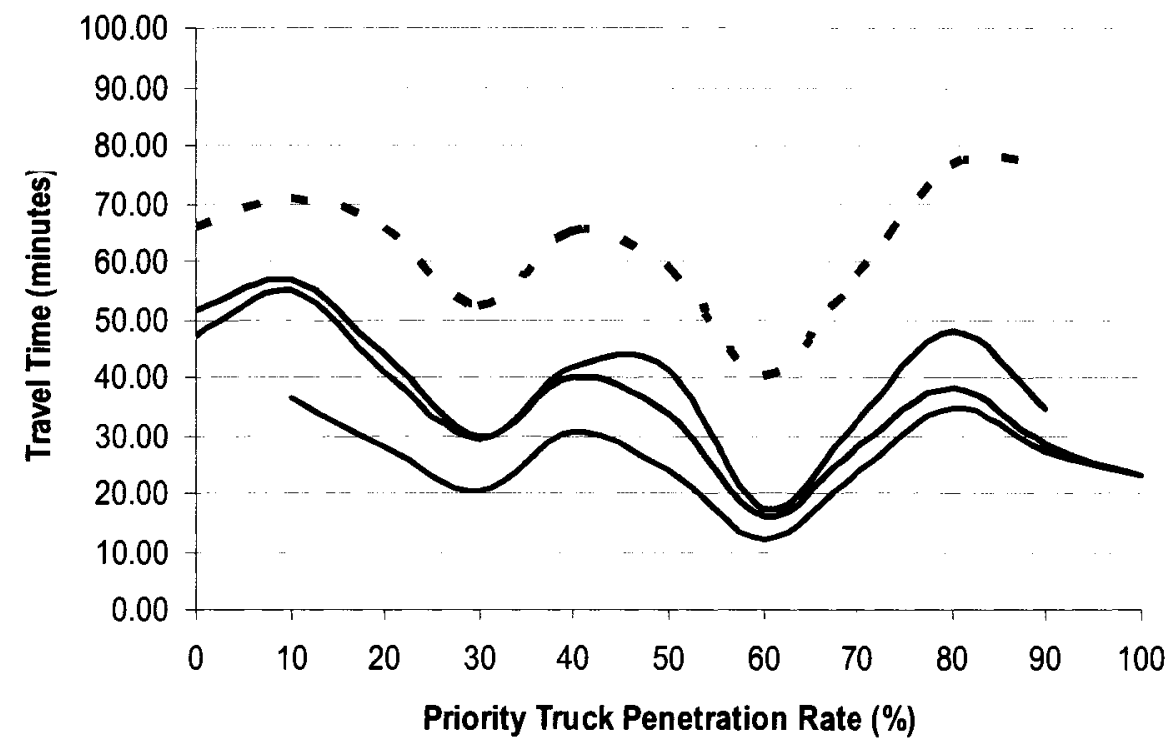

Figure A-18: Average Truck Travel Time

$100 \%$ Increase in Demand; Increased Customs Times and Queue Jump Lanes

$\begin{array}{lll}\text { Overall Auto/ } & \text { Priority Auto/ } \\ \text { Overall Truck } & \text { Priority Truck }\end{array} \quad \begin{aligned} & \text { Non-Priority Auto/ } \\ & \text { Non-Priority Truck }\end{aligned}-\begin{aligned} & \text { Secondary } \\ & \text { Truck }\end{aligned}$ 


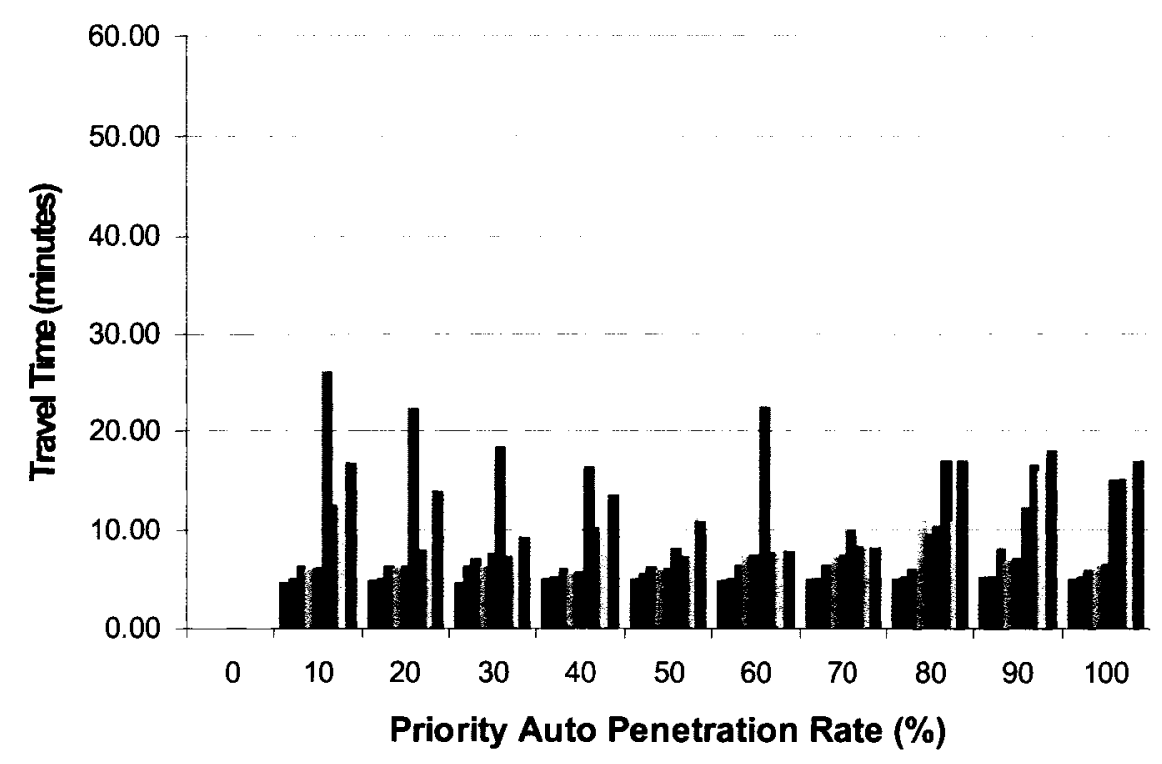

Figure A-19: Priority Auto Average Travel Time Across Scenarios

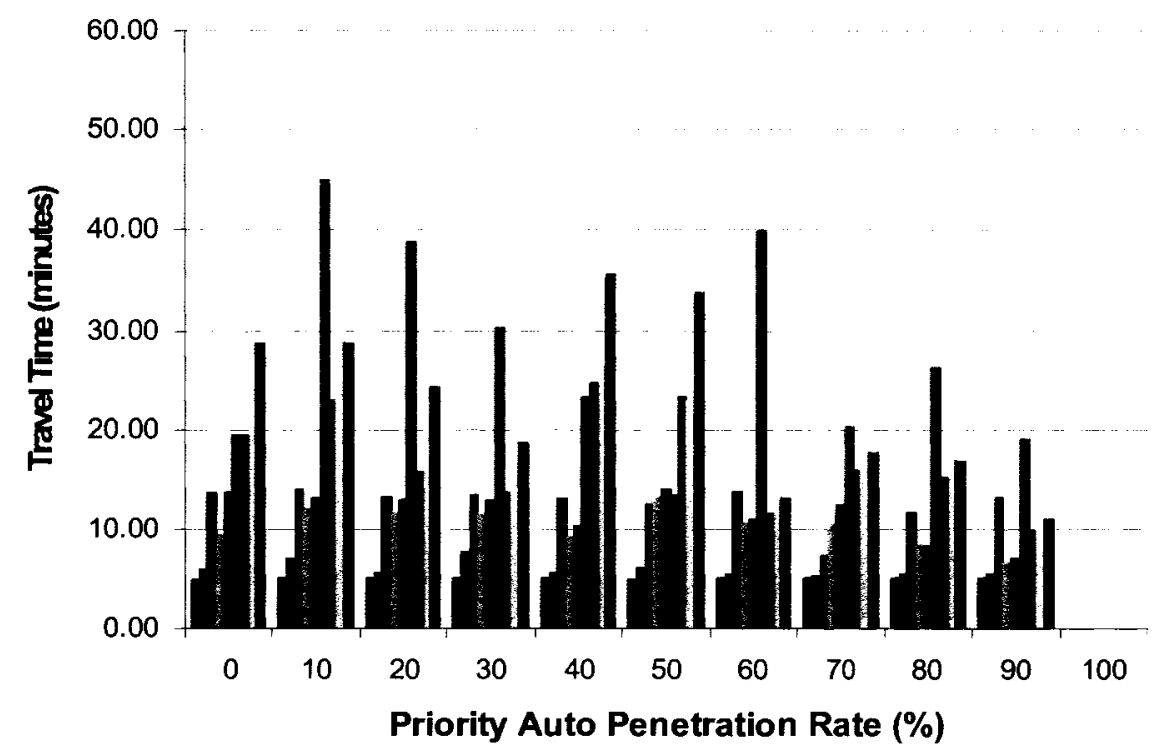

Figure A-20: Non-Priority Auto Average Travel Time Across Scenarios

Basecase Demand \& Customs Processing Times

Basecase Demand \& inc. Customs Processing Times

$20 \%$ Inc. Demand \& Inc. Cust. Process.

$20 \%$ Inc. Demand \& Basecase

$20 \%$ Inc. Demand \& Inc.

Times (No Queue Jump Lanes)

Proc. Times (Queue Jump Lanes)

Proc. Times (Q Jump Lanes)

- $50 \%$ Increased Demand and Inc. Processing Times (No Queue Jump Lanes)

$50 \%$ Increased Demand and Inc. Processing Times (With Queue Jump Lanes)

100\% Increased Demand and Inc. Processing Times (No Queue Jump Lanes)

$100 \%$ Increased Demand and Inc. Processing Times (With Queue Jump Lanes) 


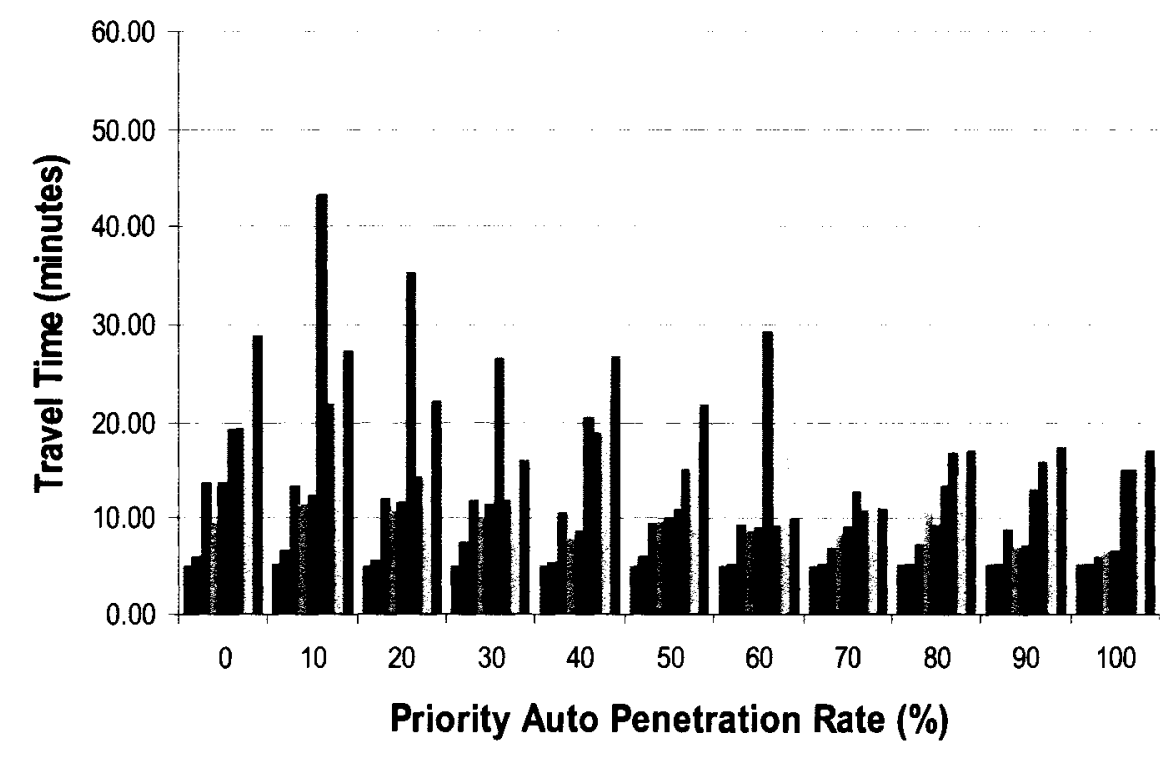

Figure A-21: Overall Auto Average Travel Time Across Scenarios

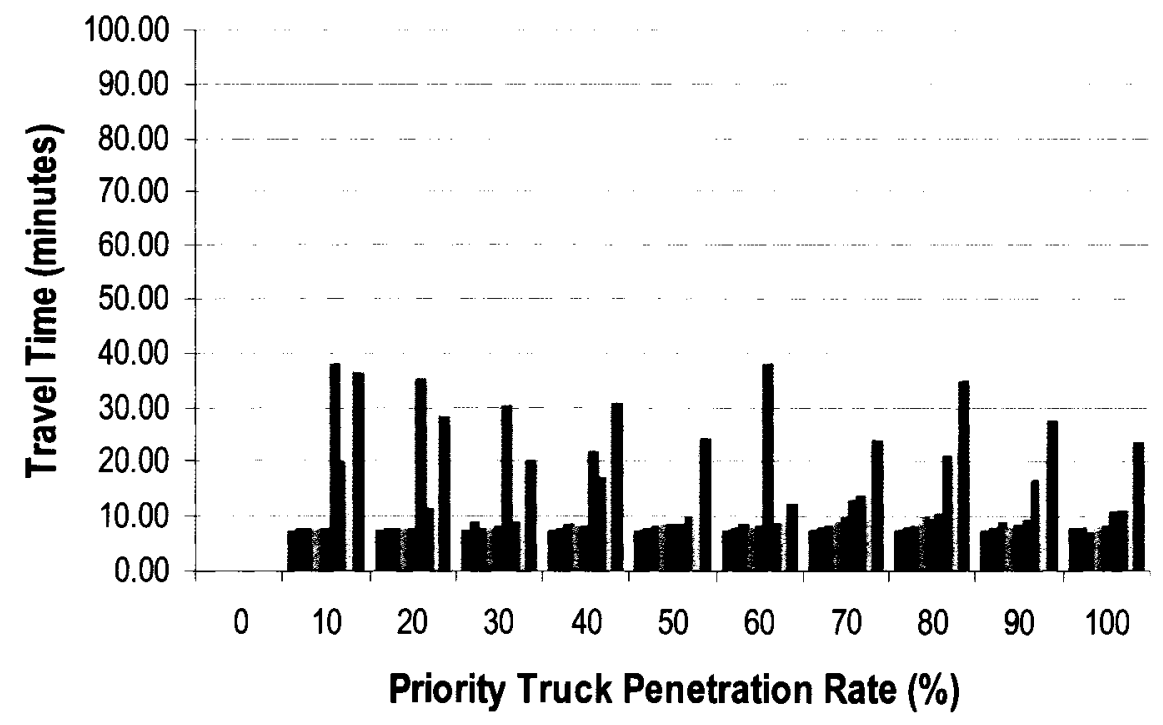

\section{Figure A-22: Priority Truck Average Travel Time Across Scenarios}

\begin{tabular}{|c|c|c|c|}
\hline \multicolumn{2}{|c|}{ Basecase Demand \& Customs Processing Times } & \multicolumn{2}{|c|}{ Basecase Demand \& Inc. Customs Processing Times } \\
\hline $\begin{array}{l}20 \% \text { Inc. Demand \& Inc. Cust. Process. } \\
\text { Times (No Queue Jump Lanes) }\end{array}$ & औ & $\begin{array}{l}20 \% \text { Inc. Demand \& Basecase } \\
\text { Proc. Times (Queue Jump Lanes) }\end{array}$ & $\begin{array}{l}20 \% \text { Inc. Demand \& Inc. } \\
\text { Proc. Times (Q Jump Lanes) }\end{array}$ \\
\hline \multicolumn{2}{|c|}{$\begin{array}{l}50 \% \text { Increased Demand and Inc. Processing Times } \\
\text { (No Queue Jump Lanes) }\end{array}$} & \multicolumn{2}{|c|}{$\begin{array}{l}50 \% \text { Increased Demand and Inc. Processing Times } \\
\text { (With Queue Jump Lanes) }\end{array}$} \\
\hline \multicolumn{2}{|c|}{$\begin{array}{l}\text { 100\% Increased Demand and Inc. Processing Times } \\
\text { (No Queue Jump Lanes) }\end{array}$} & $\begin{array}{r}100 \% \text { Increased Der } \\
\text { (Wit }\end{array}$ & $\begin{array}{l}\text { nd Inc. Processing Times } \\
\text { e Jump Lanes) }\end{array}$ \\
\hline
\end{tabular}




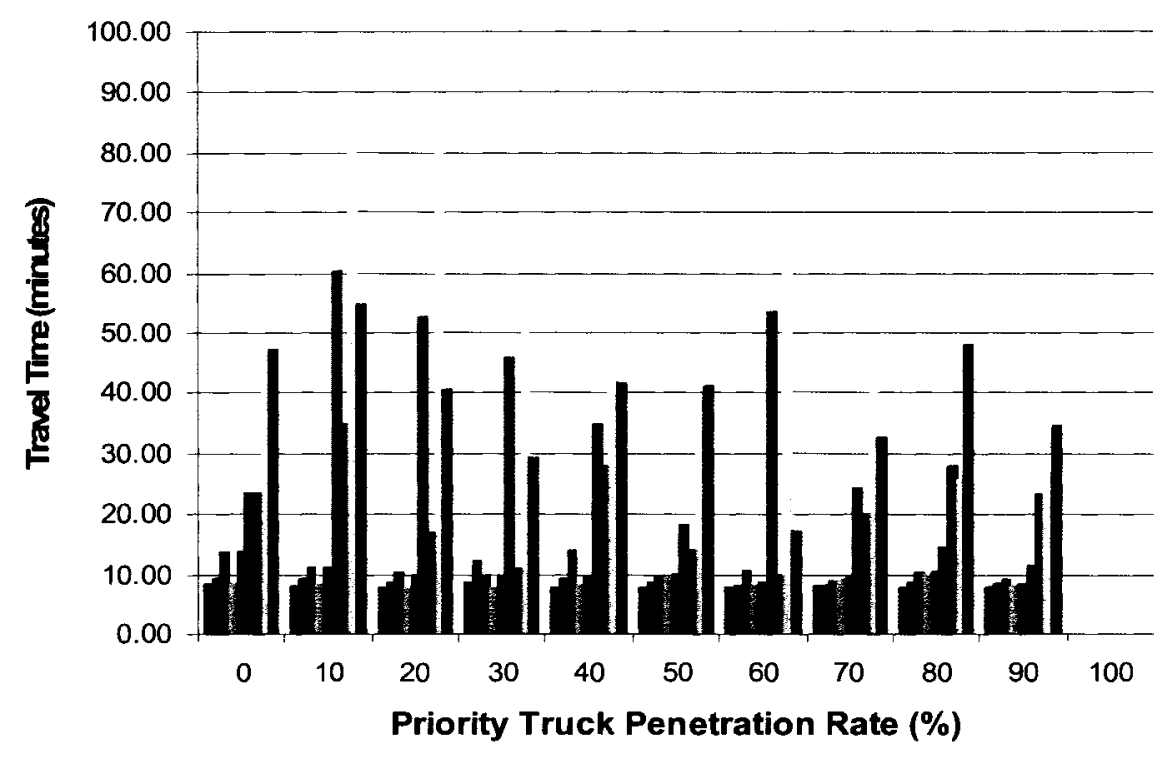

Figure A-23: ROL Truck Average Travel Time Across Scenarios

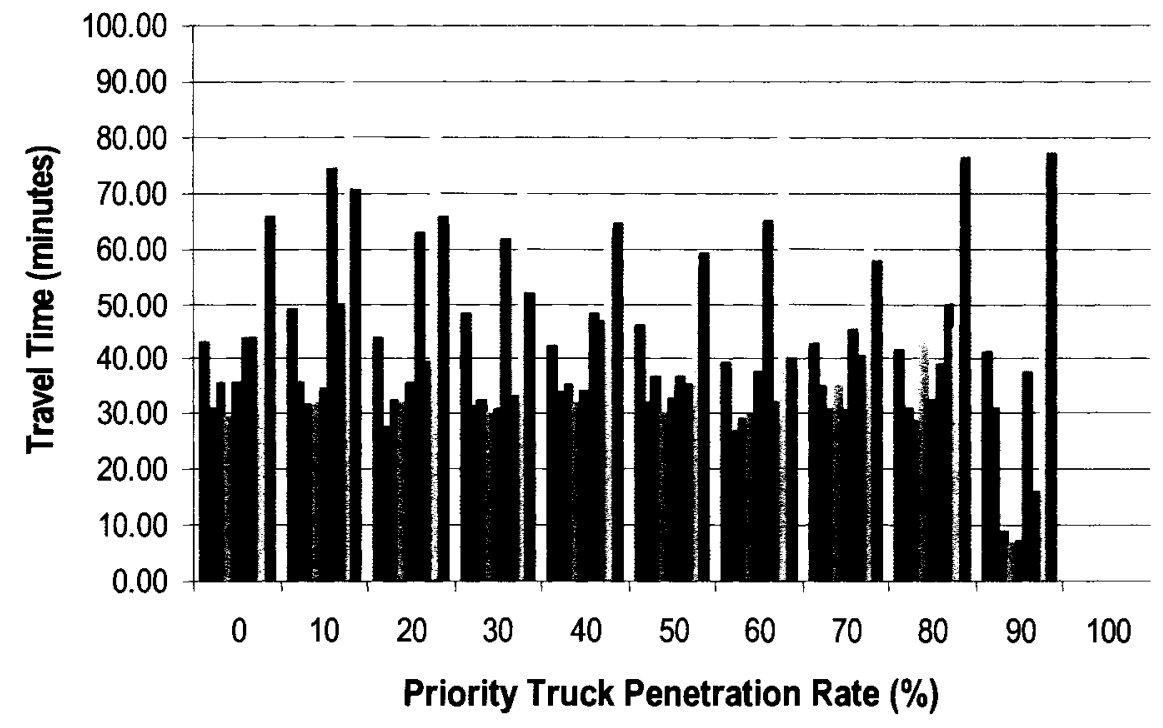

\section{Figure A-24: Secondary Inspection Truck Average Travel Time Across Scenarios}

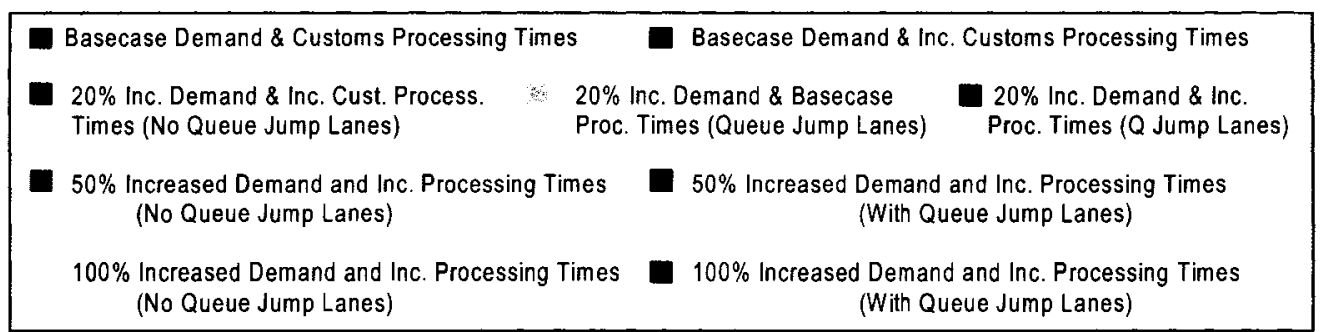




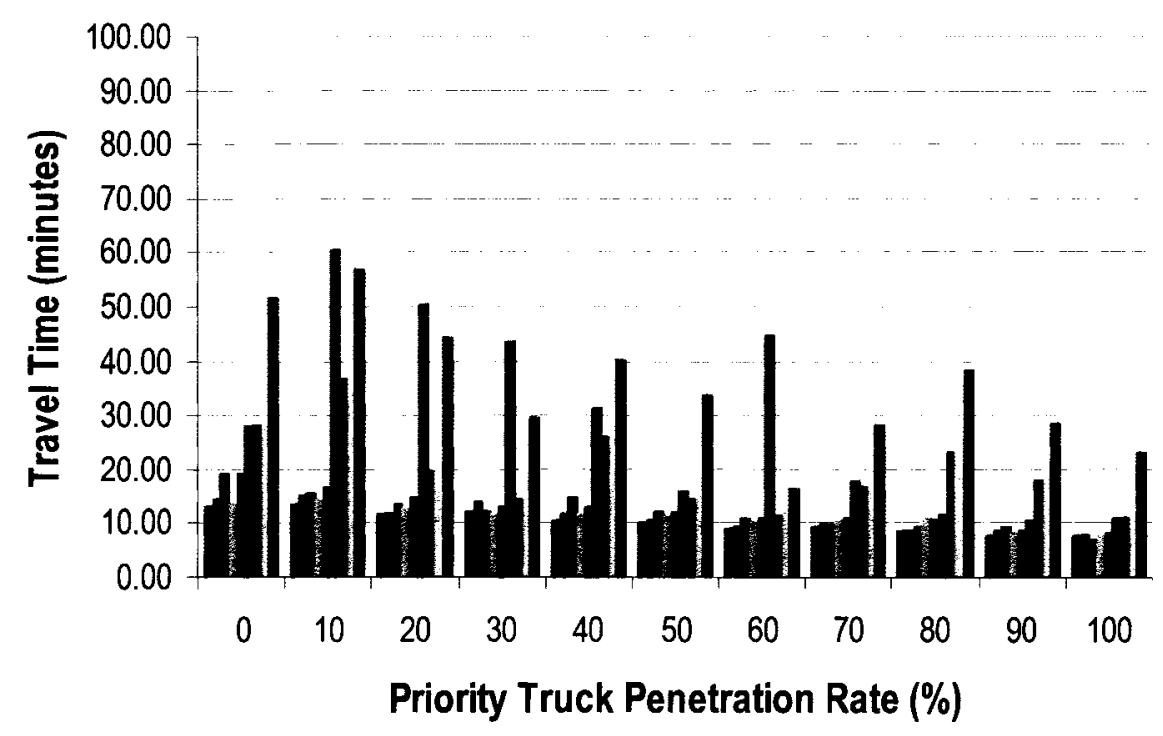

Figure A-25: Overall Truck Average Travel Time Across Scenarios

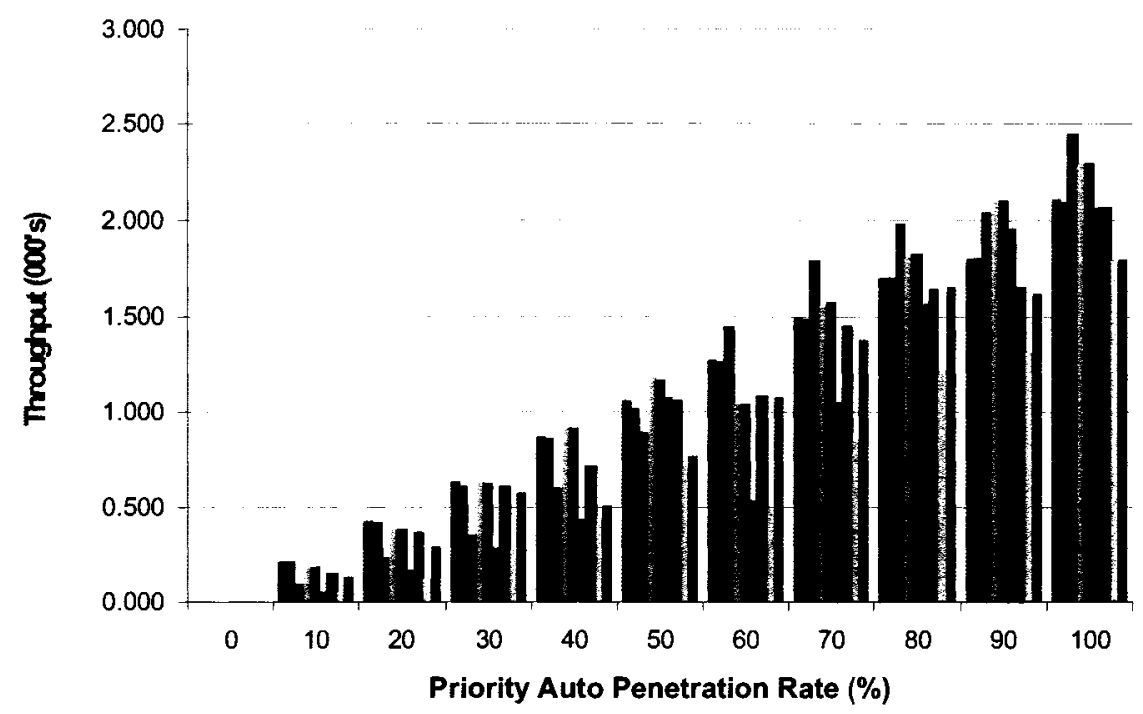

\section{Figure A-26: Priority Auto Throughput Across Scenarios}

\begin{tabular}{|c|c|c|c|}
\hline \multicolumn{2}{|c|}{ Basecase Demand \& Customs Processing Times } & Basecase $D$ & s \\
\hline $\begin{array}{l}20 \% \text { Inc. Demand \& Inc. Cust. Process. } \\
\text { Times (No Queue Jump Lanes) }\end{array}$ & 4 & $\begin{array}{l}20 \% \text { inc. Demand \& Basecase } \\
\text { Proc. Times (Queue Jump Lanes) }\end{array}$ & $\begin{array}{l}20 \% \text { Inc. Demand \& Inc. } \\
\text { Proc. Times (Q Jump Lanes) }\end{array}$ \\
\hline \multicolumn{2}{|c|}{$\begin{array}{l}50 \% \text { Increased Demand and Inc. Processing Times } \\
\text { (No Queue Jump Lanes) }\end{array}$} & \multicolumn{2}{|c|}{$\begin{array}{l}50 \% \text { Increased Demand and Inc. Processing Times } \\
\text { (With Queue Jump Lanes) }\end{array}$} \\
\hline \multicolumn{2}{|c|}{$\begin{array}{l}\text { 100\% Increased Demand and Inc. Processing Times } \\
\text { (No Queue Jump Lanes) }\end{array}$} & $\begin{array}{r}100 \% \text { Increased Dem } \\
\text { (With }\end{array}$ & $\begin{array}{l}\text { nd Inc. Processing Times } \\
\text { e Jump Lanes) }\end{array}$ \\
\hline
\end{tabular}




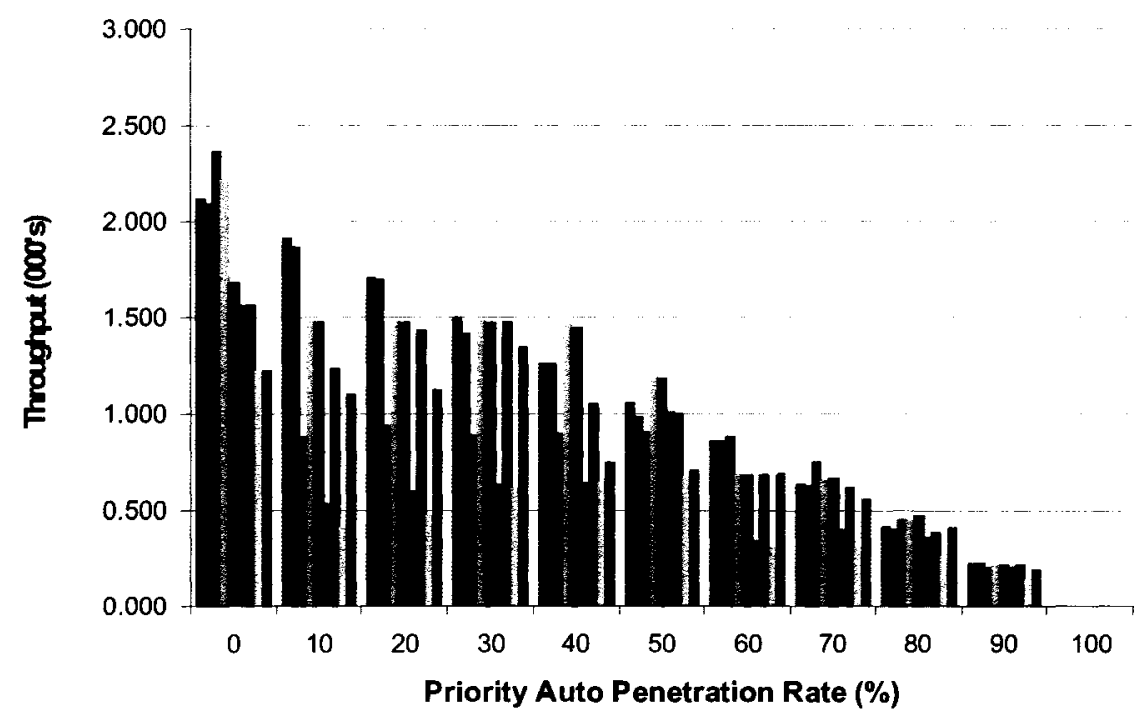

Figure A-27: Non-Priority Auto Throughput Across Scenarios

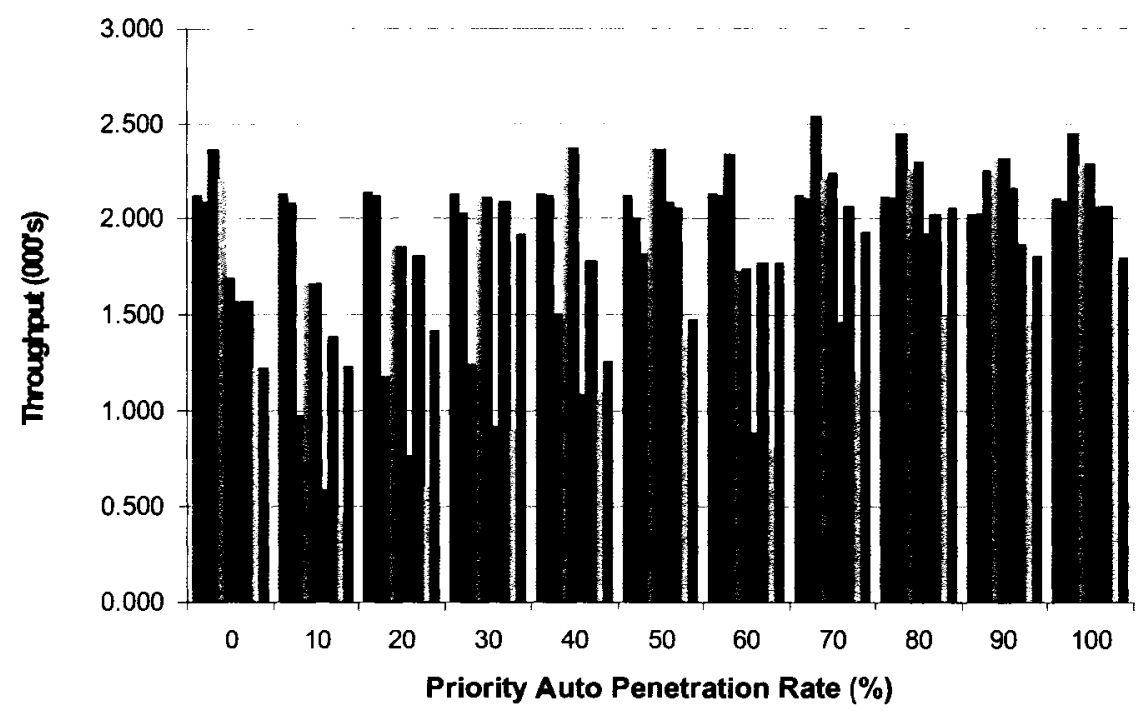

\section{Figure A-28: Overall Auto Throughput Across Scenarios}

Basecase Demand \& Customs Processing Times $\quad$ Basecase Demand \& Inc. Customs Processing Times

$20 \%$ Inc. Demand \& Inc. Cust. Process. Times (No Queue Jump Lanes)

$20 \%$ Inc. Demand \& Basecase Proc. Times (Queue Jump Lanes)

$20 \%$ Inc. Demand \& inc. Proc. Times (Q Jump Lanes)

- $50 \%$ Increased Demand and Inc. Processing Times (No Queve Jump Lanes)

$50 \%$ Increased Demand and Inc. Processing Times (With Queue Jump Lanes)

100\% Increased Demand and Inc. Processing Times (No Queue Jump Lanes)

$100 \%$ Increased Demand and Inc. Processing Times (With Queue Jump Lanes) 


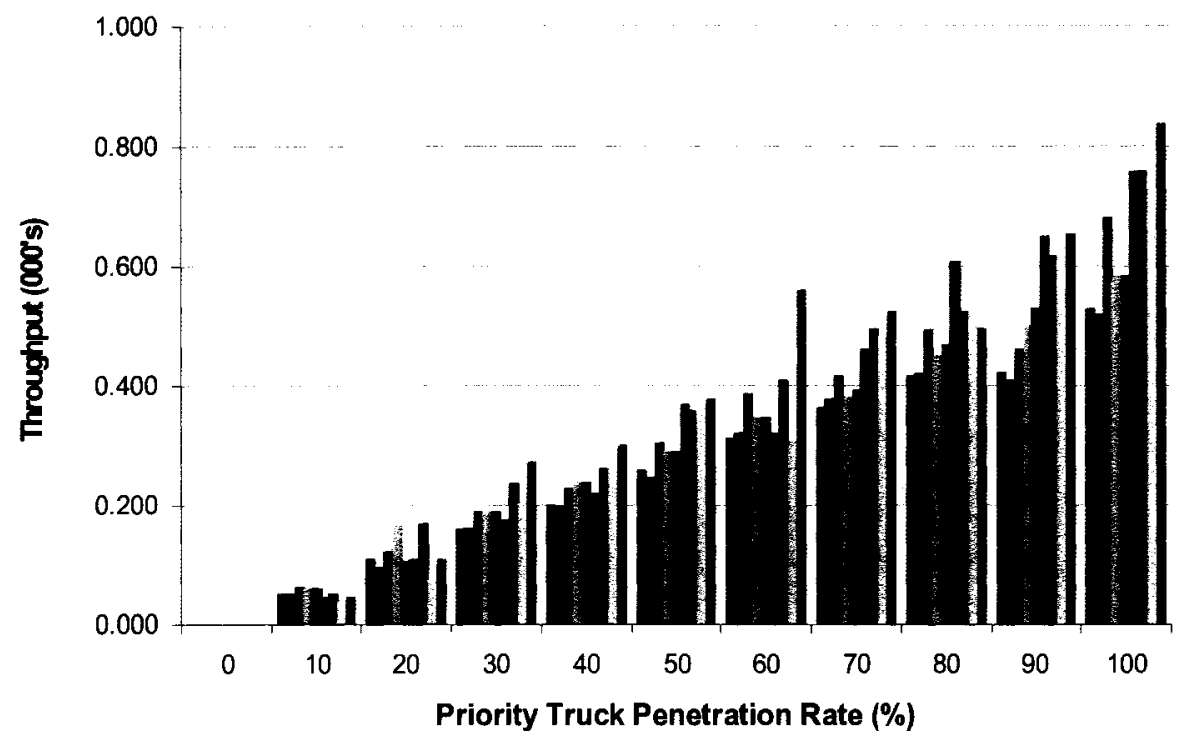

\section{Figure A-29: Priority Truck Throughput Across Scenarios}

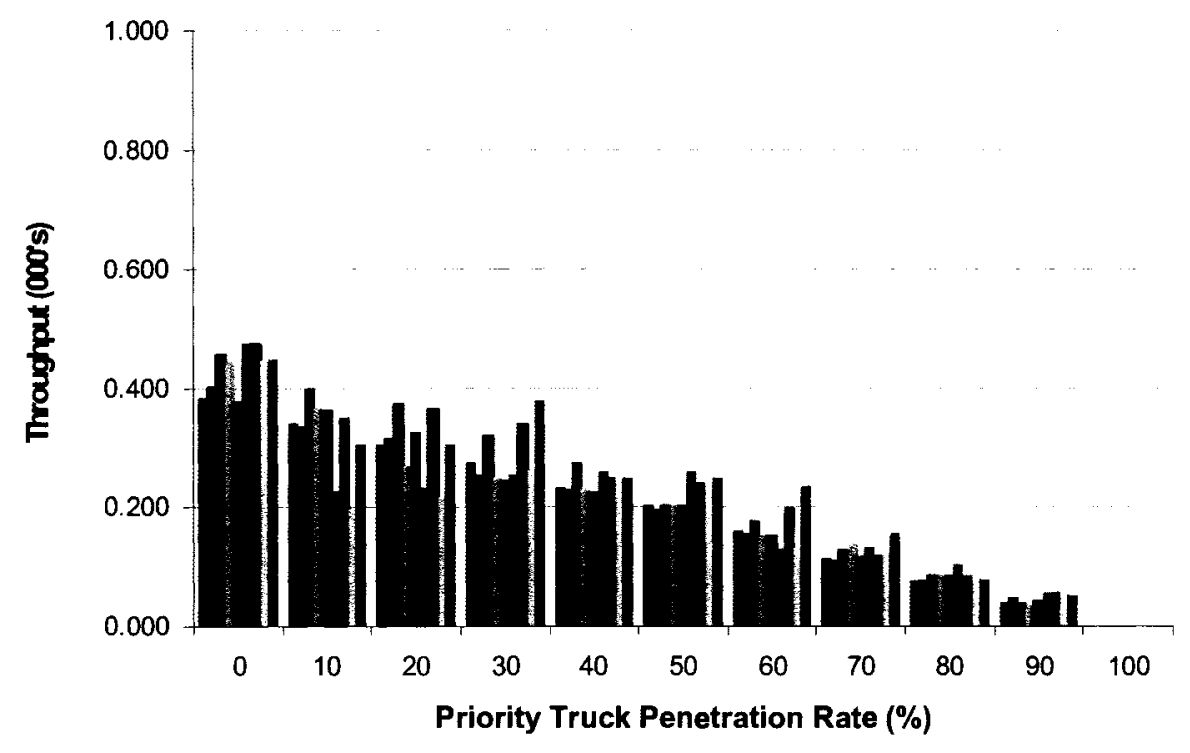

Figure A-30: ROL Truck Throughput Across Scenarios

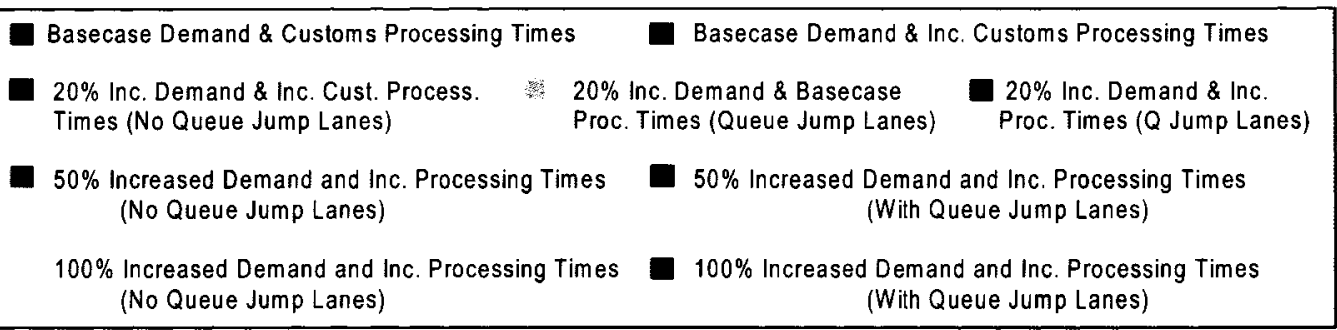




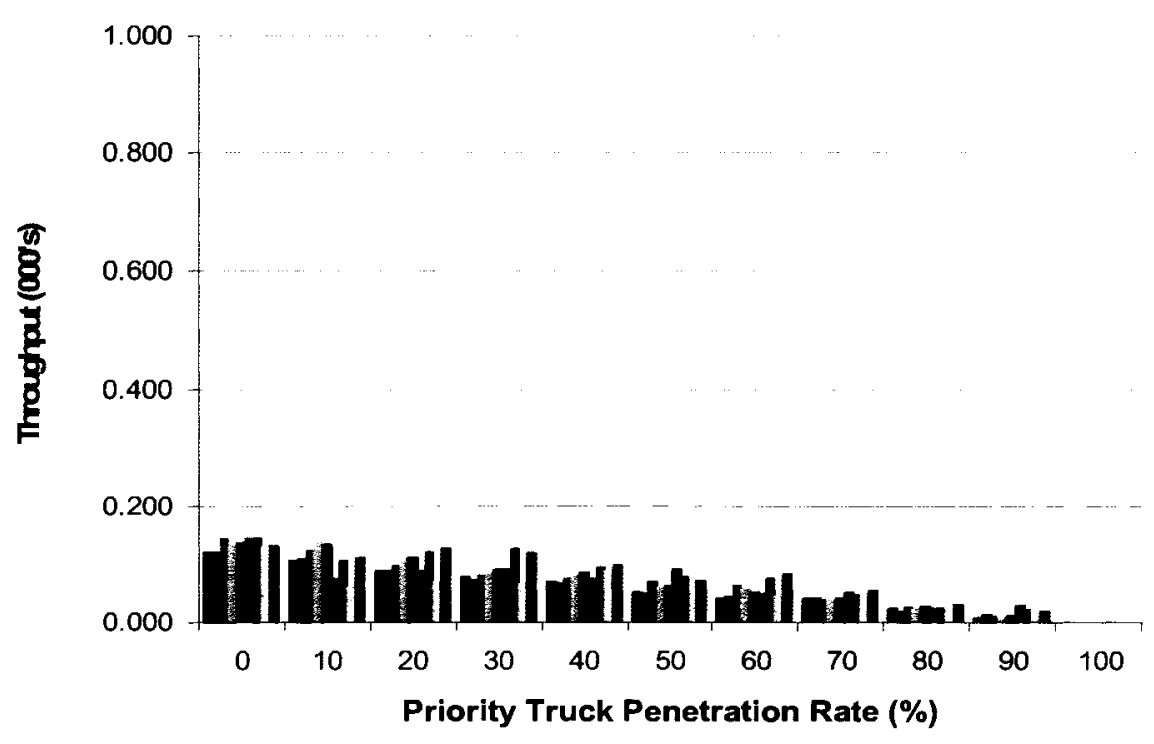

Figure A-31: Secondary Inspection Truck Throughput Across Scenarios

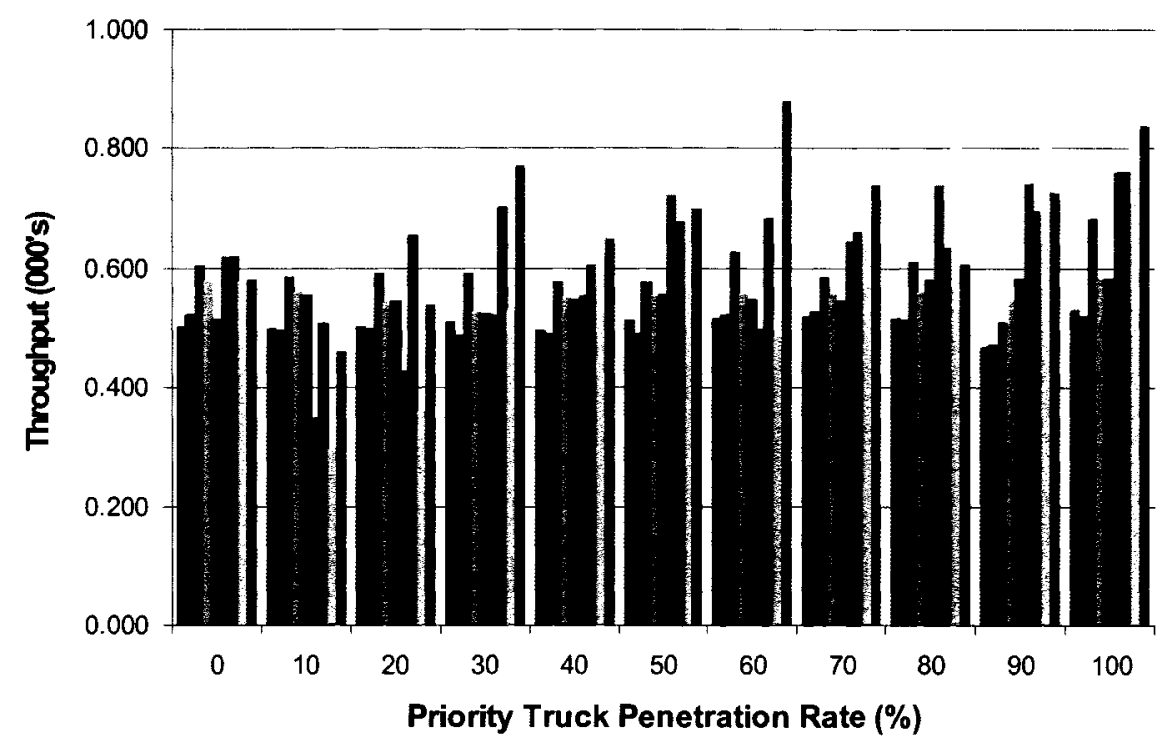

\section{Figure A-32: Overall Truck Throughput Across Scenarios}

Basecase Demand \& Customs Processing Times Basecase Demand \& Inc. Customs Processing Times

$20 \%$ Inc. Demand \& Inc. Cust. Process. Times (No Queue Jump Lanes)

$50 \%$ Increased Demand and Inc. Processing Times (No Queue Jump Lanes)

$100 \%$ Increased Demand and Inc. Processing Times (No Queve Jump Lanes)
$20 \%$ Inc. Demand \& Inc. Proc. Times ( $Q$ Jump Lanes) 


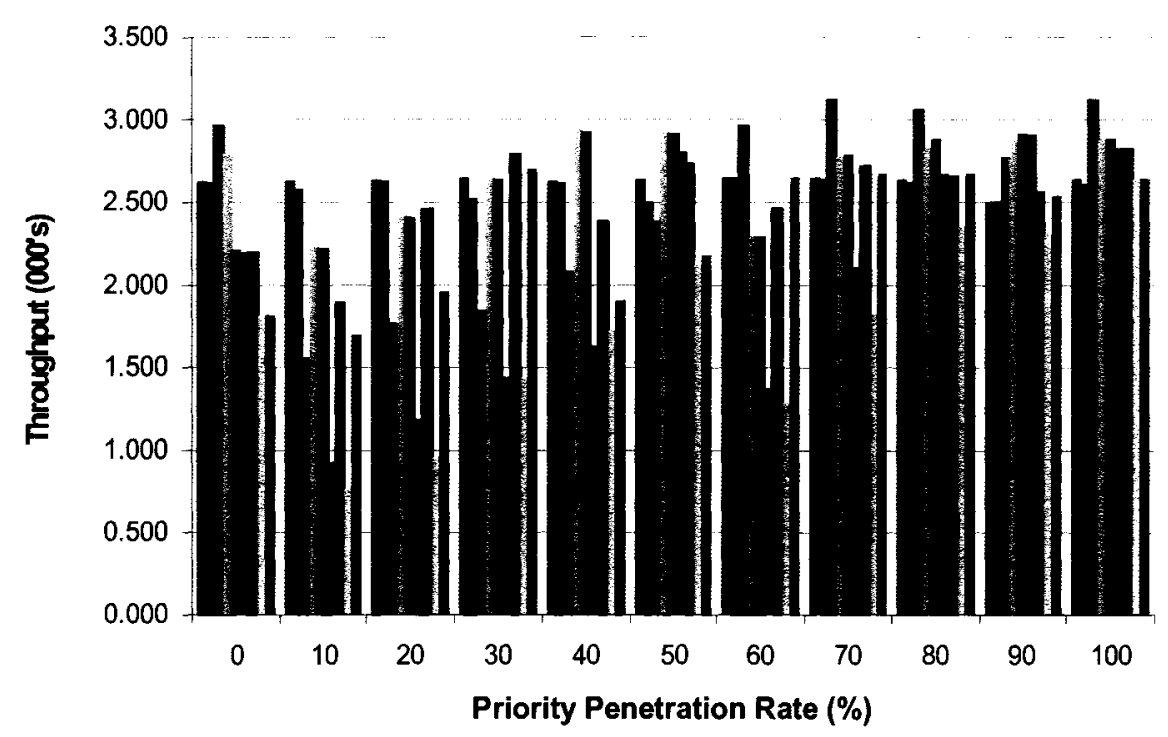

\section{Figure A-33: Overall Auto and Truck Throughput Across Scenarios}

Basecase Demand \& Customs Processing Times

Basecase Demand \& Inc. Customs Processing Times

$20 \%$ Inc. Demand \& Inc. Cust. Process.

Times (No Queue Jump Lanes)

$20 \%$ Inc. Demand \& Basecase

$20 \%$ Inc. Demand \& Inc

$50 \%$ Increased Demand and Inc. Processing Times (No Queue Jump Lanes)

$50 \%$ Increased Demand and Inc. Processing Times (With Queue Jump Lanes)

$100 \%$ Increased Demand and Inc. Processing Times (No Queue Jump Lanes)

100\% Increased Demand and Inc. Processing Times (With Queue Jump Lanes) 


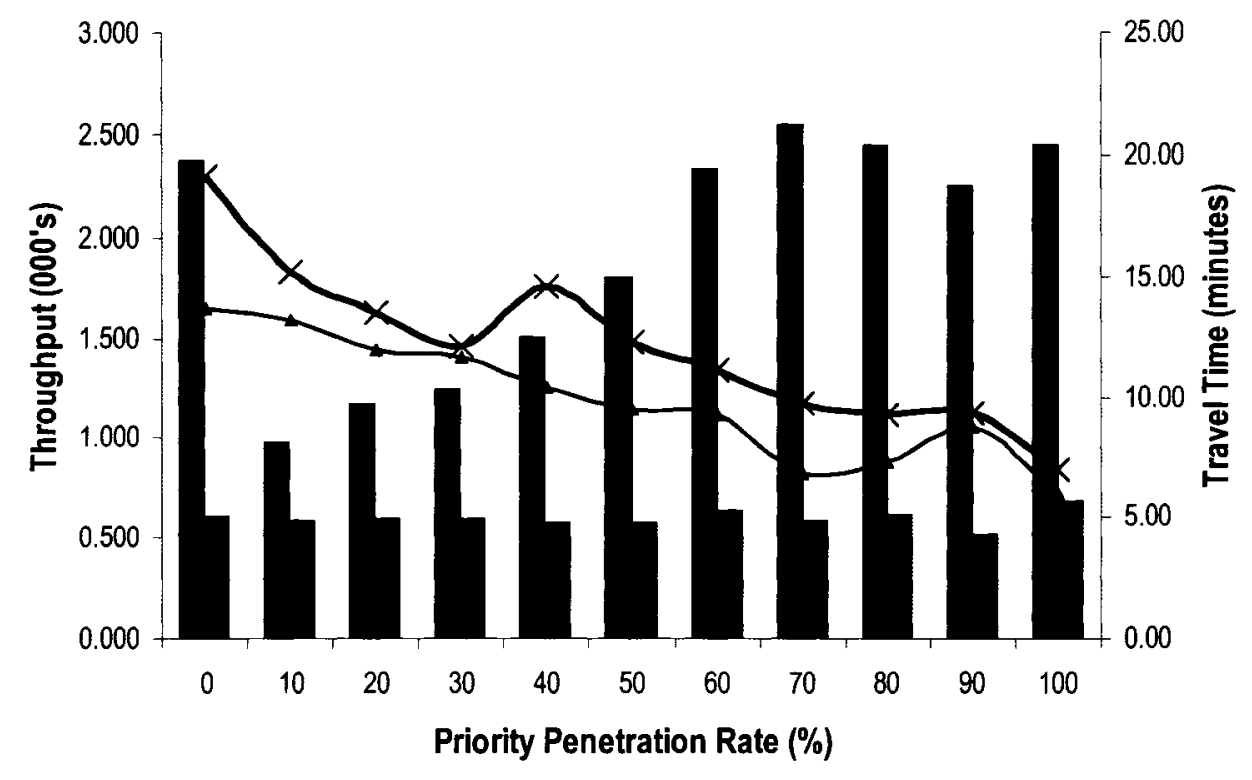

Figure A-34: Autos and Trucks Throughput and Travel Time Comparison $20 \%$ Increase in Demand; Increased Customs Times and No Queue Jump Lanes

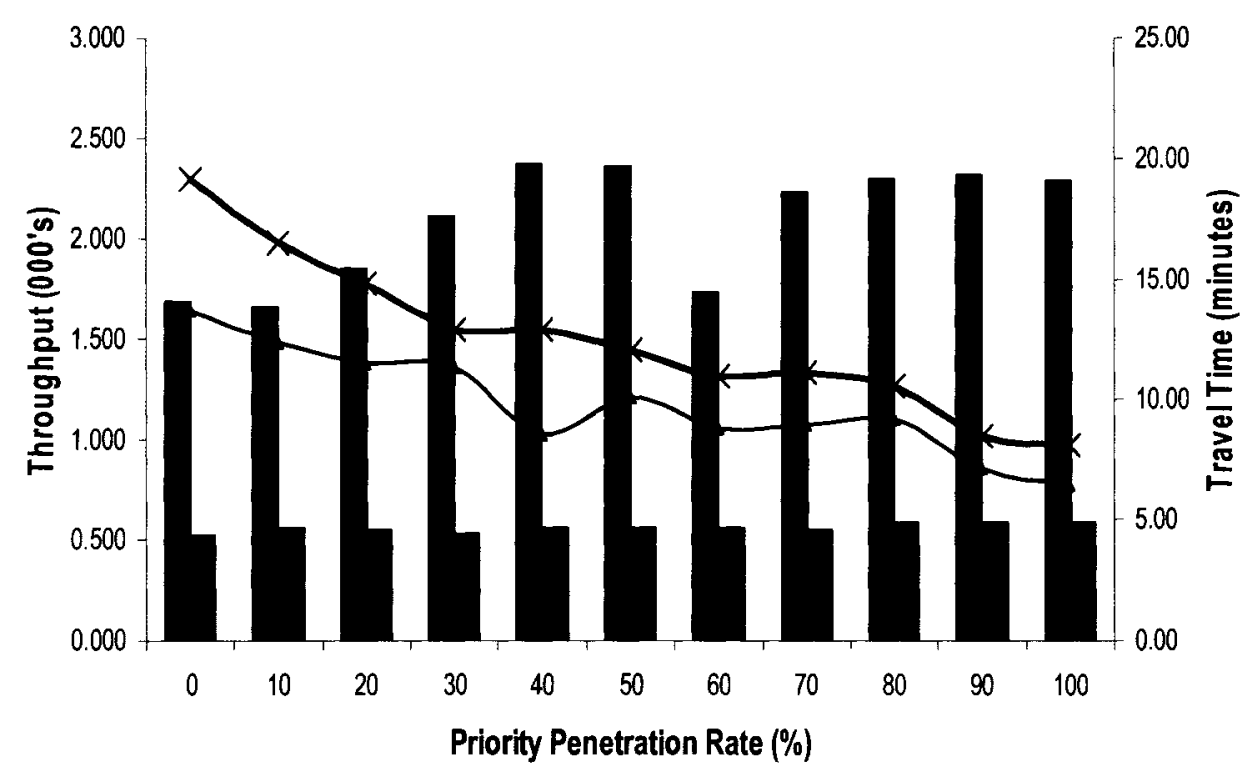

Figure A-35: Autos and Trucks Throughput and Travel Time Comparison $20 \%$ Increase in Demand; Increased Customs Times and Queue Jump Lanes
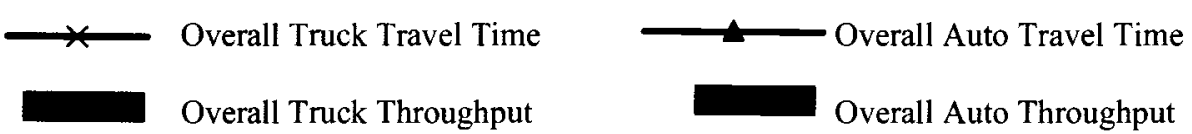


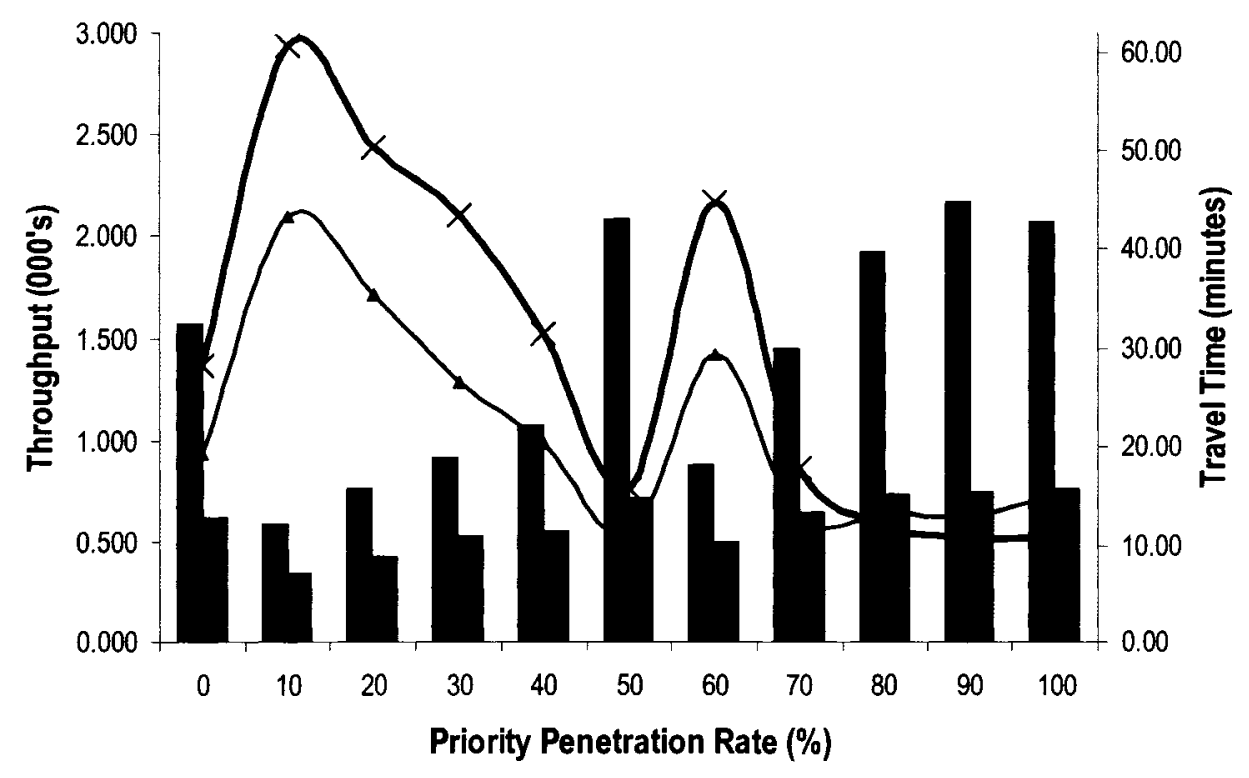

Figure A-36: Autos and Trucks Throughput and Travel Time Comparison $50 \%$ Increase in Demand; Increased Customs Times and No Queue Jump Lanes

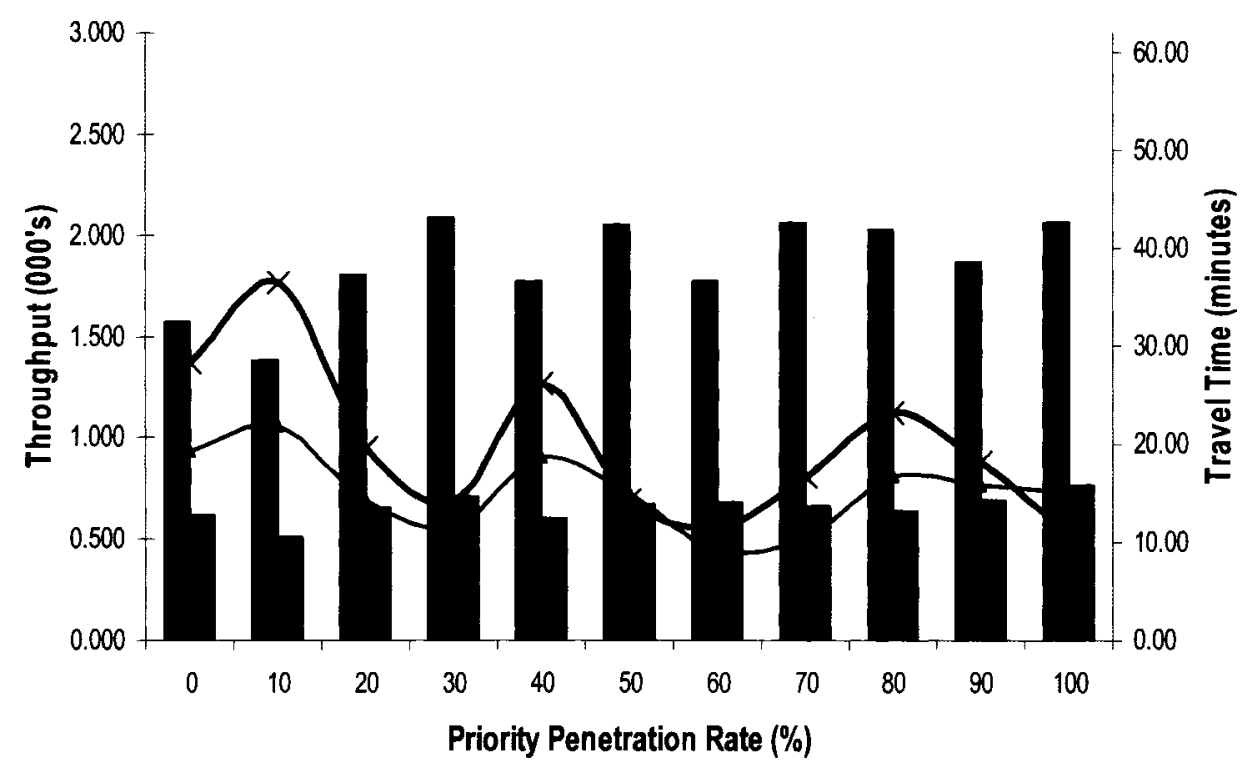

Figure A-37: Autos and Trucks Throughput and Travel Time Comparison $50 \%$ Increase in Demand; Increased Customs Times and Queue Jump Lanes
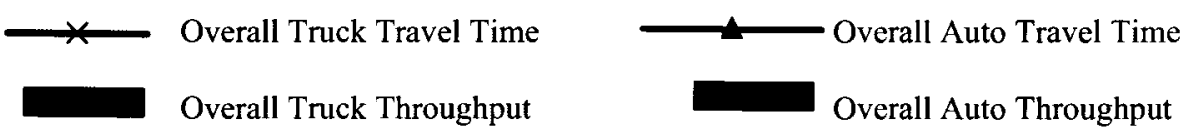


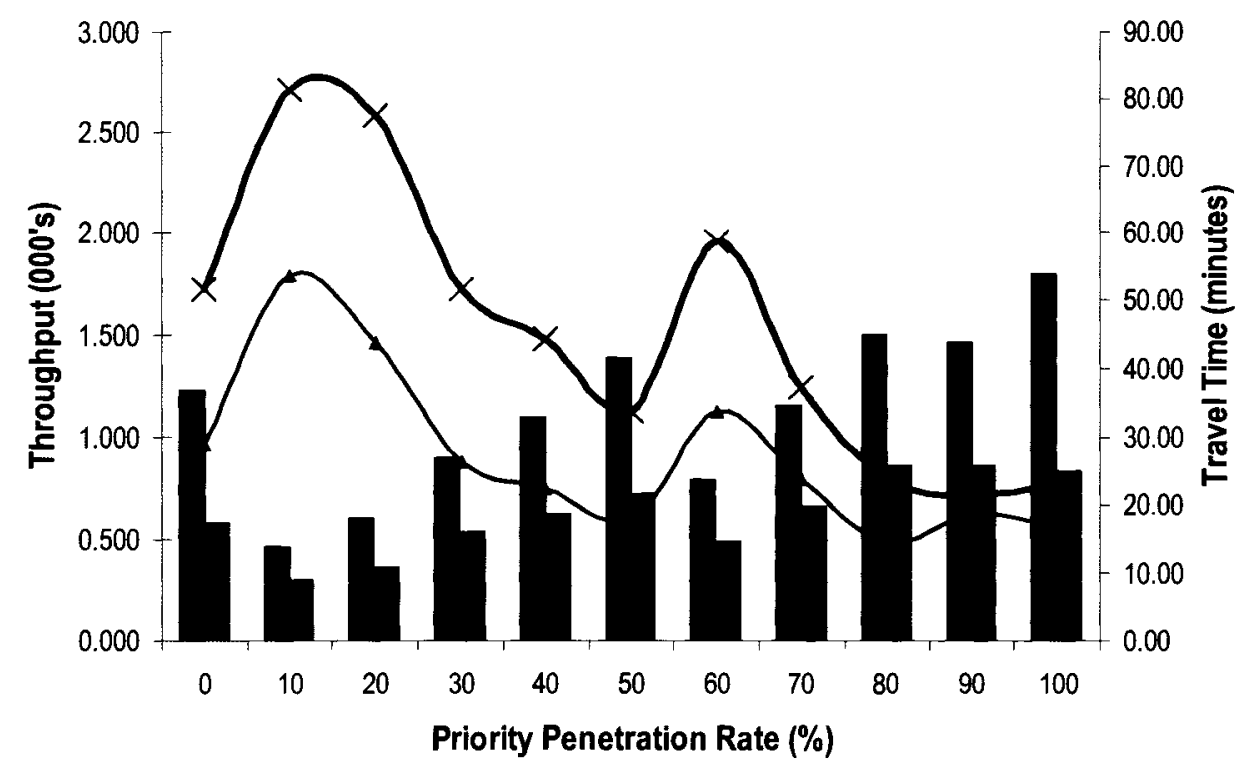

Figure A-38: Autos and Trucks Throughput and Travel Time Comparison $100 \%$ Increase in Demand; Increased Customs Times and No Queue Jump Lanes

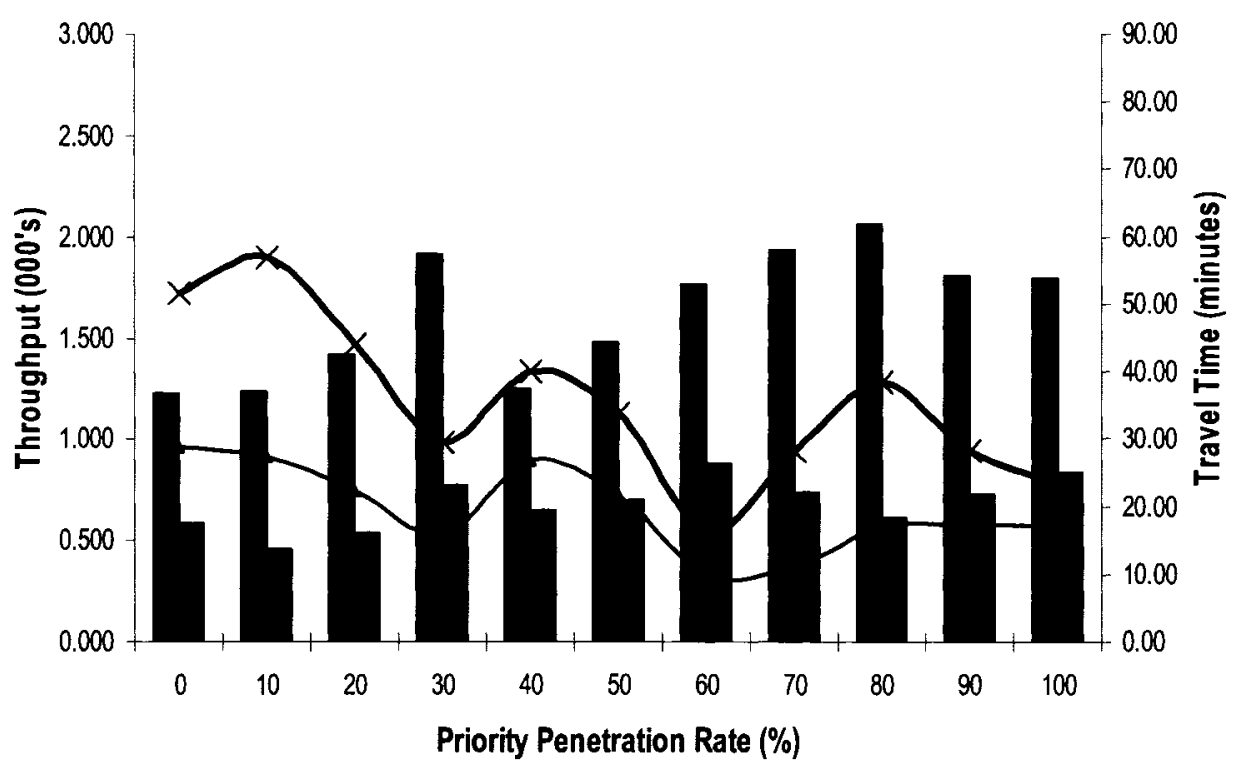

Figure A-39: Autos and Trucks Throughput and Travel Time Comparison $100 \%$ Increase in Demand; Increased Customs Times and Queue Jump Lanes
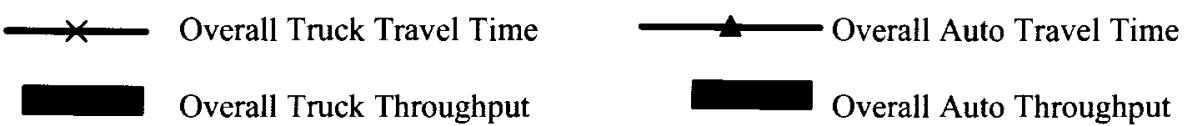


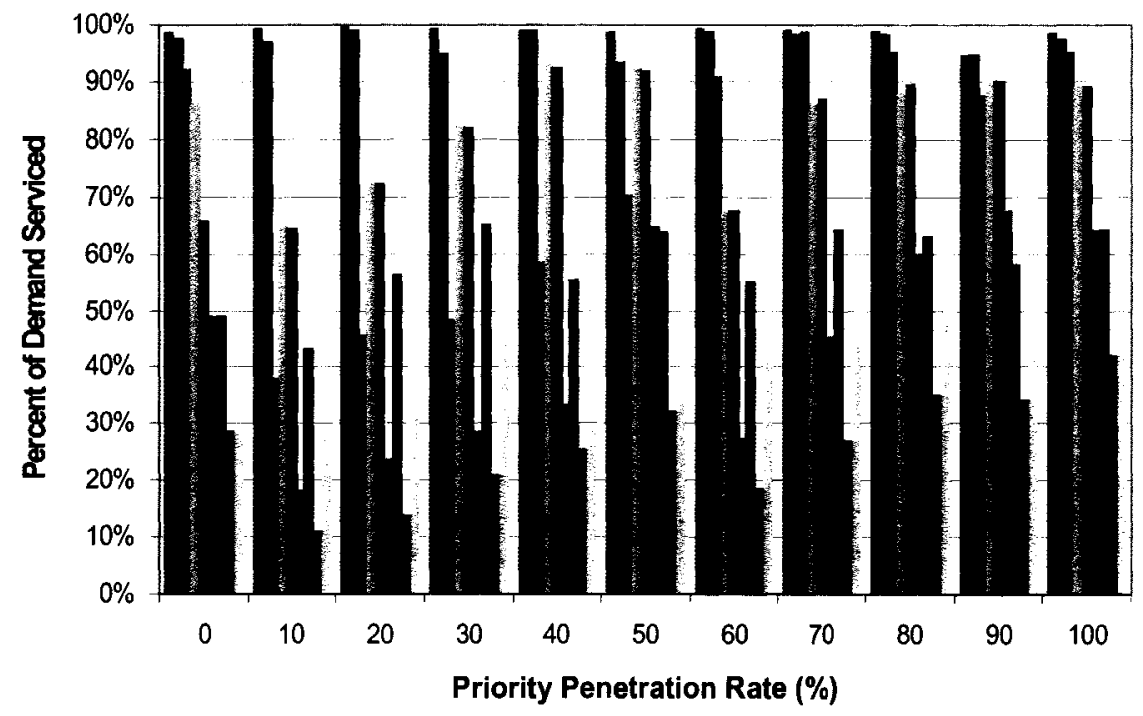

Figure A-40: Overall Auto Percent of Demand Serviced Across Scenarios

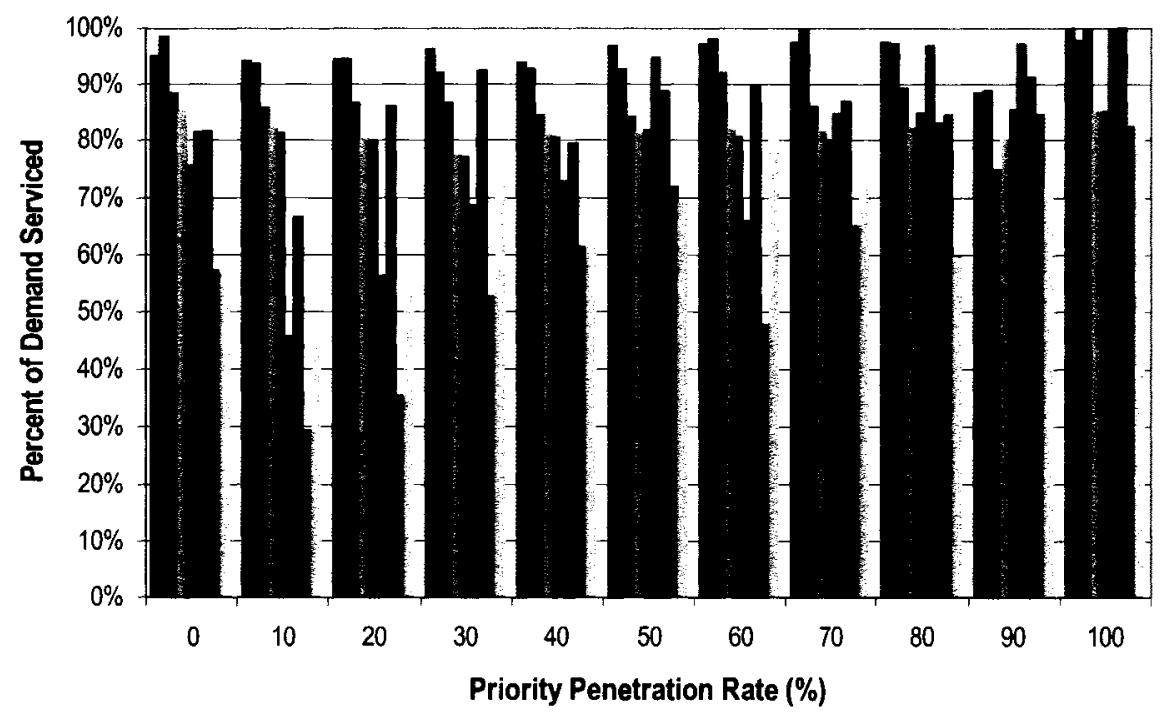

Figure A-41: Overall Truck Percent of Demand Serviced Across Scenarios

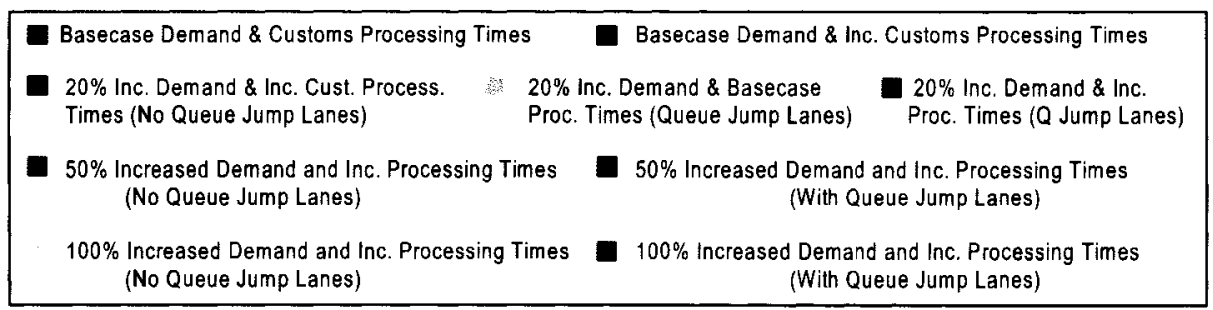




\section{APPENDIX B}


Auto Demand Hourly Variation - Ambassador Bridge US Bound

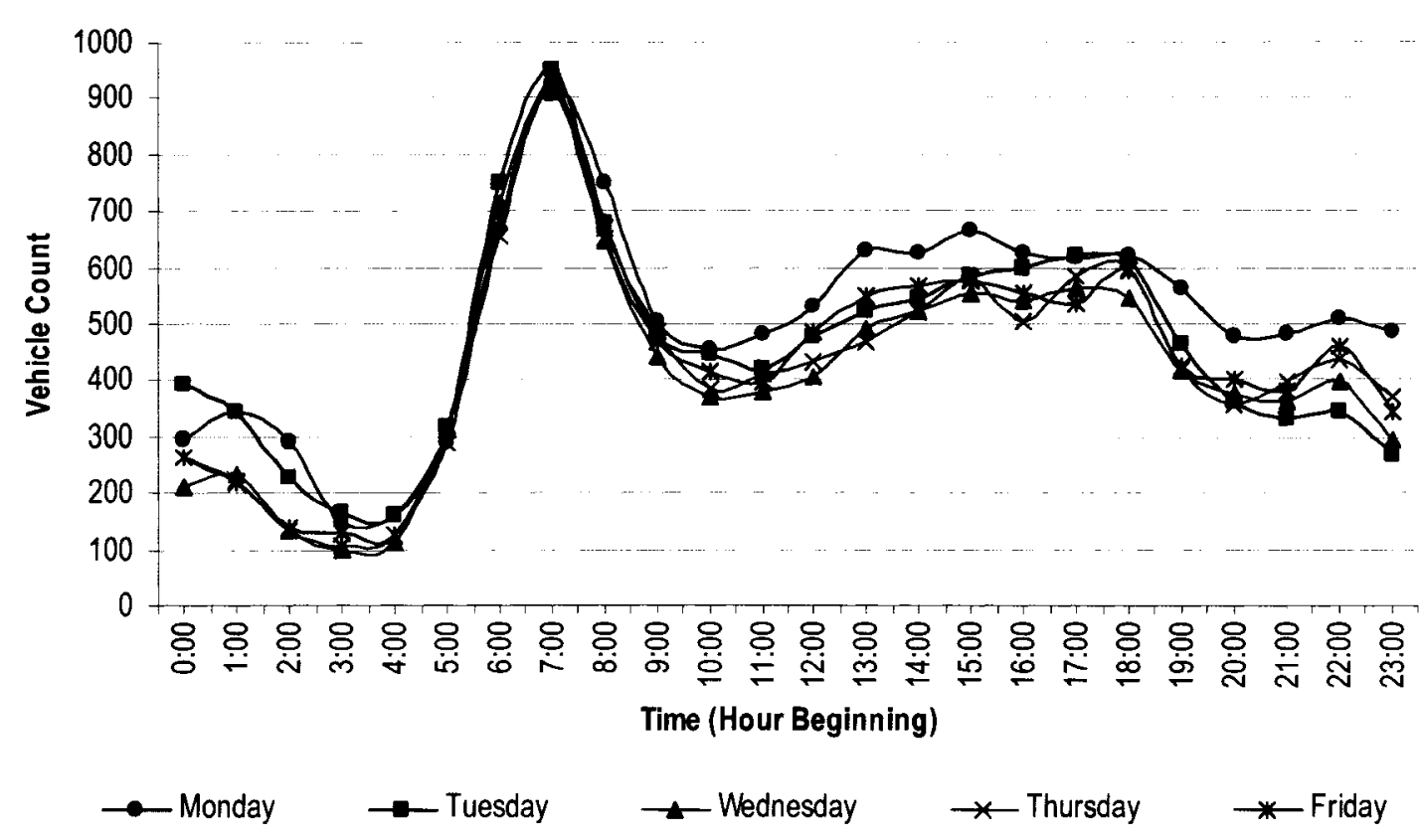

Figure B-1: Auto Demand Hourly Variation - Ambassador Bridge US Bound Source: Data Management and Analysis Office, "Commercial Vehicle Survey Data", MTO, 1999.

Truck Demand Hourly Variation - Ambassador Bridge US Bound

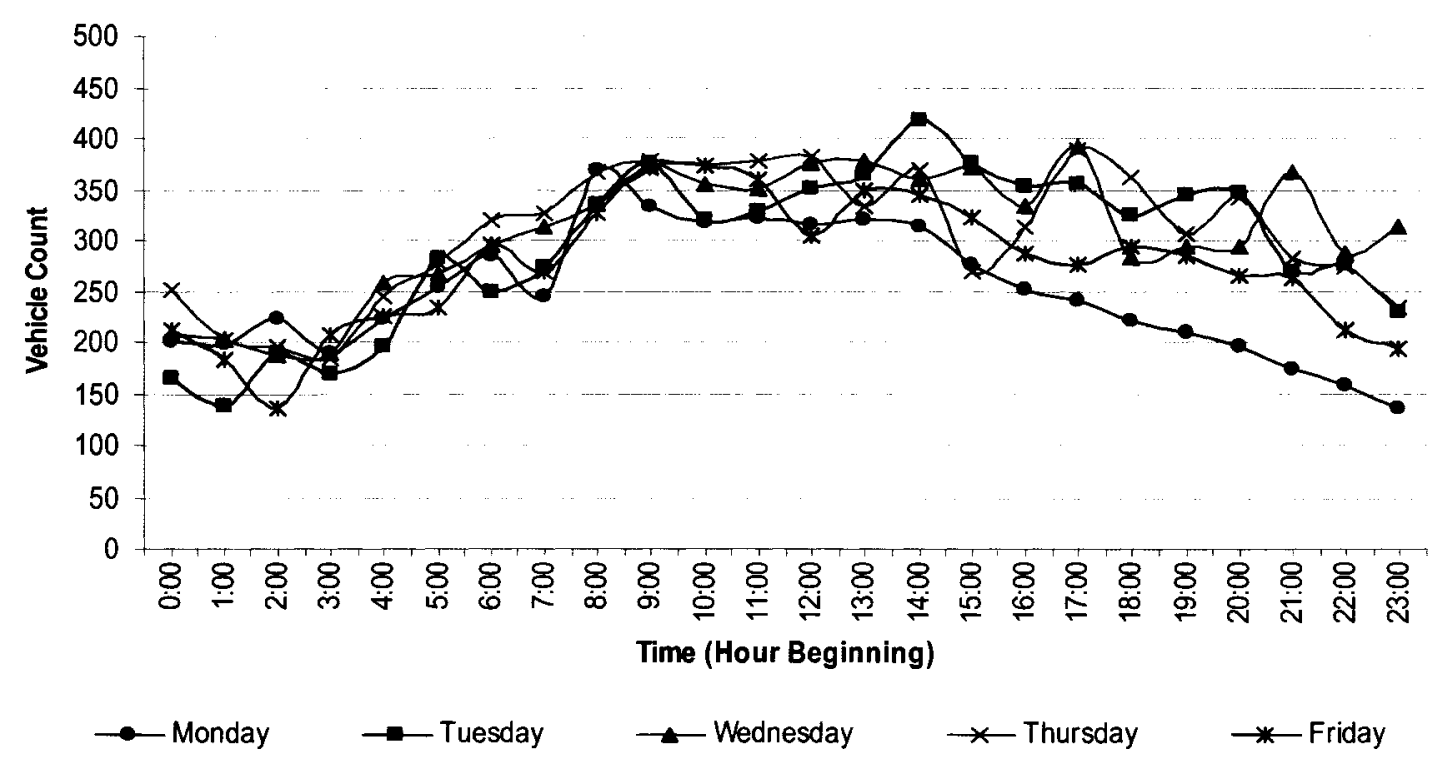

Figure B-2: Truck Demand Hourly Variation - Ambassador Bridge US Bound Source: Data Management and Analysis Office, “Commercial Vehicle Survey Data”, MTO, 1999. 
Table B-1: Adjusted Demand Values Used For Base-Case Model

\begin{tabular}{|c|c|c|c|c|}
\hline Hour Interval & Autos (1999)28 & Adjusted Autos (2003) & Trucks (1999) ${ }^{28}$ & Adjusted Trucks (2003) \\
\hline 5:00-6:00 & 312 & 284 & 234 & 222 \\
\hline $6: 00-7: 00$ & 684 & 622 & 296 & 281 \\
\hline $7: 00-8: 00$ & 927 & 844 & 269 & 255 \\
\hline $\mathbf{8 : 0 0 - 9 : 0 0}$ & 650 & 592 & 326 & 309 \\
\hline
\end{tabular}

Table B-2: Processing Times Primary and Secondary Customs Inspection

\begin{tabular}{|c|c|c|}
\hline Component & Autos (s/vehicle) & Trucks (s/vehicle) \\
\hline Tolls 5 & 8 & 35 \\
\hline Primary Customs 5 & 30 & 80 \\
\hline \multirow{2}{*}{ Secondary Inspection 22} & \multirow{2}{*}{$N A^{*}$} & 1520 - Consult Brokers \\
\hline & & 2220 - Physical Inspectior \\
\hline
\end{tabular}

Source: 1. URS and IBI Group, Planning/Need and Feasibility Study "Existing and Future Travel Demand - Working Paper", Canada-US-OntarioMichigan Transportation Partnership, November 2002.5

2. Glassco R. A. and Wunderlich K. E., "Simulation and Analysis of North American Trade Automation Prototype (NATAP) Operations at the Ambassador Bridge", FHWA, September 1999.22

* Information not available but considered to have negligible impact on simulation results because of small percentage of auto traffic sent to secondary inspection.

Table B-3: Comparison Between VISSIM Model Output and Real Data

\begin{tabular}{|c|c|c|}
\hline Description & Model Output (min.) & $\begin{array}{c}\text { Comparison Data } \\
\text { (min.) }\end{array}$ \\
\hline Average Total Truck Travel Time (across all categories) & 21.2 & $25^{29}$ \\
\hline Minimum Truck Travel Time (across all categories) & 6.5 & $72^{29}$ \\
\hline Maximum Truck Travel Time (across all categories) & 70.8 & $69^{29}$ \\
\hline $\begin{array}{c}\text { Standard Deviation of Total Truck Travel Time (across all } \\
\text { categories) }\end{array}$ & 15.3 & 10.129 \\
\hline Average Total Auto Travel Time (for entire peak period) & 8.4 & $<10^{30}$ \\
\hline Average Hour 1 (5:00 to 6:00) & 6.5 & $<10^{30}$ \\
\hline Average Hour 2 (6:00 to 7:00) & 8.1 & $<10^{30}$ \\
\hline Average Hour 3 (7:00 to 8:00) & 9.2 & $<10^{30}$ \\
\hline Average Hour 4 (8:00 to 9:00) & 8.5 & $<10^{30}$ \\
\hline
\end{tabular}


Table B-4: Web Survey Summary for Border Crossing Times for Autos, Ambassador Bridge U.S. Bound

\begin{tabular}{|c|c|c|}
\hline Time & Canadian Customs Website ${ }^{30}$ & U.S. Customs Website ${ }^{31}$ \\
\hline $5: 00$ to $6: 00$ & No Delay & No Delay \\
\hline $6: 00$ to $7: 00$ & No Delay & No Delay \\
\hline $7: 00$ to $8: 00$ & No Delay & No Delay \\
\hline $8: 00$ to $9: 00$ & No Delay & No Delay \\
\hline
\end{tabular}

Note: These observations were done over a period of 10 week days during April, 2005 and there was consistently no delay for auto crossings. No delay means a travel time of less than ten minutes from point of entry in the Canada to point of exit in U.S.

\section{Auto Travel Time vs Simulated Time}

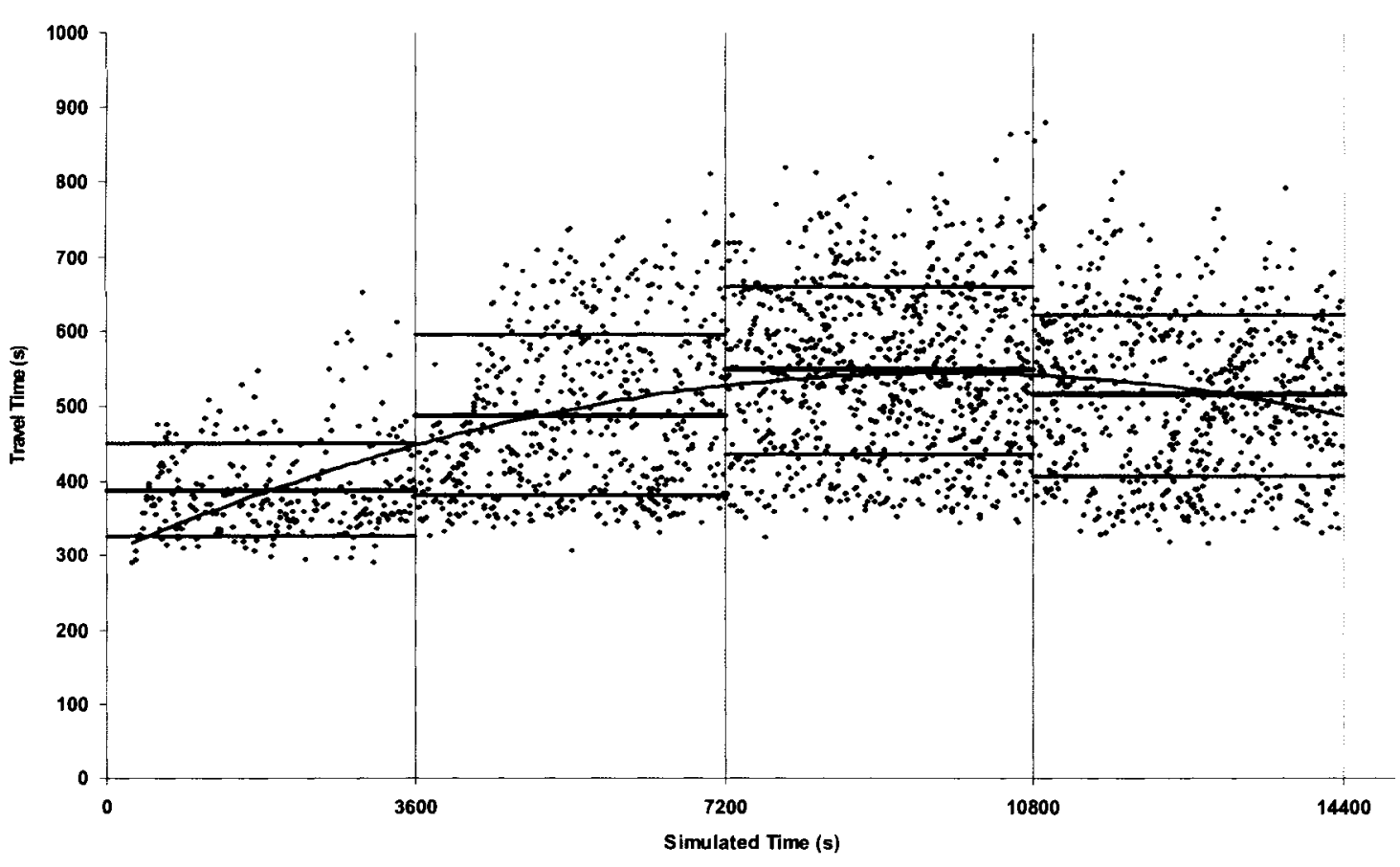

Overall trend line of average auto travel time

Average travel time by hour segment

Upper and lower standard deviation from mean travel time by hour segment

Figure B-3: Summary Of Total Auto Travel Times Output For Base-case Model, Ambassador Bridge, U.S. Bound 
Primay and Secondary Truck Travel Time vs Simulated Time

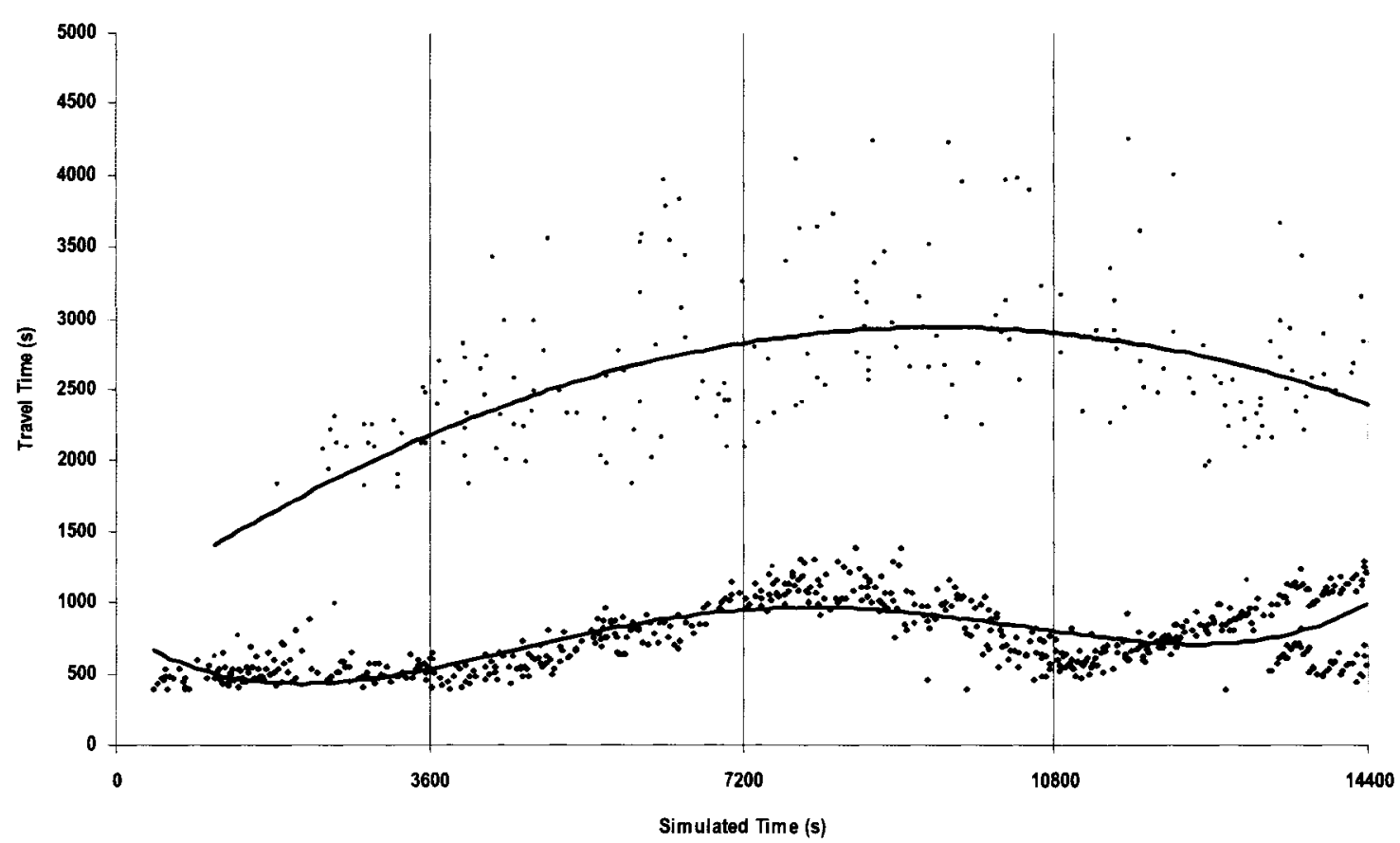

Overall trend line of average primary truck travel time

Overall trend line of average secondary truck travel time

Figure B-4: Summary Of Total Truck (Primary and Secondary) Travel Times Output For Base-case Model, Ambassador Bridge, U.S. Bound 


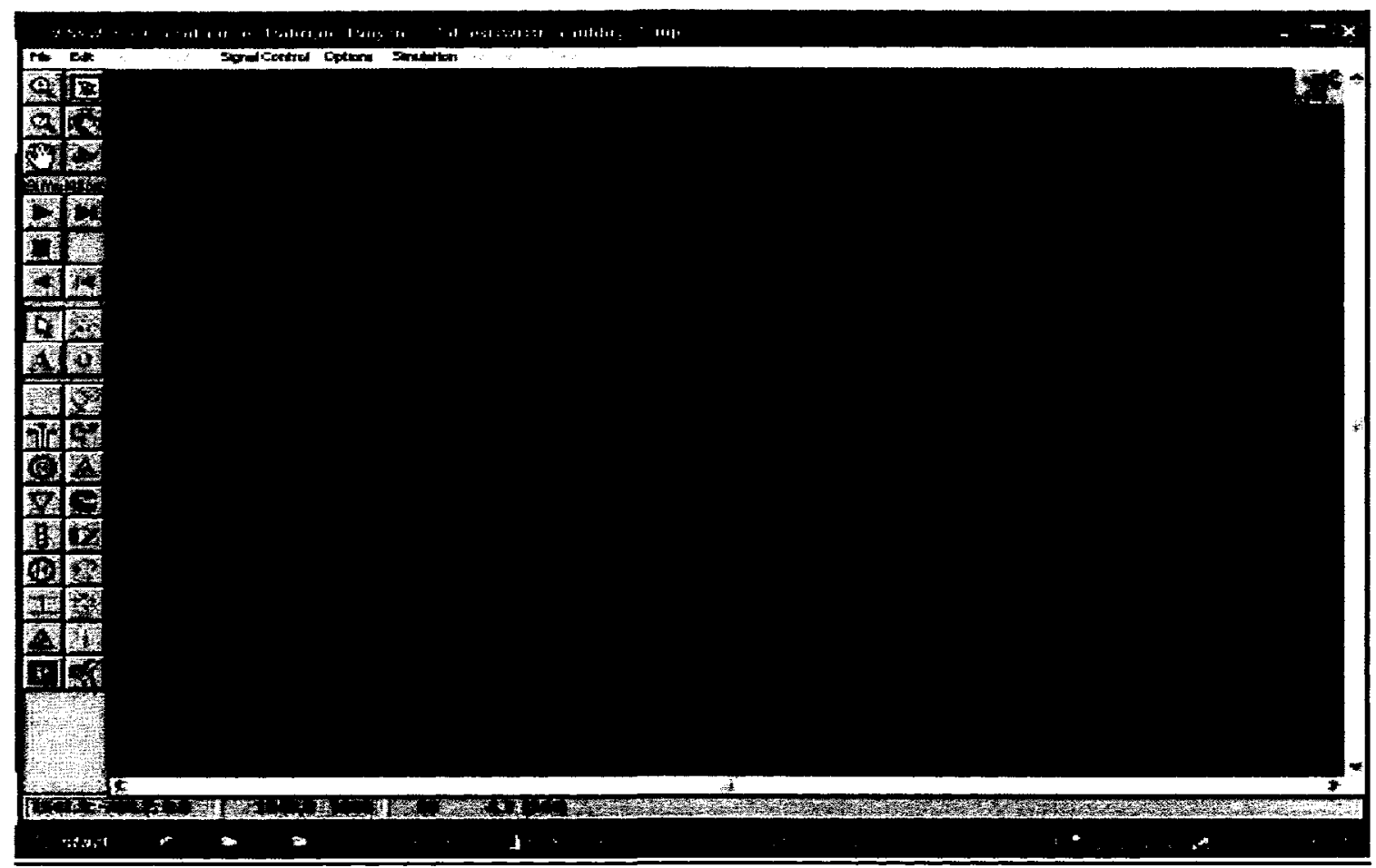

\section{Figure B-5: Ambassador Bridge US- Bound Canadian Side}

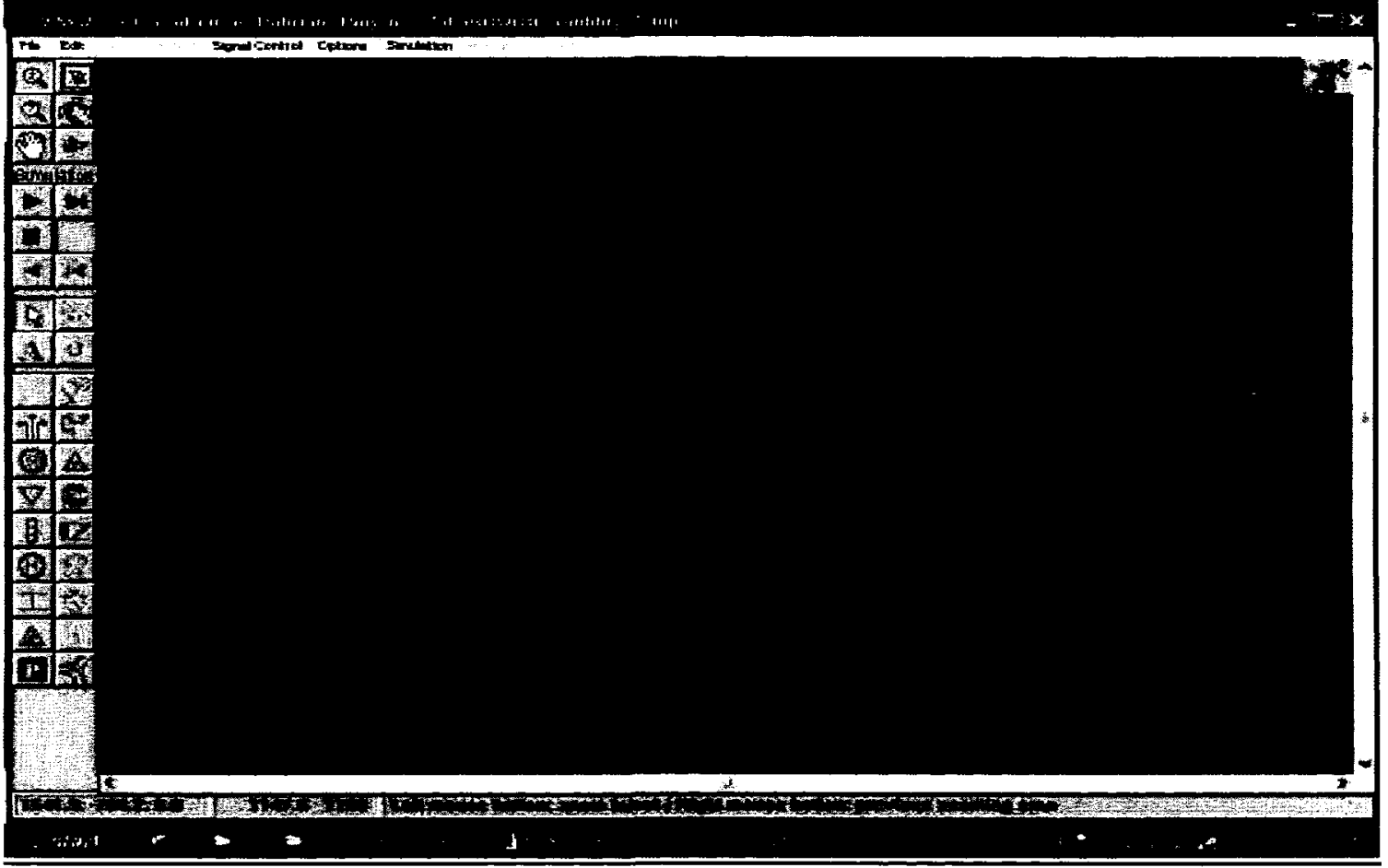

Figure B-6: Ambassador Bridge U.S. - Bound, U.S. Side 
Table B-5: Summary of Model Inputs and Outputs for VISSIM Model - No QJL Scenario

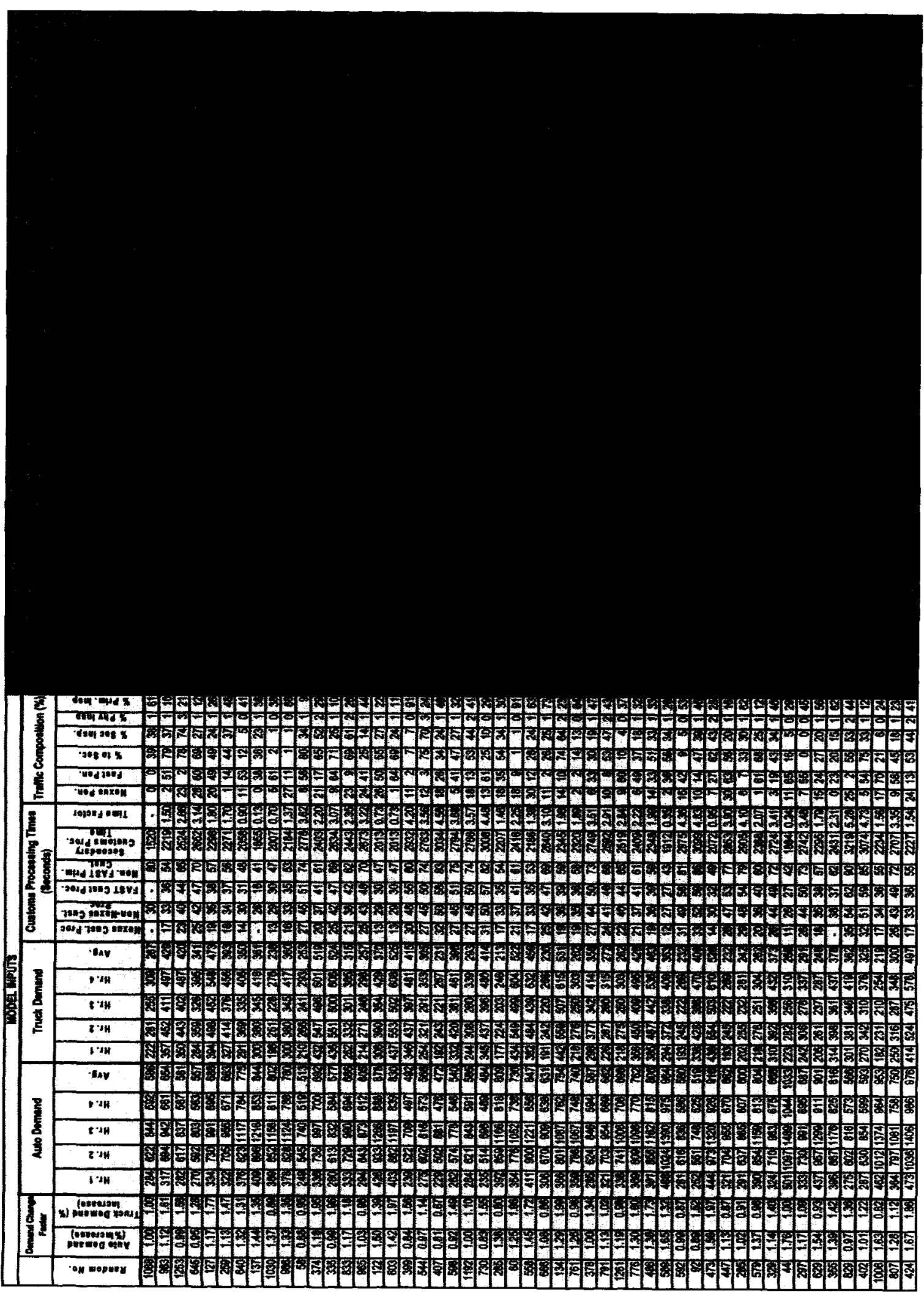


Table B-5: Summary of Model Inputs and Outputs for VISSIM Model - No QJL Scenario (cont'd)

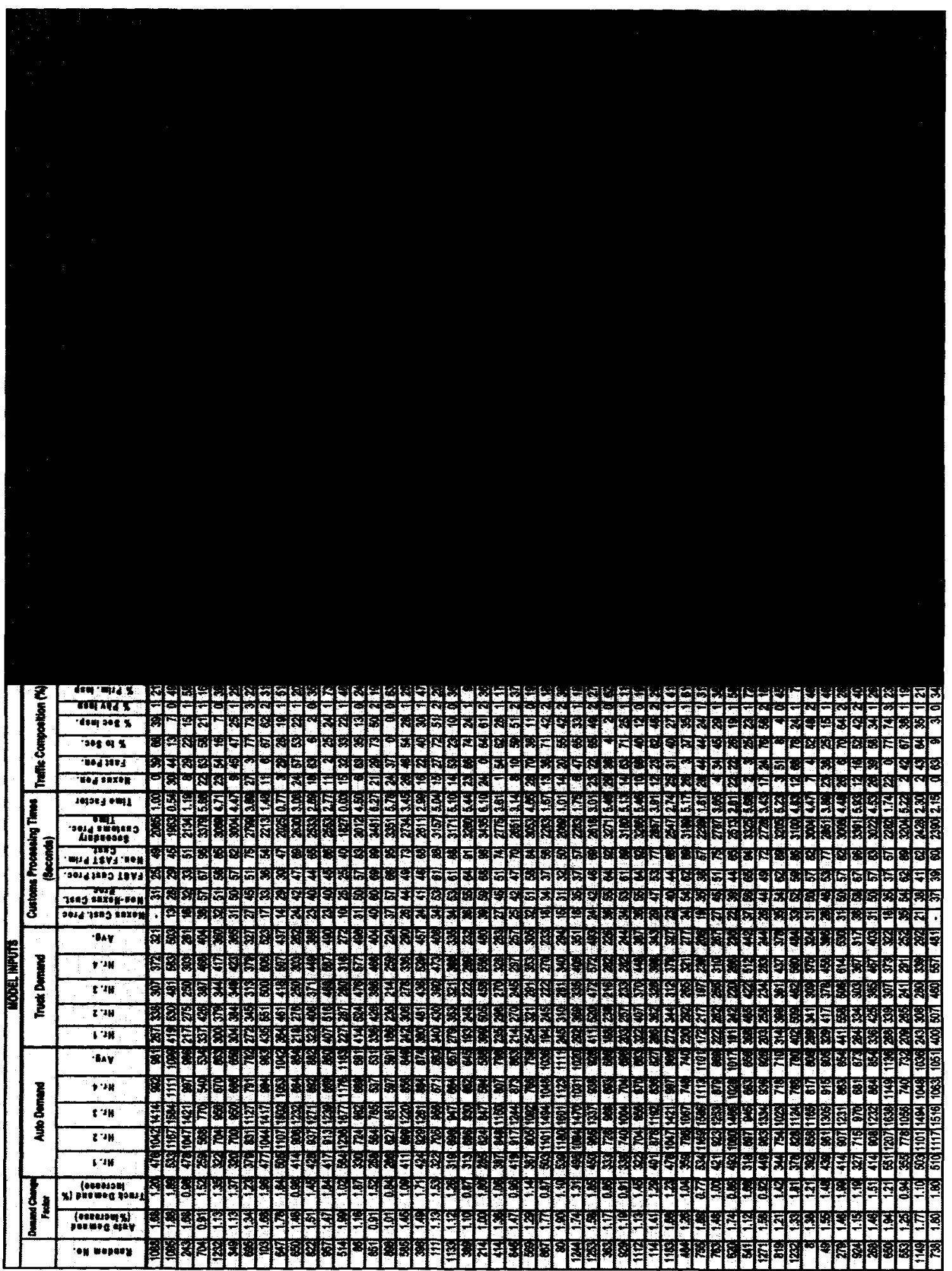


Table B-5: Summary of Model Inputs and Outputs for VISSIM Model - No QJL Scenario (cont'd)

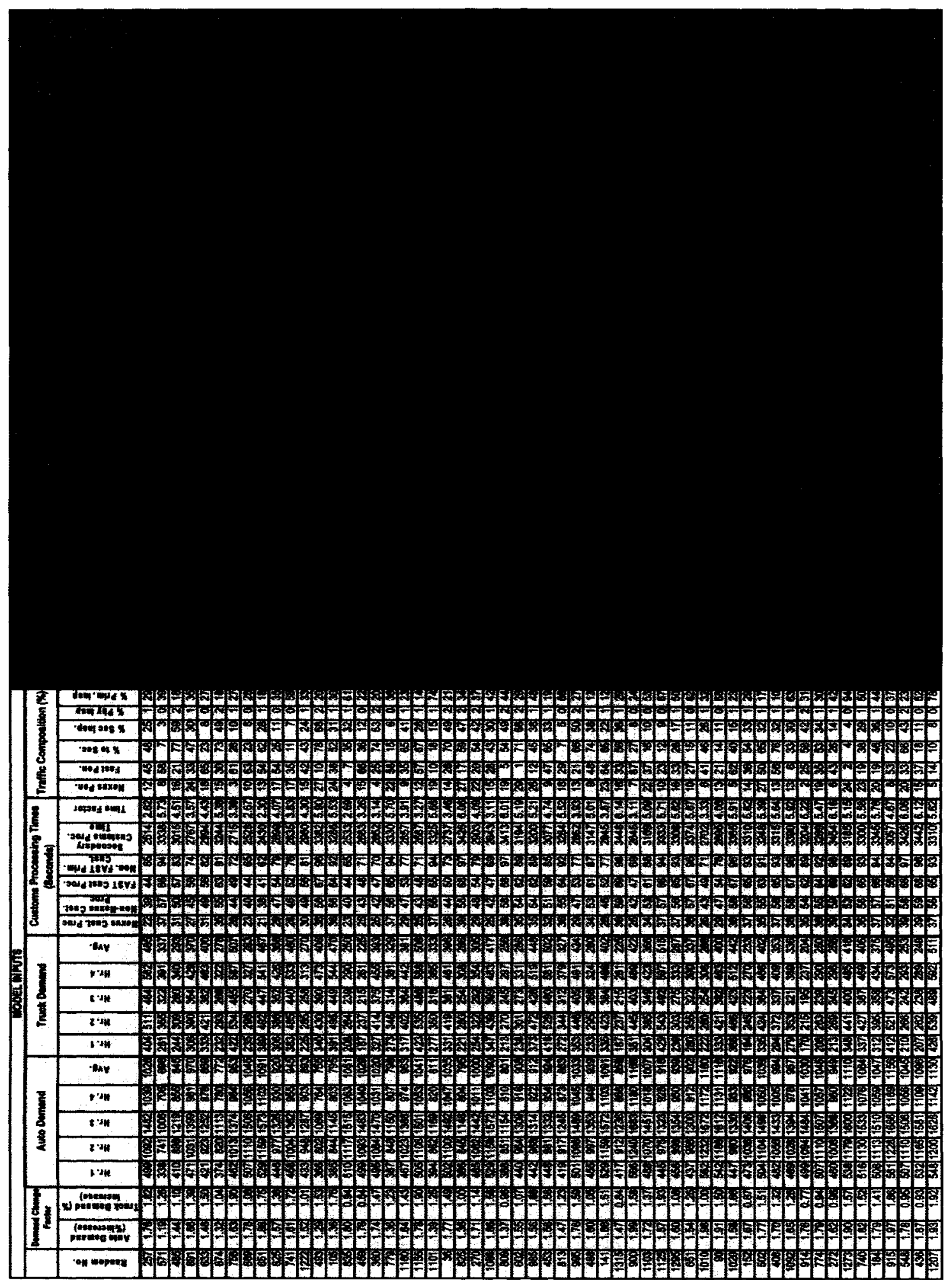


Table B-6: Summary of Model Inputs and Outputs for VISSIM Model - QJL Scenario

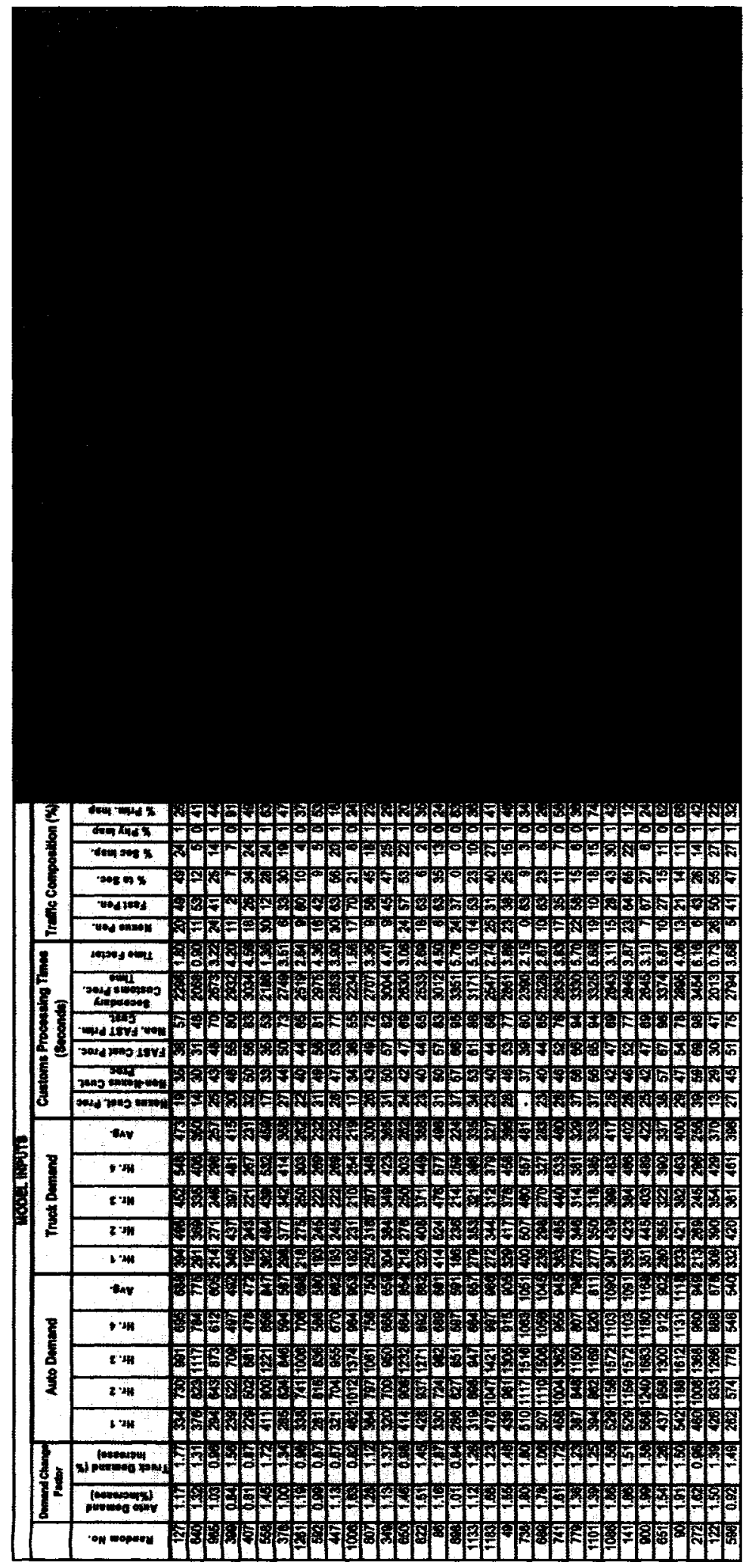




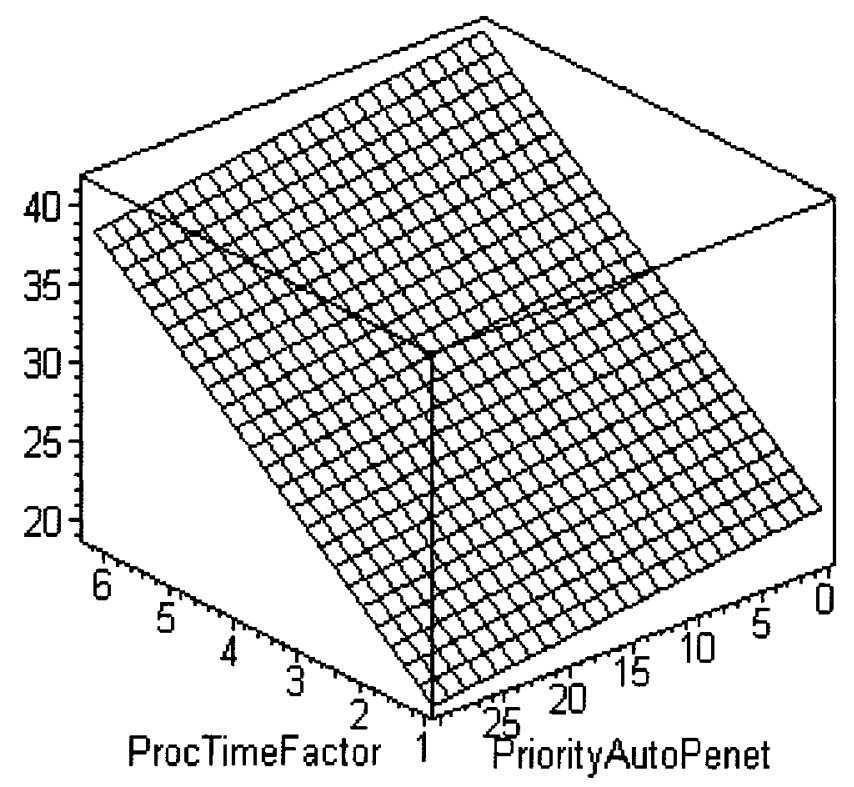

$z$ - Average Overall Auto Travel Time (minutes) Average Hourly Auto Demand $=1168$

\section{Figure B-7: Overall Average Auto Travel Time - No QJL Scenario}

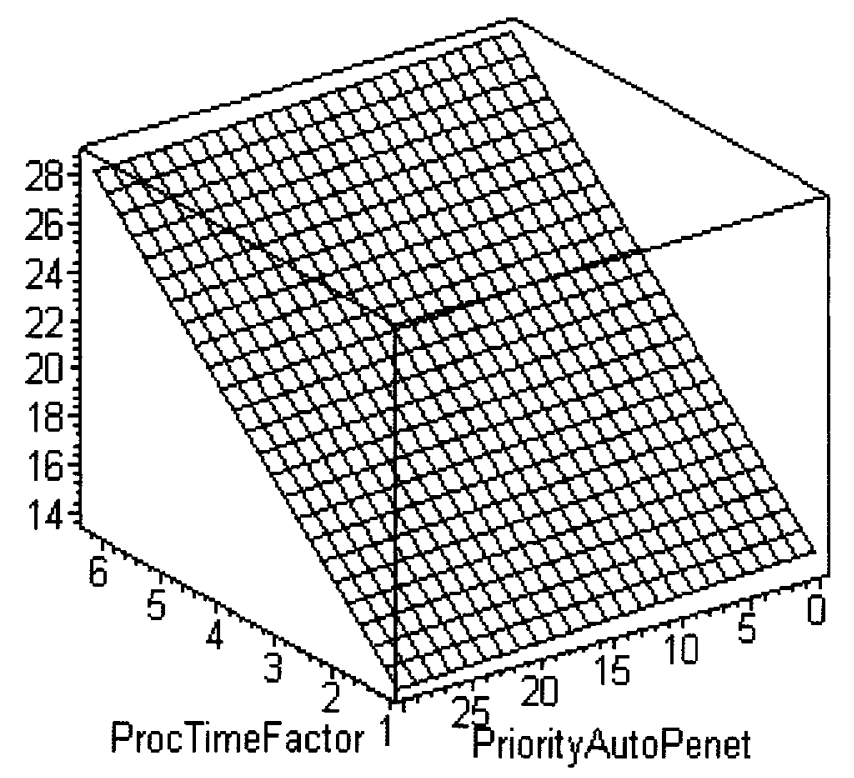

z - Average Overall Auto Travel Time (minutes)

Average Hourly Auto Demand $=1168$

Figure B-8: Overall Average Auto Travel Time - QJL Scenario 


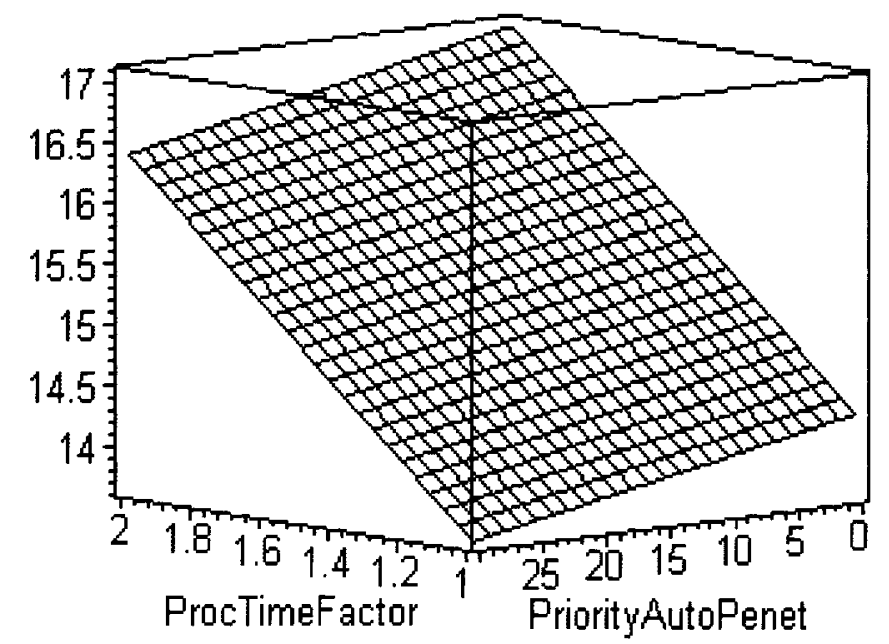

z - Average Overall Auto Travel Time (minutes) Average Hourly Auto Demand $=1168$

Figure B-9: Overall Average Auto Travel Time - QJL Scenario (with unit scale for ProcTimeFactor)

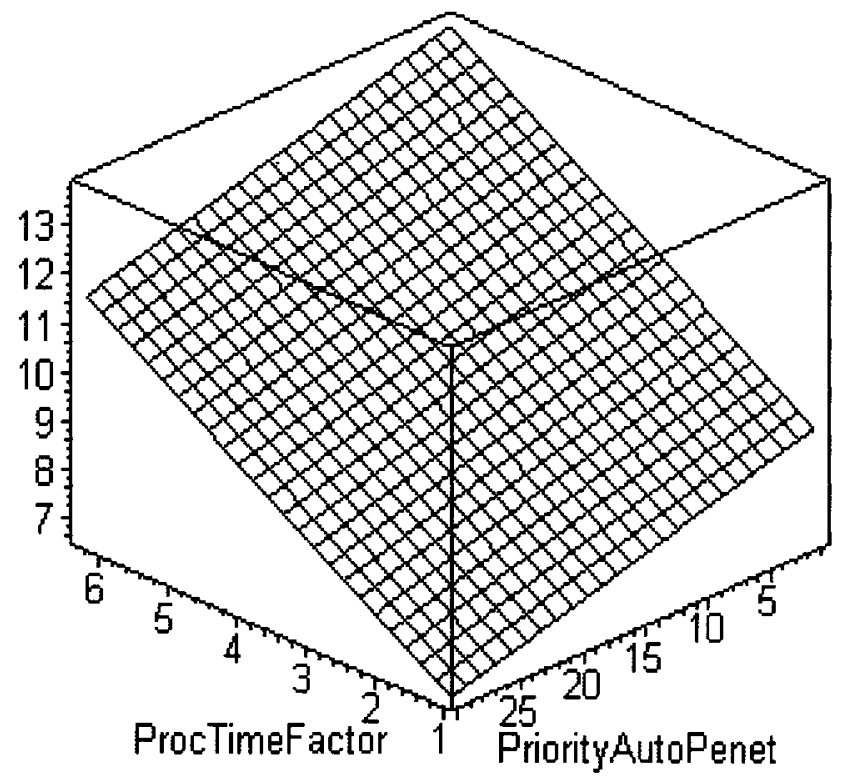

$z$ - Average Overall Auto Travel Time (minutes)

Average Hourly Auto Demand $=1168$

Figure B-10: Overall Average Auto Travel Time - No QJL - QJL Scenario 


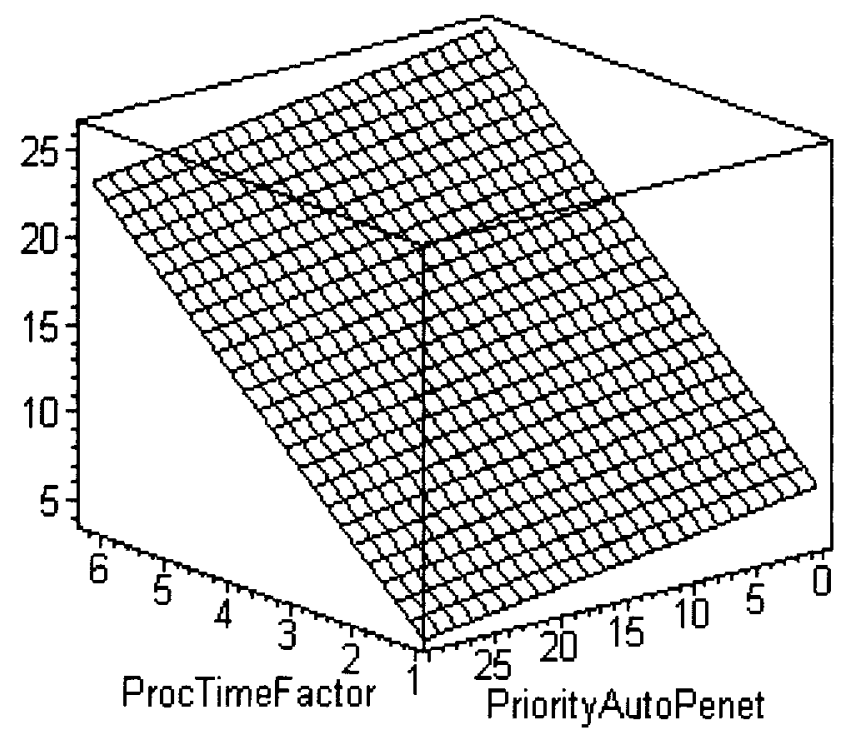

z - Average Overall Auto Travel Time (minutes) Average Hourly Auto Demand $=586$

Figure B-11: Overall Average Auto Travel Time - Base-case Demand Scenario 

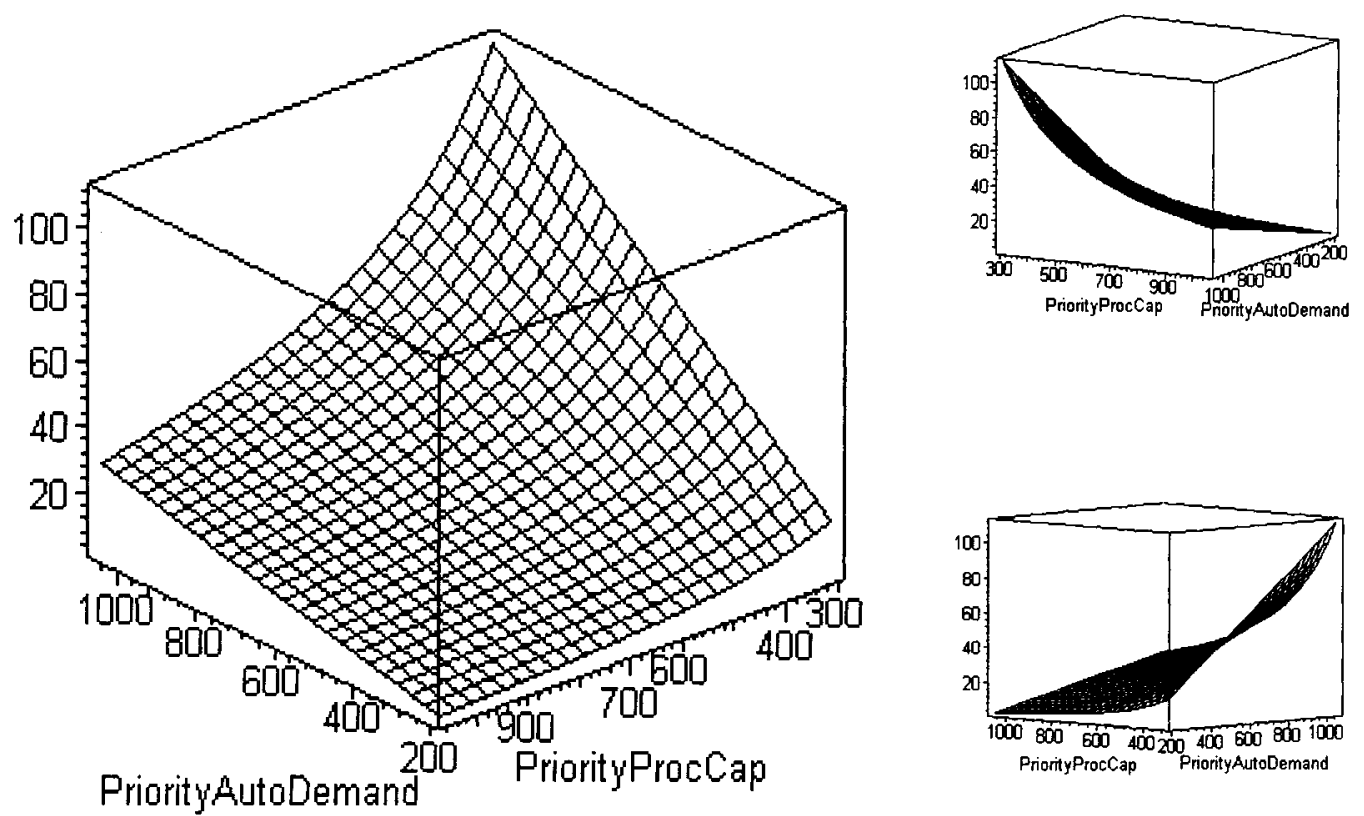

z - Average Priority Auto Travel Time (minutes)

Figure B-12: Average Priority Auto Travel Time - No QJL Scenario

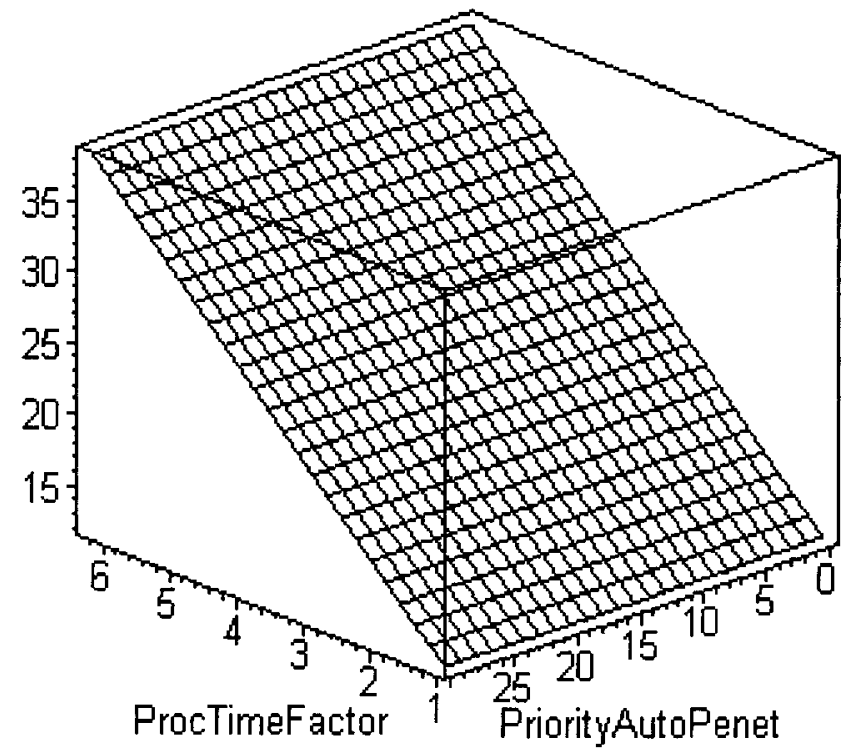

$z$ - Average Priority Auto Travel Time (minutes)

Average Hourly Demand $=1168$

Figure B-13: Average Priority Auto Travel Time - No QJL Scenario 


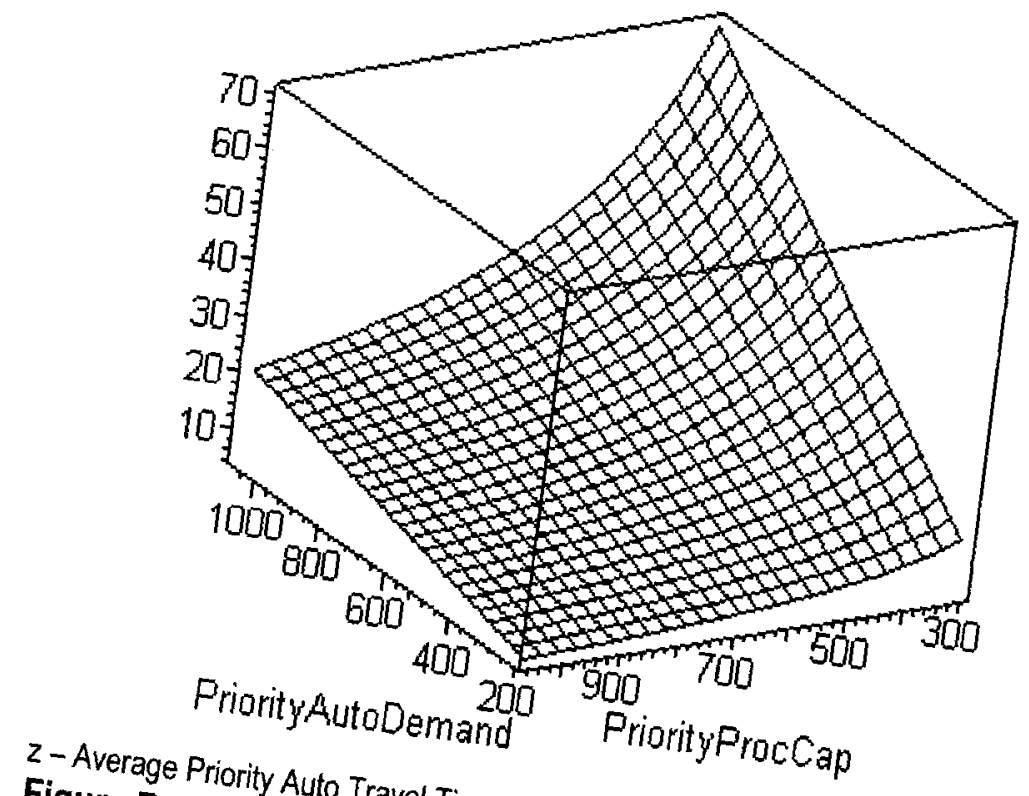

Figure B-14: Average Prel Time (minutes)
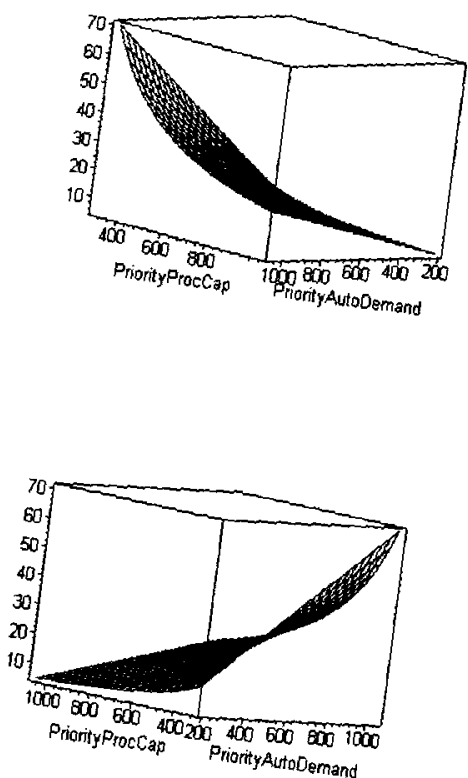

Priority Auto Travel Time - QJL Scenario

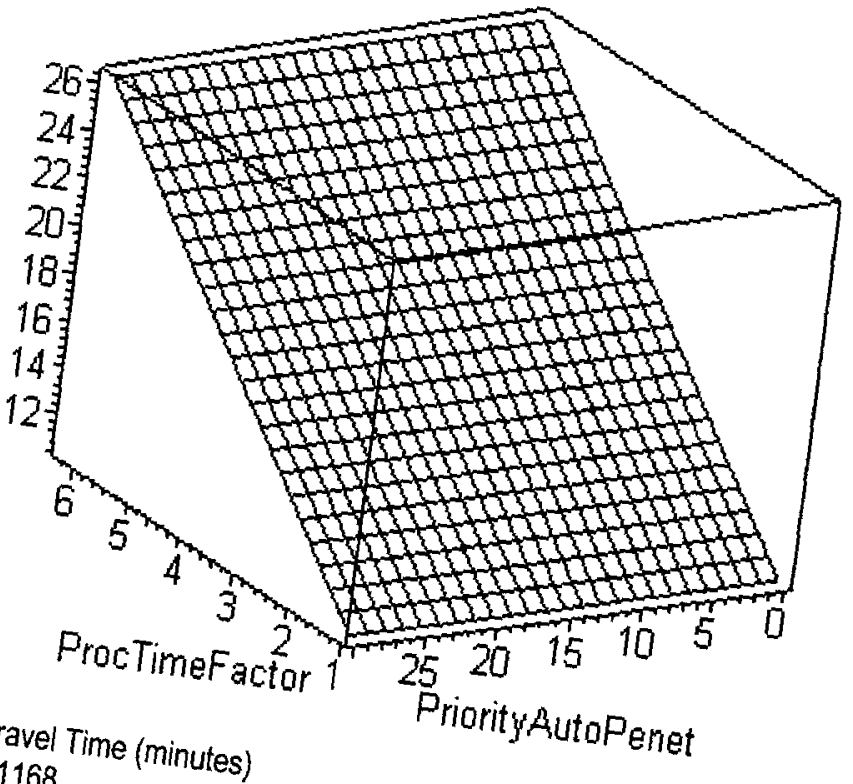

Average Hourly Demand $=1168$
Figure B-15: Averame (minutes)

PriorityAutopenet

Priority Auto Travel Time - QJL Scenario

Reproduced with permission of the copyright owner. Further reproduction prohibited without permission. 

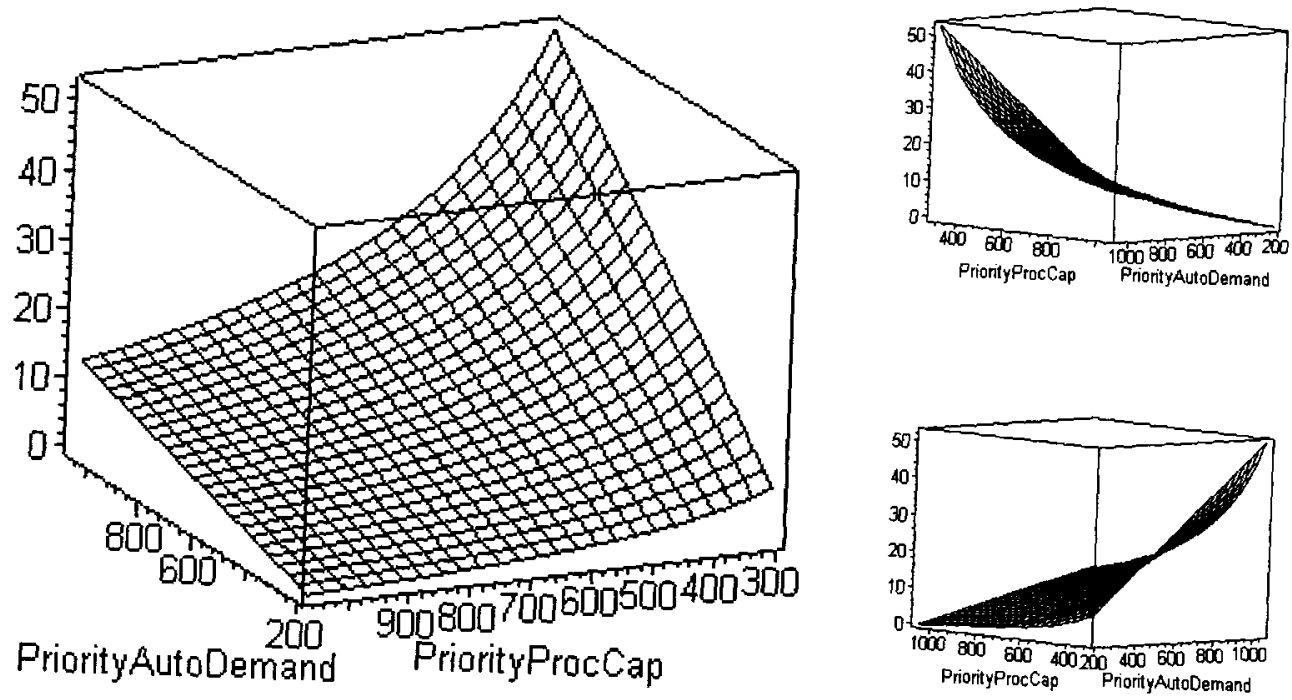

$z$ - Average Priority Auto Travel Time Difference (minutes)

Figure B-16: Average Priority Auto Travel Time - No QJL - QJL Scenario

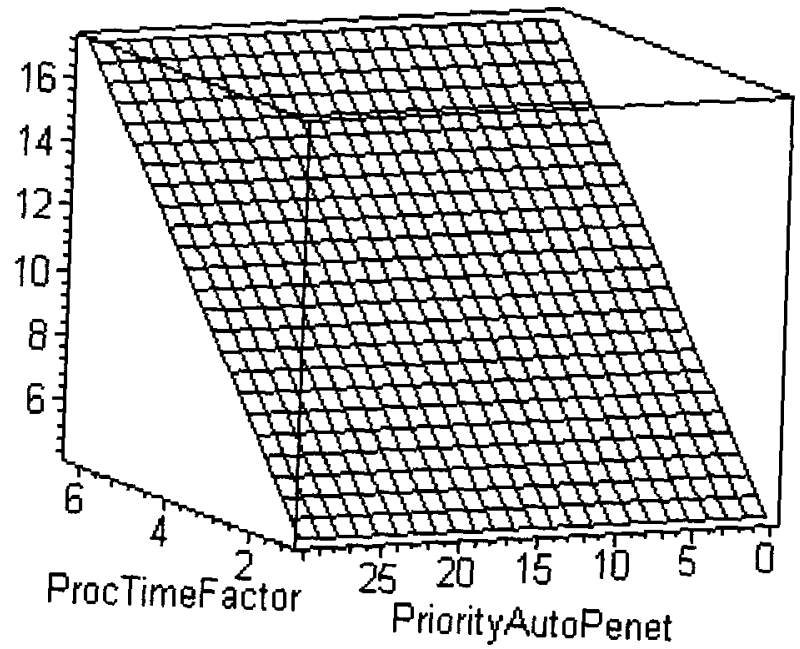

z-Average Priority Auto Travel Time Difference (minutes)

Average Hourly Auto Demand $=1168$

Figure B-17: Average Priority Auto Travel Time - No QJL - QJL Scenario 

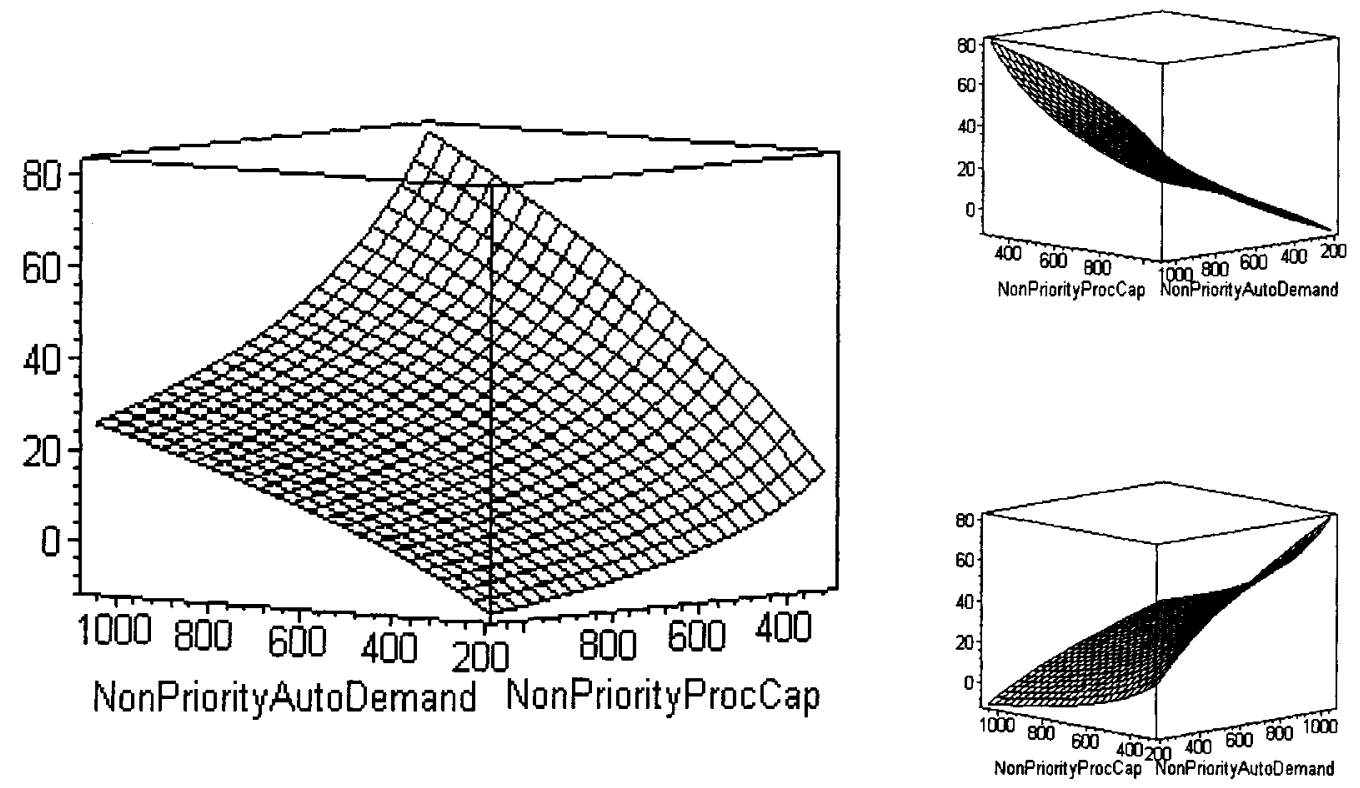

Z - Average Non-Priority Auto Travel Time (minutes)

Figure B-18: Average Non-Priority Auto Travel Time - No QJL Scenario

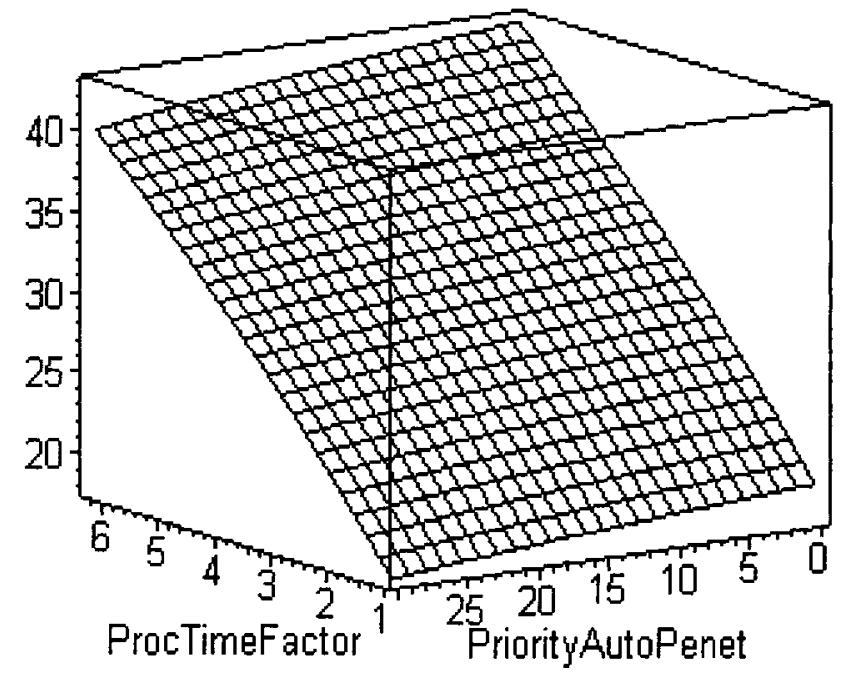

z - Average Non-priority Auto Travel Time (minutes)

Average Hourly Auto Demand $=1168$

Figure B-19: Average Non-Priority Auto Travel Time - No QJL Scenario 

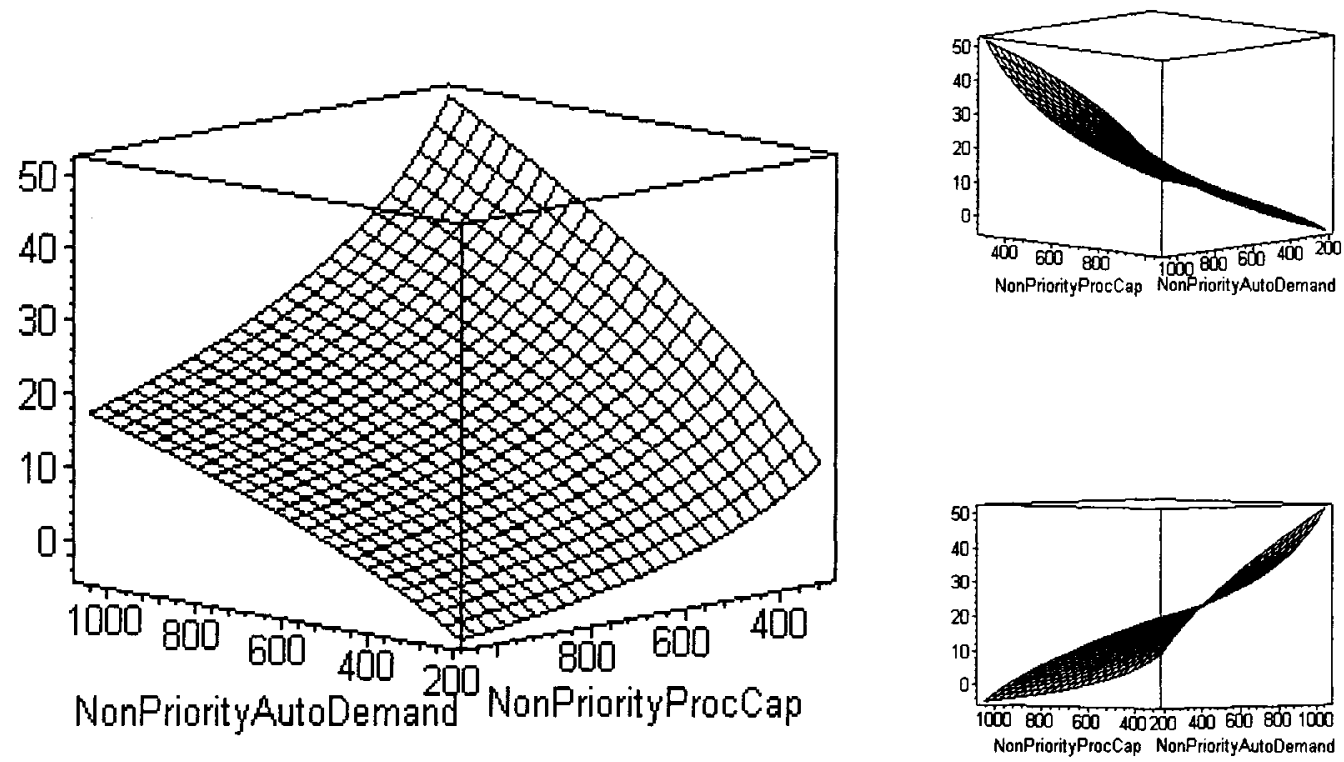

$z$ - Average Non-Priority Auto Travel Time (minutes)

Figure B-20: Average Non-Priority Auto Travel Time - QJL Scenario

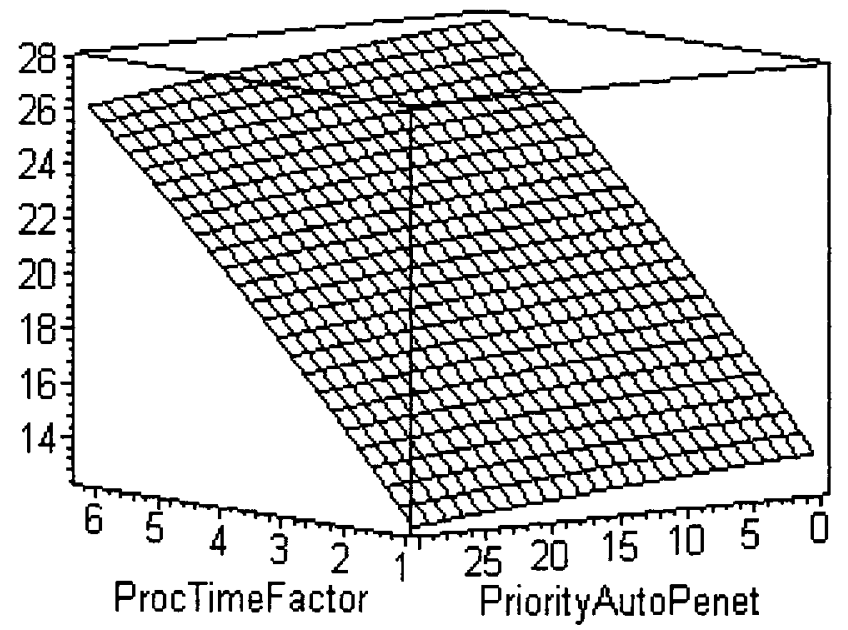

z - Average Non-priority Auto Travel Time (minutes)

Average Hourly Auto Demand $=1168$

Figure B-21: Average Non-Priority Auto Travel Time - QJL Scenario 

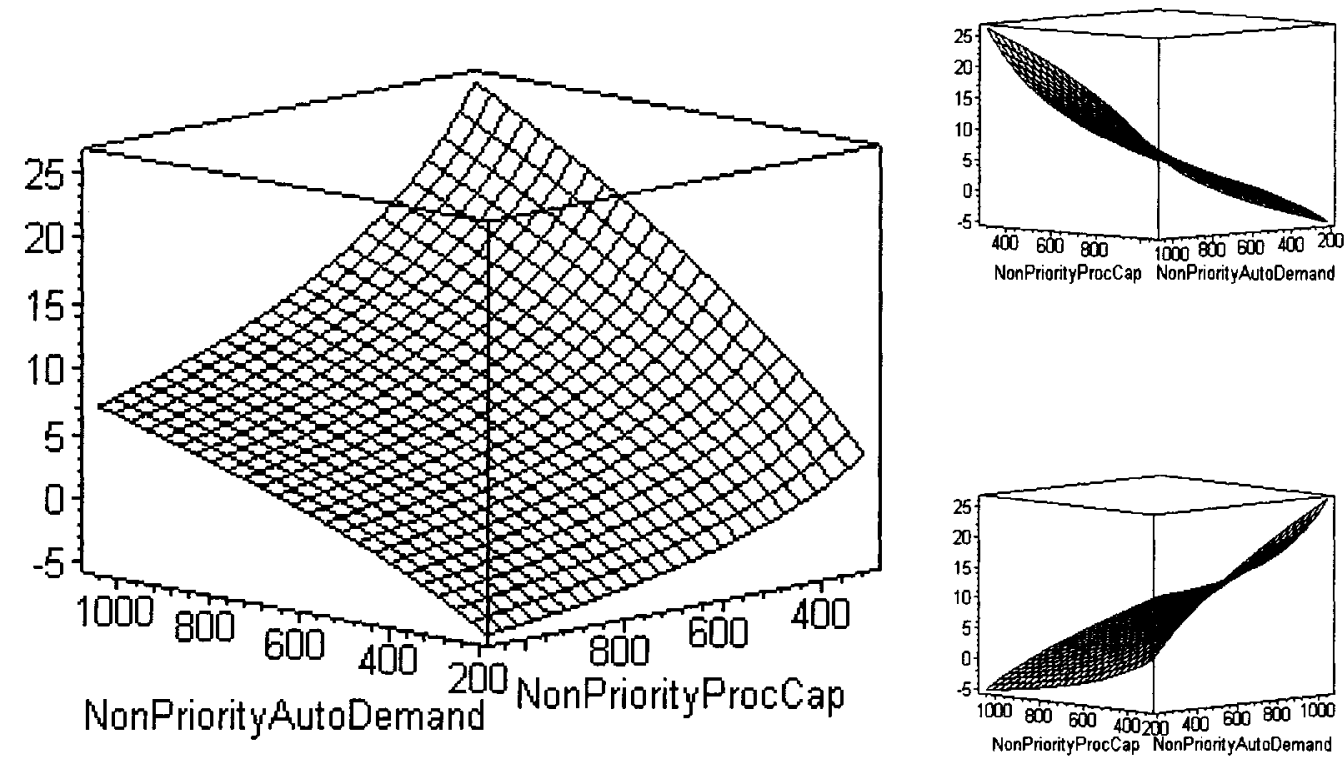

z - Average Non-priority Auto Travel Time Difference (minutes)

Figure B-22: Average Non-priority Auto Travel Time - No QJL - QJL Scenario

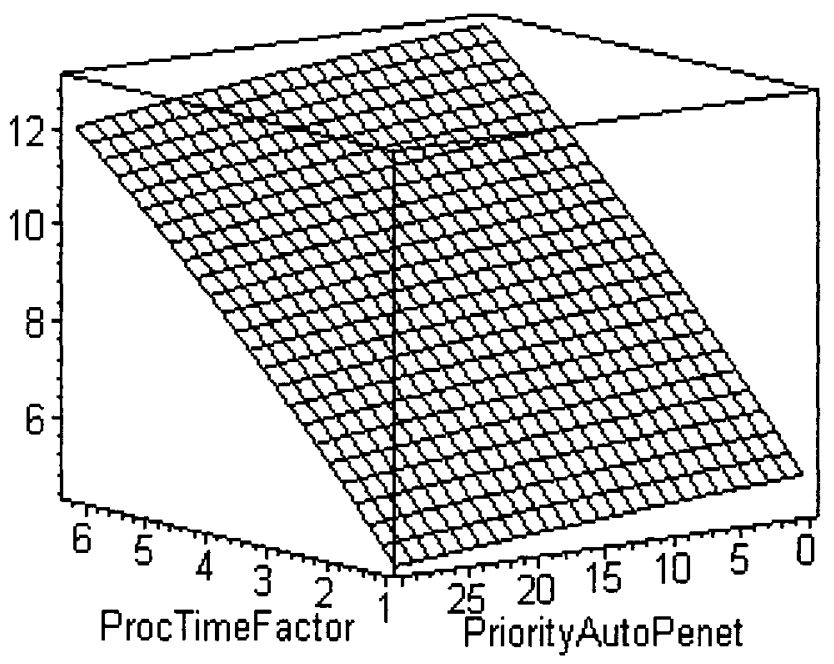

z - Average Non-priority Auto Travel Time Difference (minutes)

Average Hourly Auto Demand $=1168$

Figure B-23: Average Non-priority Auto Travel Time - No QJL - QJL Scenario 


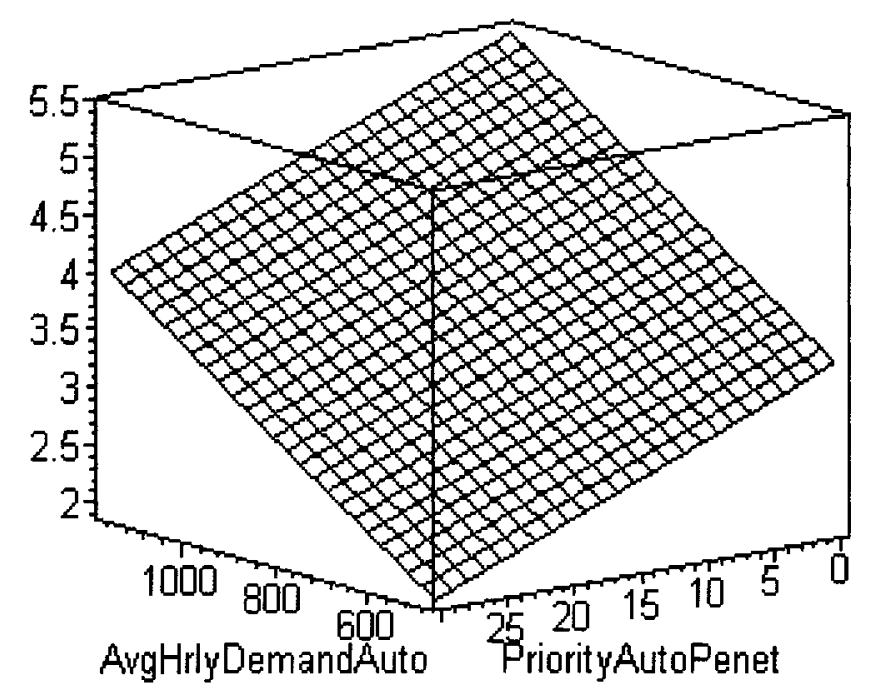

z - Average Priority Auto Travel Time Advantage (minutes)

Process Time Factor $=6.27$

Figure B-24: Average Priority Auto Travel Time Advantage - No QJL Scenario

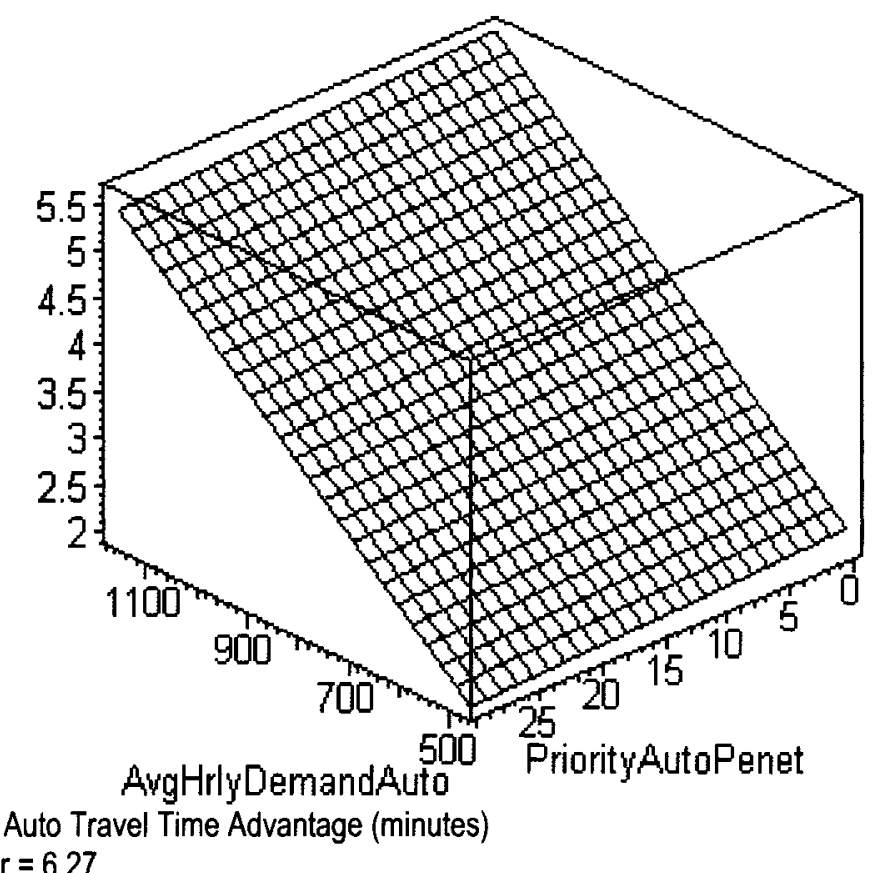

Process Time Factor $=6.27$

Figure B-25: Average Priority Auto Travel Time Advantage - QJL Scenario 


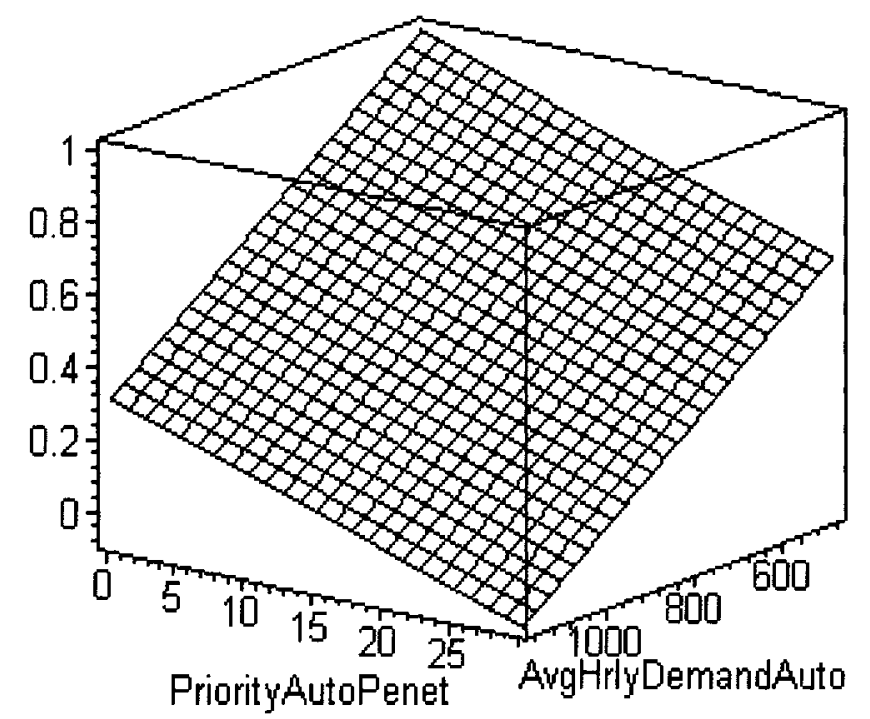

z - Average Priority Auto Travel Time Advantage (minutes)

Process Time Factor $=6.27$

Figure B-26: Average Priority Auto Travel Time Advantage - No QJL - QJL Scenario 


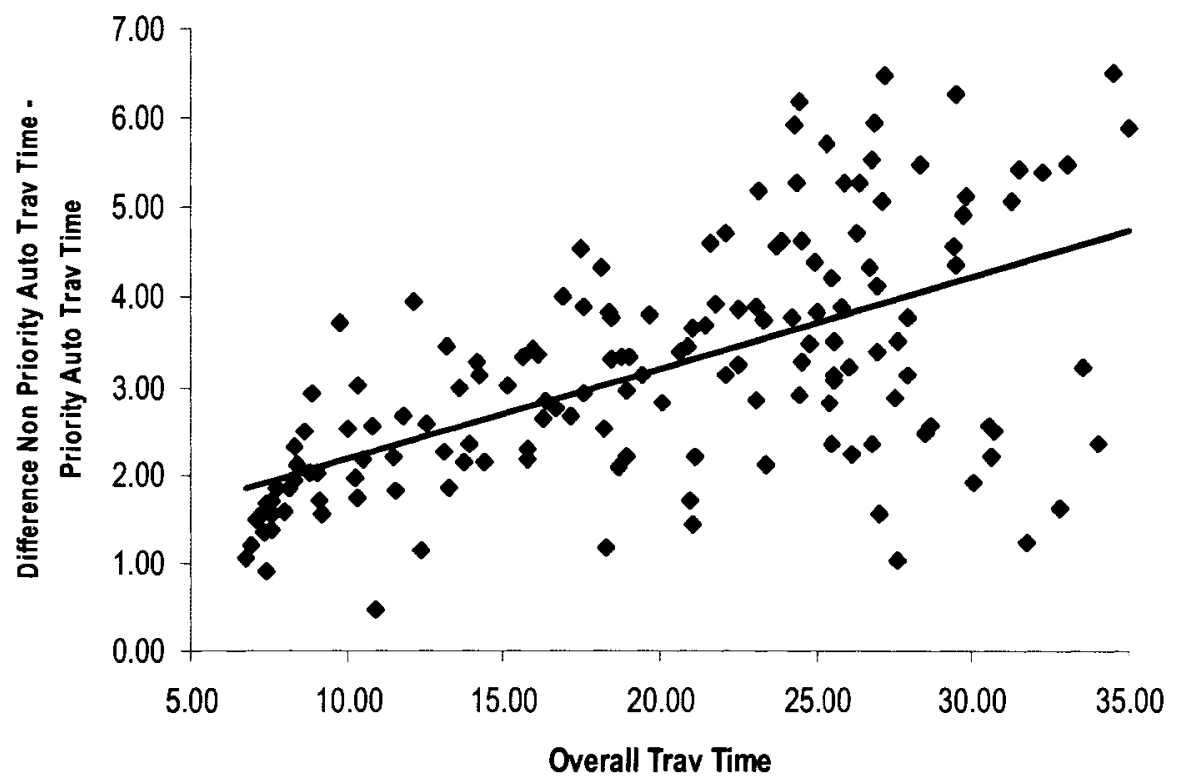

Figure B-27: Average Priority Auto Travel Time Advantage - No QJL Scenario

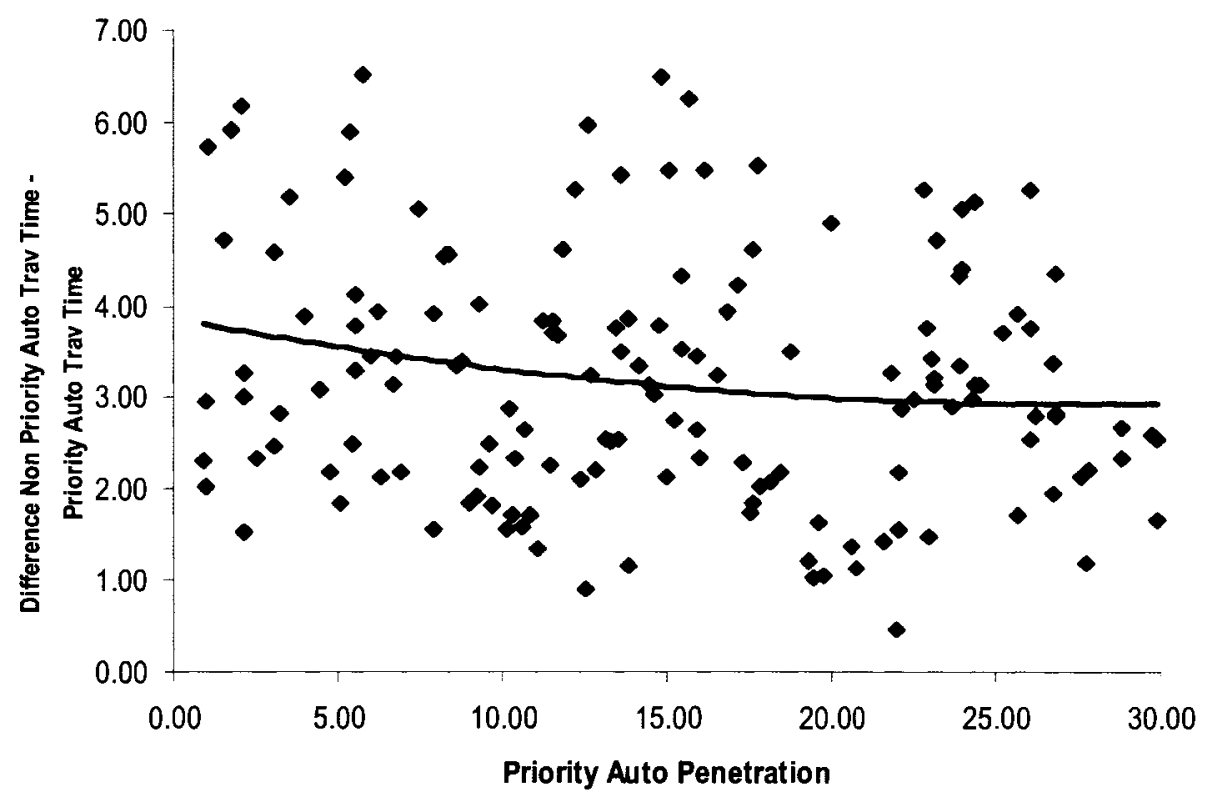

Figure B-28: Average Priority Auto Travel Time Advantage - No QJL Scenario 


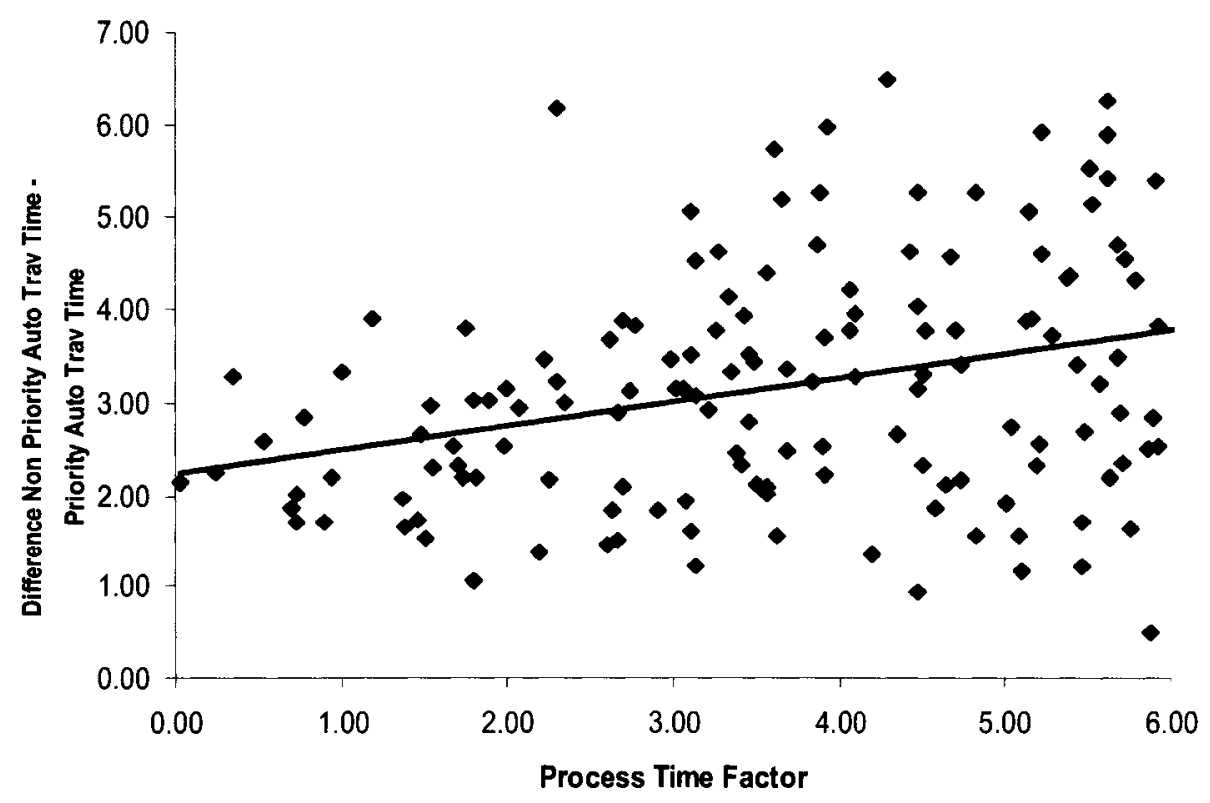

Figure B-29: Average Priority Auto Travel Time Advantage - No QJL Scenario 


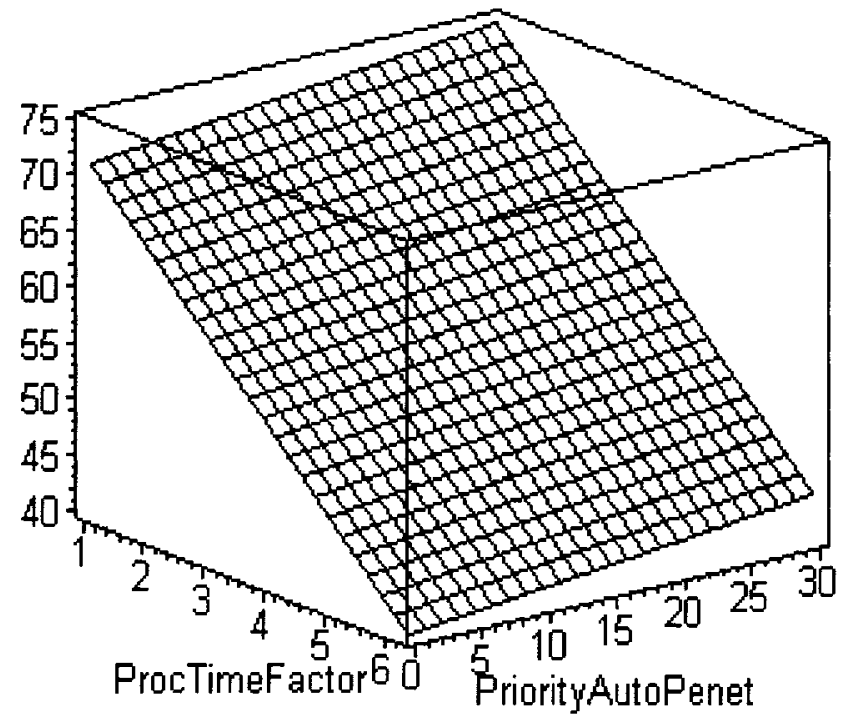

z - Overall Auto Percent of Demand Serviced Average Hourly Auto Demand $=1168$

Figure B-30: Overall Auto Percent of Demand Serviced - No QJL Scenario

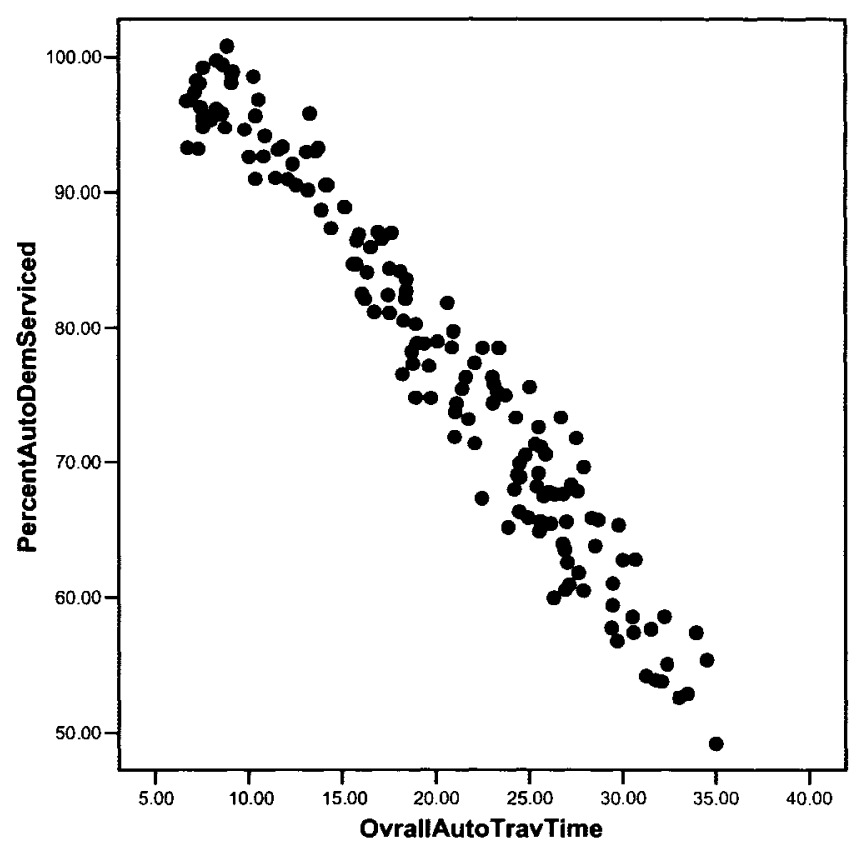

Figure B-31: Overall Auto Travel Time vs Percent Overall Auto Demand Serviced - No QJL $\underline{\text { Scenario }}$ 


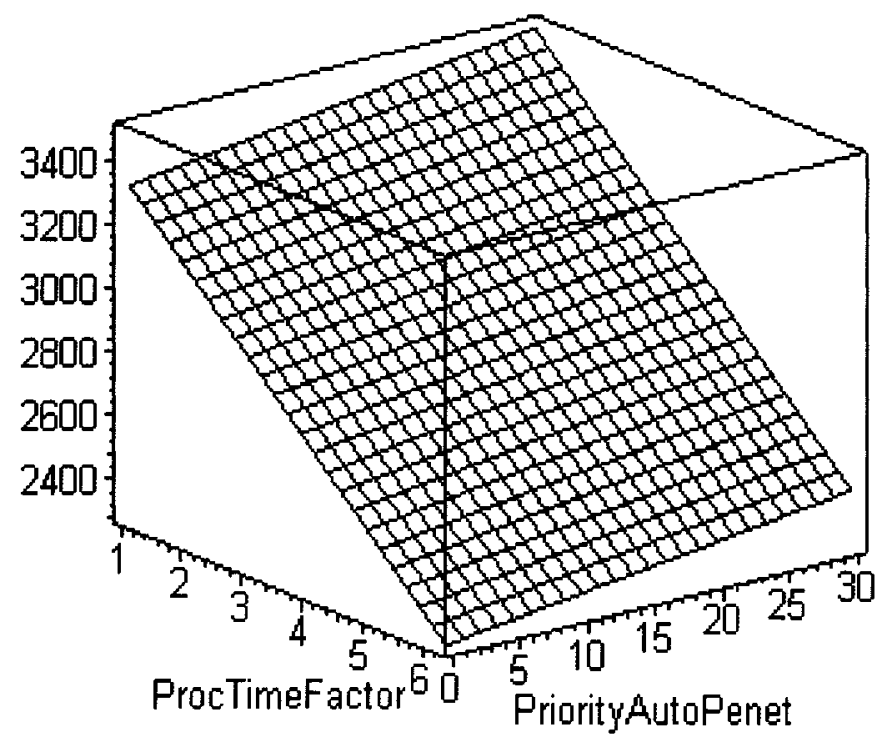

z - Auto Throughput (4 - hour)

Average Hourly Auto Demand $=1168$

Figure B-32: Auto Throughput - No QJL Scenario

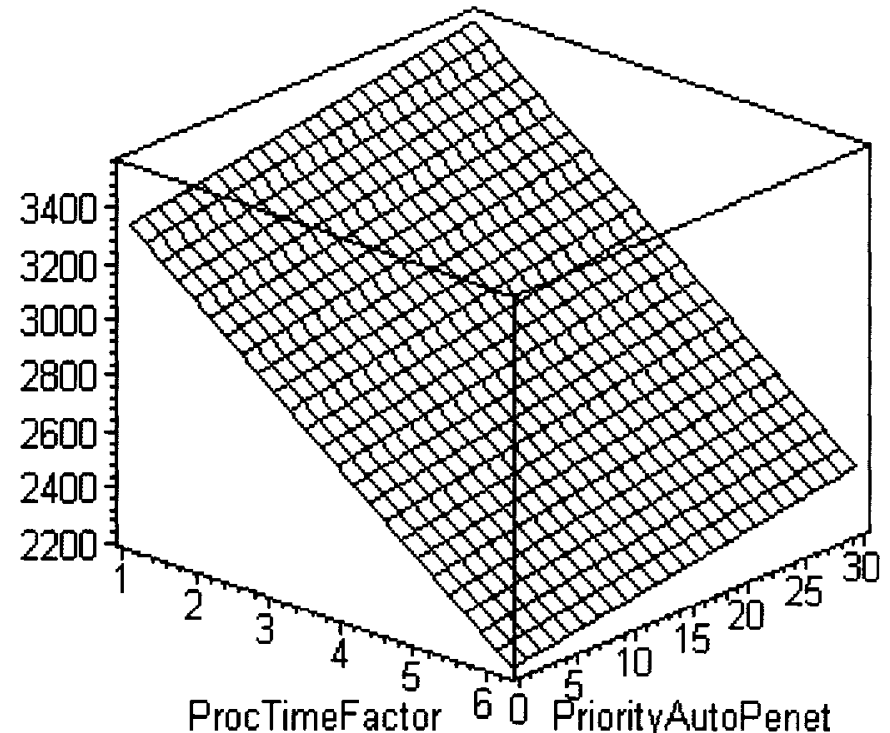

z - Auto Throughput (4 - hour)

Average Hourly Auto Demand $=1168$

Figure B-33: Auto Throughput - QJL Scenario 


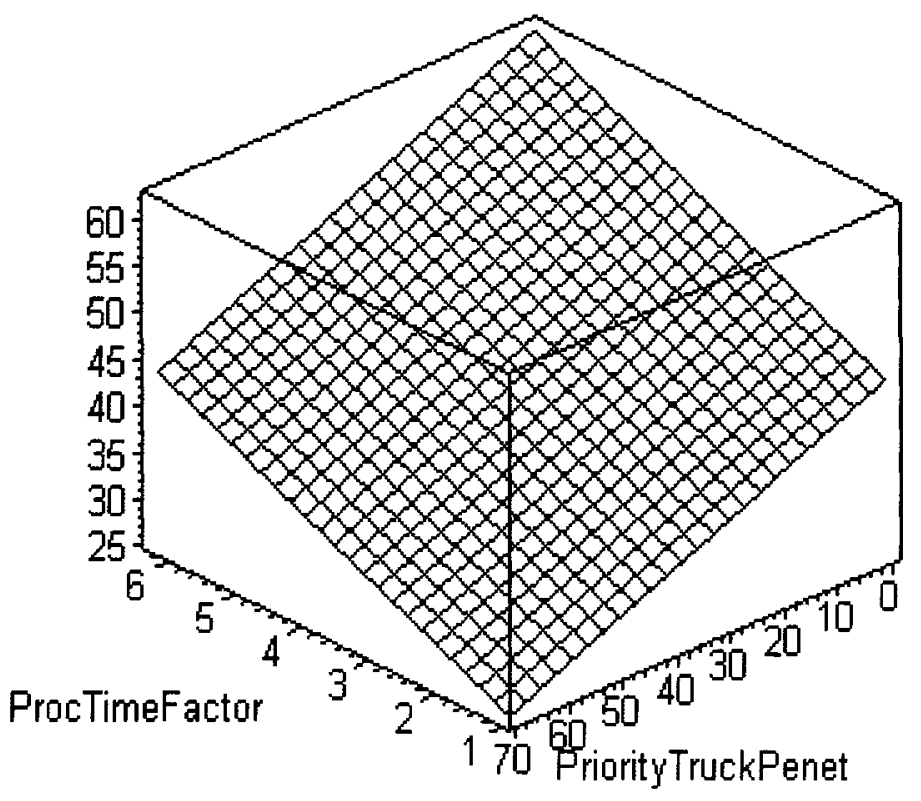

z - Average Overall Truck Travel Time

Average Hourly Truck Demand $=531$

Percent Secondary Truck $=20$

Figure B-34: Overall Average Truck Travel Time - No QJL Scenario

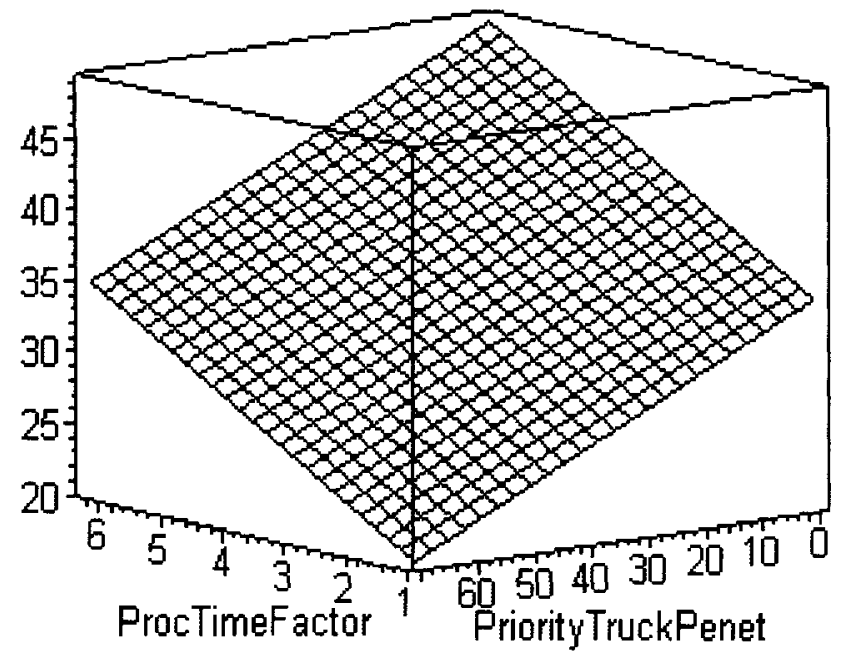

z - Average Overall Truck Travel Time

Average Hourly Truck Demand $=531$

Percent Secondary Truck $=20$

Figure B-35: Overall Average Truck Travel Time - QJL Scenario 


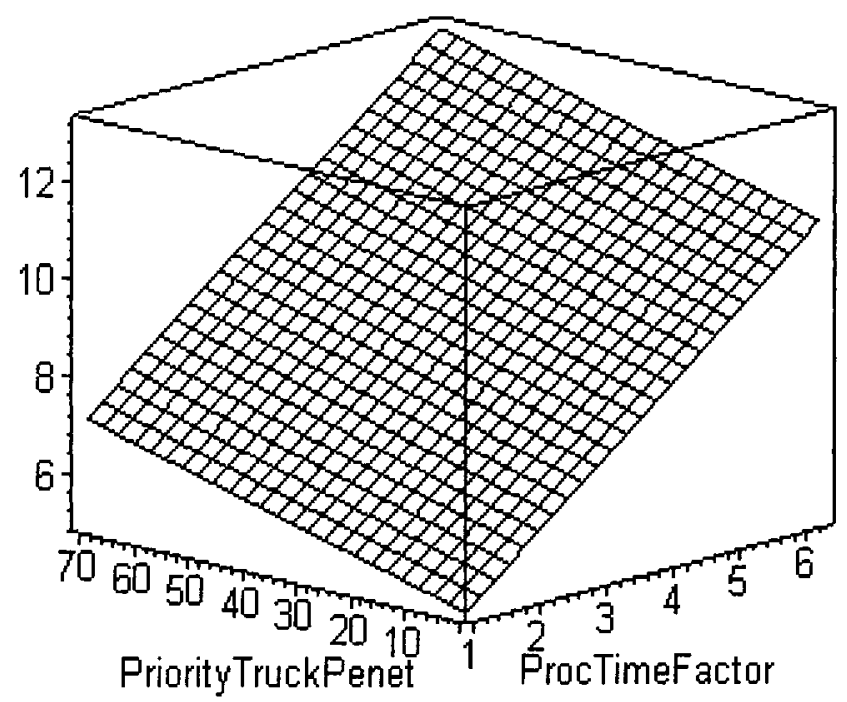

z - Average Overall Truck Travel Time

Average Hourly Truck Demand $=531$

Percent Secondary Truck $=20$

Figure B-36: Overall Average Truck Travel Time - No QJL-QJL Scenario
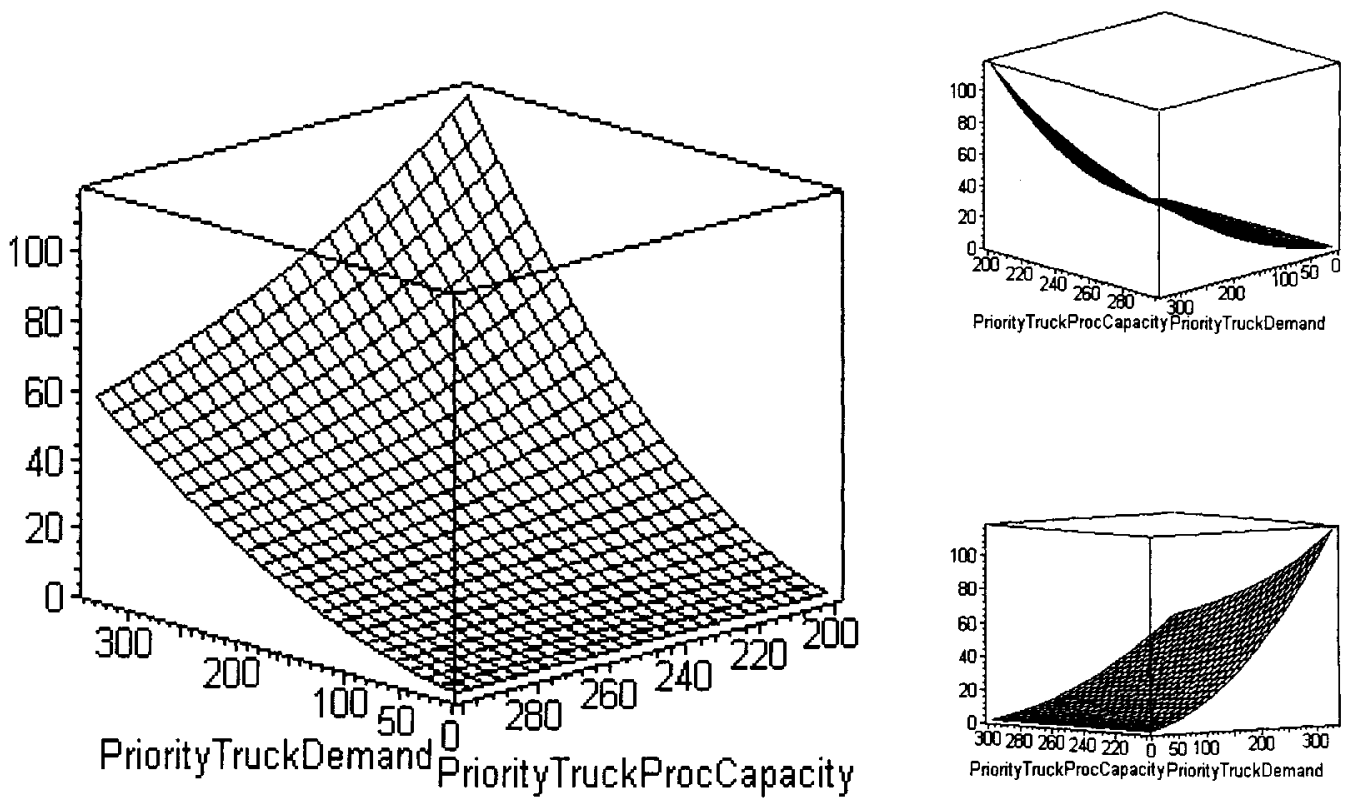

z - Average Priority Truck Travel Time

Figure B-37: Average Priority Truck Travel Time - No QJL Scenario 

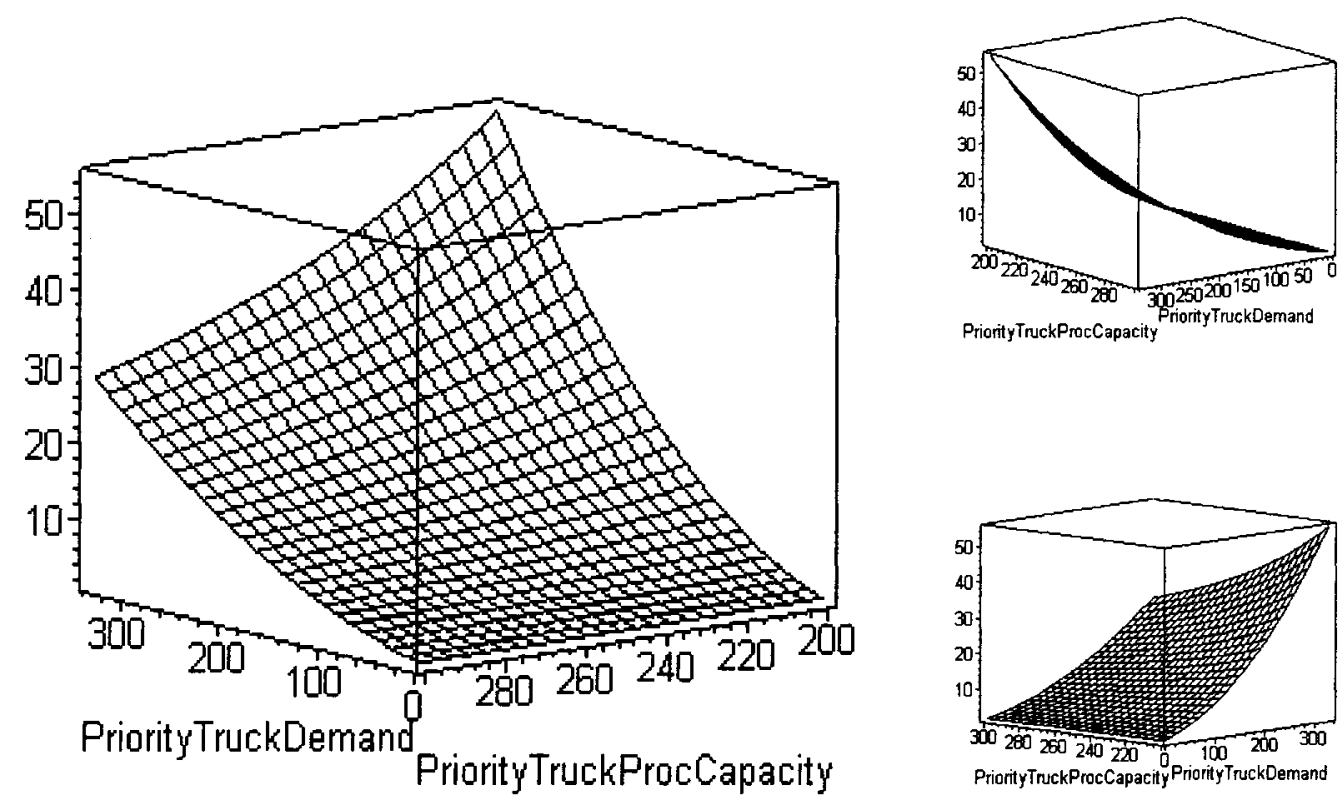

z - Average Priority Truck Travel Time

Figure B-38: Average Priority Truck Travel Time - QJL Scenario
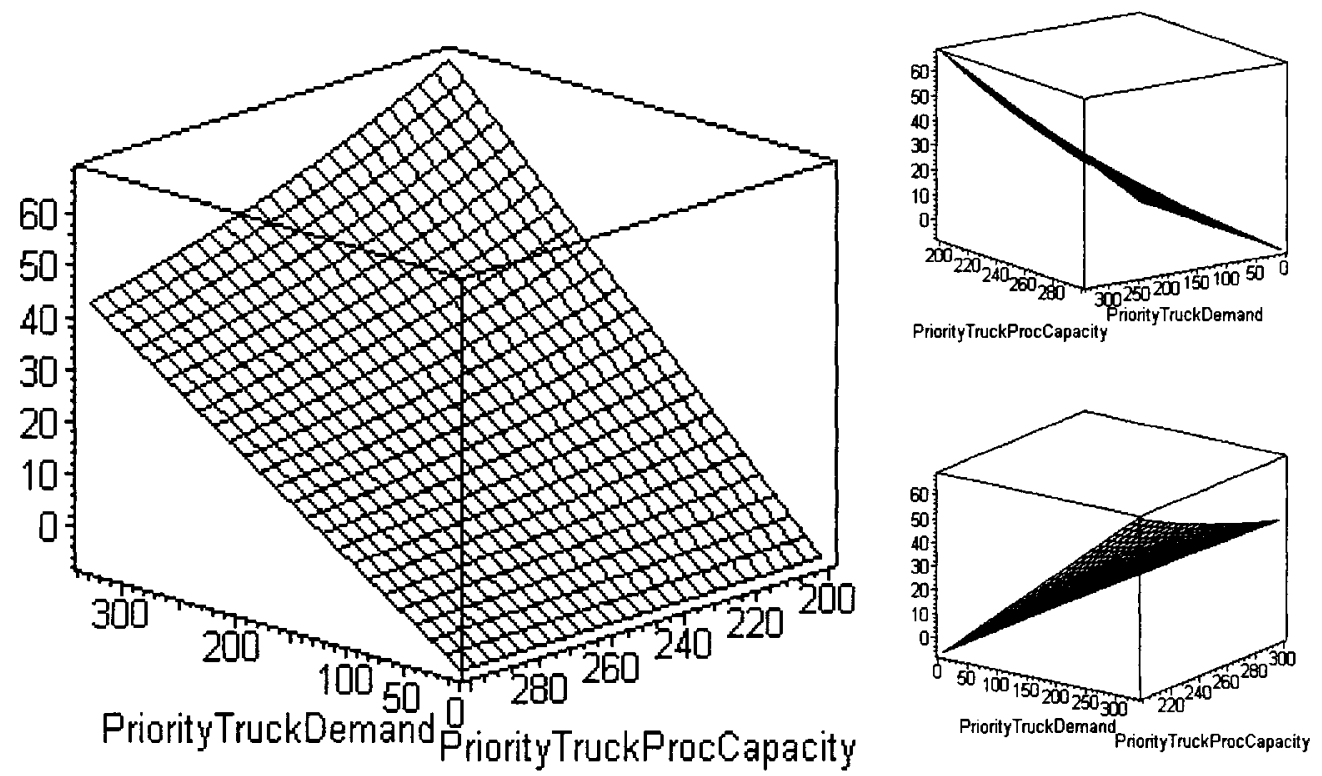

z - Average Priority Truck Travel Time Difference

Figure B-39: Average Priority Truck Travel Time - No QJL-QJL Scenario 

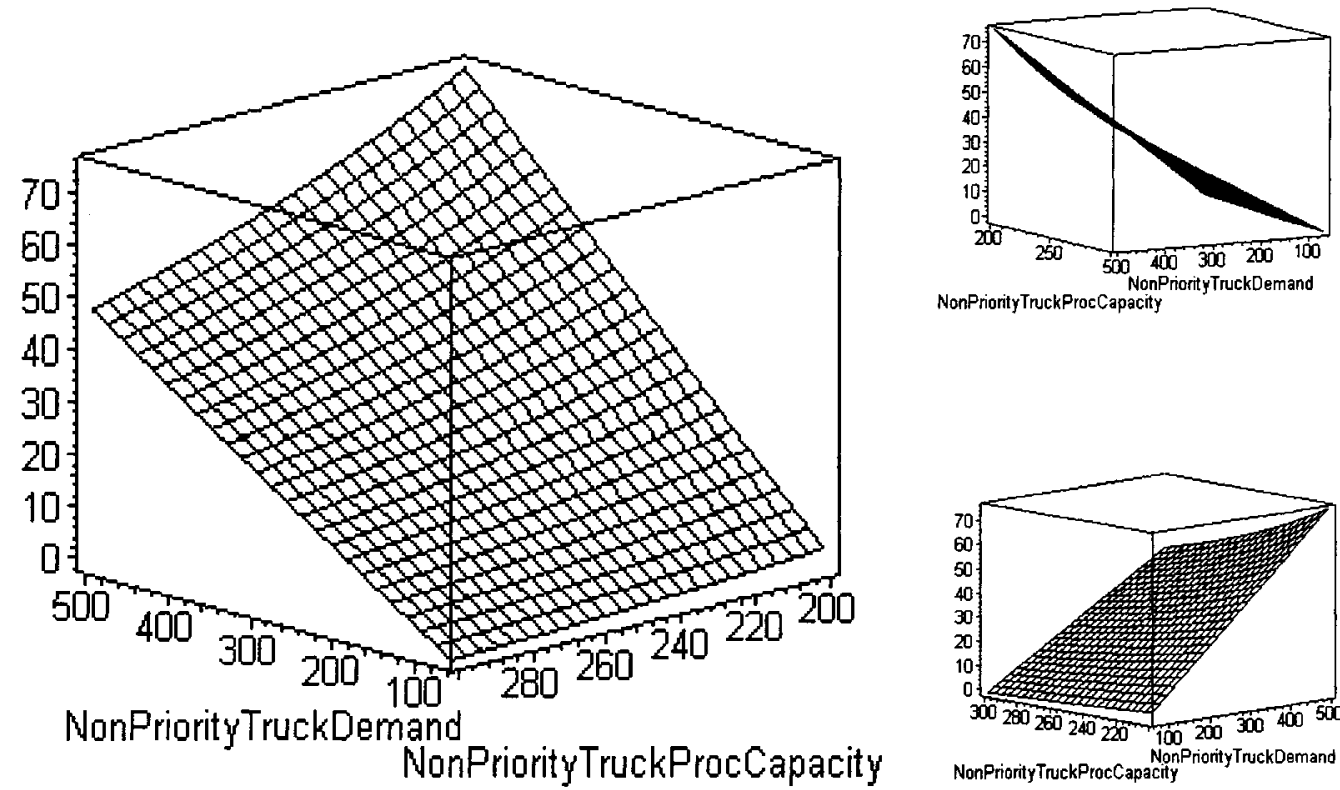

NonPriorityTruckFrocCapacity

$z$ - Average Non-priority Truck Travel Time

Figure B-40: Average Non-priority Truck Travel Time - No-QJL Scenario
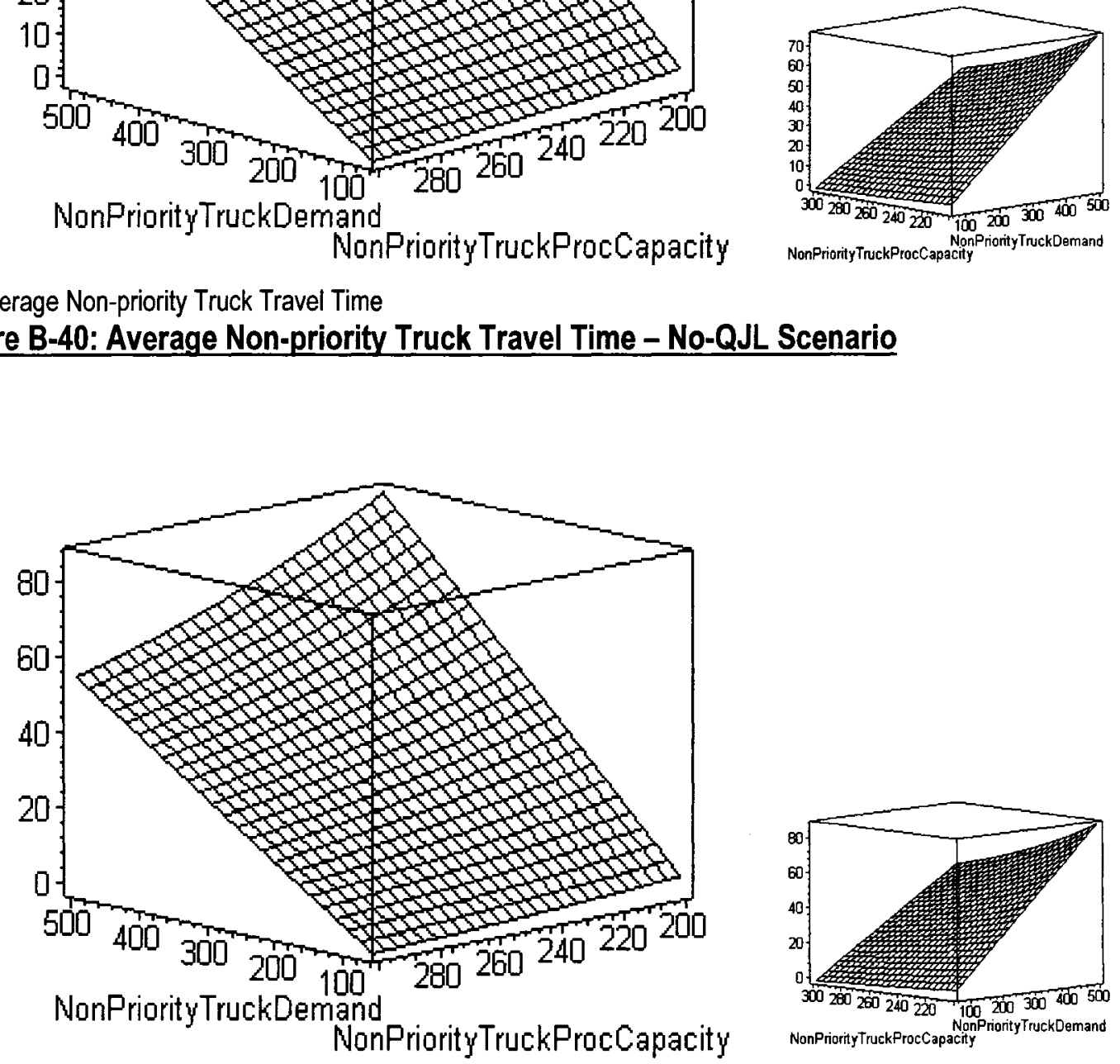

z-Average Non-priority Truck Travel Time Difference

Figure B-41: Average Non-priority Truck Travel Time - QJL Scenario 

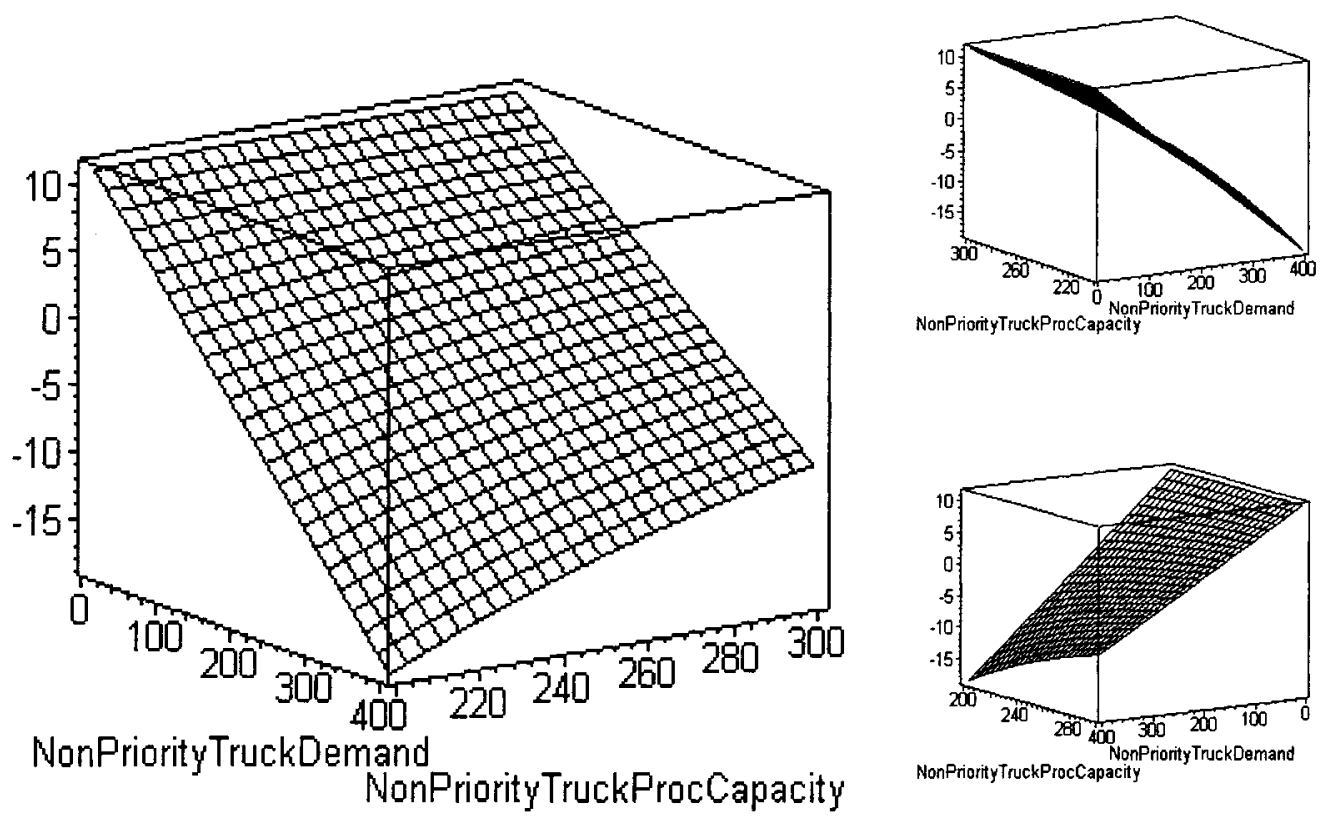

z-Average Non-priority Truck Travel Time

Figure B-42: Average Non-priority Truck Travel Time - No-QJL - QJL Scenario
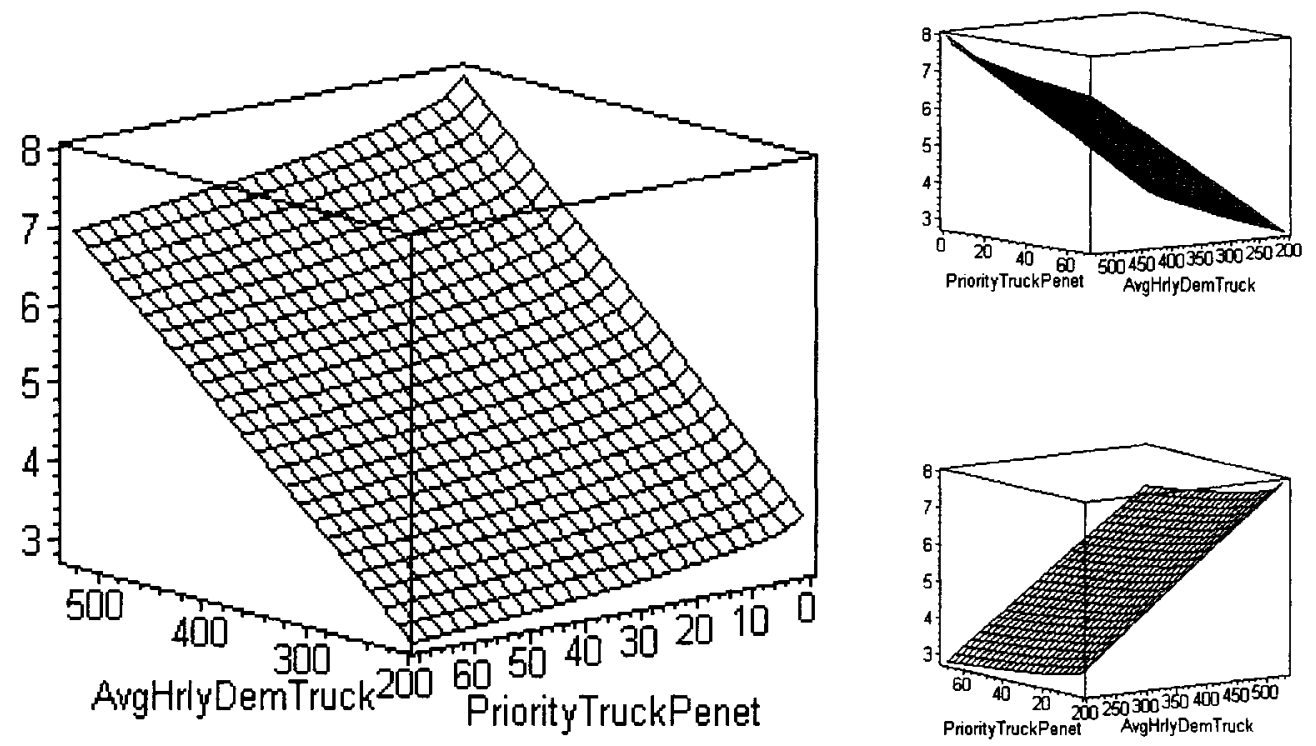

z - Average Non-priority Truck Travel Time Difference

Process Time Factor - 6.27

Figure B-43: Average Priority Truck Travel Time Advantage - No QJL Scenario 

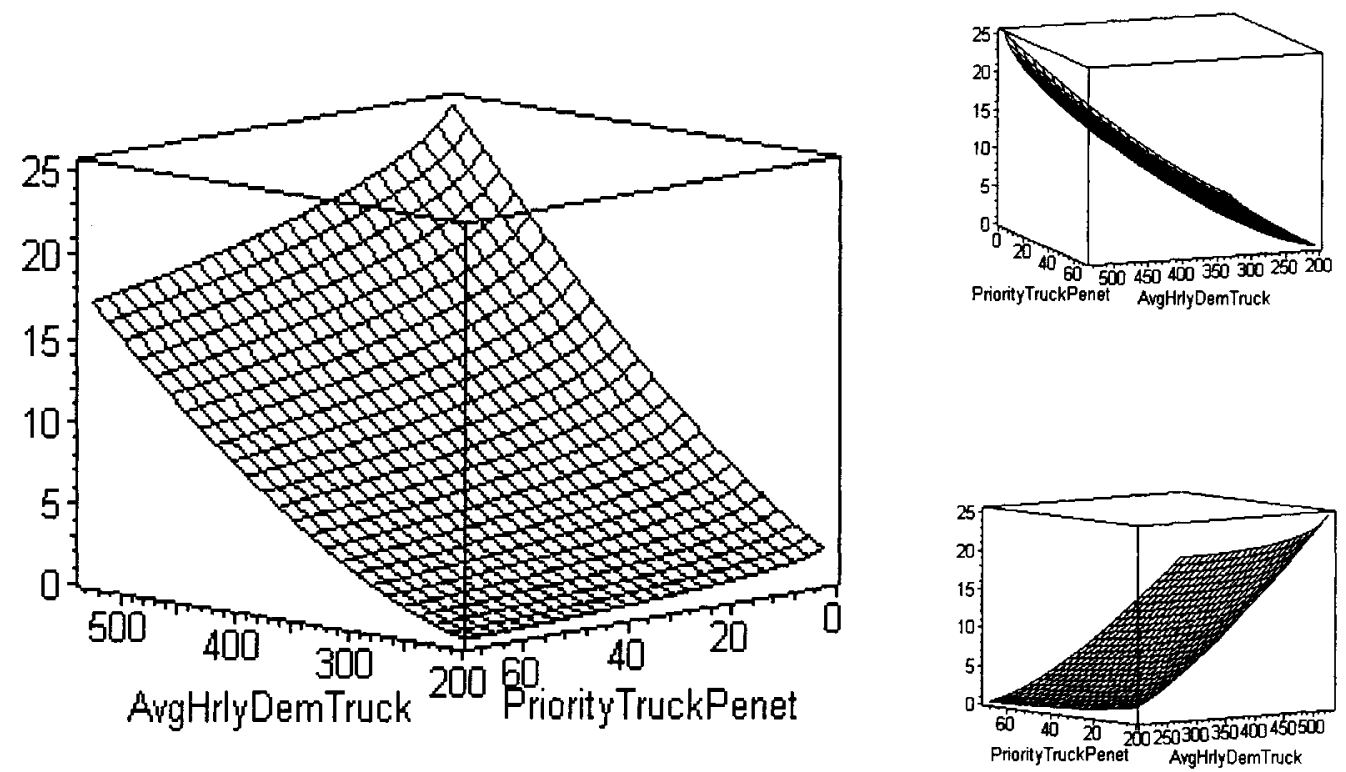

z - Average Priority Truck Travel Time Difference

Process Time Factor -6.27

Figure B-44: Average Priority Truck Travel Time Advantage - QJL Scenario
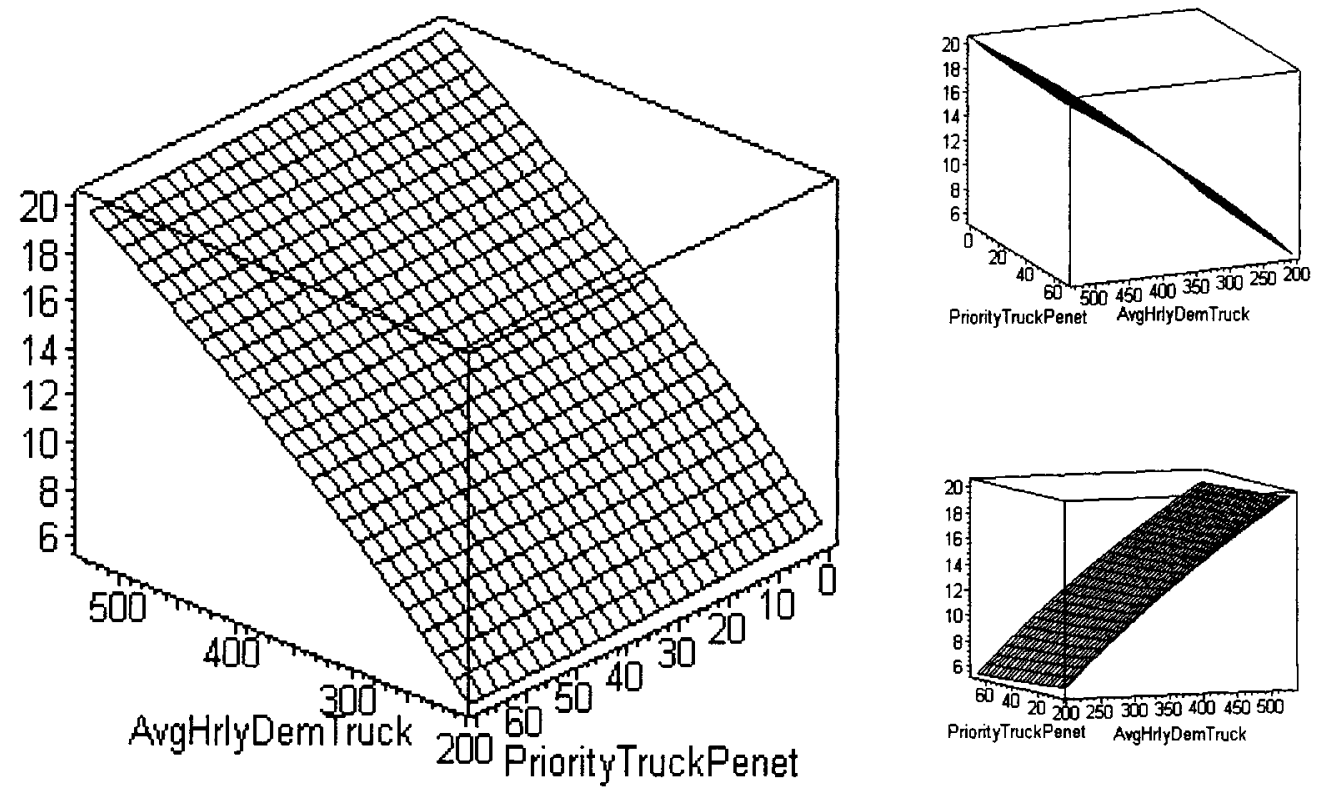

z - Average Non-priority Truck Travel Time Difference

Process Time Factor - 6.27

Figure B-45: Average Priority Truck Travel Time Advantage - No QJL-QJL Scenario 


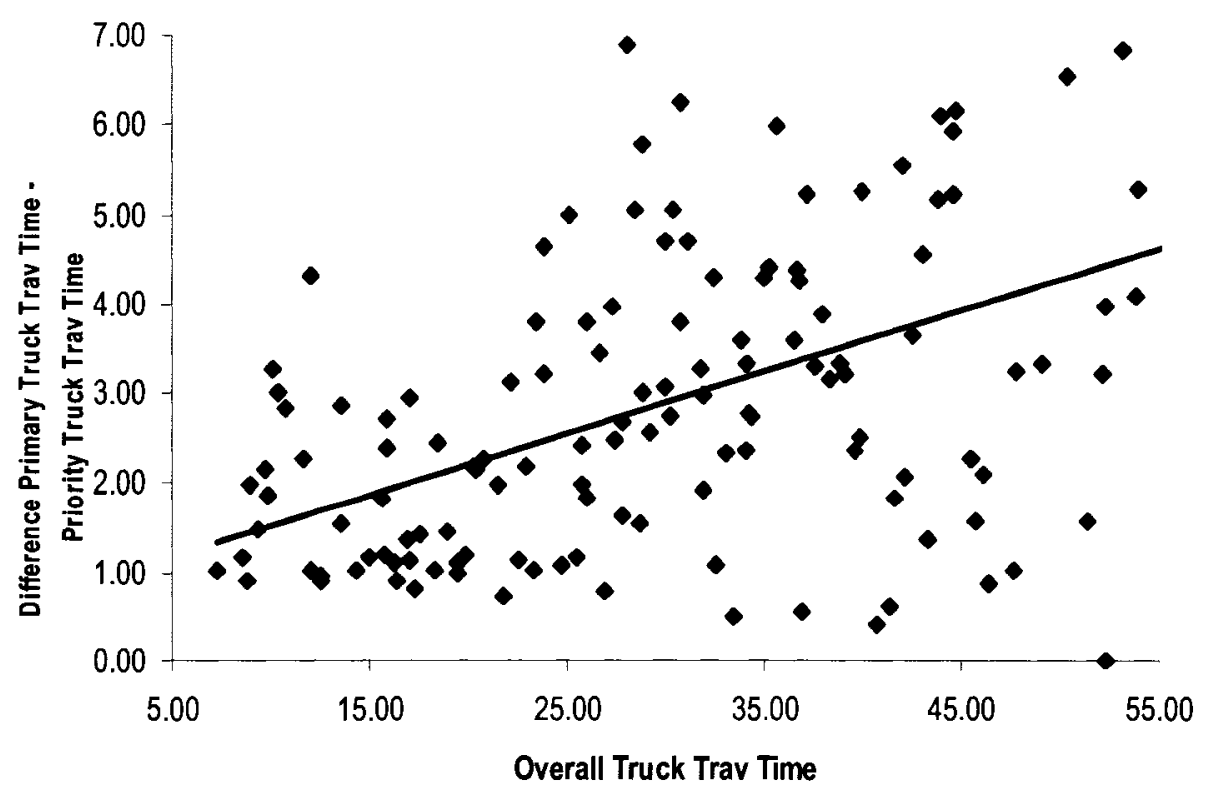

Figure B-46: Average Priority Truck Travel Time Advantage - No QJL Scenario

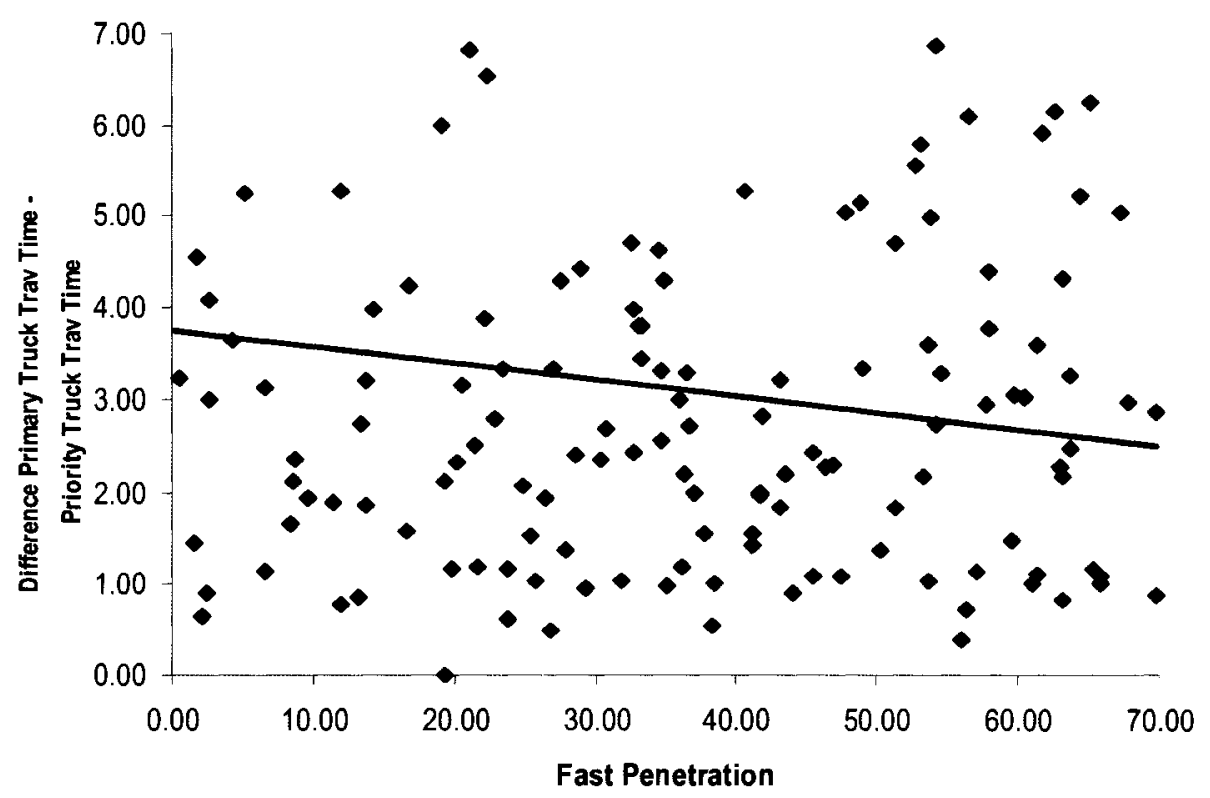

Figure B-47: Average Priority Truck Travel Time Advantage - No QJL Scenario 


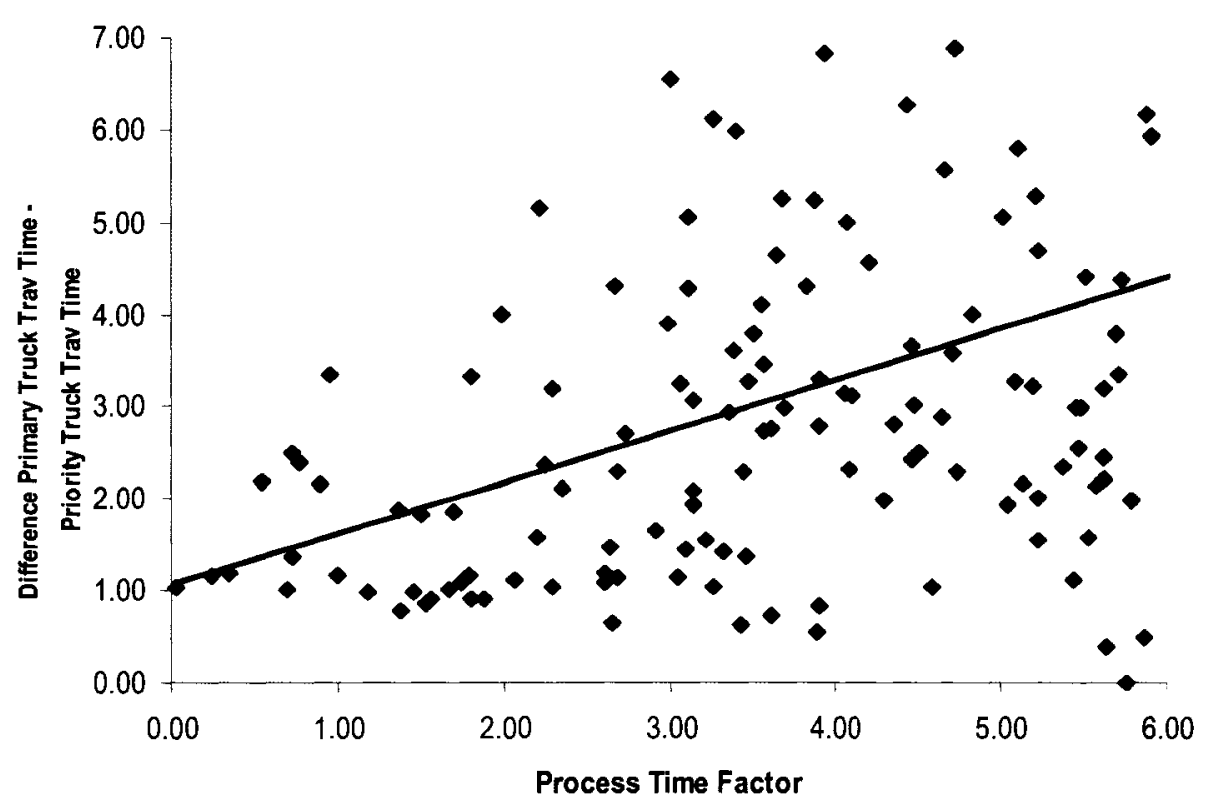

Figure B-48: Average Priority Truck Travel Time Advantage - No QJL Scenario 


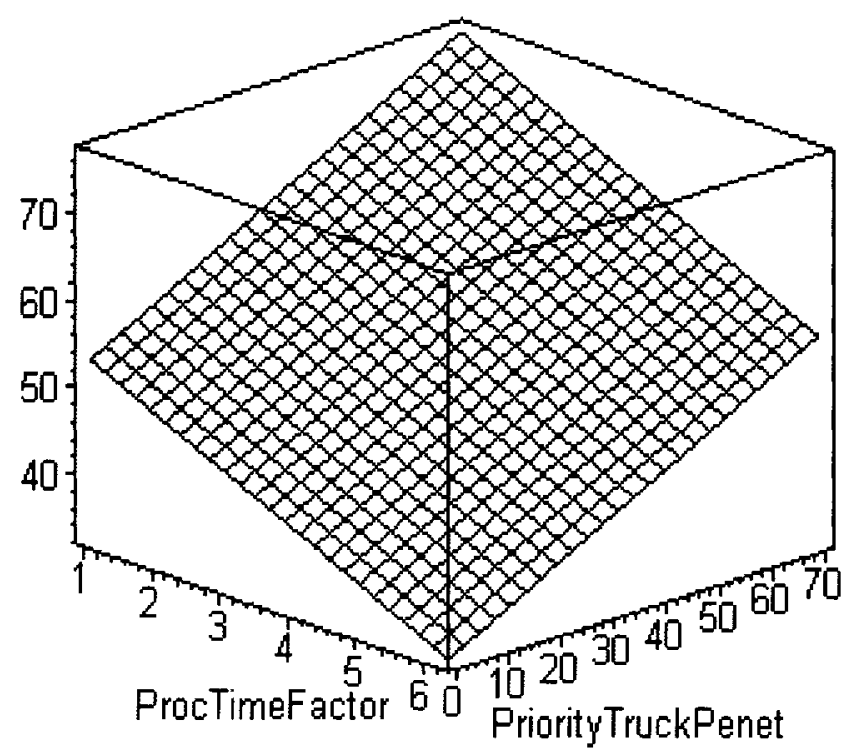

z - Overall Truck Percent of Demand Serviced

Average Hourly Truck Demand = 531

Percent Secondary Inspection = 20

\section{Figure B-49: Overall Truck Percent of Demand Serviced - No QJL Scenario}

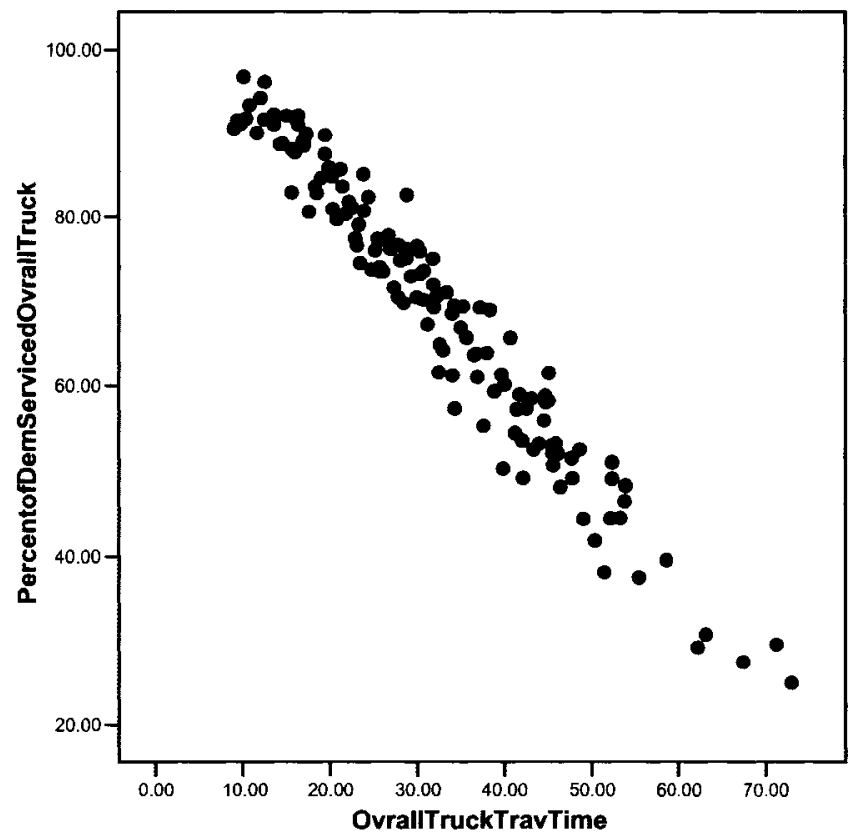

Figure B-50: Overall Truck Travel Time vs Percent Overall Truck Demand Serviced - No

\section{QJL Scenario}




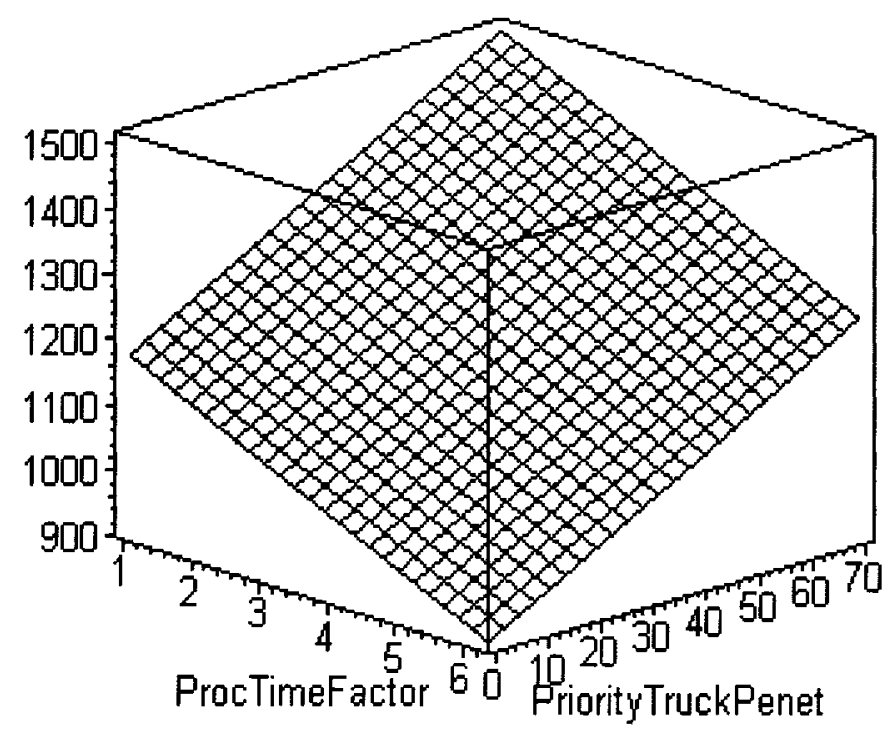

$z$ - Overall Truck Throughput

Average Hourly Truck Demand $=531$

Percent Secondary Truck $=20$

Figure B-51: Overall Truck Throughput - No QJL Scenario

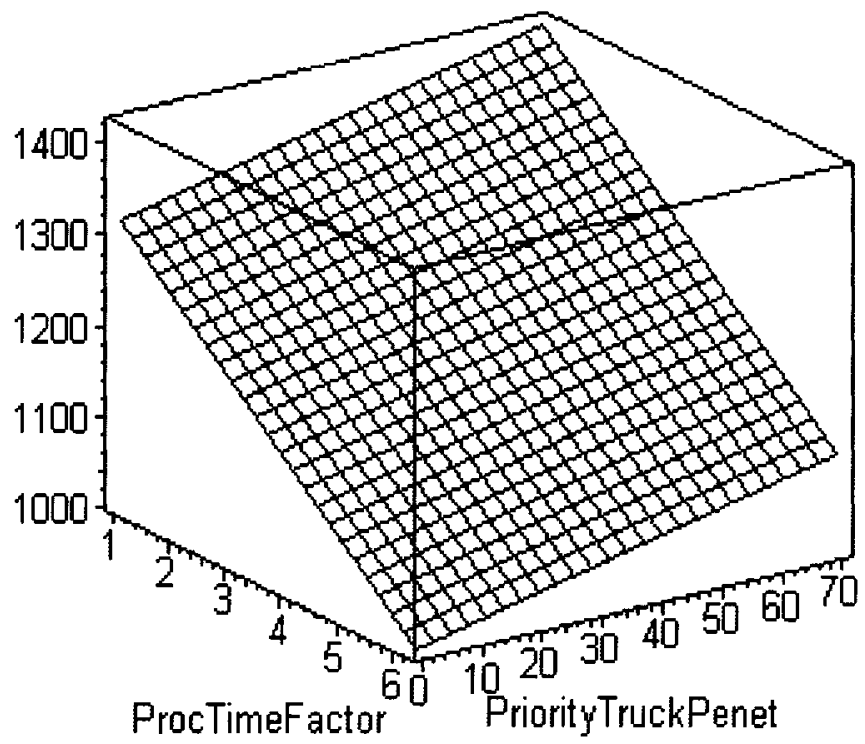

$z$ - Overall Truck Throughput

Average Hourly Truck Demand $=531$

Percent Secondary Truck $=20$

Figure B-52: Average Truck Throughput - QJL Scenario 


\section{Linear Multivariate Regression Analysis CLRM Assumptions}

\section{Average Overall Auto Travel Time - No QJL Scenario}

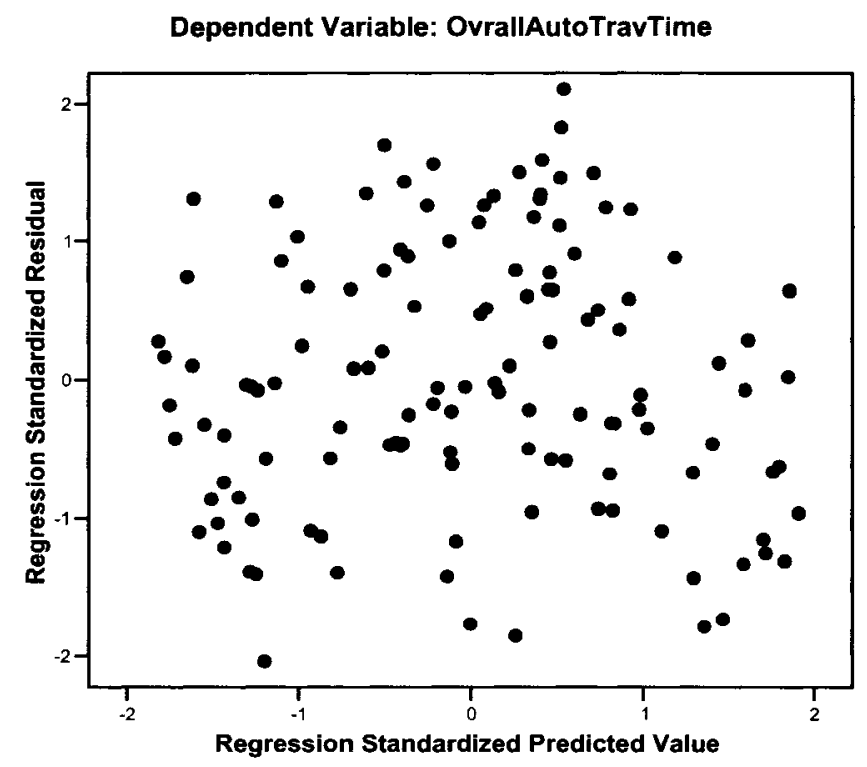

O.K for linearity and homoskedasticity

Figure B-53: Scatterplot Standardized Residuals vs Standardized Predicted Value

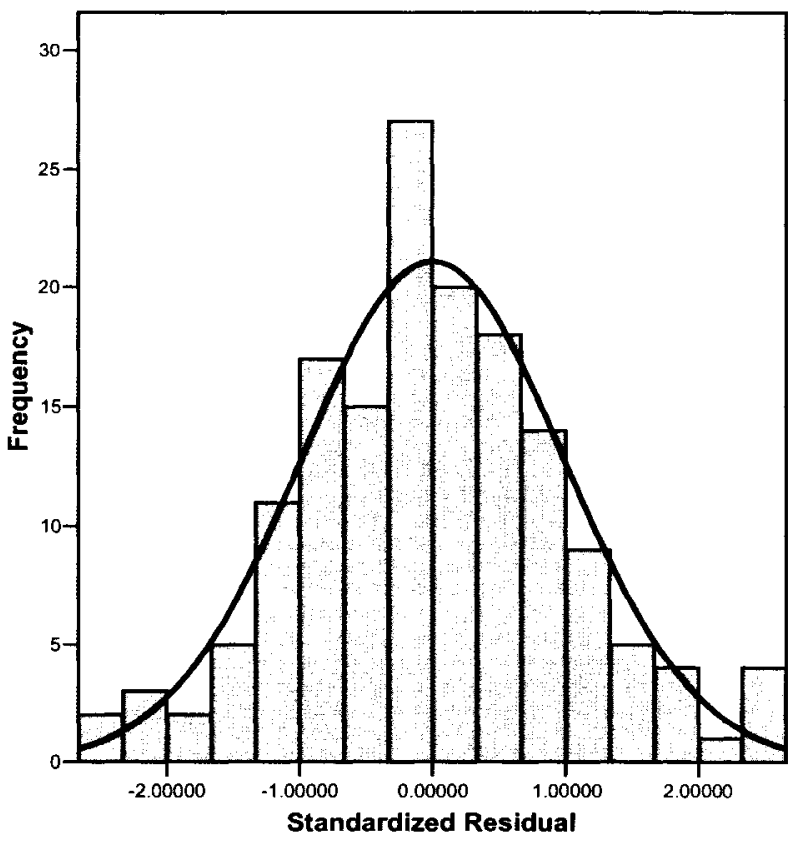

O.K. for normality

Figure B-54: Histogram - Standardized Residuals 
Average Overall Auto Travel Time - QJL Scenario

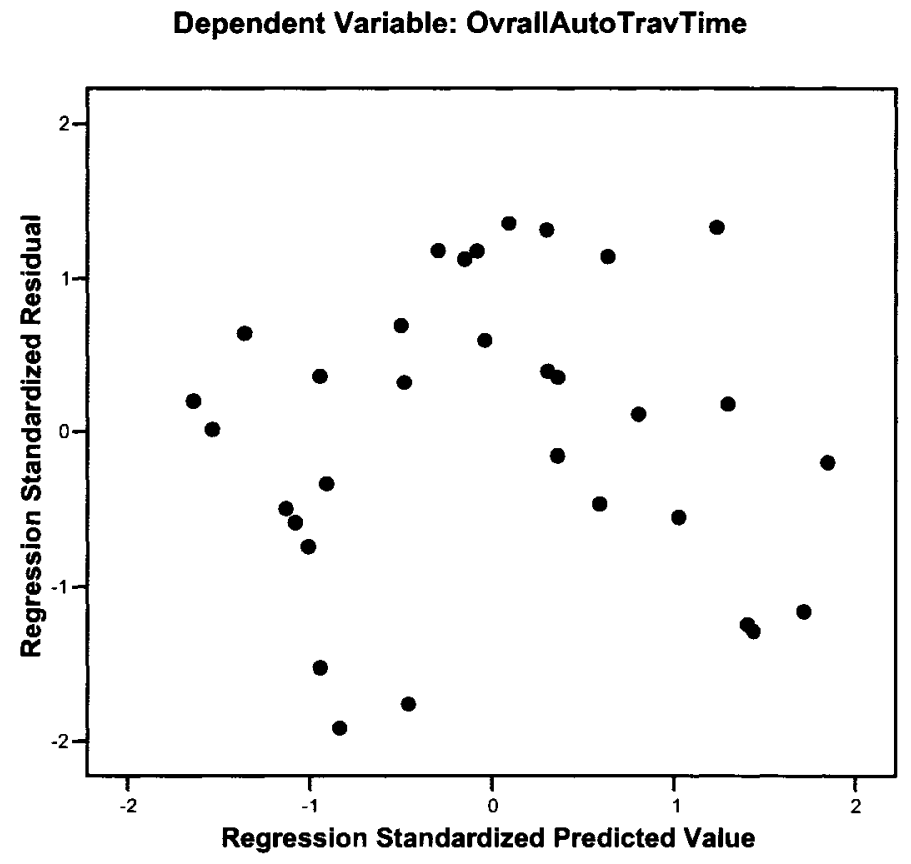

O.K for linearity and homoskedasticity

Figure B-55: Scatterplot Standardized Residuals vs Standardized Predicted Value

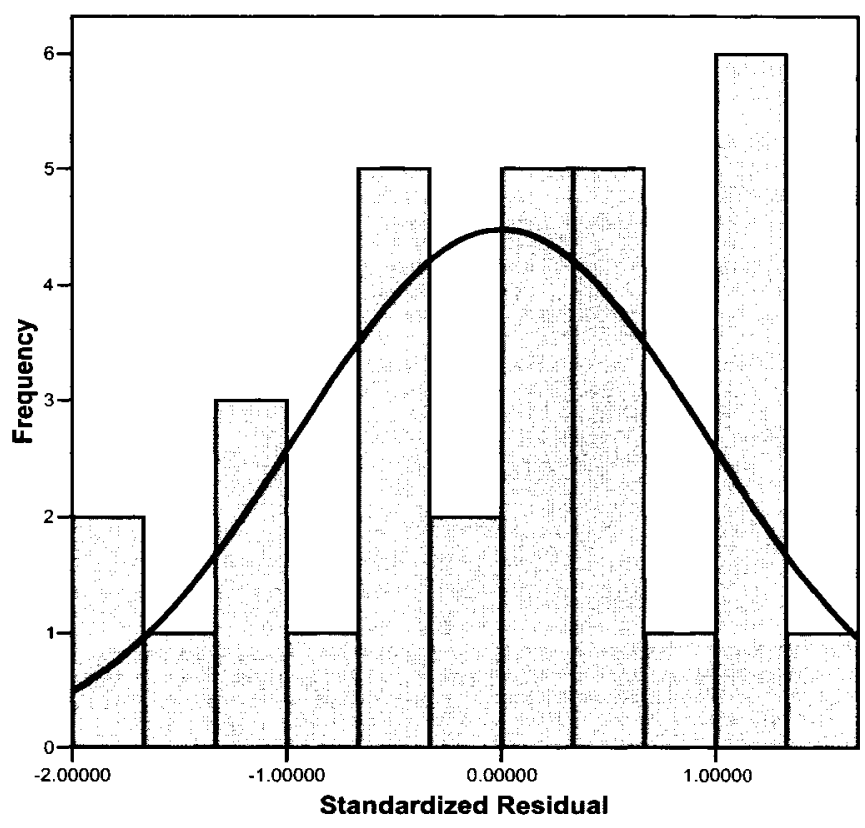

O.K. for normality

Figure B-56: Histogram - Standardized Residuals 


\section{Average Overall Auto Travel Time - No QJL - QJL Scenario}

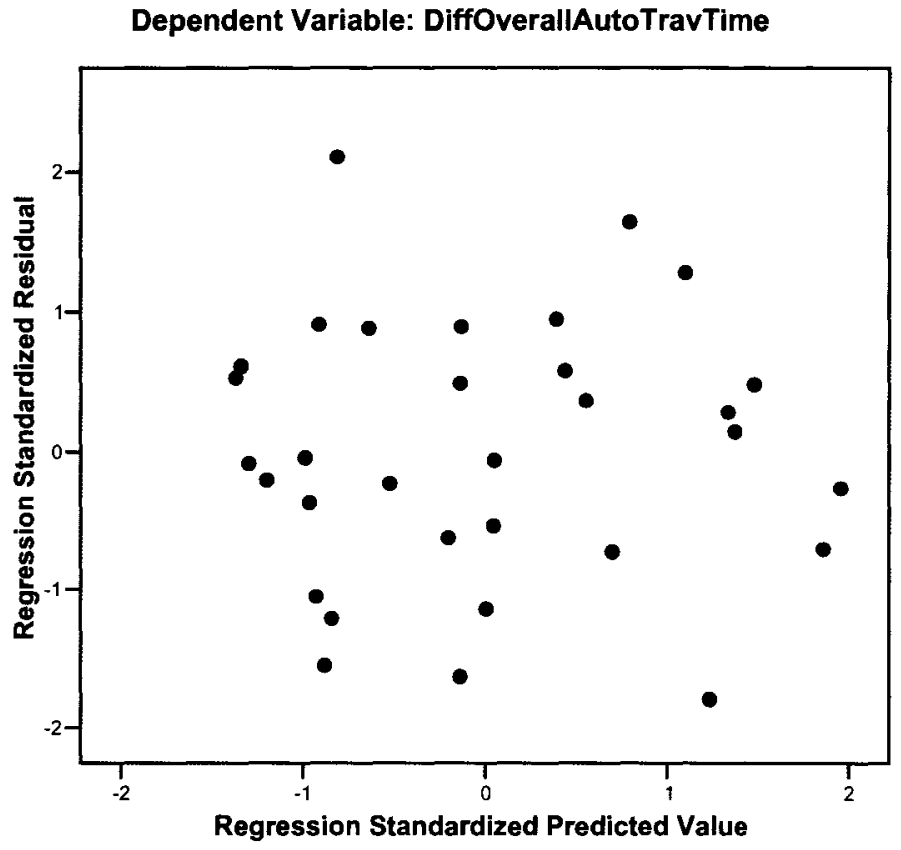

O.K for linearity and homoskedasticity

Figure B-57: Scatterplot Standardized Residuals vs Standardized Predicted Value

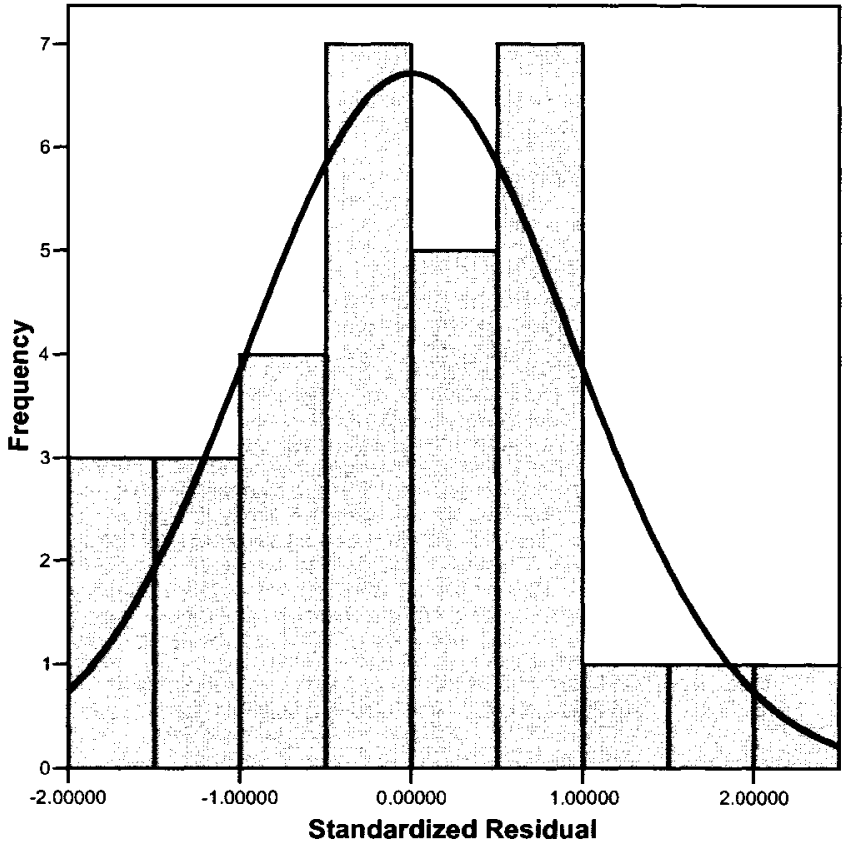

O.K. for normality

Figure B-58: Histogram - Standardized Residuals 
Average Priority Auto Travel Time - No QJL Scenario

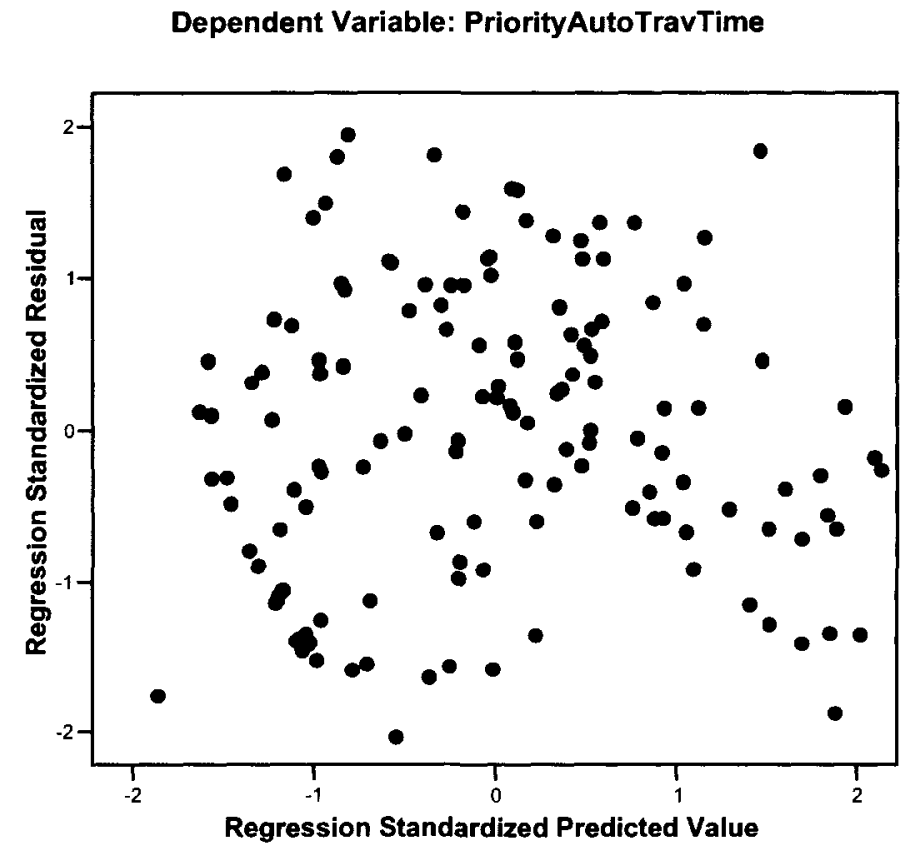

O.K for linearity and homoskedasticity

Figure B-59: Scatterplot Standardized Residuals vs Standardized Predicted Value

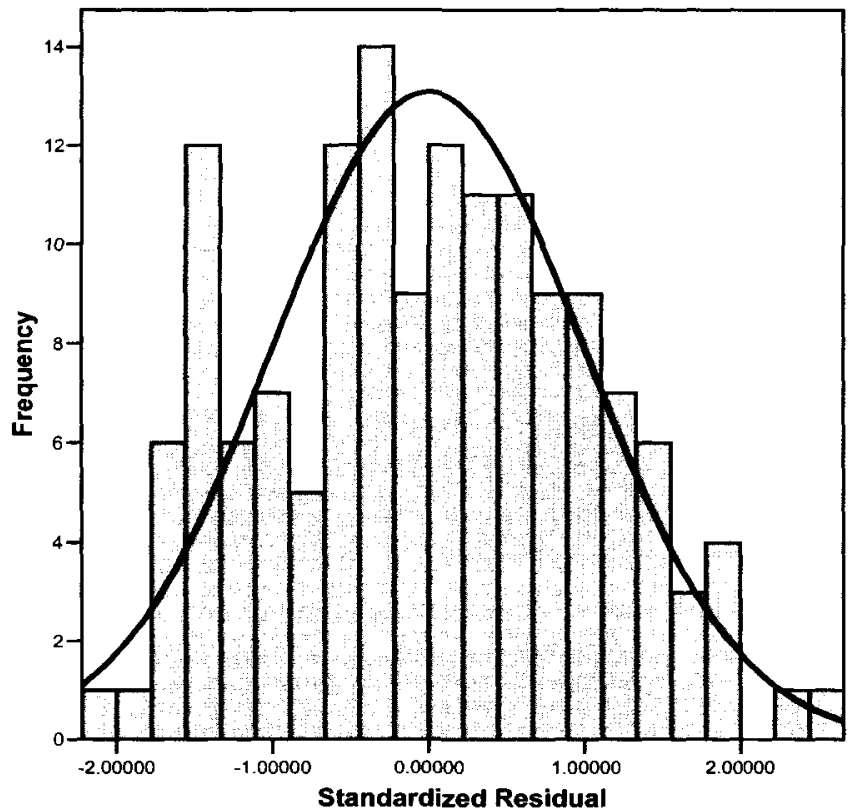

O.K. for normality

Figure B-60: Histogram - Standardized Residuals 


\section{Average Priority Auto Travel Time - QJL Scenario}

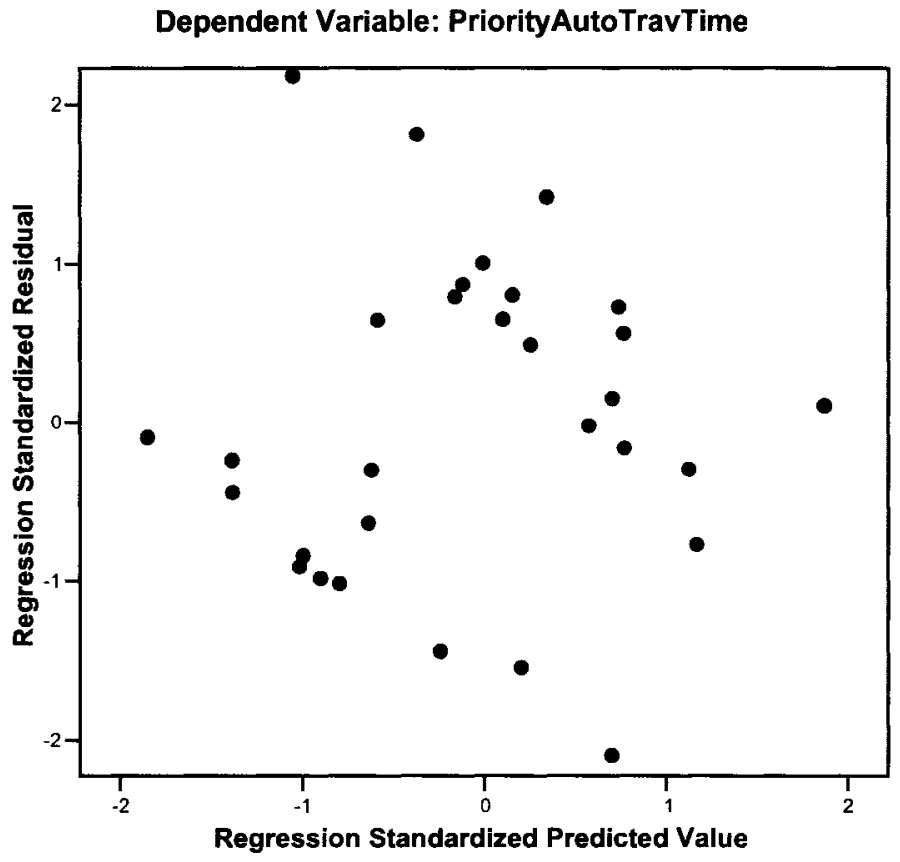

O.K for linearity and homoskedasticity

Figure B-61: Scatterplot Standardized Residuals vs Standardized Predicted Value

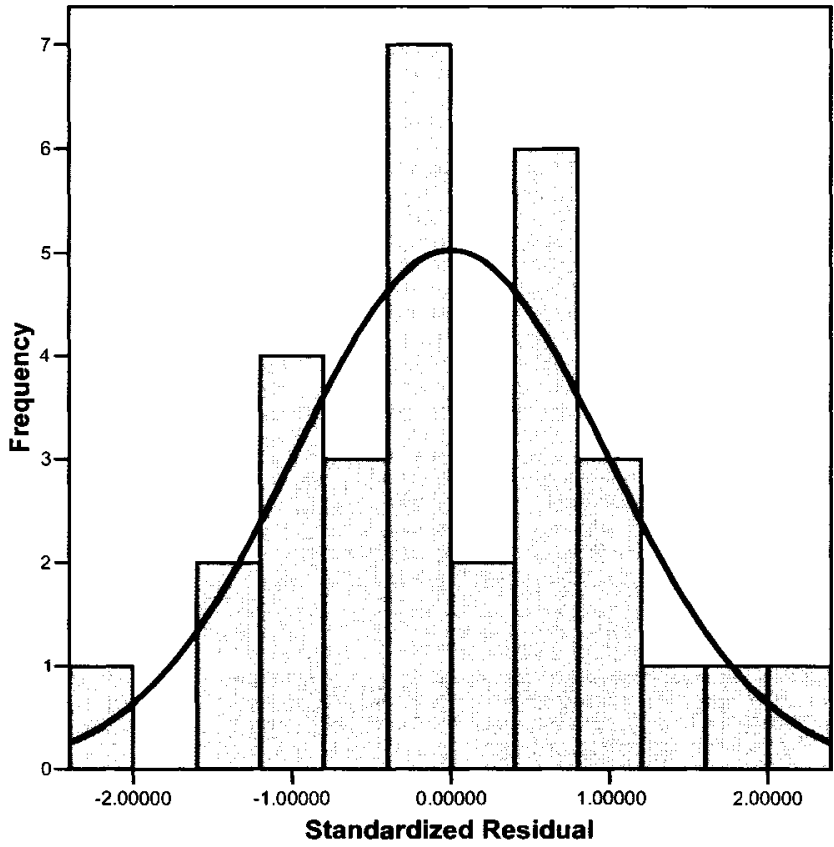

O.K. for normality

Figure B-62: Histogram - Standardized Residuals 
Average Priority Auto Travel Time - No QJL - QJL Scenario

Dependent Variable: DiffPriorityAutoTravTime

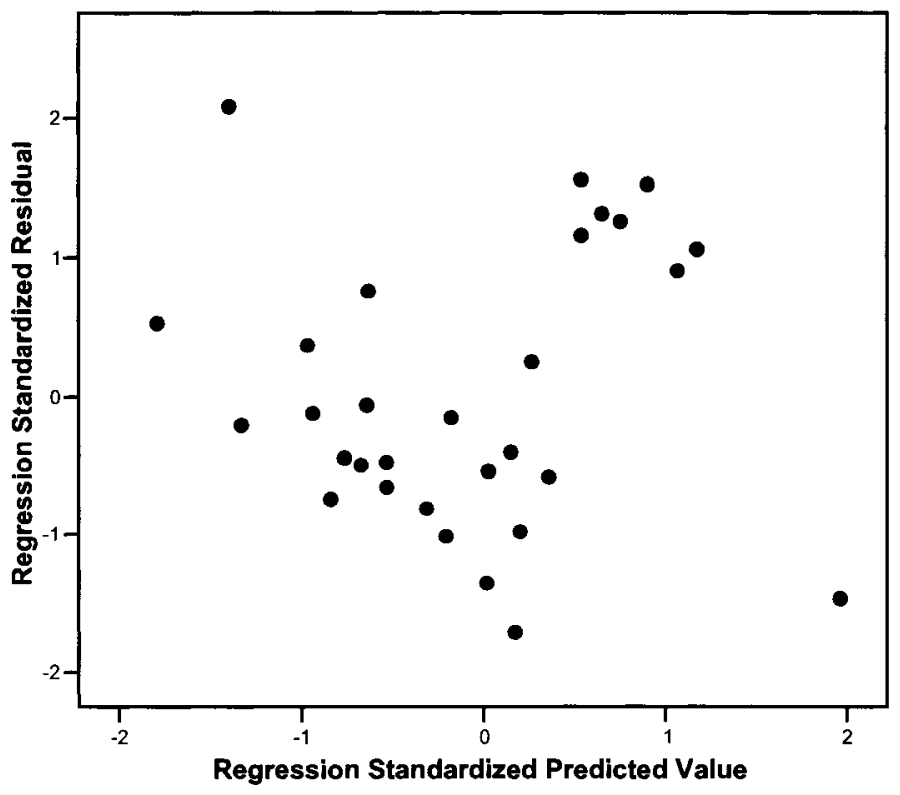

O.K for linearity and homoskedasticity

Figure B-63: Scatterplot Standardized Residuals vs Standardized Predicted Value

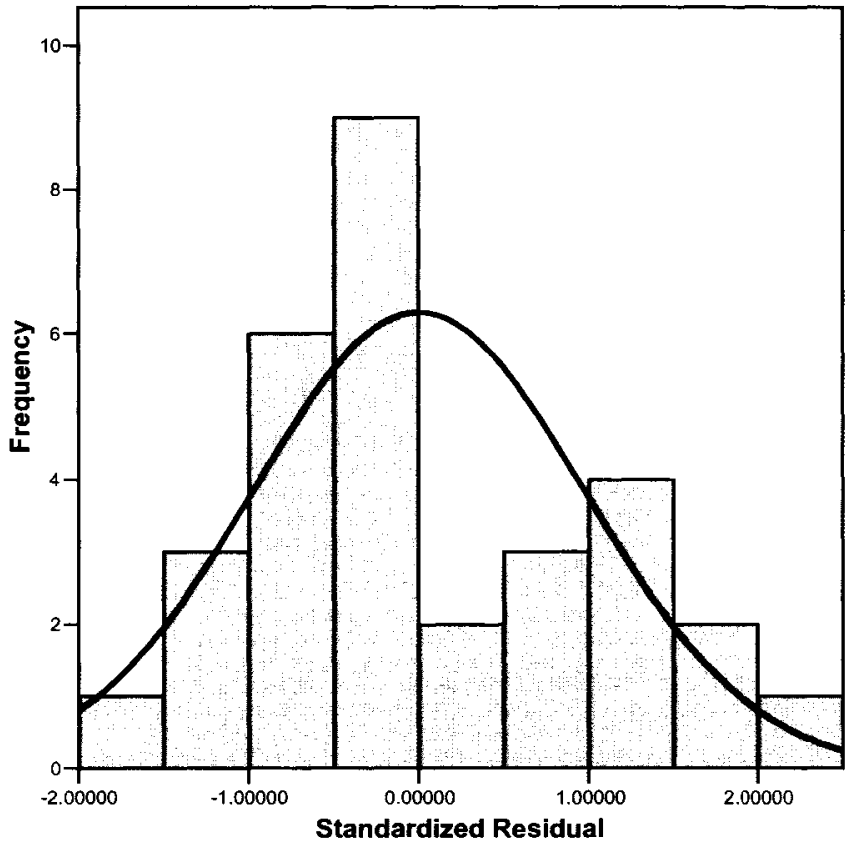

O.K. for normality

Figure B-64: Histogram - Standardized Residuals 


\section{Average Non-Priority Auto Travel Time - No QJL Scenario}

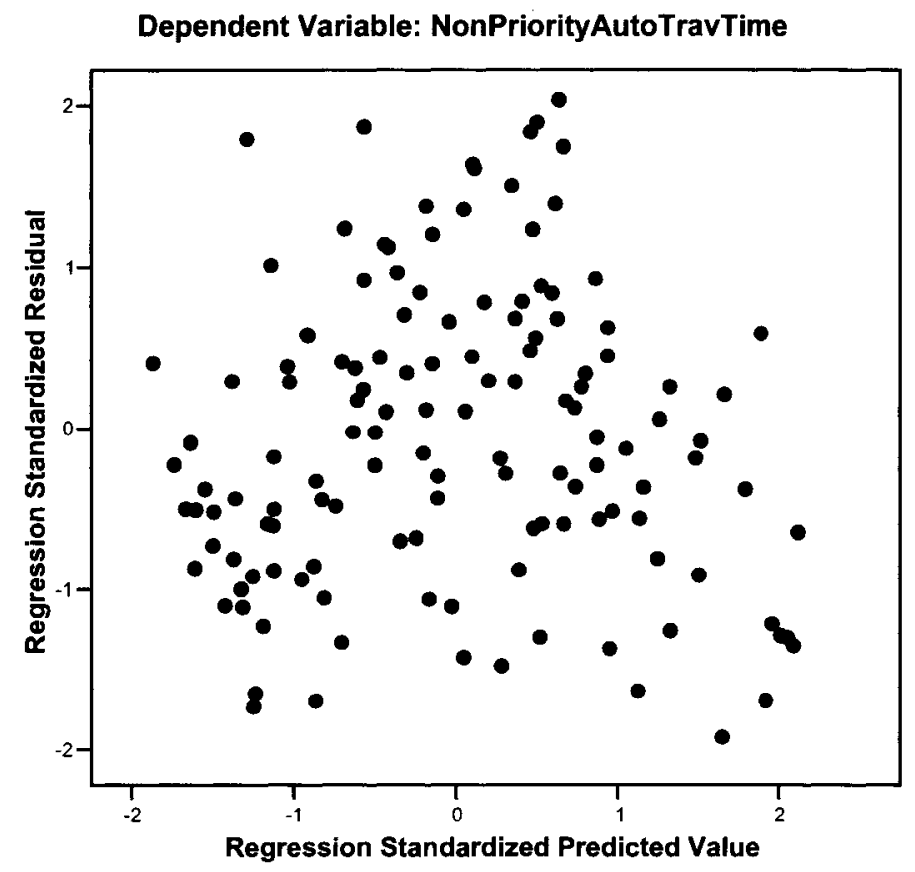

O.K for linearity and homoskedasticity

Figure B-65: Scatterplot Standardized Residuals vs Standardized Predicted Value

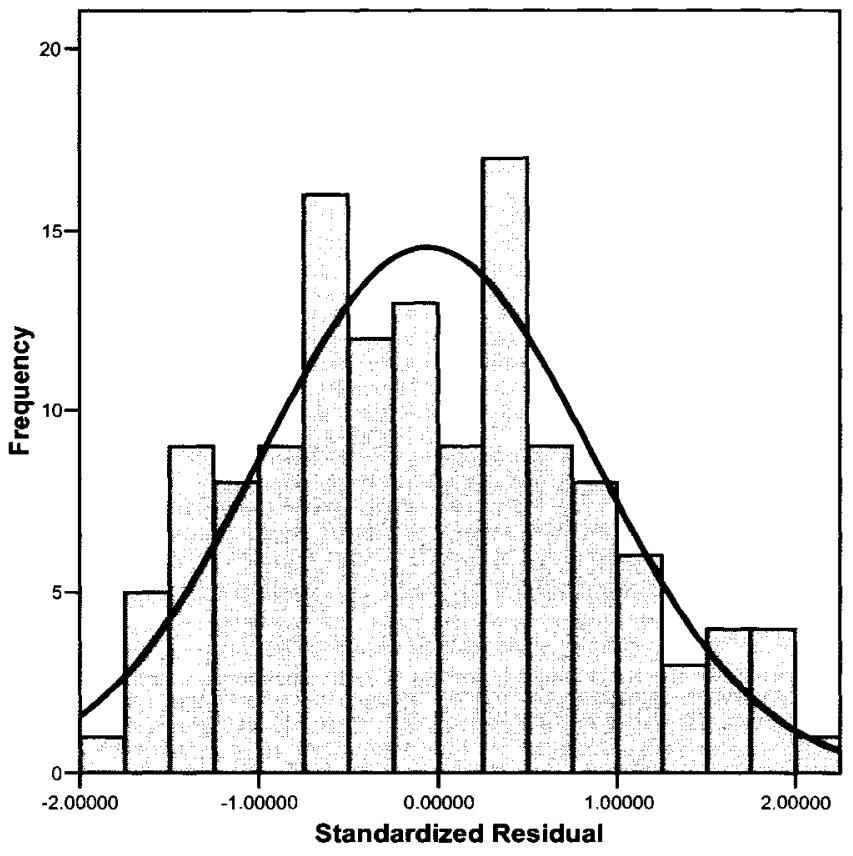

O.K. for normality

Figure B-66: Histogram - Standardized Residuals 
Average Non-Priority Auto Travel Time - QJL Scenario

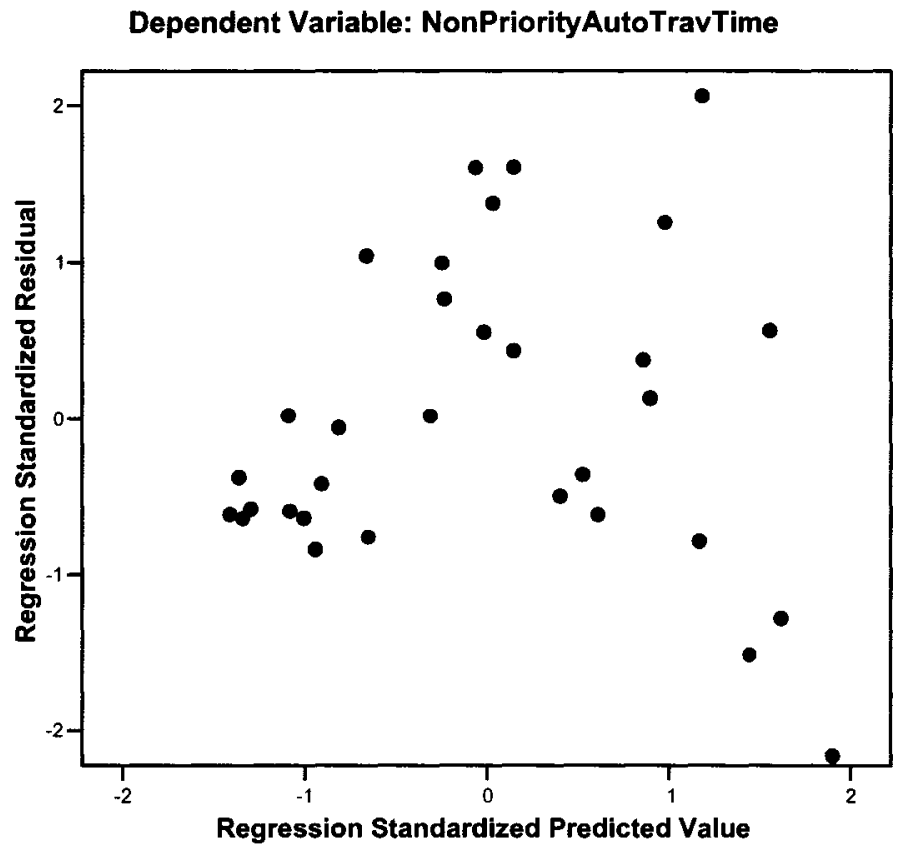

O.K for linearity and homoskedasticity

Figure B-67: Scatterplot Standardized Residuals vs Standardized Predicted Value

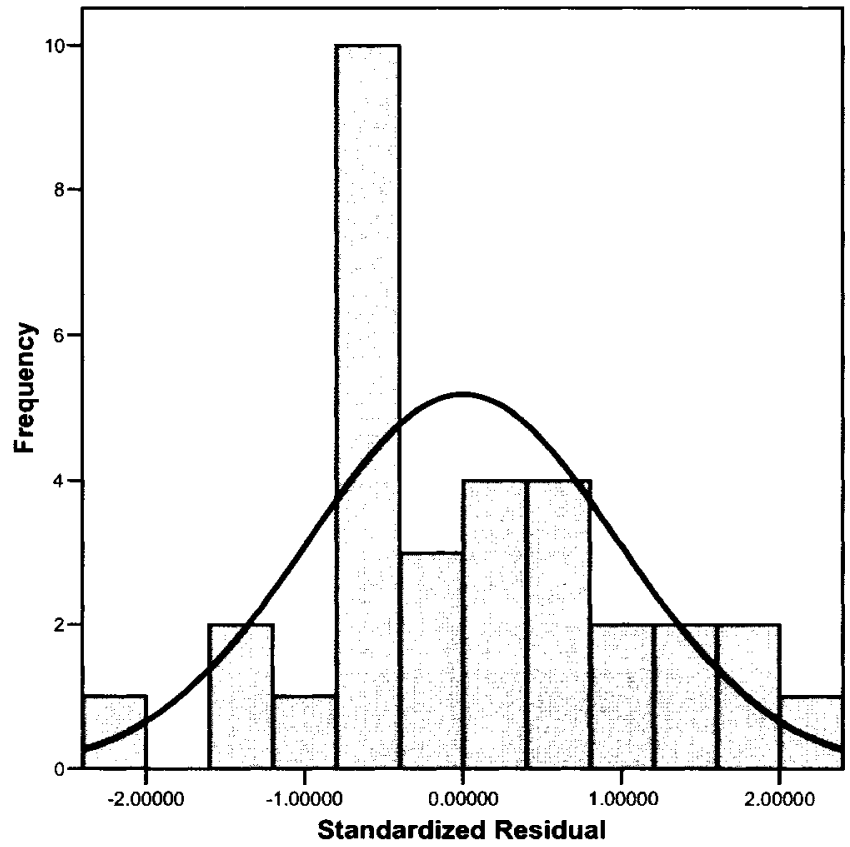

O.K. for normality

Figure B-68: Histogram - Standardized Residuals 
Average Non-Priority Auto Travel Time - No QJL - QJL Scenario

Dependent Variable: DiffNonPriorityAutoTravTime

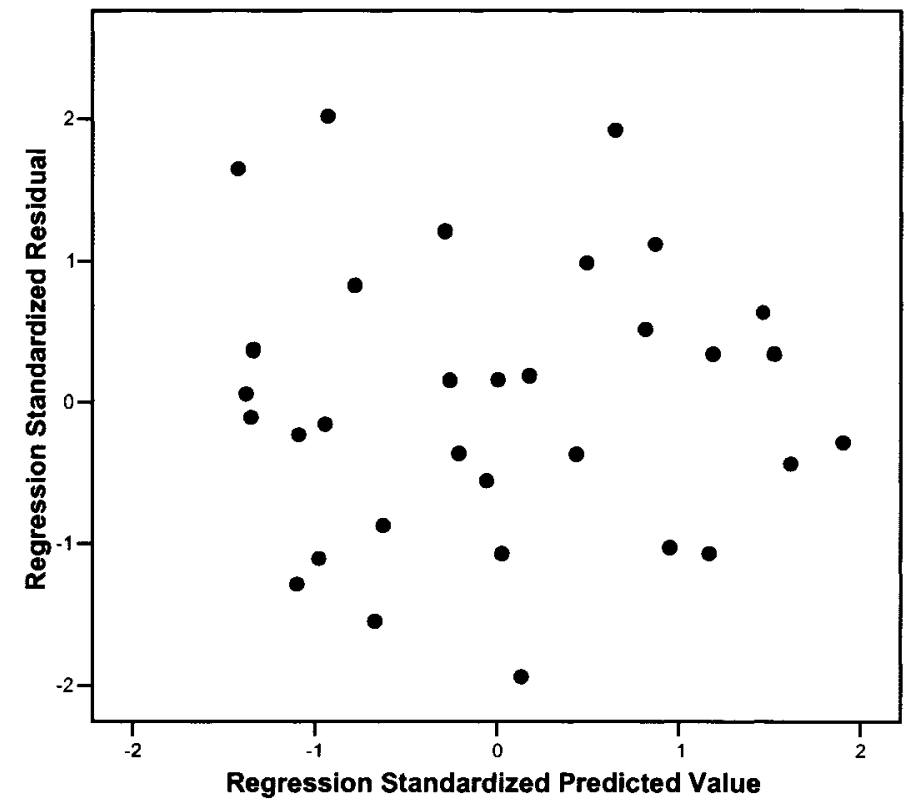

O.K for linearity and homoskedasticity

Figure B-69: Scatterplot Standardized Residuals vs Standardized Predicted Value

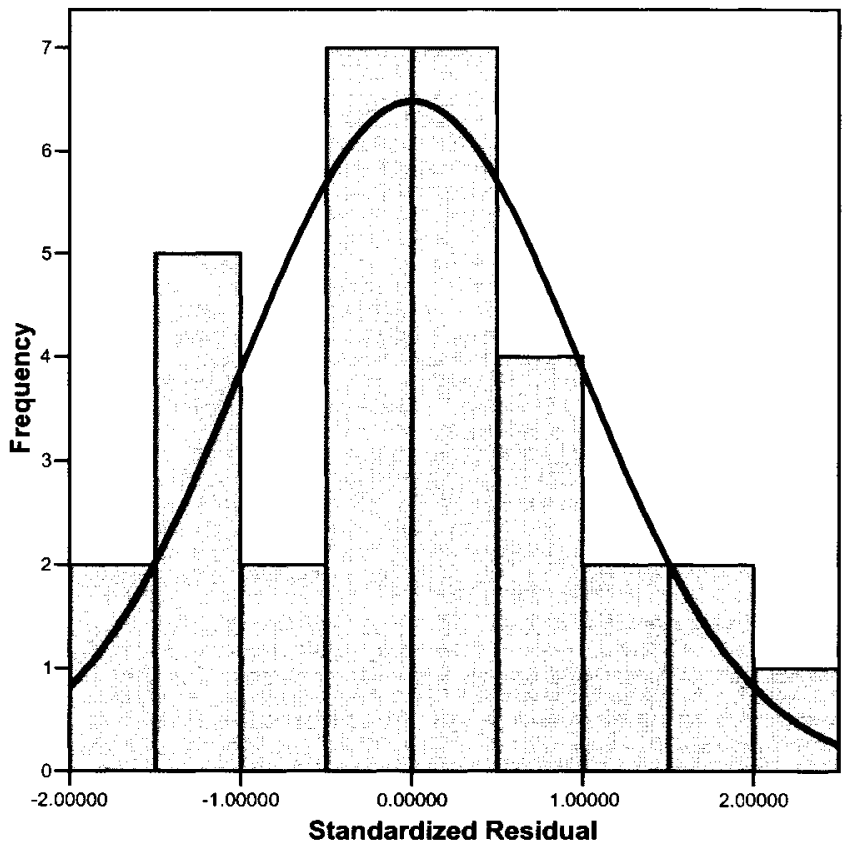

O.K. for normality

Figure B-70: Histogram - Standardized Residuals 


\section{Average Priority Auto Travel Time Advantage - No QJL Scenario}

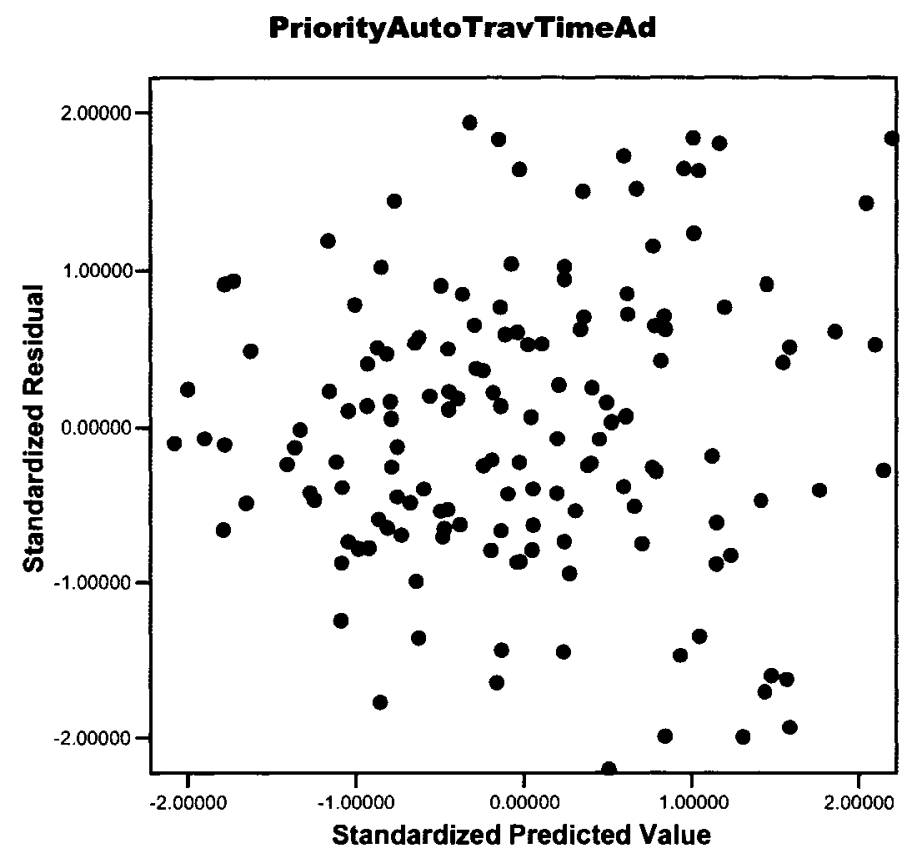

O.K for linearity and homoskedasticity

Figure B-71: Scatterplot Standardized Residuals vs Standardized Predicted Value

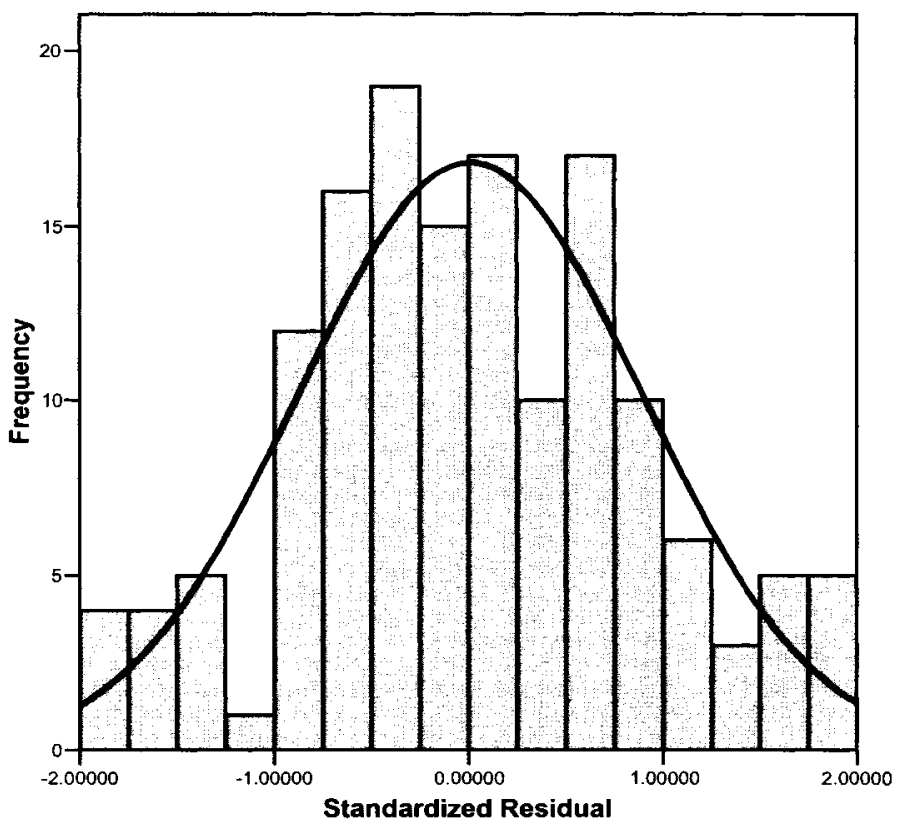

O.K. for normality

Figure B-72: Histogram - Standardized Residuals 
Average Priority Auto Travel Time Advantage - QJL Scenario

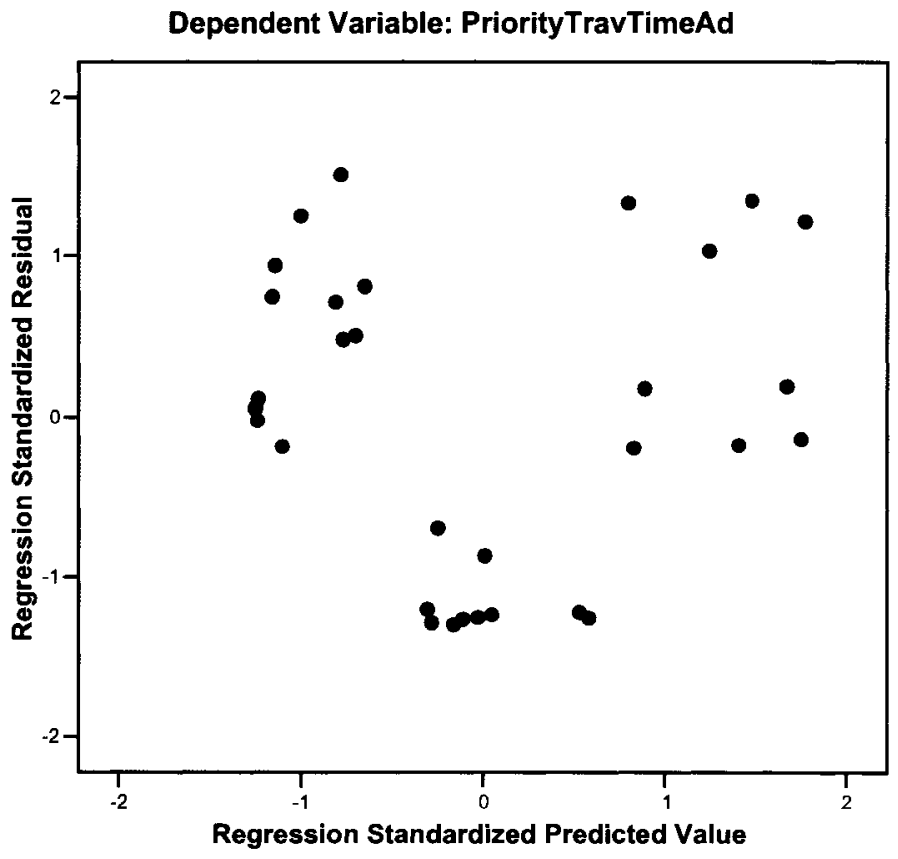

O.K for linearity and homoskedasticity

Figure B-73: Scatterplot Standardized Residuals vs Standardized Predicted Value

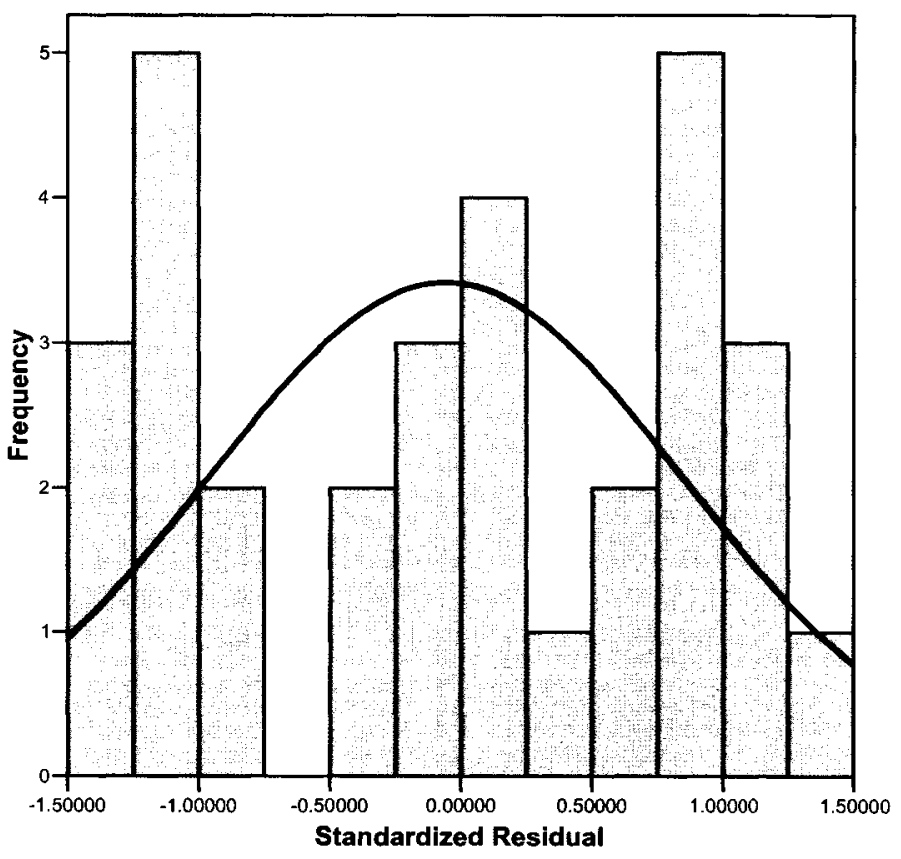

O.K. for normality

Figure B-74: Histogram - Standardized Residuals 
Average Priority Auto Travel Time Advantage - No QJL - QJL Scenario

Dependent Variable: DiffAutoTravTimesAdvantage

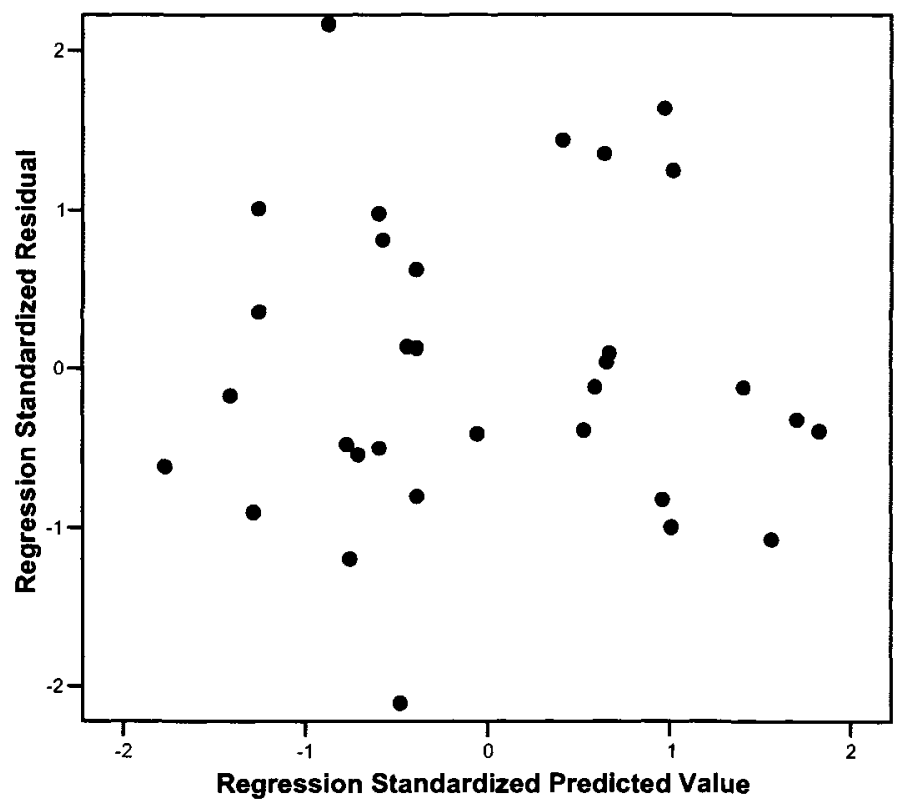

O.K for linearity and homoskedasticity

Figure B-75: Scatterplot Standardized Residuals vs Standardized Predicted Value

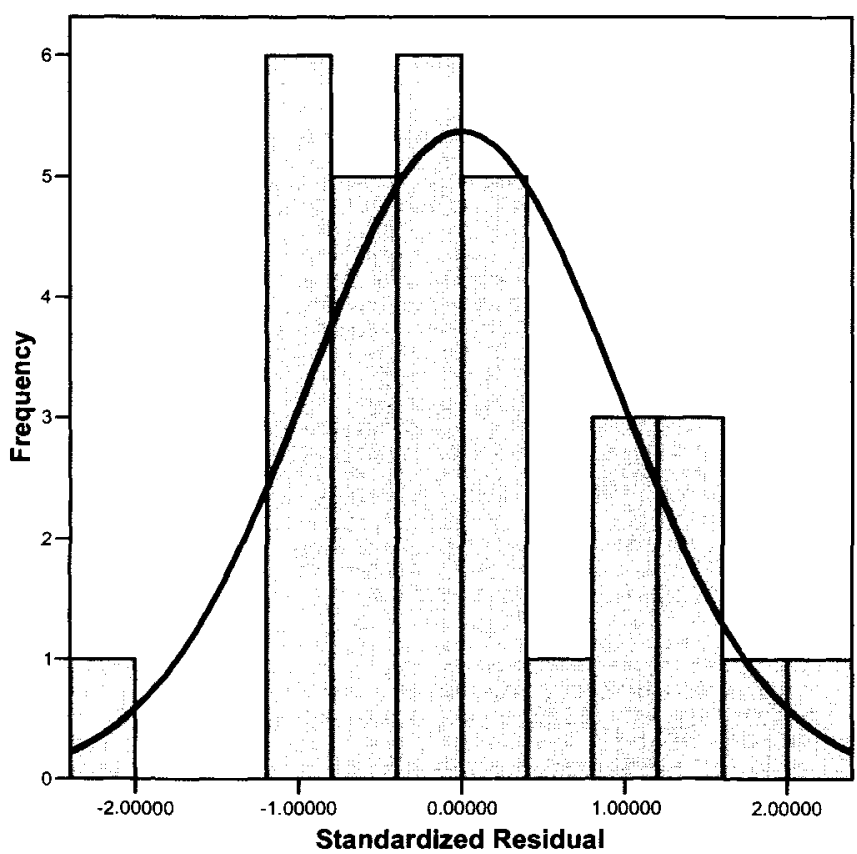

O.K. for normality

Figure B-76: Histogram - Standardized Residuals 
Average Overall Truck Travel Time- No QJL Scenario

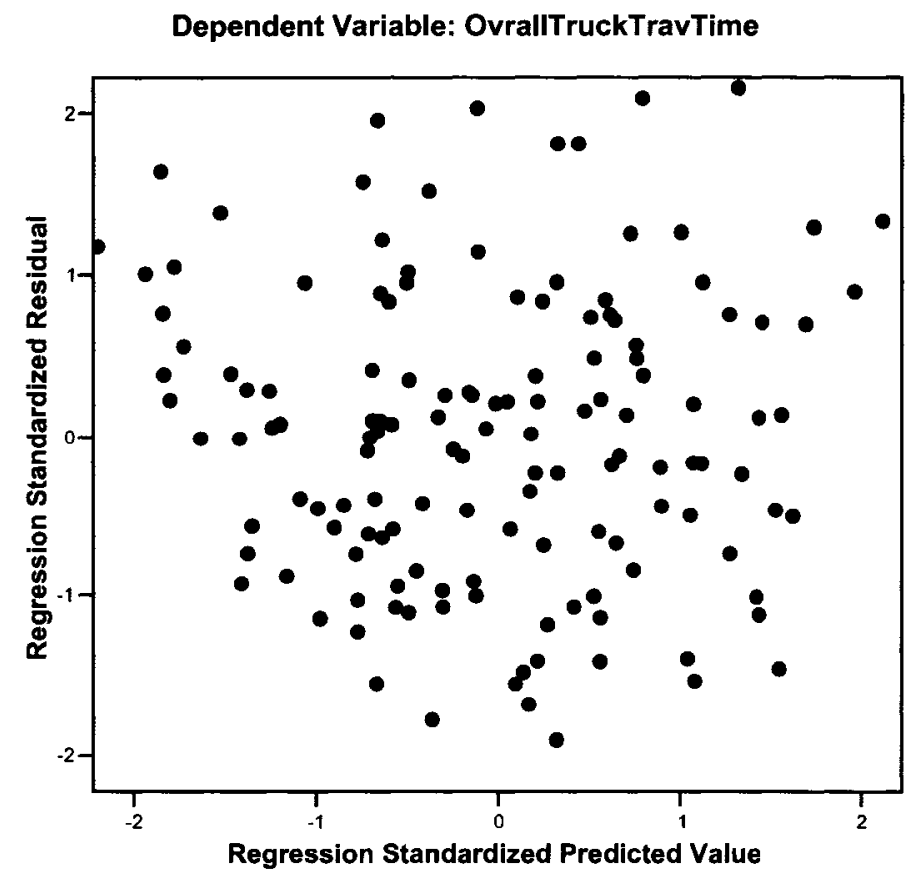

O.K for linearity and homoskedasticity

Figure B-77: Scatterplot Standardized Residuals vs Standardized Predicted Value

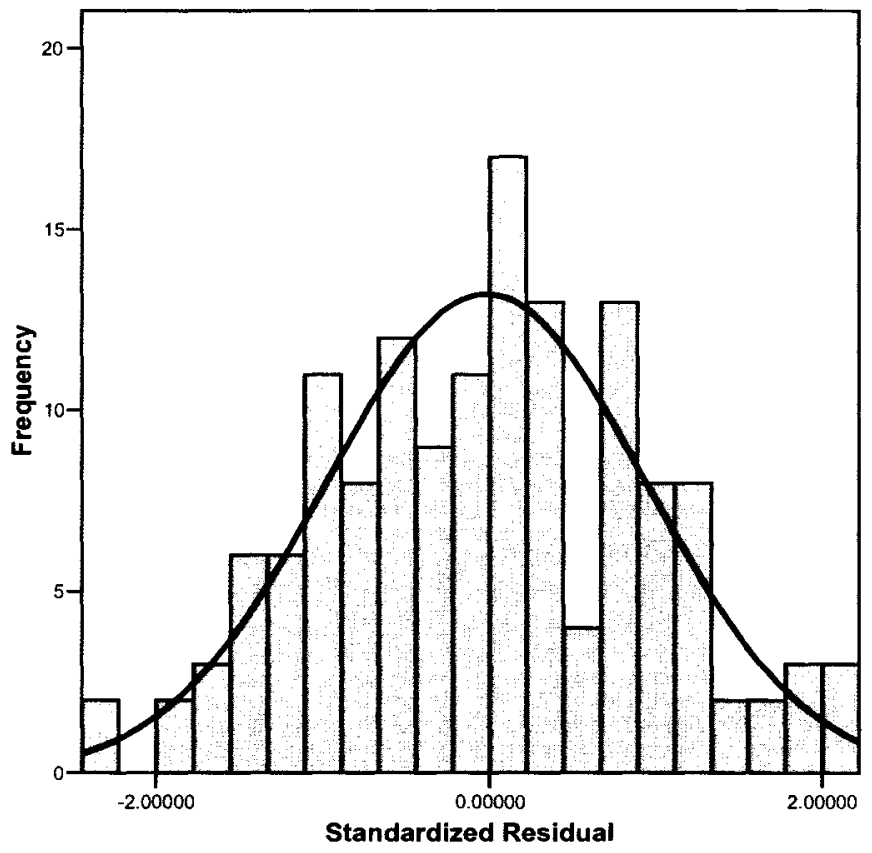

O.K. for normality

Figure B-78: Histogram - Standardized Residuals 


\section{Average Overall Truck Travel Time- QJL Scenario}

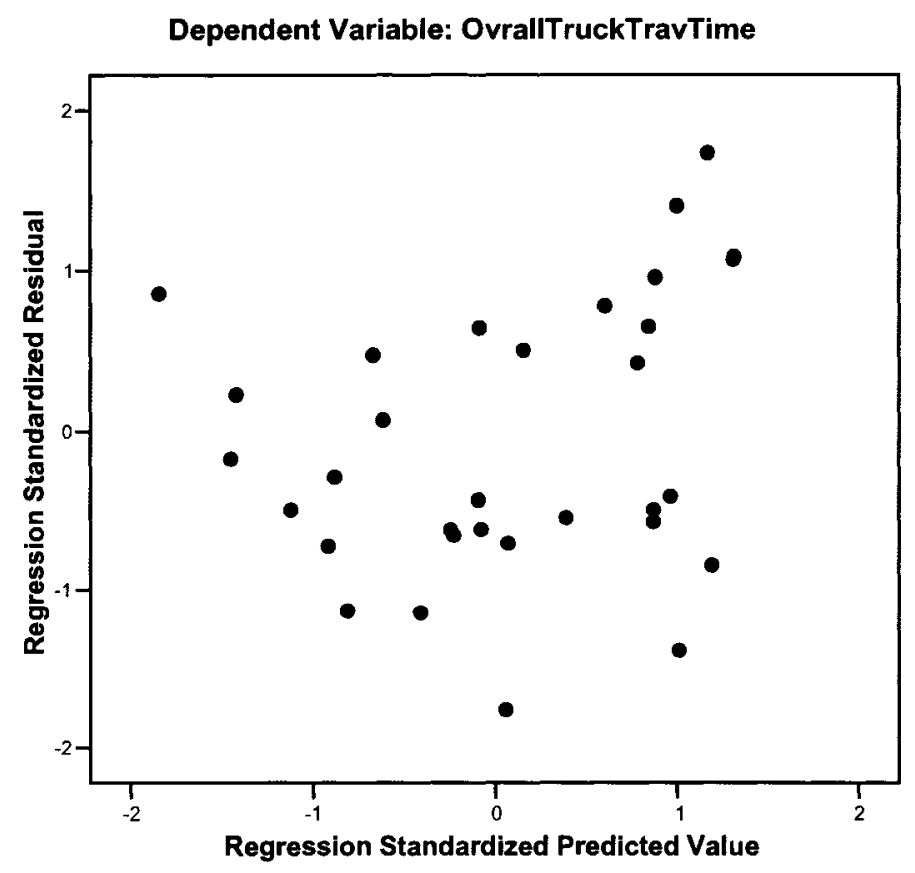

O.K for linearity and homoskedasticity

Figure B-79: Scatterplot Standardized Residuals vs Standardized Predicted Value

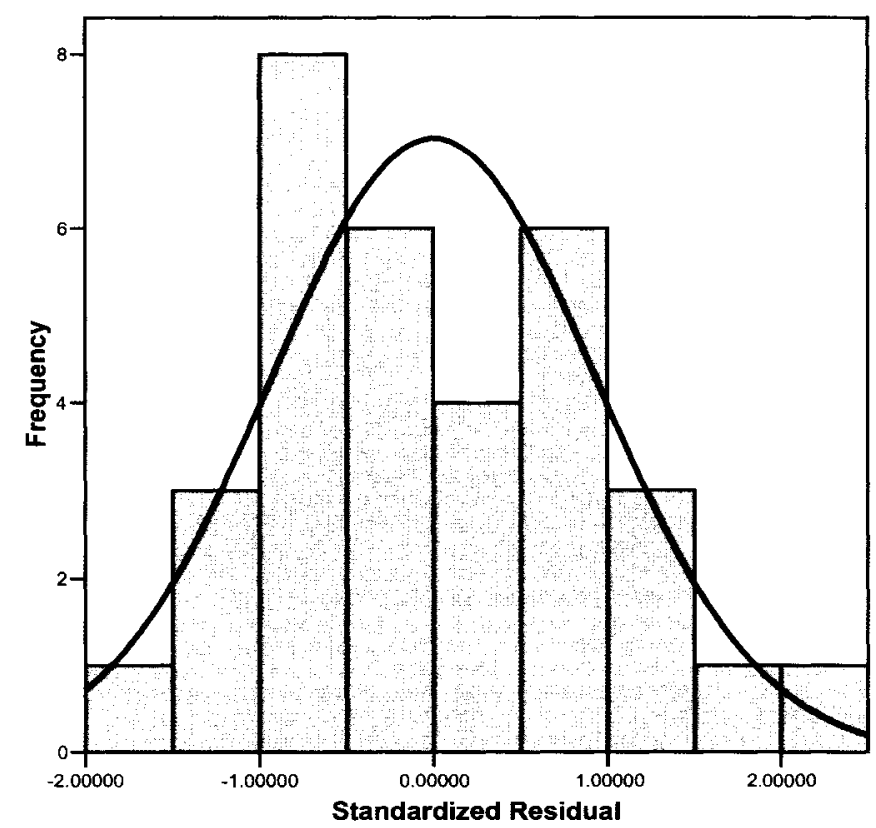

O.K. for normality

Fiqure B-80: Histogram - Standardized Residuals 
Average Overall Truck Travel Time- No QJL - QJL Scenario

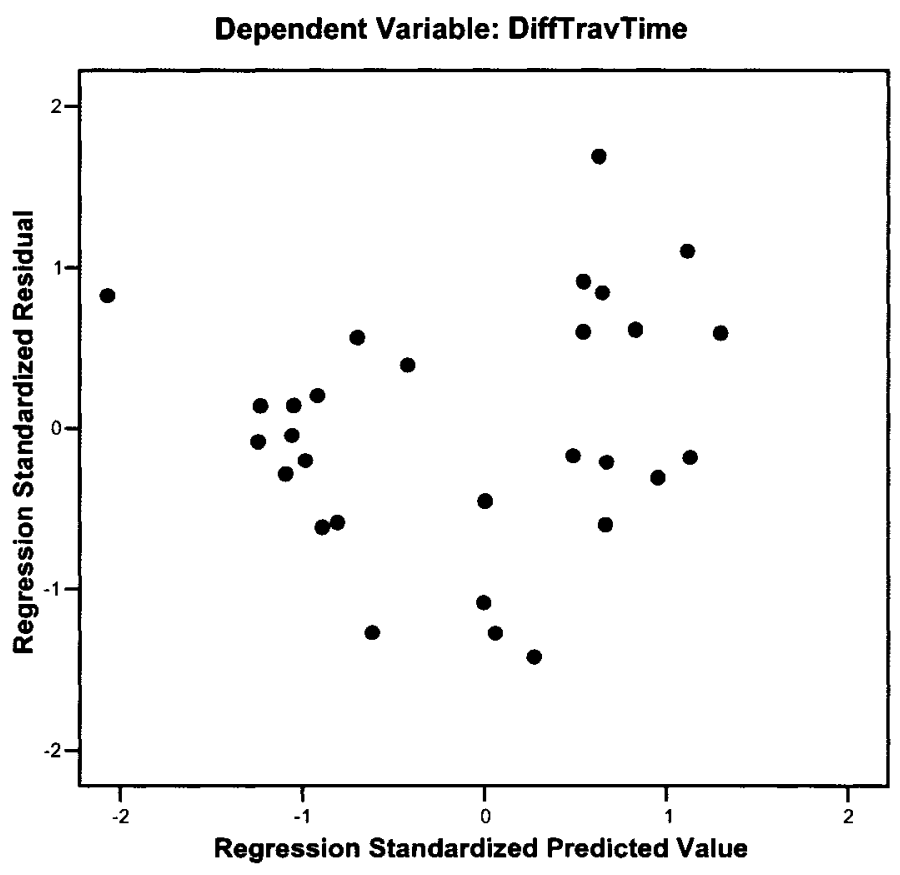

O.K for linearity and homoskedasticity

Figure B-81: Scatterplot Standardized Residuals vs Standardized Predicted Value

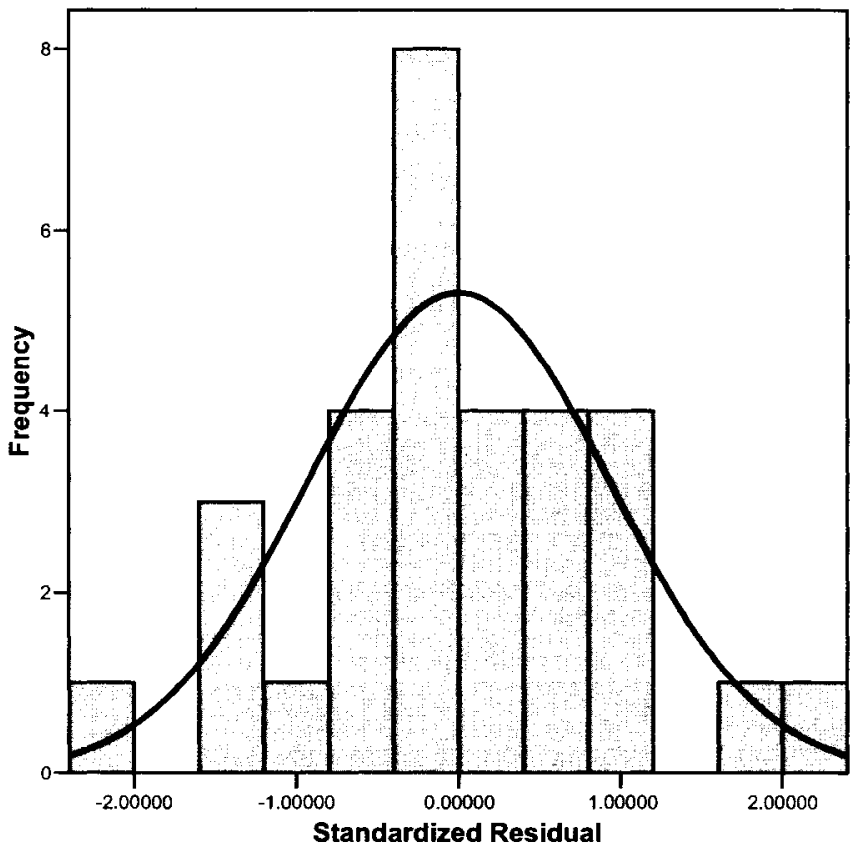

O.K. for normality

Figure B-82: Histogram - Standardized Residuals 
Average Priority Truck Travel Time- No QJL Scenario

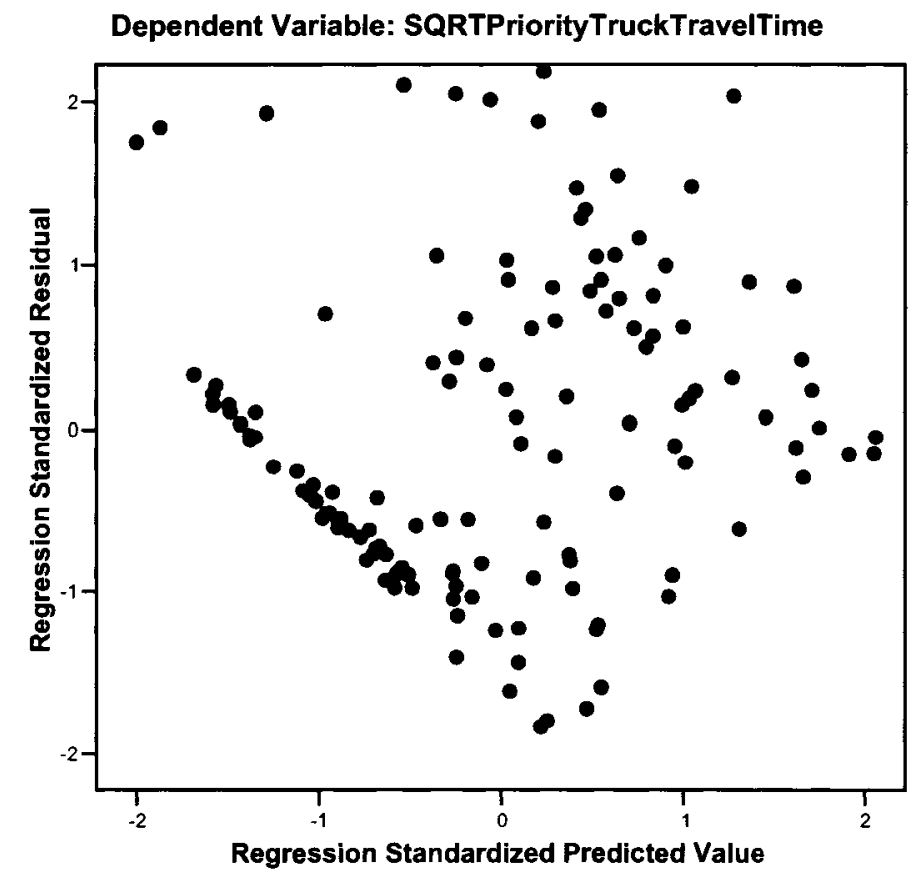

O.K for linearity and homoskedasticity

Figure B-83: Scatterplot Standardized Residuals vs Standardized Predicted Value

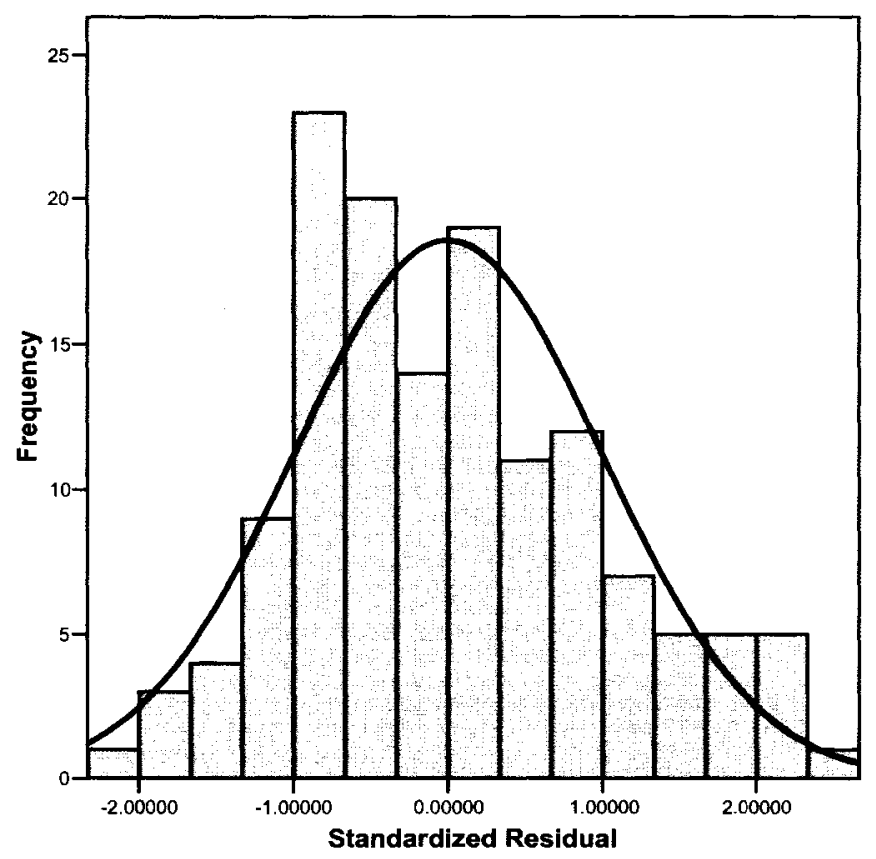

O.K. for normality

Figure B-84: Histogram - Standardized Residuals 


\section{Average Priority Truck Travel Time- QJL Scenario}

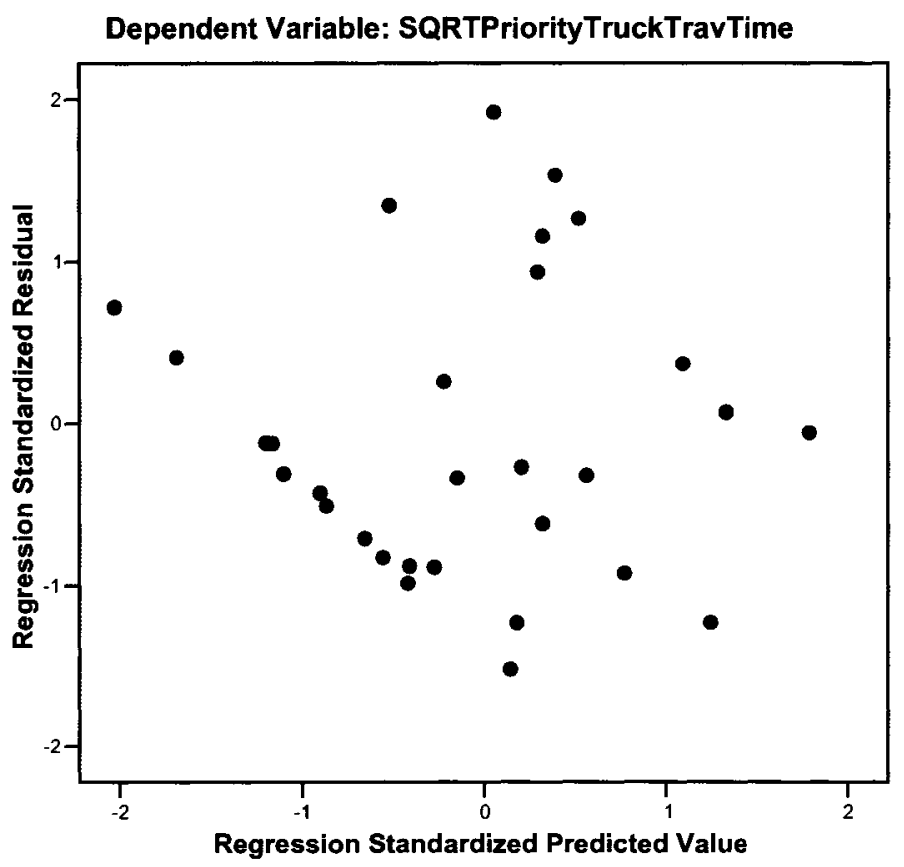

O.K for linearity and homoskedasticity

Figure B-85: Scatterplot Standardized Residuals vs Standardized Predicted Value

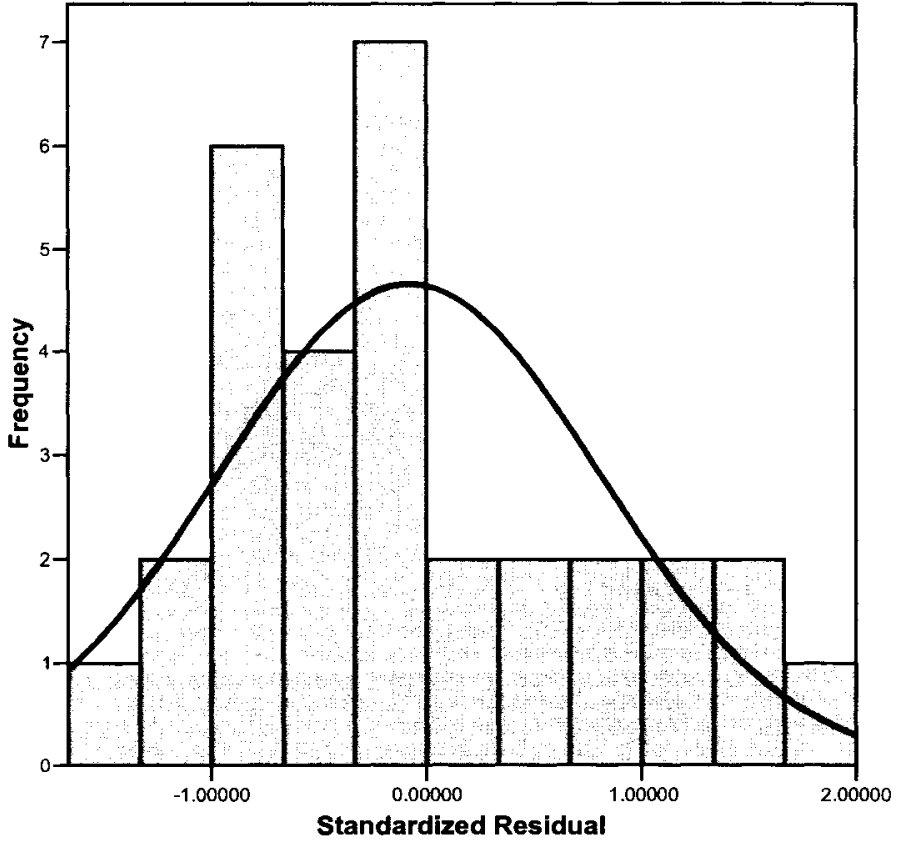

O.K. for normality

Figure B-86: Histogram - Standardized Residuals 
Average Priority Truck Travel Time- No QJL-QJL Scenario

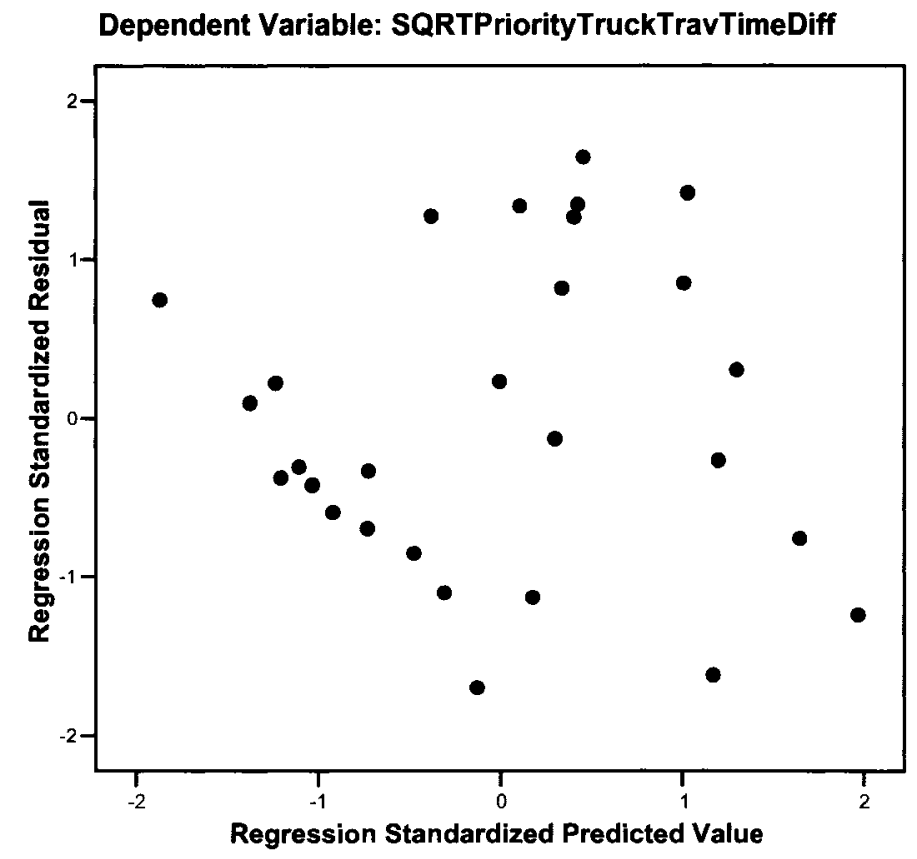

O.K for linearity and homoskedasticity

Figure B-87: Scatterplot Standardized Residuals vs Standardized Predicted Value

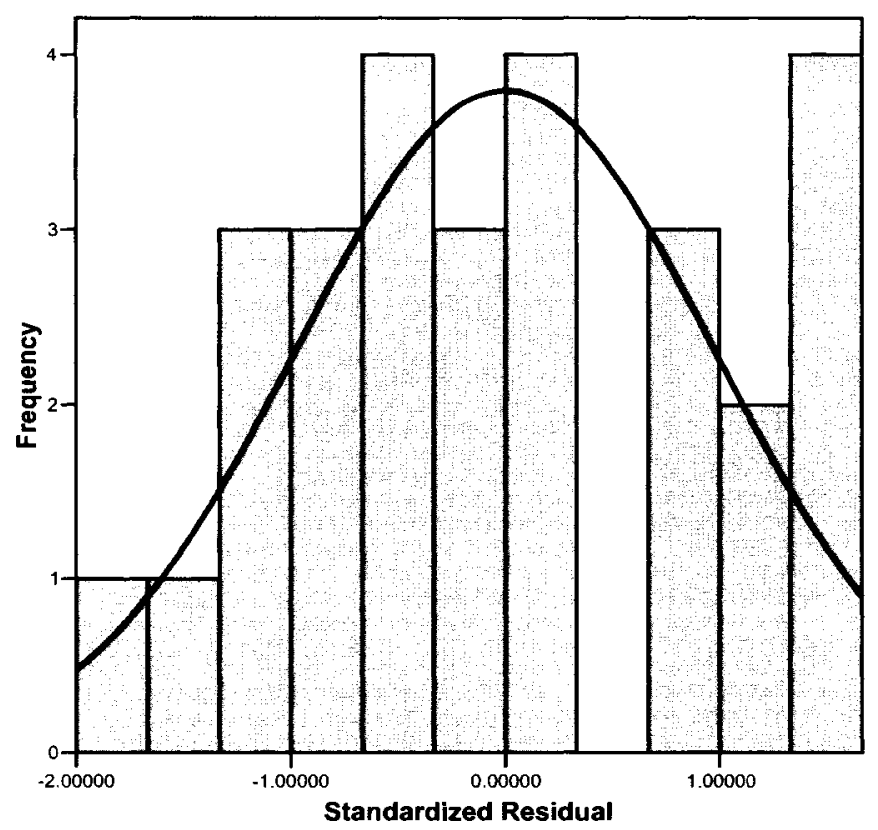

O.K. for normality

Figure B-88: Histogram - Standardized Residuals 


\section{Average Non-Priority Primary Truck Travel Time- No QJL Scenario}

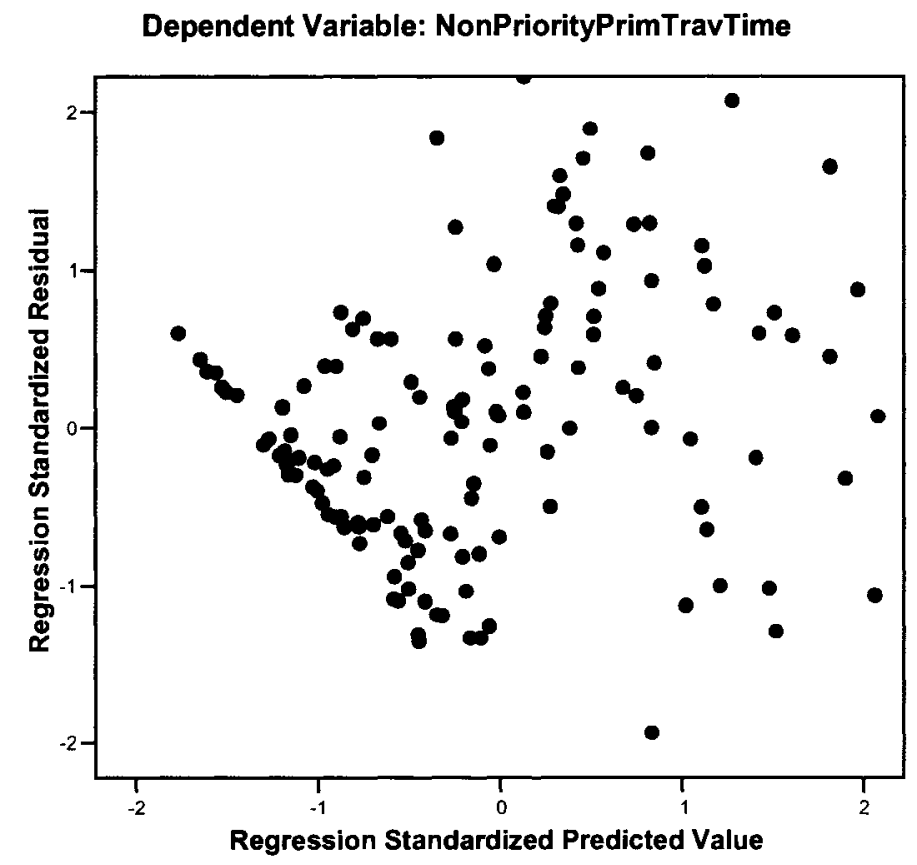

O.K for linearity and homoskedasticity

Figure B-89: Scatterplot Standardized Residuals vs Standardized Predicted Value

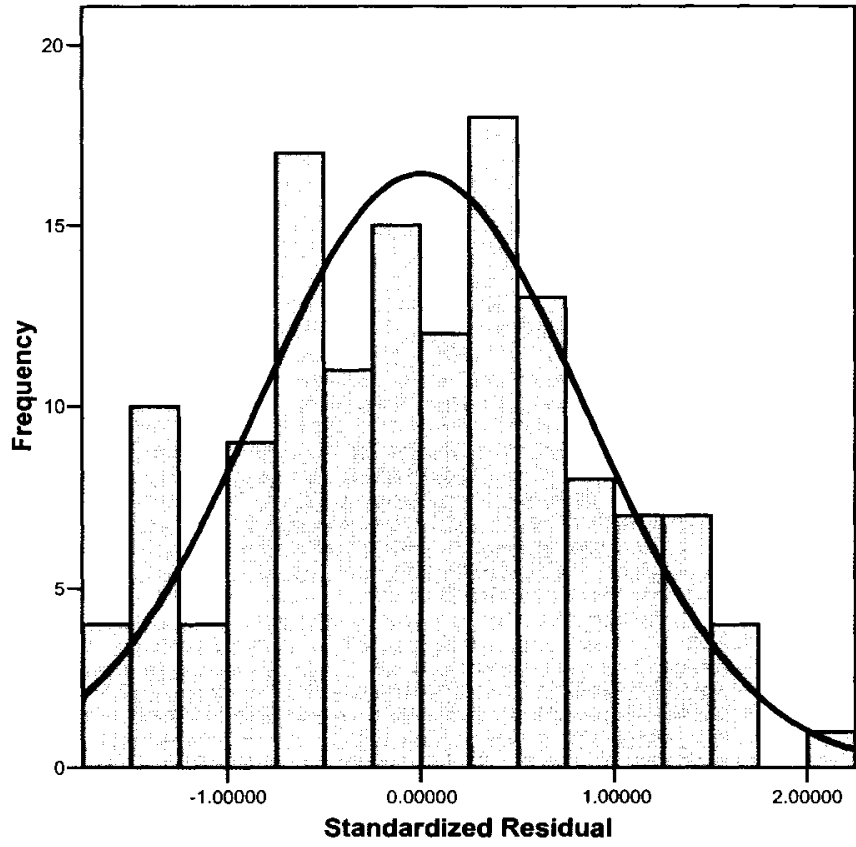

O.K. for normality

Figure B-90: Histogram - Standardized Residuals 
Average Non-Priority Primary Truck Travel Time-QJL Scenario

Dependent Variable: NonPriorityTruckPrimTravTime

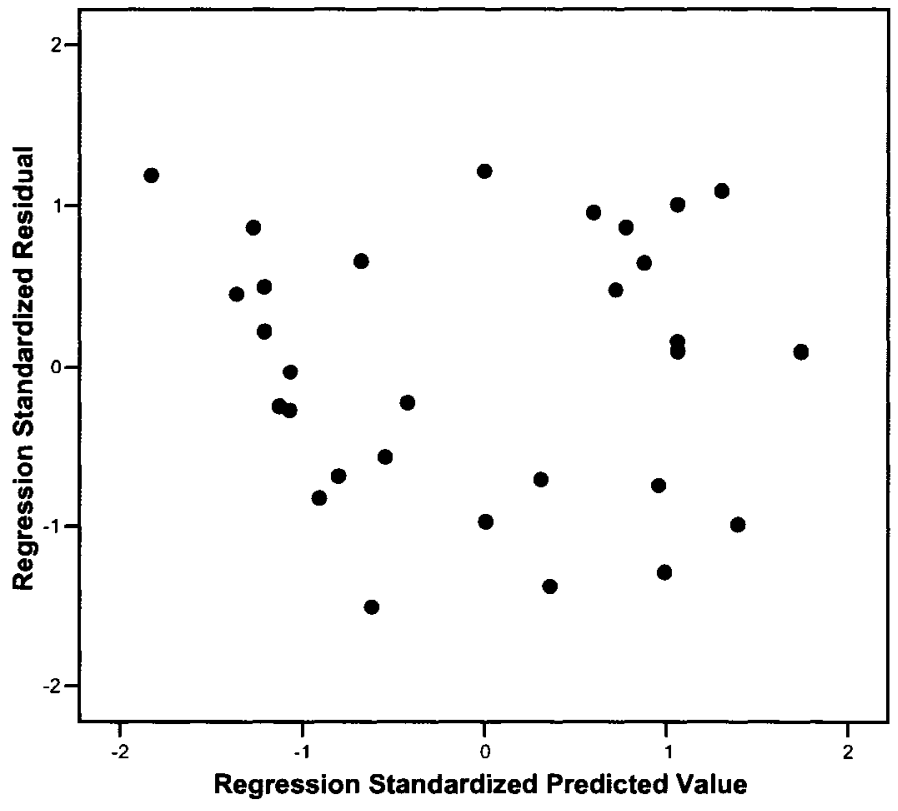

O.K for linearity and homoskedasticity

Figure B-91: Scatterplot Standardized Residuals vs Standardized Predicted Value

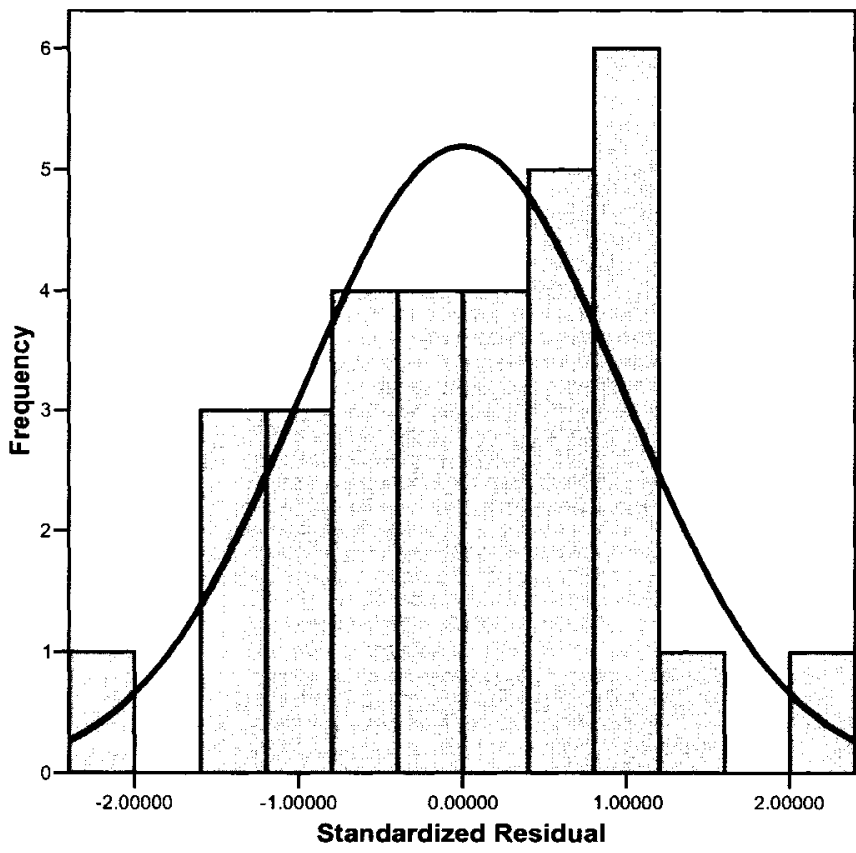

O.K. for normality

Figure B-92: Histogram - Standardized Residuals 
Average Non-Priority Primary Truck Travel Time- No QJL - QJL Scenario

Dependent Variable: NonPriorityTruckTravelTimeDiff

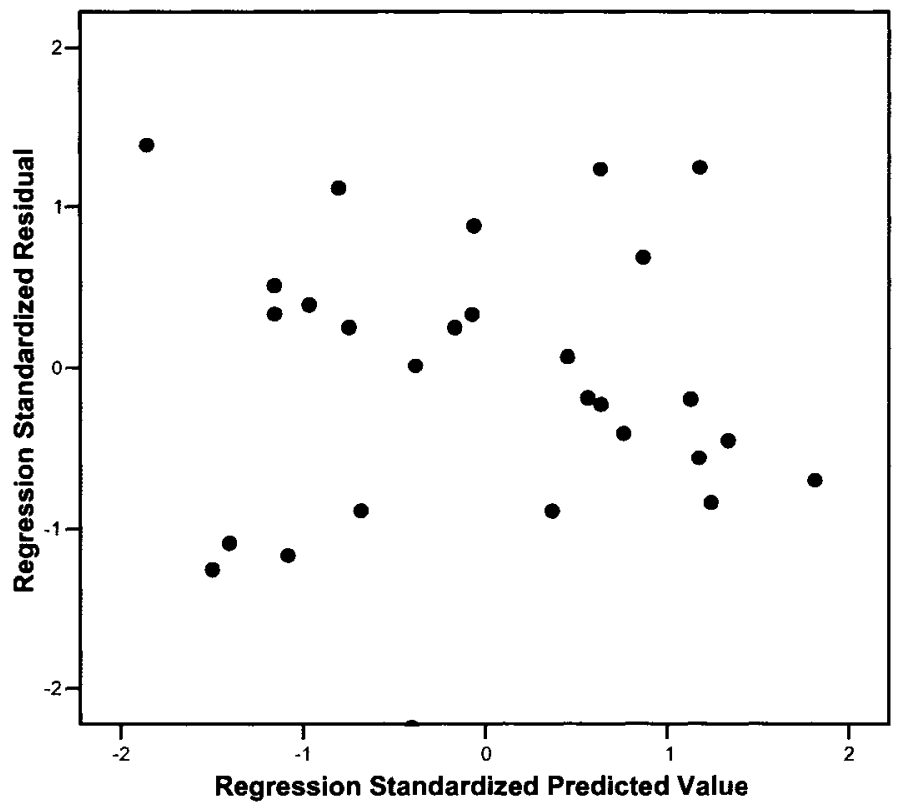

O.K for linearity and homoskedasticity

Figure B-93: Scatterplot Standardized Residuals vs Standardized Predicted Value

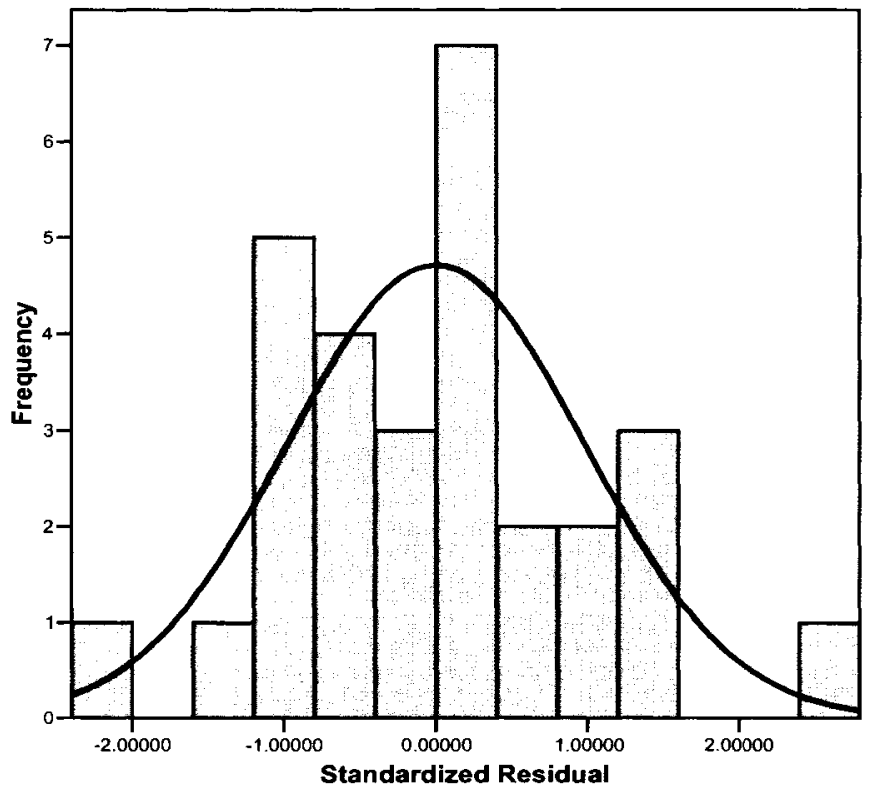

O.K. for normality

Figure B-94: Histogram - Standardized Residuals 


\section{Average Priority Truck Travel Time Advantage - No QJL Scenario}

Dependent Variable: SQRTPriorityTruckTravelTimeAd

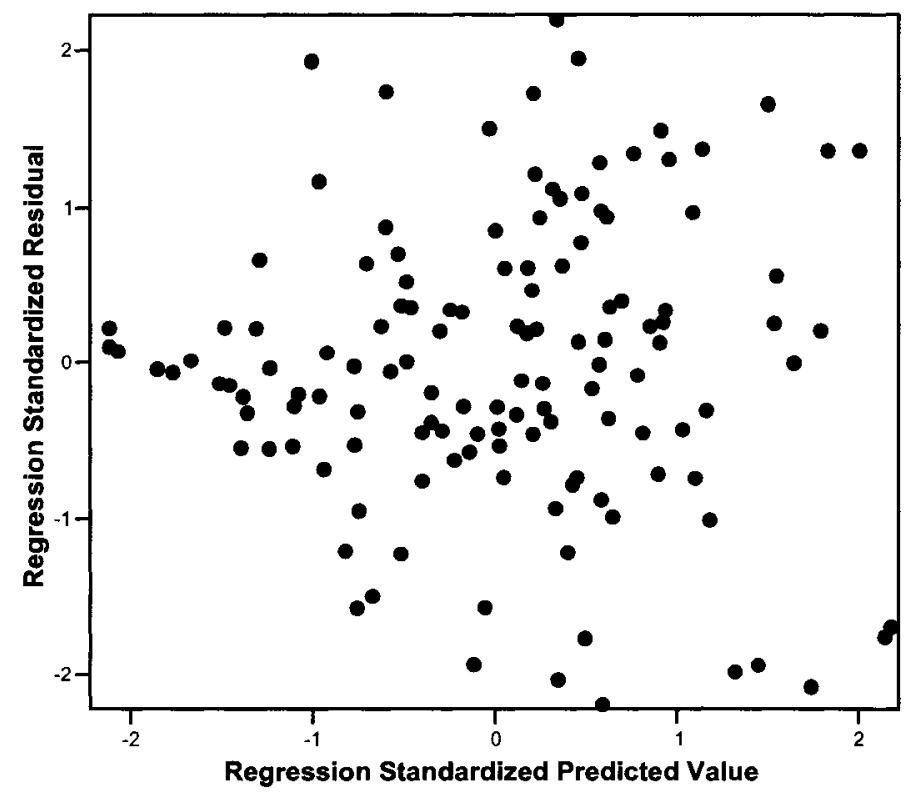

O.K for linearity and homoskedasticity

Figure B-95: Scatterplot Standardized Residuals vs Standardized Predicted Value

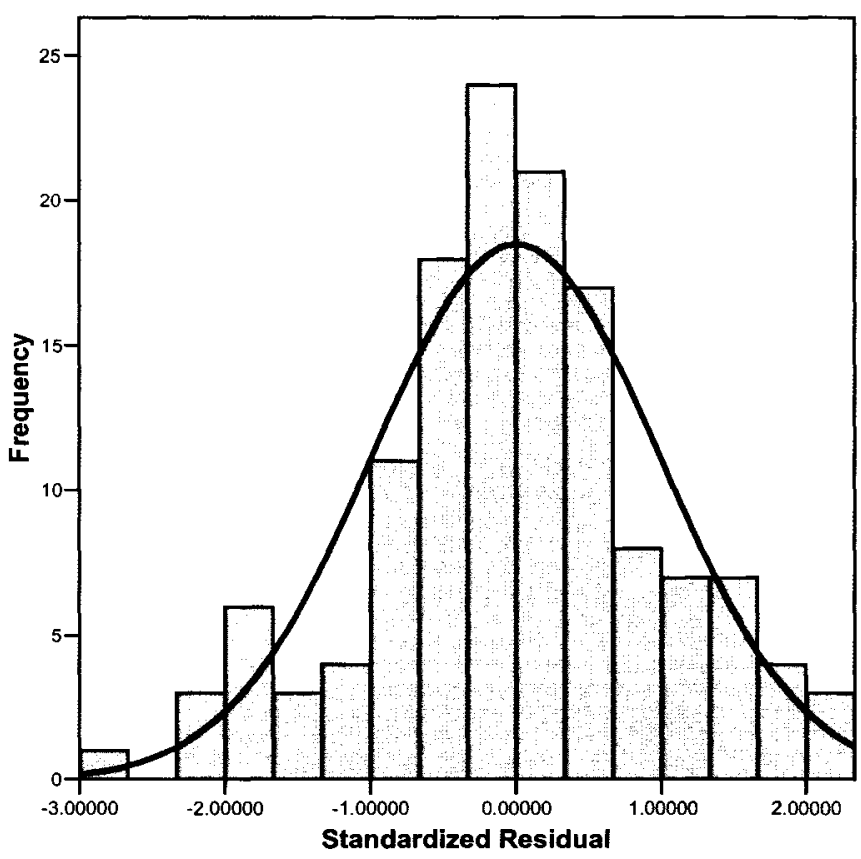

O.K. for normality

Figure B-96: Histogram - Standardized Residuals 
Average Priority Truck Travel Time Advantage - QJL Scenario

Dependent Variable: SQRTTruckTravTimeAd

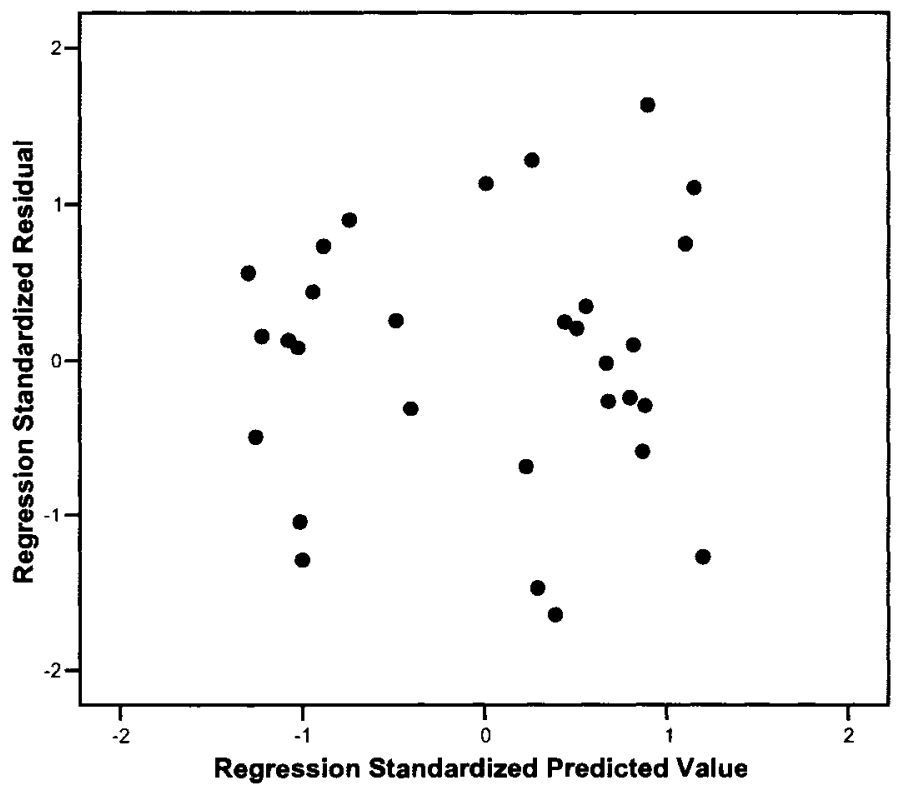

O.K for linearity and homoskedasticity

Figure B-97: Scatterplot Standardized Residuals vs Standardized Predicted Value

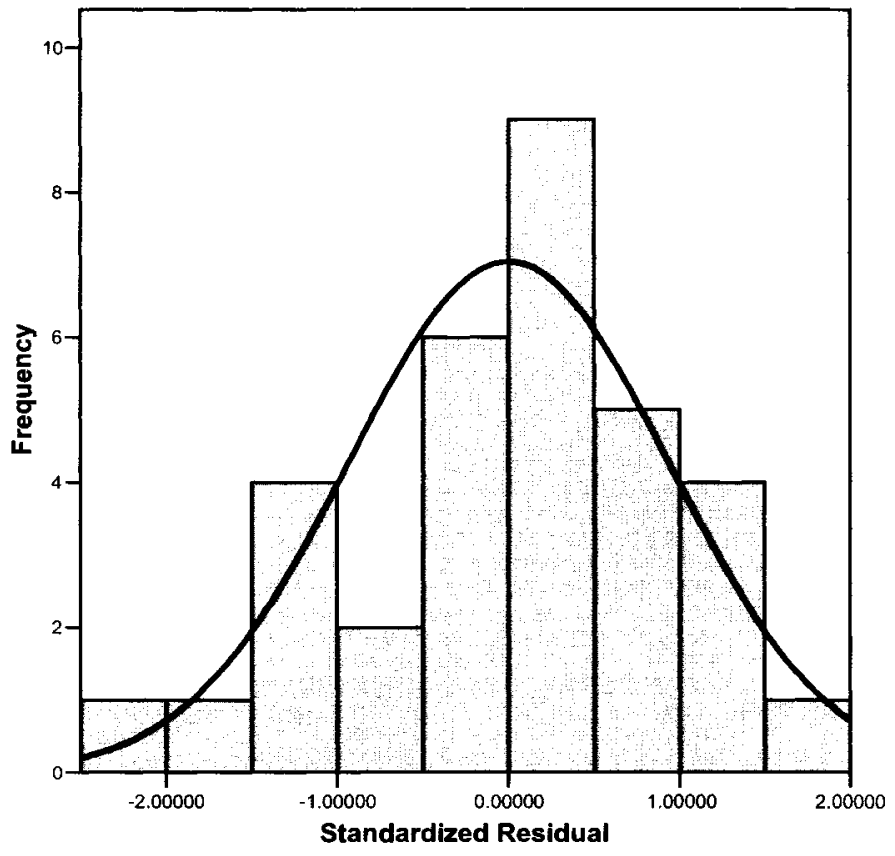

O.K. for normality

Figure B-98: Histogram - Standardized Residuals 
Average Priority Truck Travel Time Advantage - No QJL - QJL Scenario

Dependent Variable: SQRTPriorityTruckTravTimeDiff

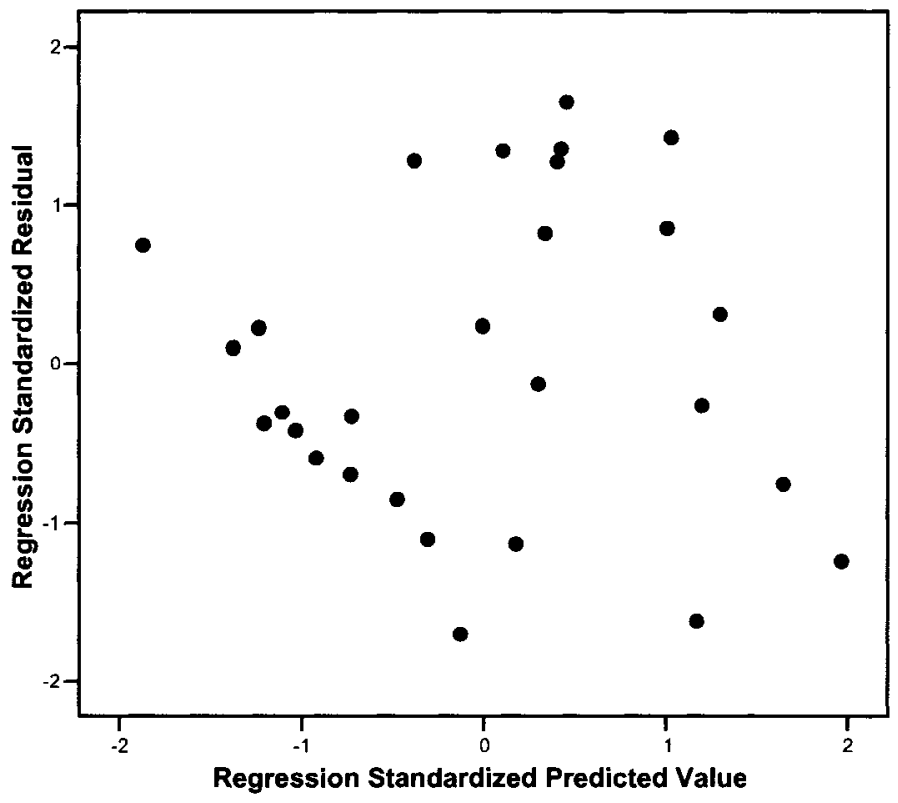

O.K for linearity and homoskedasticity

Figure B-99: Scatterplot Standardized Residuals vs Standardized Predicted Value

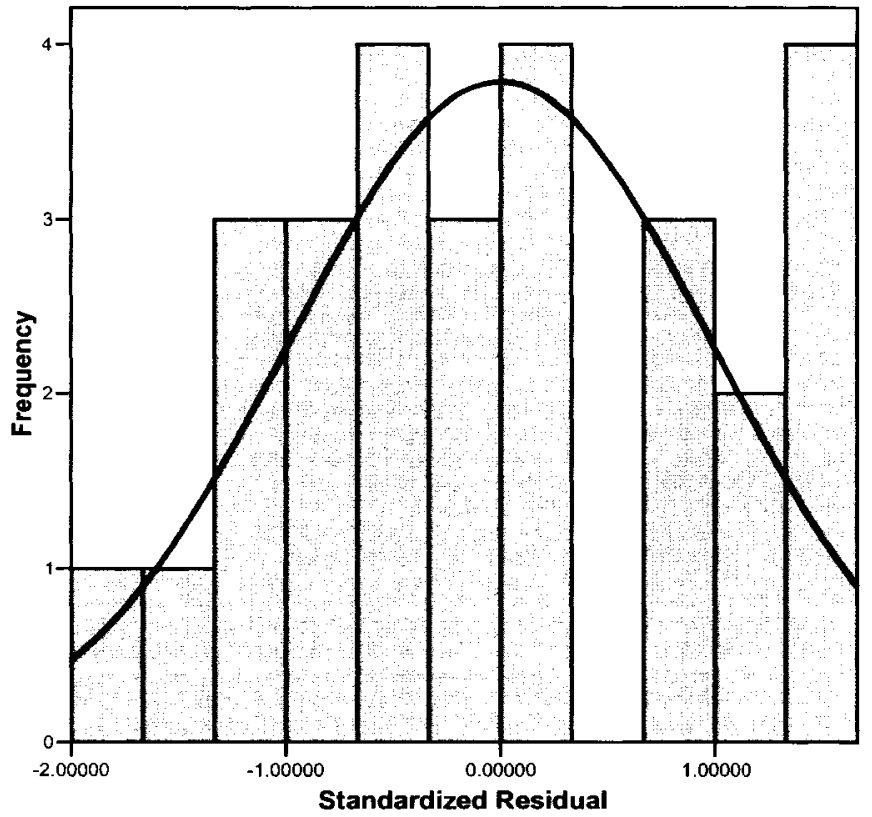

O.K. for normality

Figure B-100: Histogram - Standardized Residuals 
Overall Truck Throughput - No QJL Scenario

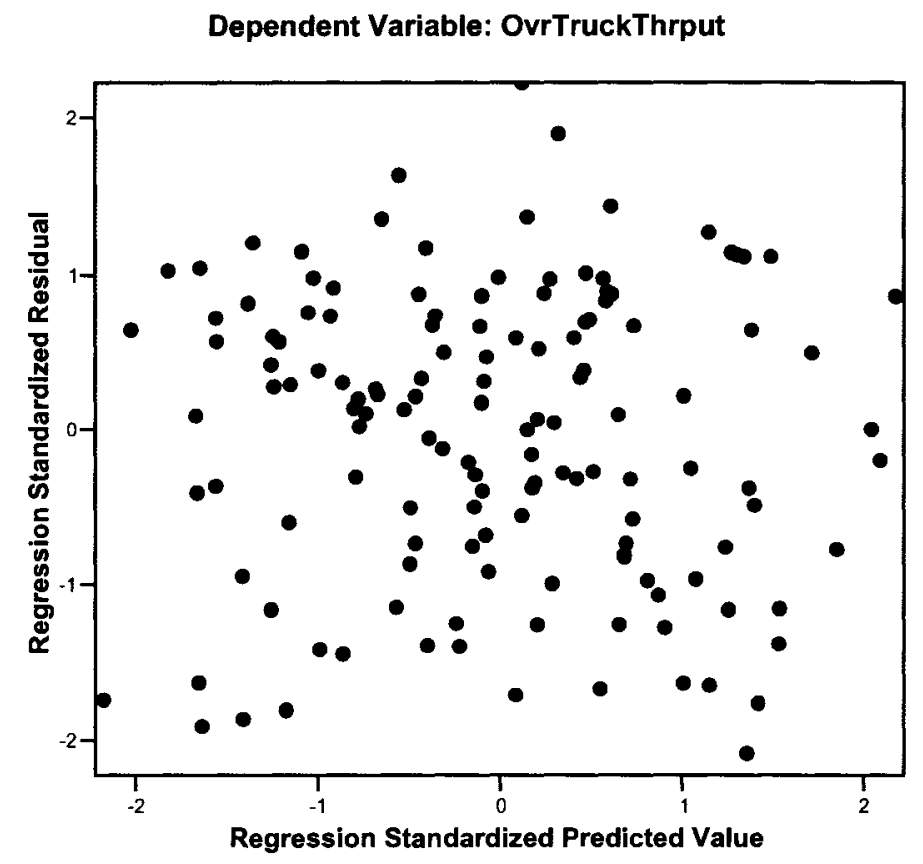

O.K for linearity and homoskedasticity

Figure B-101: Scatterplot Standardized Residuals vs Standardized Predicted Value

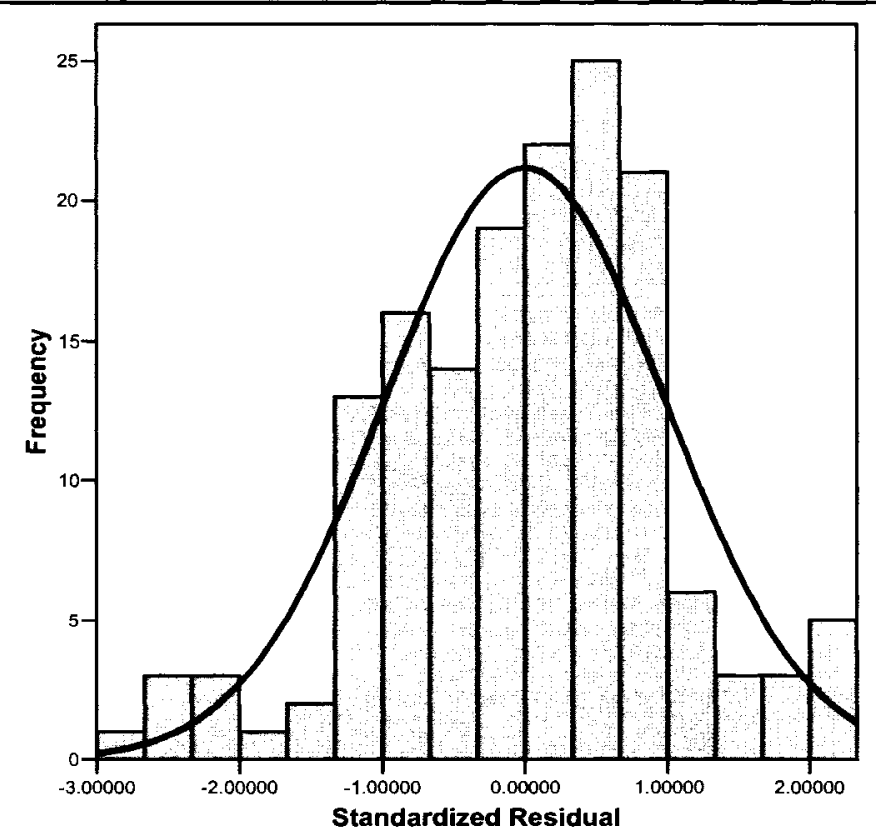

O.K. for normality

Figure B-102: Histogram - Standardized Residuals 
Overall Truck Throughput - QJL Scenario

Dependent Variable: OvrTruckThrput

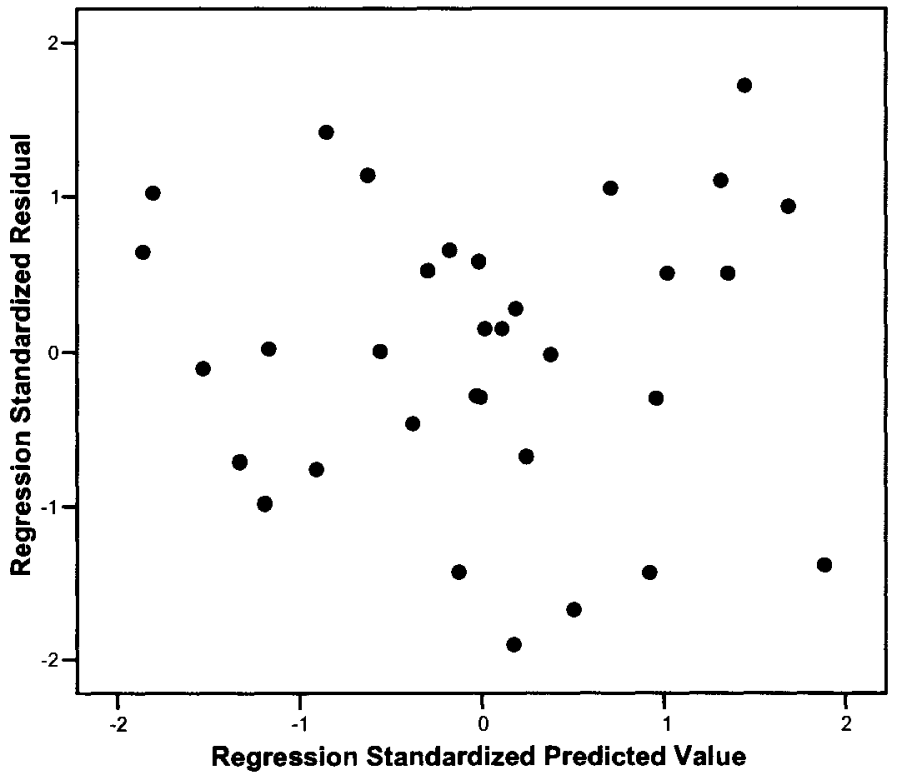

O.K for linearity and homoskedasticity

Figure B-103: Scatterplot Standardized Residuals vs Standardized Predicted Value

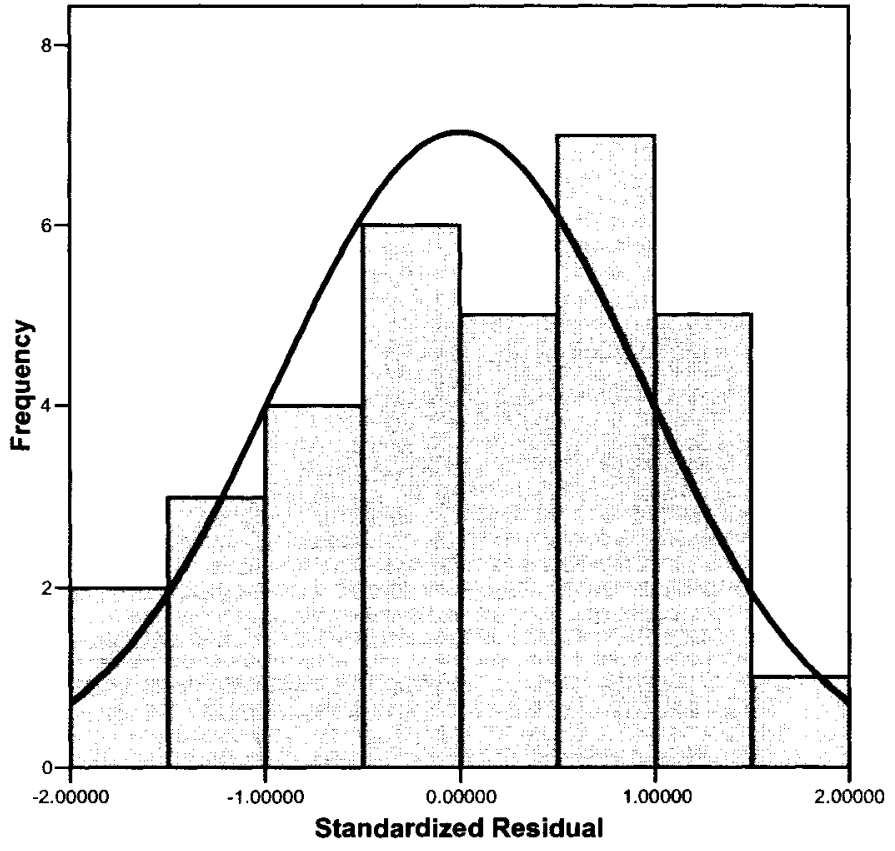

O.K. for normality

Figure B-104: Histogram - Standardized Residuals 
Overall Auto Percent of Demand Serviced - No QJL Scenario

Dependent Variable: PercentAutoDemSer

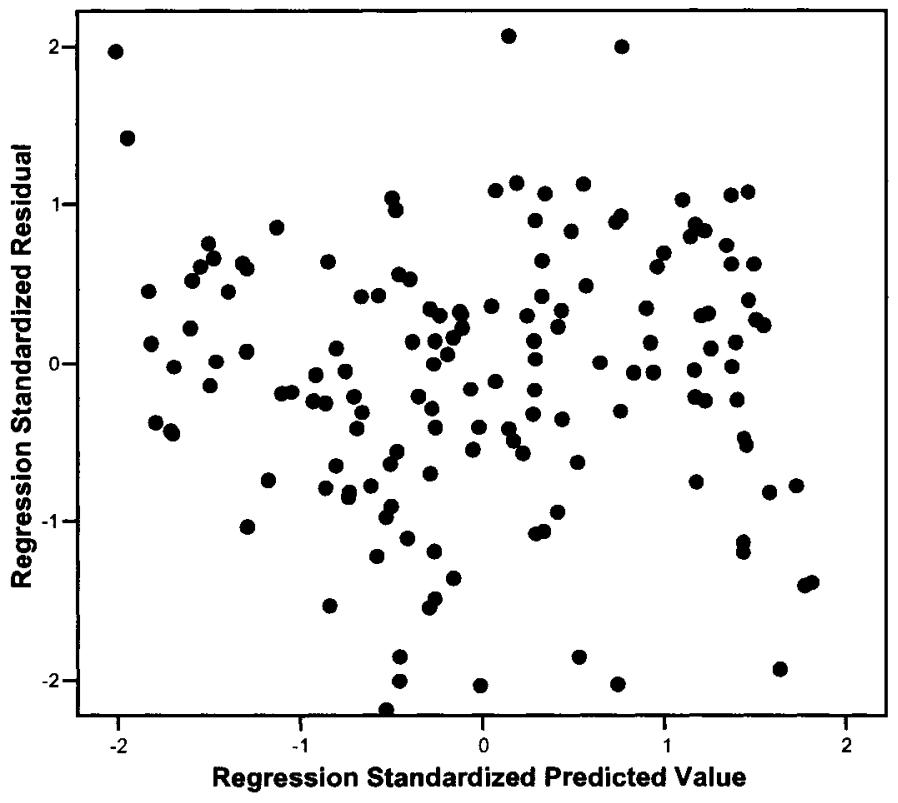

O.K for linearity and homoskedasticity

Figure B-105: Scatterplot Standardized Residuals vs Standardized Predicted Value

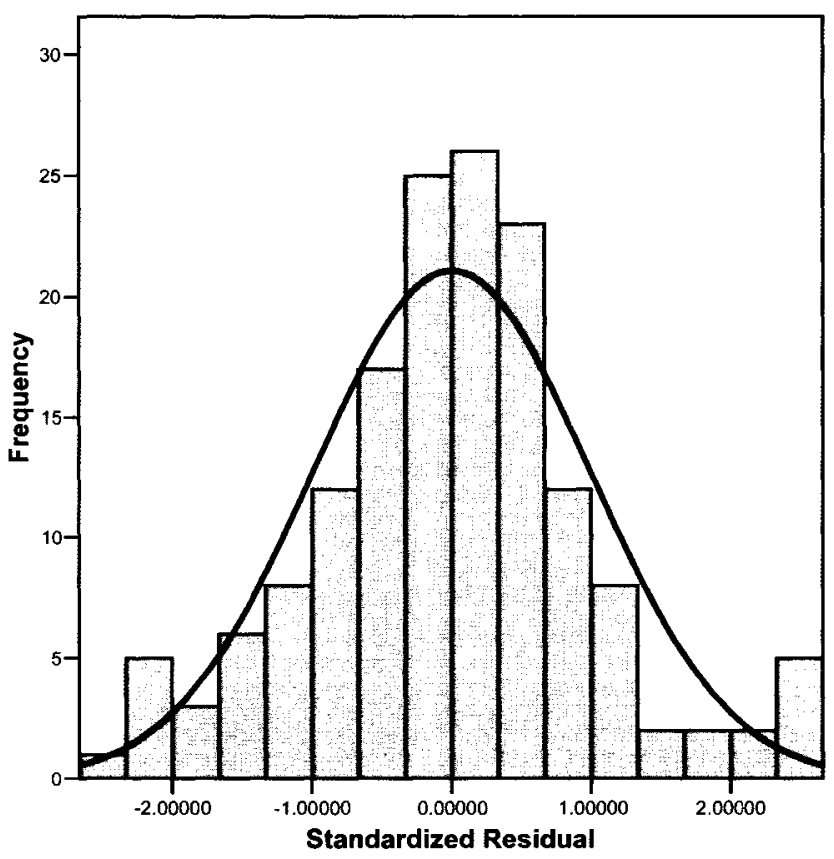

O.K. for normality

Figure B-106: Histogram - Standardized Residuals 
Overall Truck Percent of Demand Serviced - No QJL Scenario

Dependent Variable: PercentofDemServicedOvrallTruck

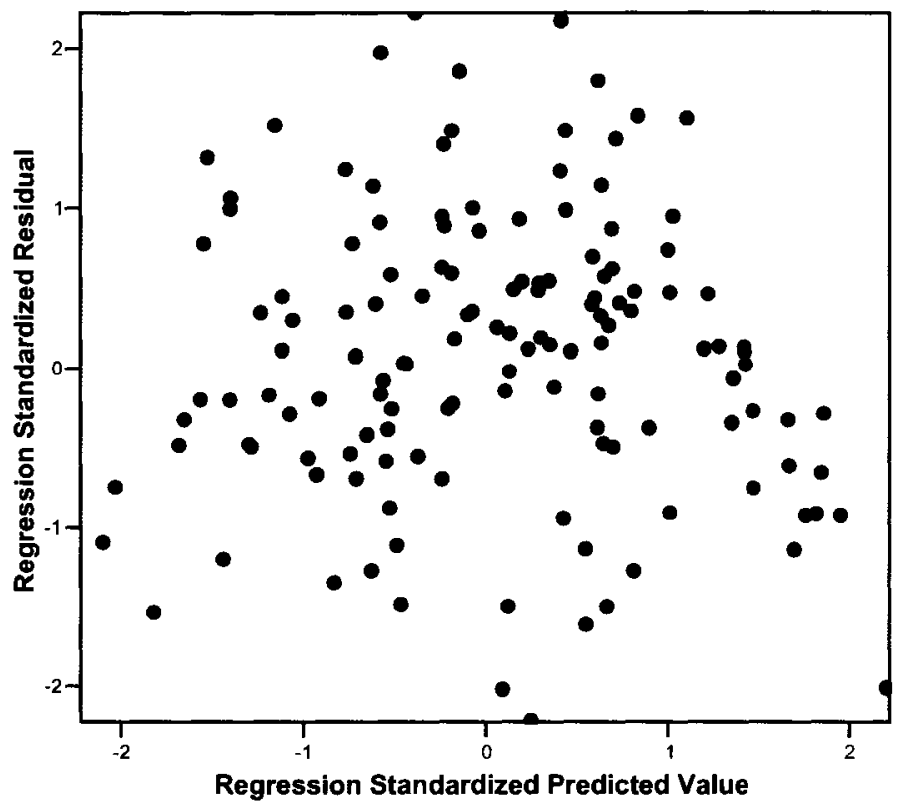

O.K for linearity and homoskedasticity

Figure B-107: Scatterplot Standardized Residuals vs Standardized Predicted Value

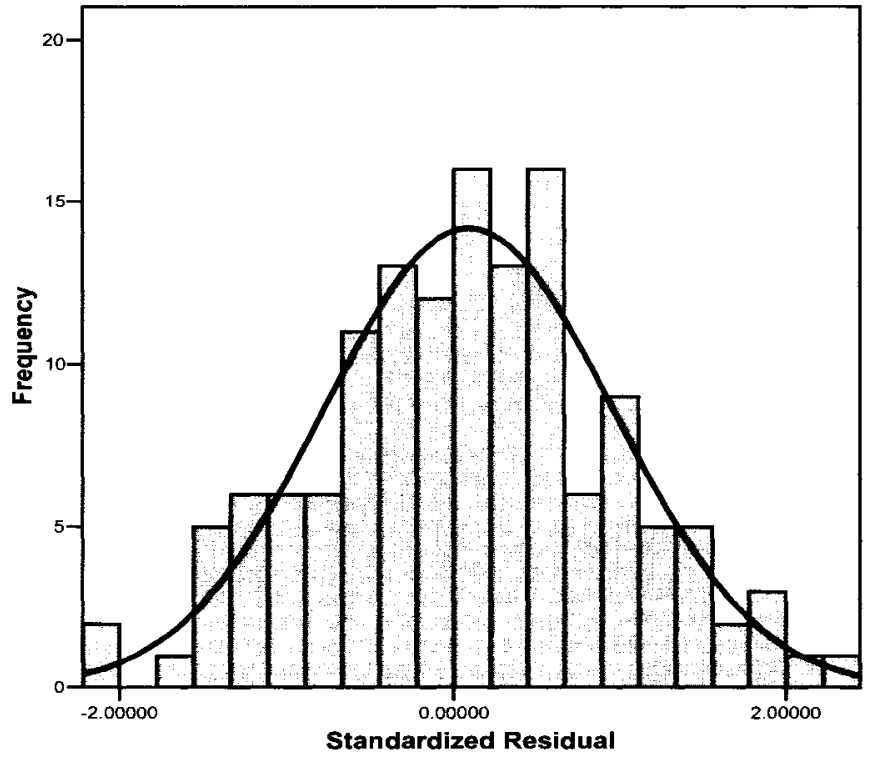

O.K. for normality

Figure B-108: Histogram - Standardized Residuals 


\section{APPENDIX C}




\section{Multivariate REgRESSION}

Regression analysis allows us the ability to map an observed data set (i.e. sample) resulting in a mathematical model that allows us to predict outcome of a dependent variable for a given combination of independent variables. Each regression model has adjustable parameters related to each independent variable which when properly adjusted can result in close agreement between the model output and the observed data set. The agreement between the model output and the observed data set is measured via the merit function which is minimized during the regression process. Once the merit function is minimized it is possible to determine how well the model describes the data (the goodness of fit).

The micro-simulation model outputs in this research were used to determine the impact of priority vehicle crossing programs on the overall efficiency of the land border crossings. Quantitative analysis in the form of graphical analysis and Multivariate Regression analysis was performed on the data obtained from the calibrated models.

Linear multivariate regression was used in this research due to its simplicity of interpretation of model equation, trends etc. In Ordinary Least Squares (OLS) Multivariate Linear Regression a best fit line is estimated for the combination of the independent variables and dependent variable. 
The general form of a Least Squares Linear regression model is:

$$
\mathrm{Y}=\sum_{\mathrm{K}=1}^{\mathrm{M}} \mathrm{b}_{\mathrm{k}} \mathrm{x}_{\mathrm{k}}+\mathrm{c}
$$

Where:

$\mathrm{Y}=$ dependent variable

$\mathrm{X}=$ independent variables

$\mathrm{b}=$ regression coefficients

$c=$ constant or intercept

$\mathbf{M}=$ number of independent variables in model

The merit function minimized for OLS Linear Multivariate Regression is as follows:

$$
\chi^{2}=\sum_{i=1}^{n}\left[\frac{\mathrm{y}_{\mathrm{i}}-\left[\sum_{\mathrm{k}=1}^{\mathrm{M}} \mathrm{a}_{\mathrm{k}} \mathrm{x}_{\mathrm{k}}+\mathrm{c}\right]}{\sigma_{\mathrm{i}}}\right]^{2}
$$

Where:

$\sigma_{i}=$ the measurement error or standard deviation of the $i^{\text {th }}$ data point.

$\mathrm{n}=$ number of observed data points

$y_{i}=$ observed value at $i^{\text {th }}$ data point

The line is considered best fit based on a minimization of the sum of the squares between the predicted dependent variables and obtained dependent variables from the simulation model. The main goal of the regression process is to estimate coefficients for each independent variable that contribute statistically to prediction ability of the model. 
The equation for linear multivariate regression in this research takes the following form:

$$
Y^{\prime}=A+B_{1} X_{1}+B_{2} X_{2}+\cdots \cdots \cdots+B_{k} X_{k}
$$

Where $X_{1}, X_{2} \ldots X_{k}$ are the independent variables and $A, B_{1}, B_{2} \ldots B_{k}$ are the parameters estimated for each independent variable during the regression process. The parameters are referred to as the unstandardized regression coefficients.

Three (3) techniques are available for collecting the independent variables that form part of the model. These are Standard Multiple Regression, Sequential Multiple Regression and Statistical (Stepwise) Regression. Each technique has a different approach in determining which variable will get the overlapping contribution towards explaining the Dependent Variable. In the standard approach all the independent variables are assigned their unique contributions to the dependent variable and the overlap is ignored. In sequential regression the researcher decides which independent variable receives the overlap while for stepwise regression the computer program decides the allocation of the overlap to the independent variables. The choice between using the three methods depends on the purpose of the research. The standard approach represents the most unbiased approach, if $\mathrm{r}^{2}$ is of more importance than the regression coefficients then the standard approach would be the best suited. The sequential multiple regression process is more suited for the testing of explicit theory or hypothesis where the goal is explanation of phenomenon. The stepwise approach is more suited for model building and builds the 
most efficient model. In this research the stepwise approach will be used to help identify the significant independent variables influencing the dependent variable and then the standard approach will be used to develop the model.

Any statistical model must meet the CLRM assumptions of normality, linearity, homoskedasticity and independence in order for it to be used as a valid predictive tool. Multivariate normality is the assumption that each variable and all linear combinations thereof are normally distributed. This condition will be checked through an examination of the residuals of the predictive analysis. Linearity is an important condition to be met since Pearson's r-value only captures the linear relationship between variables, non-linear relationships if they exist are ignored. Nonlinearity will be diagnosed through a plot of residuals obtained from the analysis. The condition of homoskedasticity requires that the variability in scores for one continuous variable is roughly the same at all values of another continuous variable. A scatter plot of residuals against standardized predicted values will help in determining if homoskedasticity is met. The scatter will be the same width all over with some bulging toward the middle. Independence is a condition that refers to the errors of prediction being independent of one another. This means that the sample/population entities in the data set do not influence each other during the sampling process. Usually this assumption is met by virtue of a large random sample being taken of the population. 
The interpretation of the unstandardized regression coefficients is based on their contribution to the dependent variable for a unit increase in the related independent variable with the other variables held constant. For example for a unit change in $X_{k}$ and holding all other independent variables constant there will be a net increase in the dependent variable of the amount $B_{k}$.

One of the outputs of the regression process is the Standardized Partial Regression Coefficients. These are determined to allow relative comparison of the impact of the independent variables on the dependent variable. The unstandardized partial regression coefficients (i.e. $B_{1}, B_{2}, \ldots B_{k}$ ) cannot be compared directly because of incomparable measurement units. The relative influence of the variables on the dependent variable cannot be assessed and hence they need to be standardized. This is done via the $\mathrm{z}$-score and the process is to find the product between the unstandardized coefficient and the ratio of the standard deviation of the independent variable to the standard deviation of the dependent variable.

$$
\beta_{\mathrm{n}}=\frac{\sigma_{\mathrm{Xk}}}{\sigma_{\mathrm{Y}}} * \mathrm{~B}_{\mathrm{k}}
$$

$\beta_{\mathrm{n}}$ - Standardized regression coefficient

$\sigma_{\mathrm{xk}}-$ Standard deviation independent variable

$\sigma_{Y}-$ Standard deviation dependent variable

$B_{k}$ - unstandardized regression coefficient 
This is done for each of the unstandardized partial regression coefficients in order to allow relative comparison.

The Squared Multiple Correlation value $\left(\mathrm{R}^{2}\right)$ is the most used value in analyzing strength of association (agreement) or explained variance of the predictor model derived from the regression process. The closer $\mathrm{R}^{2}$ is to 1.0 the greater the predictive power of the model usually values of $\mathrm{R}^{2}$ greater than 0.8 indicates that the model is a good predictor. The value of $\mathrm{R}^{2}$ obtained for the sample should be close to the population value with some fluctuations due to population trends not caught in the sample. The magnitude of the difference between sample $\mathrm{R}^{2}$ and population $\mathrm{R}^{2}$ tends to be larger for smaller sample sizes. Since $\mathrm{R}^{2}$ does not take on a negative value it always tends to be overestimated for the regression models, especially for smaller samples. For this reason in estimating the population value of $R^{2}$ adjustments are made for expected inflation in sample $R^{2}$ using the following equation provided by Wherry (1931).

$$
\overline{\mathrm{R}}^{2}=1-\left(1-\mathrm{R}^{2}\right)\left[\frac{\mathrm{N}-1}{\mathrm{~N}-\mathrm{k}-1}\right]
$$

where $\mathrm{N}=$ sample size

$\mathrm{k}=$ number of independent variables

$\mathrm{R}^{2}=$ squared multiple correlation 
Another output of the regression process is the Partial Correlation coefficients. This is a measure of the contribution of each of the independent variables in the equation towards explaining the variance. The Partial Correlation Coefficient is found by holding all the independent variables constant except for the one for which the coefficient is needed. In this way a measure of the strength of association of each individual independent variable with the dependent variable can be found.

Significance testing is used in regression analysis to provide estimates of the percent chance of the estimated parameters being within a range (i.e. Confidence Interval) or being statistically different from zero (i.e. hypothesis testing). Confidence limits for unstandardized regression coefficients are calculated using the following equation:

$\mathrm{CL}_{\mathrm{Bi}}=\mathrm{B}_{\mathrm{i}} \pm \mathrm{SE} \mathrm{Bi}_{\mathrm{Bi}}\left(\mathrm{t}_{\alpha / 2}\right)$

where:

$\mathrm{SE}_{\mathrm{Bi}}=$ standard error of the regression coefficient

$t_{\alpha / 2}=$ critical value of $t$ for the degree of confidence required (usually $95 \%$ or $99 \%$ )

In hypothesis testing two hypothetical states of reality are set up each representing an alternative hypothesis about the true nature of events. The null hypothesis is that the strength of relationship between 2 variables (i.e. the DV and one of the IV's) is not statistically different from zero. The alternative hypothesis states that there exists a statistically significant relationship between the DV and the IV. A rejection of the null hypothesis means qualification of the alternative hypothesis. Parametric $t$-tests are used 
in this research for hypothesis testing. The critical value of $t$ is estimated from the table values of the $t$ distribution for a level of significance of $95 \%$. The parameter $t$ value is compared to the critical range and if it falls outside the null hypothesis is rejected meaning that a statistically significant relationship exists between the two variables. 